ABSTRACT

Title of Document:

Directed By:
EVALUATION OF THE ABILITY OF FIRE DYNAMICS SIMULATOR TO SIMULATE POSITIVE PRESSURE VENTILATION IN THE LABORATORY AND PRACTICAL SCENARIOS

Stephen Kerber, Master of Science, 2005

Dr. James Milke, Fire Protection Engineering

Positive Pressure Ventilation (PPV) is a tactic that is used on fire grounds across the world everyday, both to improve tenability after the extinguishment of a fire and/or offensively during fire attack to improve firefighting conditions. PPV has proven that it can be a useful tool on the fire ground, but it can also kill or injure fire fighters and civilians if used improperly. Data from three full-scale experiments are compared with simulations completed with the computational fluid dynamic model Fire Dynamic Simulator (FDS). The full-scale experiments characterize a Positive Pressure Ventilation (PPV) fan in an open atmosphere, in a simple room geometry and in a room fire.

All experiments qualify and quantify the comparison of the experimental results with the FDS results. A concluding scenario is modeled utilizing the calibration of the full-scale experiments to examine the effects of PPV on a fire in a two-story, colonial style house. 


\title{
EVALUATION OF THE ABILITY OF FIRE DYNAMICS SIMULATOR TO SIMULATE POSITIVE PRESSURE VENTILATION IN THE LABORATORY AND PRACTICAL SCENARIOS
}

\author{
By \\ Stephen Kerber \\ Thesis submitted to the Faculty of the Graduate School of the \\ University of Maryland, College Park, in partial fulfillment \\ of the requirements for the degree of \\ Master of Science \\ 2005
}

Advisory Committee:

Associate Professor James Milke, Chair Associate Professor Frederick Mowrer Associate Professor Arnaud Trouve 
(C) Copyright by Stephen Kerber 


\section{Acknowledgements}

The author would like to thank staff members of the Building and Fire Research Laboratory at NIST: William D. Walton, Daniel Madrzykowski, Kevin McGrattan, and Glenn Forney for their technical assistance and Robert Vettori, David Stroup, William Twilley, Roy McLane, Andrew Milliken, Jessica Naff, Laurean DeLauter, Ed Hnetkovsky, Jack Lee, Robert Anleitner, Jay McElroy and Alexander Maranghides for the support they provided during this set of experiments. In addition, the author expresses gratitude to the United States Fire Administration, part of the Department of Homeland Security, Robert McCarthy and William Troup for their support of this important research program.

A special thank you to Dr. James Milke for guiding me through this process, and to Dr. Frederick Mowrer and Dr. Arnaud Trouve for participating as part of the advisory committee. 


\section{Table of Contents}

Acknowledgements ................................................................................................................. ii

Table of Contents ............................................................................................................. iii

List of Tables ................................................................................................................. v

List of Figures............................................................................................................ vi

Chapter 1: Introduction .......................................................................................................... 1



$1.2 \quad$ Fire Dynamic Simulator.......................................................................... 4



Chapter 2: Mapping the PPV Velocity Flow Field .................................................. 6

$2.1 \quad$ Experimental Description ..................................................................... 6

2.1.1 Experimental Facility......................................................................... 7

2.1.2 Experiment Components................................................................... 7

2.1.3 Experiment Procedure.................................................................... 10

2.1.4 Flow Visualization Experiment ...................................................... 12







2.2.3 Output Files..................................................................................... 14



Chapter 3: Simple Room Experiment............................................................................ 21

3.1 Experimental Description ...................................................................... 21



3.1.2 Experiment Components.................................................................... 21

3.1.3 Experiment Layout............................................................................ 23

3.1.4 Experiment Procedure........................................................................ 24

3.1.5 Flow Visualization Experiment ........................................................ 25

3.2 Computer Simulation ..................................................................... 26



3.2.2 Geometry and Vents ...................................................................... 29

3.2.3 Output Files.................................................................................... 30



3.4 Mapping and Simple Room Summary...................................................... 34

Chapter 4: Room Fire Experiments ............................................................................ 39



4.1.1 Instrumentation ............................................................................... 44



4.1.3 Procedure ………………………………………………….... 55














\begin{tabular}{|c|c|}
\hline \\
\hline 4.2.6 & oom Differential Pressure... \\
\hline 4.2.7 & Window Gas Velocity.. \\
\hline 4.2.8 & Doorway Gas Velocity. \\
\hline \multicolumn{2}{|r|}{  } \\
\hline 4.3.1 & Domain... \\
\hline 4.3.2 & Geometry... \\
\hline 4.3.3 & Materials . \\
\hline 4.3.4 &  \\
\hline 4.3.5 & Output Files... \\
\hline \multicolumn{2}{|c|}{ 4.4 Simulation Results .... } \\
\hline 4.4.1 & Naturally Ventilated Simulation .. \\
\hline \multicolumn{2}{|r|}{ Positive Pressure Ventilated Simulation..... } \\
\hline 4.5 &  \\
\hline 4.6 & Room Fire Summary.. \\
\hline \multicolumn{2}{|c|}{ Chapter 5: C } \\
\hline 5.1 &  \\
\hline 5.2 &  \\
\hline 5.2.1 & Domain.. \\
\hline 5.2 .2 & ................................................... 132 \\
\hline 5.2 .3 &  \\
\hline 5.2 .4 &  \\
\hline 5.2 .5 & (1) \\
\hline 5.2 .6 & …가. \\
\hline \multicolumn{2}{|l|}{  } \\
\hline 5.3.1 & nd Smoke Spread................................................ 14 \\
\hline $\begin{array}{l}5.3 .2 \\
5.33\end{array}$ &  \\
\hline 5.3.3 &  \\
\hline 5.3.4 &  \\
\hline 5.3.5 & . \\
\hline 5.4 & 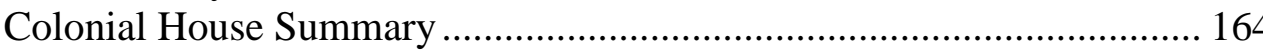 \\
\hline \multicolumn{2}{|c|}{  } \\
\hline 6.1 & ………....................... \\
\hline 6.2 &  \\
\hline & nclusi \\
\hline
\end{tabular}




\section{List of Tables}

Table 1. Comparison of Experimental and FDS Velocity Mapping Results ............. 17

Table 2. Comparison of Experimental and FDS Simple Room Results ..................... 31

Table 3. Summary of FDS Fan Characteristics Needed to Create an Accurate



Table 4. Summary of Multiblock Characteristics Needed to Create and













Table 10. Mapping and Simple Room Experimental Uncertainty............................ 170

Table 11. Room Fire Experimental Uncertainty .................................................. 171 


\section{List of Figures}

Figure 1-1. Two Common PPV Fans........................................................................ 3

Figure 1-2. PPV Cone of Air ……………….............................................. 3

Figure 2-1. The Flow Characterization Grid.......................................................... 8

Figure 2-2. Flow Visualization Threads ............................................................ 8

Figure 2-3. Front and Back of PPV Fan ……………....................................... 9

Figure 2-4. Anemometer......................................................................................... 10

Figure 2-5. Anemometer in Indexer on Track ....................................................... 10

Figure 2-6. Velocity Mapping Experimental Layout................................................... 11

Figure 2-7. Velocity Mapping Measurement Points.................................................... 11

Figure 2-8. Smoke Generator Flowing …………………....................................... 12

Figure 2-9. Layout for Supplemental Experiment .................................................. 12



Figure 2-11. Fan and Smoke Generator.............................................................. 12

Figure 2-12. FDS Layout Visualized with Smokeview …………………………...... 15

Figure 2-13. Fine Grid Cell Visualization .............................................................. 15

Figure 2-14. FDS PPV Fan Visualized in Smokeview ............................................... 15

Figure 2-15. Smokeview Visualization of FDS PPV Flow Pattern ............................. 17

Figure 2-16. Experimental Velocities $1830 \mathrm{~mm}$ (6 ft) From the Fan .......................... 18

Figure 2-17. FDS Velocities $1830 \mathrm{~mm}$ (6 ft) From the Fan ....................................... 18

Figure 2-18. Experimental Velocities $2440 \mathrm{~mm}$ (8 ft) From the Fan ......................... 19

Figure 2-19. FDS Velocities $2440 \mathrm{~mm}$ (8 ft) From the Fan ...................................... 19

Figure 2-20. Experimental Velocities $3050 \mathrm{~mm}$ (10 ft) From the Fan ........................ 20

Figure 2-21. FDS Velocities $3050 \mathrm{~mm}$ (10 ft) From the Fan .................................... 20

Figure 3-1. Floor Plan of Simple Room ............................................................. 22

Figure 3-2. Simple Room Experimental Layout........................................................... 23

Figure 3-3. Experimental Layout Looking at Room Inlet and Outlet.......................... 23

Figure 3-4. Inlet and Outlet From a Different Perspective ........................................ 23

Figure 3-5. Doorway (Inlet) Measurements Points..................................................... 24

Figure 3-6. Window (Outlet) Measurement Points.................................................... 25

Figure 3-7. Visualization of Supplemental Experiment as Soon as Room is

Pressurized ................................................................................................ 26

Figure 3-8. Visualization of Supplemental Experiment Once Constant Flow is



Figure 3-9. FDS Layout for Simple Room Experiement .............................................. 28

Figure 3-10. Grid Cell Visualization, Multiblocking................................................... 29

Figure 3-11. FDS Layout Looking at Room Inlet and Outlet...................................... 29

Figure 3-12. FDS Layout with Fan Operating ........................................................... 31

Figure 3-13. Experimental Velocity Measurements in the Doorway (Inlet) .............. 32

Figure 3-14. FDS Velocities in the Doorway (Inlet) …………….............................. 32

Figure 3-15. Experimental Measurements in the Window (Outlet) ............................ 33

Figure 3-16. FDS Velocities in the Window (Outlet).................................................. 33

Figure 3-17. Smokeview Visualization of FDS PPV Flow Pattern .............................. 36

Figure 3-18. Experimental Visualization of the PPV Flow Pattern............................. 36 
Figure 3-19. FDS Visualization of Supplemental Experiment as Soon as Room is

Pressurized

Figure 3-20. Visualization of Supplemental Experiment as Soon as Room is

Pressurized

Figure 3-21. FDS Visualization of Supplemental Experiment Once Constant

Flow is Achieved

Figure 3-22. Visualization of Supplemental Experiment Once Constant Flow is

Achieved 38

Figure 4-1. Experimental Floor Plan

Figure 4-2. External View of Window in Closed Position ...................................... 42

Figure 4-3. External View of Open Corridor Doorway ........................................... 42



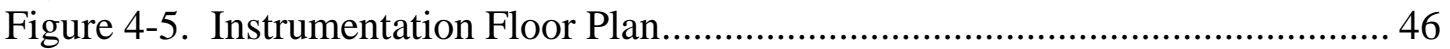

Figure 4-6. Doorway and Window Probe and Thermocouple Combination ............. 47

Figure 4-7. View of Doorway From Inside the Room into Corridor and



Figure 4-8. Bidirectional Probe and Thermocouple Combination............................ 48



Figure 4-10 - Book Case .............................................................................. 50

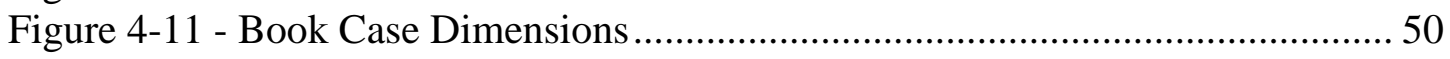

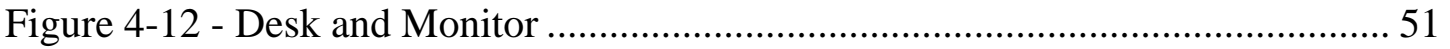

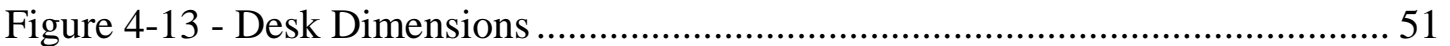

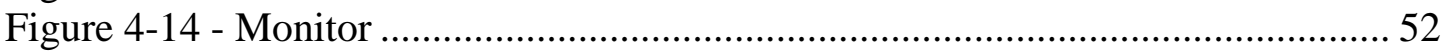



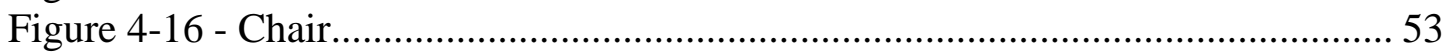

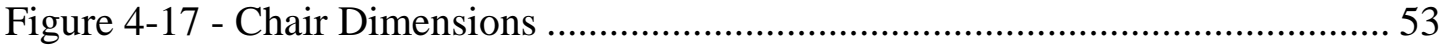



Figure 4-19 - Bunk Bed Dimensions ................................................................ 54



Figure 4-21. Electrically Activated Matchbook Locations ...................................... 57

Figure 4-22. Exterior View of Doorway to Corridor After the Start of Forced



Figure 4-23. Exterior View of Window After the Start of Forced Ventilation



Figure 4-24. Doorway During Natural Ventilation Experiment (645 s).................... 61

Figure 4-25. Window During Natural Ventilation Experiment (470 s).................... 61

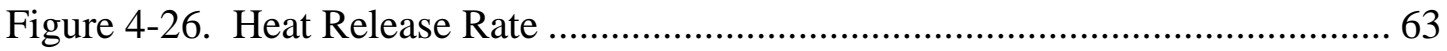

Figure 4-27. Heat Release Rate Detail For 200secondsFollowing Peak Output ....... 64



Figure 4-29. PPV Room Temperatures, Distances Measured From Ceiling............. 66



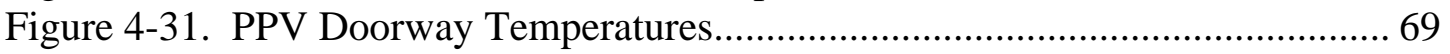

Figure 4-32. Natural Ventilation Doorway Temperatures ...................................... 70



Figure 4-34. Natural Ventilation Window Temperatures....................................... 72

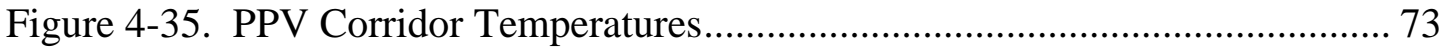


Figure 4-36. Natural Ventilation Corridor Temperatures ............................................. 74

Figure 4-37. PPV Room Differential Pressure ........................................................ 75

Figure 4-38. Natural Ventilation Room Differential Pressure..................................... 76

Figure 4-39. PPV Window Velocities .................................................................... 77

Figure 4-40. Natural Ventilation Window Velocities.................................................. 78

Figure 4-41. PPV Room Doorway Velocities............................................................ 80

Figure 4-42. Natural Ventilation Room Doorway Velocities....................................... 81

Figure 4-43. FDS Naturally Ventilated Domain.......................................................... 83

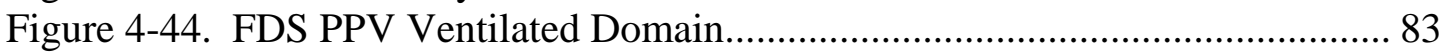

Figure 4-45. Grid Cell Visualization ..................................................................... 84

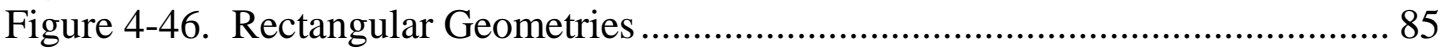

Figure 4-47. Location of Ignition Source ………………....................................... 87

Figure 4-48. Bunkbed View at Time of Ignition (0 seconds) ................................... 89

Figure 4-49. Doorway and Window View at Time of Ignition (0 seconds) ............... 89

Figure 4-50. Fire Starting on Corner of Mattress (90 seconds) .................................. 90

Figure 4-51. Flames Involving Bunkbed (230 seconds) ............................................ 91

Figure 4-52. Onset of Flashover (275 seconds) ......................................................... 91

Figure 4-53. Visibility Lost in Bunk Bed View (300 seconds) ................................. 92

Figure 4-54. Combustion Products Flow From Corridor Doorway (330 seconds) ... 93

Figure 4-55. Flames Extend From Corridor Doorway Once Window is

Opened (360 seconds)..................................................................................... 93

Figure 4-56. Flames From Window (360 seconds) .................................................. 94

Figure 4-57. Flames Continue From Window (430 seconds)..................................... 94

Figure 4-58. Fire in Decay Stage (540 seconds).................................................... 95

Figure 4-59. Room Continues to Burn (720 seconds) …………………………....... 96

Figure 4-60. FDS and Experimental Naturally Ventilated Heat Release Rate.......... 98

Figure 4-61. FDS and Experimental Naturally Ventilated Total Heat Released....... 99

Figure 4-62. FDS Naturally Ventilated Room Temperatures..................................... 101

Figure 4-63. FDS Naturally Ventilated Room Doorway Temperatures .................... 102

Figure 4-64. FDS Naturally Ventilated Corridor Doorway Temperatures ................ 103

Figure 4-65. FDS Naturally Ventilated Window Velocities...................................... 104

Figure 4-66. FDS Naturally Ventilated Room Doorway Velocities.......................... 105

Figure 4-67. External Door View With Fan Prior to Ignition (0 seconds) ............... 106

Figure 4-68. Bunkbed View as Flames Involve Corner of Mattress (60 seconds).. 107

Figure 4-69. Doorway and Window View as Flames Spread to Top Mattress

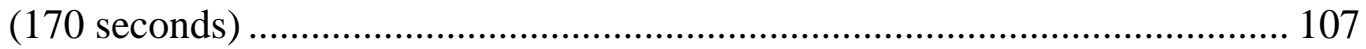

Figure 4-70. Flames Involving Bunk Bed (240 seconds) ....................................... 108

Figure 4-71. Visibility Lost in Bunk Bed View (300 seconds) ................................ 108

Figure 4-72. Thick Smoke Flows From Corridor Doorway (300 seconds)............. 109

Figure 4-73. Doorway and Window View Obstructed by Flames (360 seconds) ... 110

Figure 4-74. Doorway View 10 seconds After Fan is Turned On (360 seconds).... 110

Figure 4-75. Flames From Window (360 seconds) ................................................. 110

Figure 4-76. Flames Continue From Window (400 seconds).................................. 111

Figure 4-77. Combustion Products Forced into Room by Fan (410 seconds)......... 112

Figure 4-78. Fire in Decay Stage (445 seconds).................................................... 112

Figure 4-79. Fan Forcing Flow Through Room (500 seconds) ............................... 113 
Figure 4-80. FDS and Experimental Positive Pressure Ventilated Heat

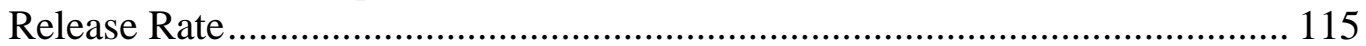

Figure 4-81. FDS Heat Release Rate Comparison............................................... 115

Figure 4-82. FDS PPV Ventilated Room Temperatures........................................ 116

Figure 4-83. FDS PPV Ventilated Room Doorway Temperatures.......................... 117

Figure 4-84. FDS PPV Ventilated Corridor Doorway Temperatures....................... 119

Figure 4-85. FDS PPV Ventilated Window Velocities ........................................ 119

Figure 4-86. FDS PPV Ventilated Room Doorway Velocities.............................. 120

Figure 5-1. Colonial House and Grid Locations................................................... 130

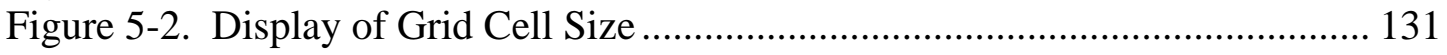

Figure 5-3. Colonial House and PPV Fan Placement .......................................... 131

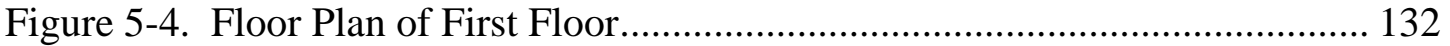

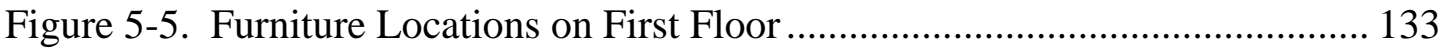

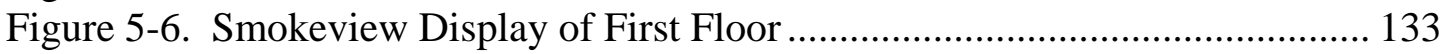

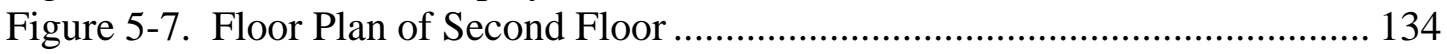

Figure 5-8. Furniture Locations on Second Floor................................................... 134

Figure 5-9. Smokeview Display of Second Floor.................................................. 135

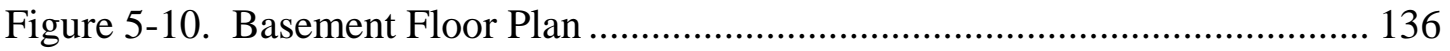

Figure 5-11. Smokeview Display of Basement .................................................. 136

Figure 5-12. Front and Rear View of House........................................................ 137

Figure 5-13. Location of Room Vents with Roof Removed................................... 138

Figure 5-14. View of Interior from Inside the Front Door .................................... 140

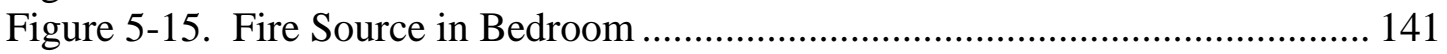

Figure 5-16. Growth of Fire Prior to Ventilation, 60 seconds to 240 seconds ........ 144

Figure 5-17. Comparison of Simulations at 250 seconds ..................................... 145

Figure 5-18. Comparison of Simulations at 360 seconds ..................................... 145

Figure 5-19. Comparison of Simulations at 360 seconds ...................................... 145

Figure 5-20. Comparison of Simulations at 600 seconds ..................................... 146

Figure 5-21. Colonial House Heat Release Rate Comparison ................................ 147

Figure 5-22. Comparison of Second Floor Temperatures 100 seconds to

300 seconds, Naturally Ventilated (Left) and PPV Ventilated (Right) ............ 151

Figure 5-23. Comparison of Second Floor Temperatures 400 seconds to 600

seconds, Naturally Ventilated (Left) and PPV Ventilated (Right) .................. 152

Figure 5-24. Comparison of First Floor Temperatures 200 seconds to 600

seconds, Naturally Ventilated (Left) and PPV Ventilated (Right) .................. 153

Figure 5-25. Comparison of Second Floor Oxygen Volume Fractions 100

seconds to 300 seconds, Naturally Ventilated (Left) and PPV Ventilated

(Right) .............................................................................................. 156

Figure 5-26. Comparison of Second Floor Oxygen Volume Fractions 300

seconds to 600 seconds, Naturally Ventilated (Left) and PPV Ventilated

(Right)

Figure 5-27. Comparison of First Floor Oxygen Volume Fractions 200 seconds

to 600 seconds, Naturally Ventilated (Left) and PPV Ventilated (Right) ........ 158

Figure 5-28. Vertical Velocity Slice Through Center of Fan .................................. 160

Figure 5-29. Velocity Slice Through Center of Vent Window During PPV

Ventilation Scenario at 320 seconds 
Figure 5-30. Velocity Slice Through Center of Vent Window During Natural

Ventilation Scenario at 320 seconds ................................................................ 161

Figure 5-31. Horizontal Velocity Slice Through Second Floor During PPV

Ventilation Scenario at 320 seconds ................................................................. 162

Figure 5-32. Horizontal Velocity Slice Through Second Floor During Natural

Ventilation Scenario at 320 seconds ............................................................... 162

Figure 5-33. Horizontal Velocity Slice Through First Floor During PPV

Ventilation Scenario at 320 seconds

163

Figure 5-34. Horizontal Velocity Slice Through First Floor During Natural

Ventilation Scenario at 320 seconds .................................................................. 163 


\section{Chapter 1: Introduction}

In the past Positive Pressure Ventilation (PPV) has been a ubiquitous tool used by fire departments to ventilate a structure after a fire has been extinguished. Typically this allowed fire fighters to complete salvage and overhaul operations in a less hazardous atmosphere. PPV has also been implemented as a tactic during a fire attack. The fan was started in coordination with a ventilation opening during the initial phase of fire attack. This tactic was designed to increase visibility and force heat away from the attack team as they locate and extinguish the fire. PPV has been implemented with some success, but also with some difficulty. PPV has not been carefully characterized in terms of gas temperatures, gas velocities and mass burning rates. Without additional understanding of the impacts or effects caused by PPV, the difficulties associated with PPV have given rise to several issues, such as: When should PPV be used, and just as important, when should it not be used? What is the best location for the fan and where should the exhaust or vent opening be made? Does PPV provide oxygen to the fire and allow for quicker fire growth? What is the consequence if fire fighters or building occupants are between the fire and the exhaust opening? Are there certain types of construction when PPV should not be used?

As early as 1989, fire department training publications questioned whether PPV fans

would intensify a fire by introducing additional oxygen. Carlson [1] responded to this question, stating that it was a possibility, but there was no evidence or research to substantiate his answer. As part of their "Roundtable" discussion in 1999, Fire 
Engineering polled fire chiefs from around the country to determine the extent to which their departments used PPV. Many of the polled departments used PPV, but some did not use it offensively with the explanation that intensifying the fire was a concern and this phenomena was not well understood [2].

In 2001, Yates conducted an investigation and survey of the usage of PPV in the Tyne and Wear Metropolitan Fire Brigade in the United Kingdom, Salt Lake City Fire Department in the United States, and the Aachen Fire Department in Germany [3]. The survey suggested a few reasons for the lack of implementation of PPV. Two of these reasons were the potential for increased damage to structures and insufficient research data and evidence available to support PPV's benefits. This is further evidence that PPV lacks the firm scientific foundation necessary for optimum use for both salvage and overhaul as well as fire suppression operations.

\subsection{Positive Pressure Ventilation}

PPV is a ventilation technique used by the fire service to remove smoke, heat and other combustion products from a structure. This allows the fire service to perform other tasks in a more tenable atmosphere. PPV fans are commonly powered with an electric or gasoline engine and range in diameter from $0.30 \mathrm{~m}$ to $0.91 \mathrm{~m}$ (12 in to 36 in) (Figure 1-1). Typically, a positive pressure ventilation fan is placed about $1.8 \mathrm{~m}$ to $3.0 \mathrm{~m}$ ( $6 \mathrm{ft}$ to $10 \mathrm{ft}$ ) outside the doorway of the structure. It is positioned so that the "cone of air" produced by the fan extends beyond the boundaries of the opening (Figure 1-2). With the doorway within the cone of air, 
pressure inside the structure increases. An exhaust opening in the structure, such as an opening in the roof or an open window, allows the air to escape due to the difference between the inside and outside air pressure. The smoke, heat and other combustion products are pushed out of the structure and replaced with ambient air [4].
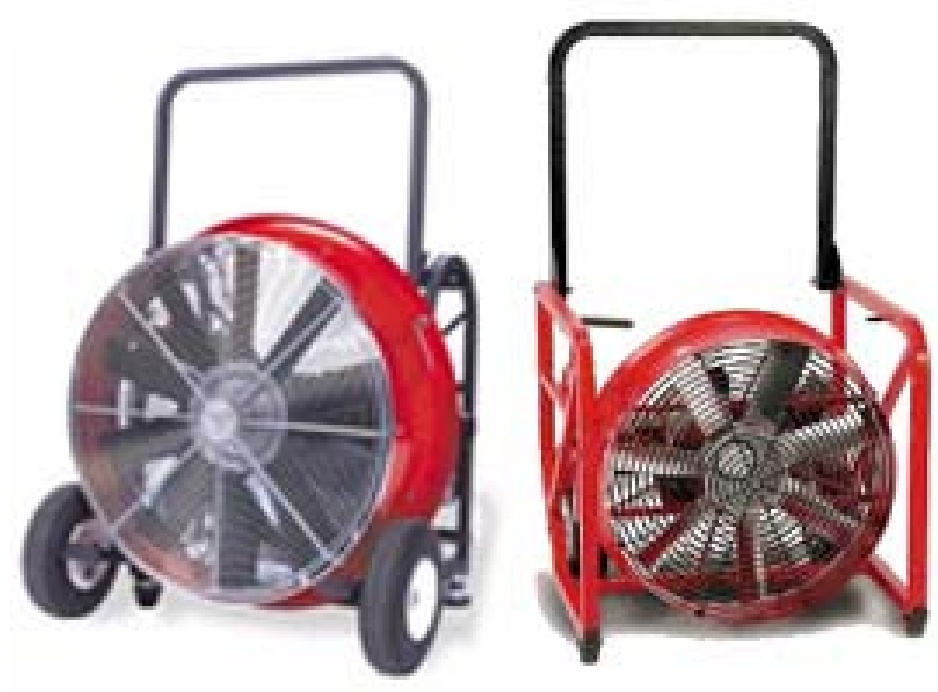

Figure 1-1. Two Common PPV Fans

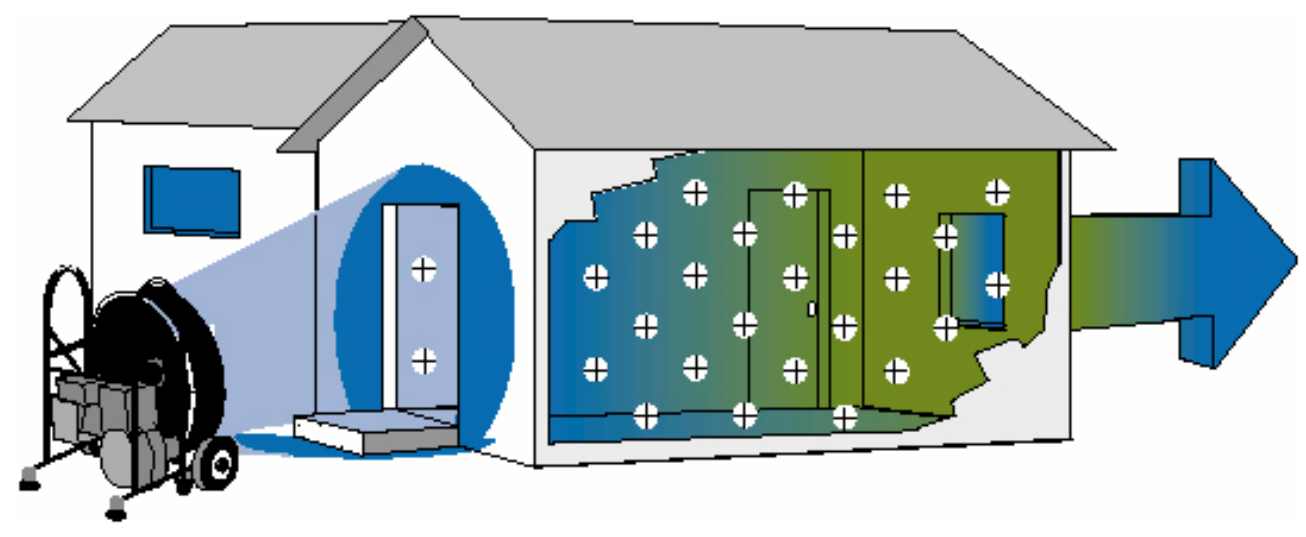

Figure 1-2. PPV Cone of Air [4] 


\subsection{Fire Dynamic Simulator}

The National Institute of Standards and Technology's Fire Dynamics Simulator (FDS) is a computational fluid dynamics (CFD) model of fire-driven fluid flow. It numerically solves a form of the Navier-Stokes equations appropriate for low-speed, thermally driven flow with an emphasis on smoke and heat transport from fires [5]. Version 1 was publicly released in February 2000. The predictions performed here were made with the public pre-release version 4 of the model [6]. Version 4 includes several new features such as multi-blocking which were critical in performing the room fire simulations.

A CFD model requires that the room or building of interest be divided into small three-dimensional rectangular control volumes or computational cells. The CFD model computes the density, velocity, temperature, pressure and species concentration of the gas in each cell as it steps through time. Based on the laws of conservation of mass, momentum, species and energy, the model tracks the generation and movement of fire gases. Radiative heat transfer is included in the model via the solution of the radiation transport equation for a non-scattering gray gas. All solid surfaces are assigned thermal boundary conditions, in addition to information about the burning behavior of the material. Heat and mass transfer to and from solid surfaces is usually handled with empirical correlations. FDS utilizes material properties of the furnishings, walls, floors, and ceilings to compute fire growth and spread. A complete description of the FDS model is given in references $[5,6]$. 
Inputs required by FDS include the geometry of the structure and furnishings, the computational cell size, the location of the ignition source, the energy release rate of the ignition source, thermal properties of walls, ceilings, floors, furnishings, and the size, location, and timing of door and window openings to the outside which critically influence fire growth and spread.

\subsection{Smokeview}

Smokeview is a scientific visualization program that was developed to display the results of an FDS model computation [7]. Smokeview allows the viewing of FDS results in three-dimensional snapshots or animations. Smokeview can display contours of temperature, velocity and gas concentration in planar slices. It can also display properties with iso-surfaces that are three-dimensional versions of a constant value of the property. Iso-surfaces are most commonly used to provide a threedimensional approximation of the flame surface where fuel and oxygen are present such that flames may exist. 


\section{Chapter 2: Mapping the PPV Velocity Flow Field}

This research effort used a series of full-scale experiments to examine how positive pressure ventilation (PPV) may impact structural ventilation. These same experiments were simulated with NIST's FDS to provide more insight into the impact of ventilation on fire behavior. The computer simulations were compared with the full-scale test results. This enabled the validation of the computer simulation and as necessary, identified areas that need improvement. Ultimately, PPV computer simulations could be used to improve fire fighter safety by enabling improved understanding of structural ventilation techniques.

PPV fans are engineered to maximize airflow while allowing the fan to remain light and durable for fire service use. Simply, a blade or impeller pulls air through a shroud creating the airflow. This blade or impeller is driven by an electric or gasoline engine all of which are mounted in a frame. The velocity field that is created is complex due to the speed at which the blade or impeller rotates to achieve a conical flow. These experiments examine FDS's ability to accurately characterize this complex flow.

\subsection{Experimental Description}

The initial series of experiments served to determine the flow field created by PPV fans. In order to implement a PPV fan in FDS it was necessary to characterize the fan in terms of FDS input parameters such as obstruction and vent locations and 
orientations. This basic environment was an open atmosphere with the fan located on a stand that had negligible effects on the flow, essentially placing the fan in open space. This placement minimized the impact from obstructions such as walls and doorways on the flow field.

\subsubsection{Experimental Facility}

These experiments were conducted at NIST's Building and Fire Research Laboratory Large Fire Facility. The experiment was located in an area inside the facility so that the airflow created by the PPV fan was not affected by external factors such as wind or weather. The facility has the interior dimensions, $36.6 \mathrm{~m}$ (120 ft) long,

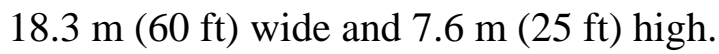

\subsubsection{Experiment Components}

\section{Grid}

A grid frame, $2.44 \mathrm{~m} \mathrm{x} 2.44 \mathrm{~m}$ ( $8 \mathrm{ft}$ x $8 \mathrm{ft}$ ), was constructed with $51 \mathrm{~mm}$ x 102mm ( 2 in $x 4$ in) wood members to form a square configuration. The corners were reinforced with plywood triangles. Cotton strings approximately $1.6 \mathrm{~mm}$ (0.0625 in) in diameter were placed on the grid both vertically and horizontally to form a grid. The center was highlighted by using orange string, while white strings were placed every $102 \mathrm{~mm}$ (4 in) for the first 305 mm (12 in) then every $152 \mathrm{~mm}$ (6 in) towards the edge of the frame in both directions. The frame was notched to keep the strings in place (Figure 2-1). Once the strings were all in place, $203 \mathrm{~mm}$ (8 in) long threads 
were added to each point on the grid. These threads made it possible to view the direction of airflow (Figure 2-2). Finally, black felt was added to the frame, parallel to the threads in order to give a contrasting background to the threads to aid in picture taking.

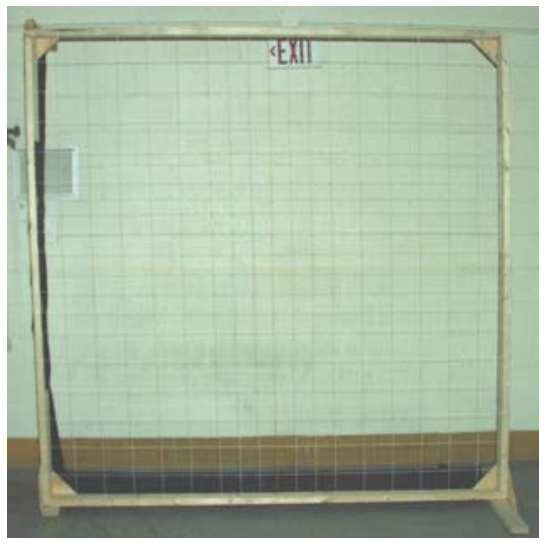

Figure 2-1. The Flow Characterization Grid

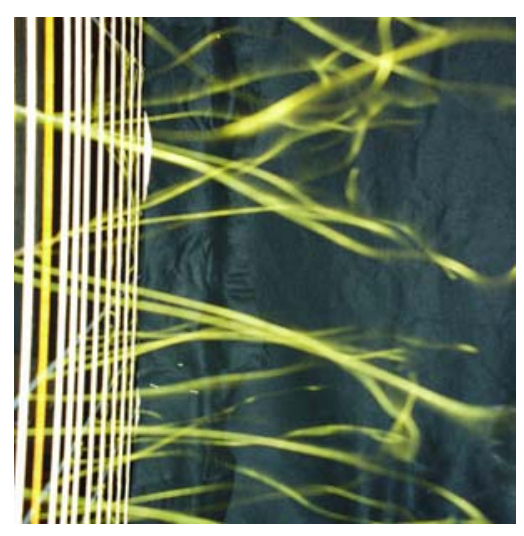

Figure 2-2. Flow Visualization Threads

\section{Fan}

The fan used was an 18-inch, variable speed, electric positive pressure ventilator.

The fan has a depth of $476 \mathrm{~mm}$ (18.75 in), width of $622 \mathrm{~mm}$ (24.5 in) and height of $622 \mathrm{~mm}$ (24.5 in). It has a maximum speed of 2200 RPM, a horsepower rating of $746 \mathrm{~W}$ (1 hp) and a flow rating of $6.64 \mathrm{~m}^{3} / \mathrm{s}\left(14,060 \mathrm{ft}^{3} / \mathrm{min}\right)$. The fan was mounted on a stand to set the fan at the proper height of $1.28 \mathrm{~m}$ (50.5 in), measured from the center of the fan to the ground (Figure 2-3). The grid was positioned so that the center of the fan impeller was on the centerline of the grid. 


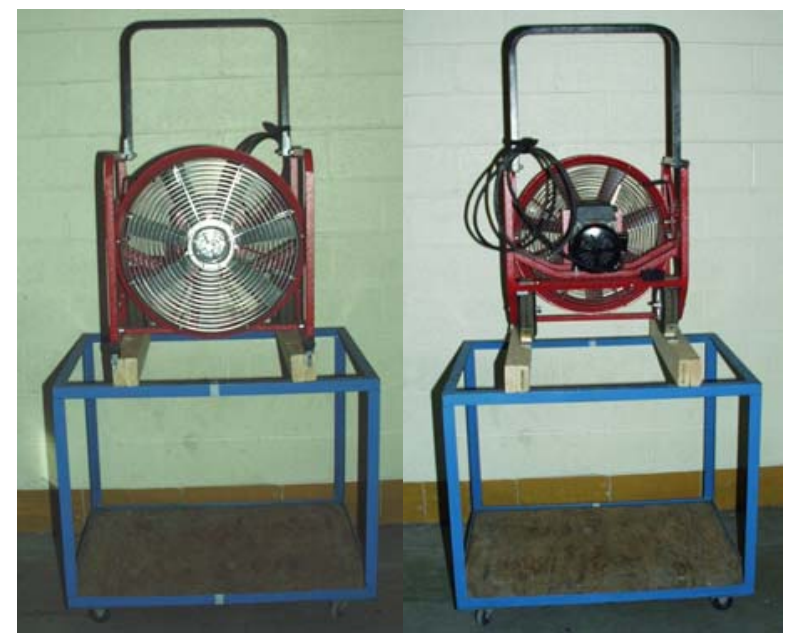

Figure 2-3. Front and Back of PPV Fan

\section{Anemometer}

The digital anemometer used was a $25.4 \mathrm{~mm}$ (1 in) diameter vane-type probe (Figure 2-4). It is microprocessor-based with a range of $0.3 \mathrm{~m} / \mathrm{s}(1.0 \mathrm{ft} / \mathrm{s})$ to $35.0 \mathrm{~m} / \mathrm{s}$ (115 ft/s) with an accuracy of $0.5 \%$ of the readings [8].

In order to position the anemometer at various locations an anemometer indexer was fabricated. The indexer allowed the anemometer to be placed at any point on the grid by moving it horizontally and vertically. The indexer also permitted the anemometer to rotate in both the $\mathrm{x}$ and $\mathrm{y}$-axis. This rotation allowed the measurement of velocities that were not parallel to the ground and perpendicular to the fan. The indexer moved horizontally across the grid on wheels that were grooved to ride an angle iron track. This track was positioned on the ground parallel with the grid (Figure 2-5). 


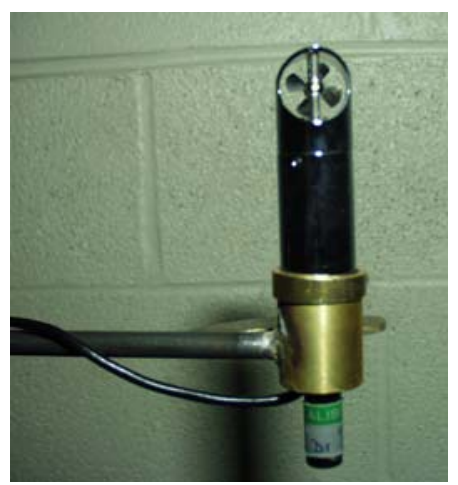

Figure 2-4. Anemometer

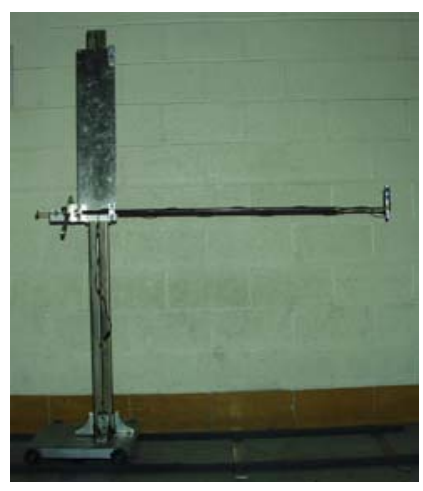

Figure 2-5. Anemometer in Indexer on Track

\subsubsection{Experiment Procedure}

The grid and track were placed perpendicular to the flow. The fan was positioned so that the flow was centered on the grid $1.28 \mathrm{~m}(4.2 \mathrm{ft})$ above the floor. The anemometer indexer was moved along the track and the height of the anemometer adjusted to correspond with the measurement position on the grid (Figure 2-6). The vane of the anemometer was maintained perpendicular to the flow. The fan was started and run for two minutes at the maximum speed of $2200 \mathrm{rpm}$. The anemometer output was recorded every two seconds for four minutes using 16 second averaging. This process was repeated for the selected points on the grid shown in Figure 2-7. 


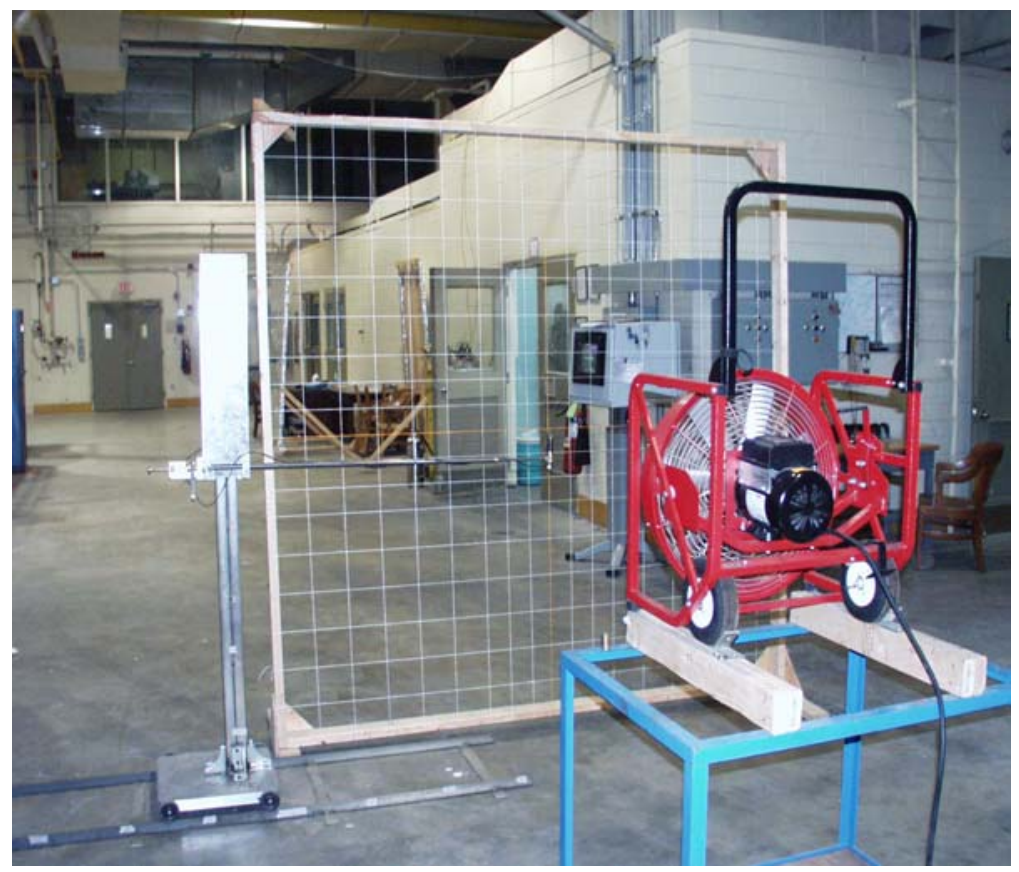

Figure 2-6. Velocity Mapping Experimental Layout

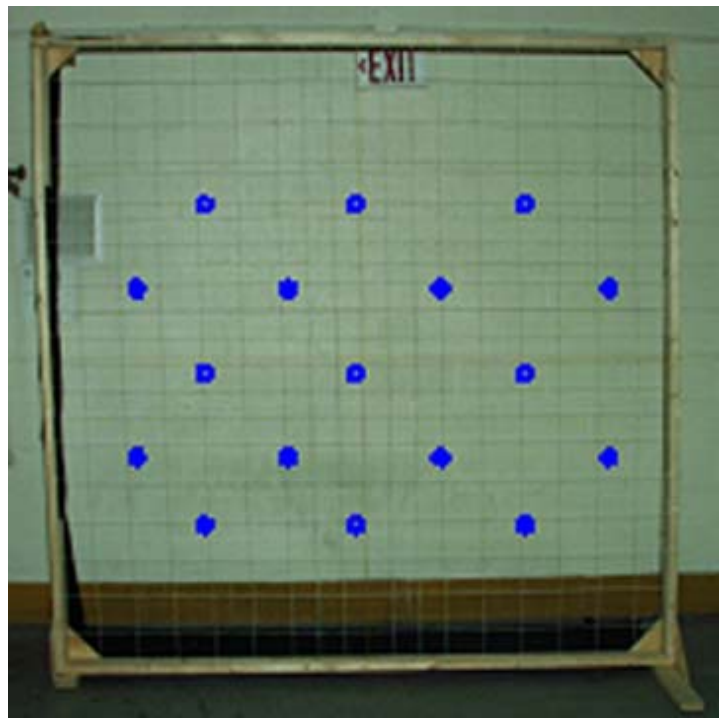

Figure 2-7. Velocity Mapping Measurement Points 


\subsubsection{Flow Visualization Experiment}

In order to visualize and qualify the flow from the fan, a supplemental test was performed. A smoke generator was placed one foot to the rear of the fan

(Figure 2-11). The fan was turned on to a speed of $2200 \mathrm{rpm}$ and allowed to reach steady state operating conditions. The smoke generator was then turned on to maximum output and pictures were taken against a black background with heights

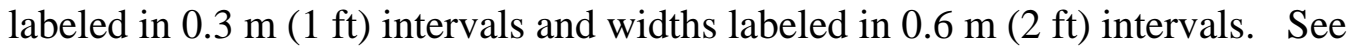

Figures 2-8 through 2-11.

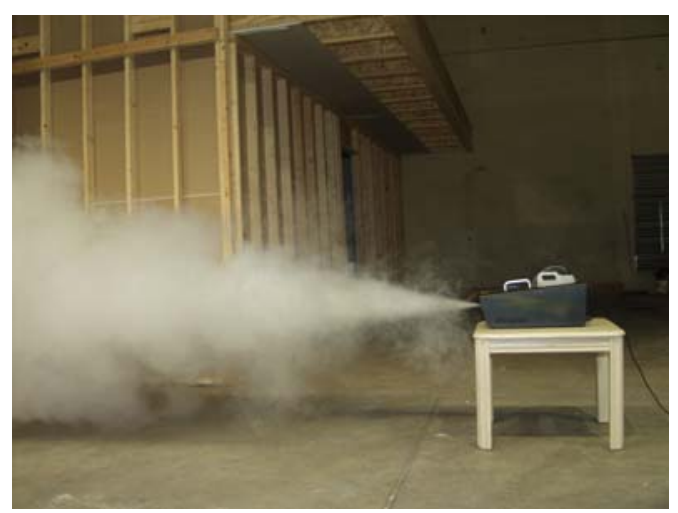

Figure 2-8. Smoke Generator Flowing

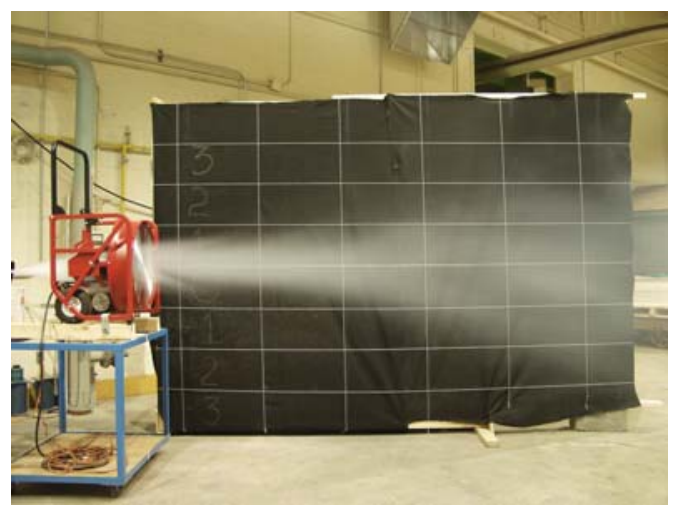

Figure 2-10. Visualization of PPV Flow

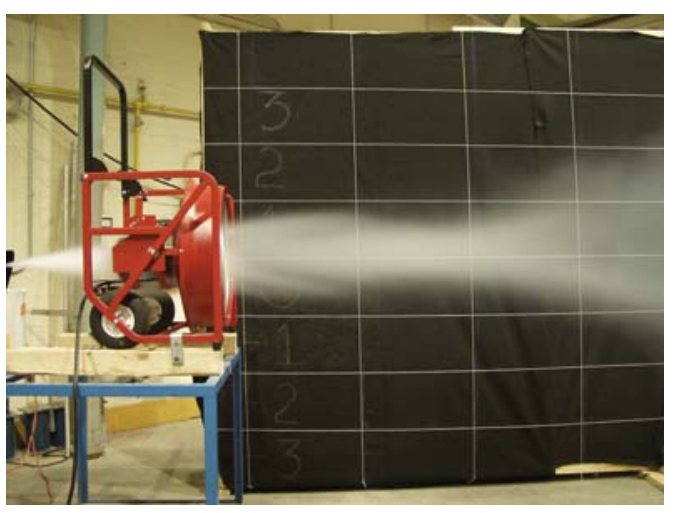

Figure 2-9. Layout for Supplemental Experiment

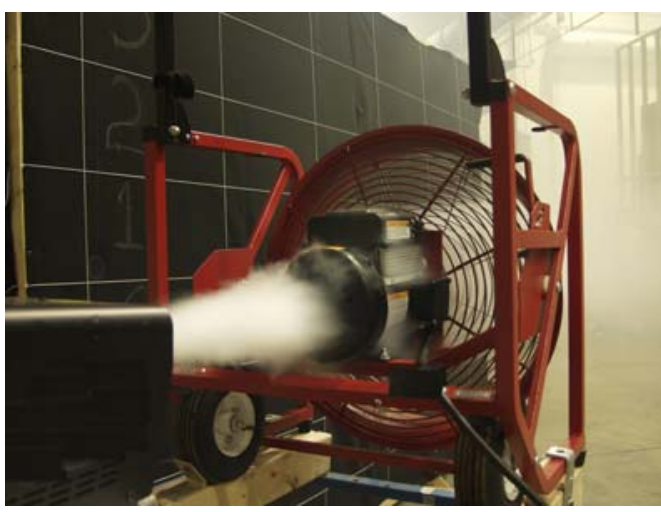

Figure 2-11. Fan and Smoke Generator 


\subsection{Computer Simulation}

Inputs required by FDS in order to model PPV fans include the following: domain size, computational cell size, vent velocity, vent geometry, fan geometry, slice location and velocity measurement points. Many inputs were used for preliminary FDS runs, which are explained in the following sections.

\subsubsection{Domain}

Many considerations need to be taken into account when modeling a PPV fan using FDS. The most important is the computational cell size. The cells need to be on the order of $16400 \mathrm{~mm}^{3}\left(1 \mathrm{in}^{3}\right)$. Once the cells are prescribed greater than $21300 \mathrm{~mm}^{3}$ $\left(1.1 \mathrm{in}^{3}\right)$ the flow from the fan becomes distorted and linear. The cell size in the computation in Figures 2-12 through 2-14 are $16400 \mathrm{~mm}^{3}\left(1 \mathrm{in}^{3}\right)$. The next consideration is the domain size. There needs to be at least $1 \mathrm{~m}(3.3 \mathrm{ft}$ ) to the rear of the fan in order for it to function accurately. If the fan is prescribed at or within $1 \mathrm{~m}$ (3.3 ft) of the boundary, whether it is "open” or not, the fan flow will not be predicted properly.

\subsubsection{Geometry and Vents}

The obstructions and vents that make up the fan itself need to be prescribed correctly. FDS only allows rectangular obstructions and vents to be created. This leads to an issue due to the cylindrical nature of the fan shroud. In order to get the proper flow pattern the shroud must be prescribed as a series of obstructions oriented in a circle 
such as Figure 2-14. The degree of roundness depends of the accuracy that is desired. The shroud in Figure 2-14 yielded good results but the shroud can be created more cylindrical if desired.

The vents are prescribed to the interior dimensions of the shroud. They also must be located on the front of the shroud, opposite the motor and handle. This allows air to be pulled through the shroud creating a more realistic flow pattern. If the vents are placed to the rear or middle of the shroud the flow pattern will appear linear and unrealistic. The vents were also prescribed a velocity. In order to match the maximum speed of the experimental PPV fan a velocity of $17.89 \mathrm{~m} / \mathrm{s}(40 \mathrm{mi} / \mathrm{h})$ was used in the FDS simulations. This input is based on the maximum speed of the experimental PPV fan from the previous section. Altering this input allows the user to characterize the fan operating at different speeds. The final items to be described are the obstructions in the center of the fan, simulating the center of the blade connected to the shaft, and the motor and handle to the rear of the shroud. Adding these obstructions created a more realistic flow pattern. They affected the air moving through the shroud in the FDS simulation similarly as they did in the experiment. Pulling air past the motor affects the flow pattern significantly so it must be included in the model.

\subsubsection{Output Files}

Slice files and prediction points were prescribed. The slice files were placed at the center of the fan in both the horizontal and vertical directions to visualize the flow 
pattern. Velocity measurement points were placed in the model in conjunction with the measurement points used experimentally, in order to make a comparison of the two at a distance of $1.83 \mathrm{~m}, 2.44 \mathrm{~m}$, and $3.05 \mathrm{~m}$ (6 ft, $8 \mathrm{ft}$ and $10 \mathrm{ft}$ ) from the PPV fan).

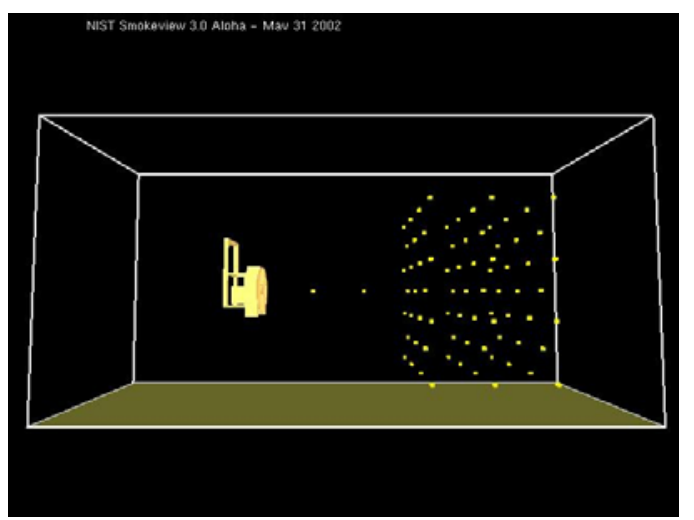

Figure 2-12. FDS Layout Visualized with Smokeview

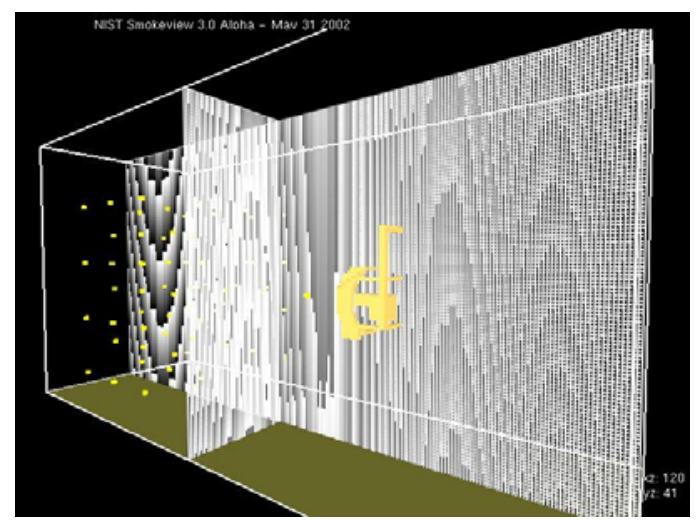

Figure 2-13. Fine Grid Cell Visualization

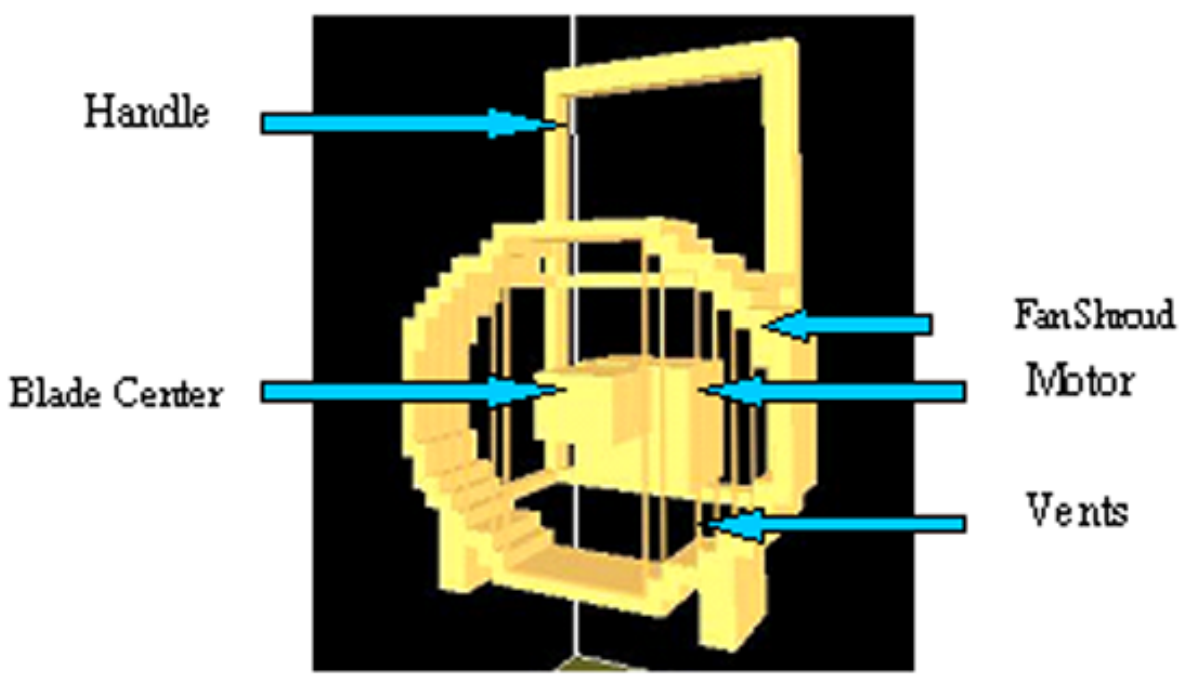

Figure 2-14. FDS PPV Fan Visualized in Smokeview 


\subsection{Results}

Velocity measurements were taken at the locations depicted in Figure 2-7. These measurements were recorded with the fan at $1.83 \mathrm{~m}, 2.44 \mathrm{~m}$, and $3.05 \mathrm{~m}(6 \mathrm{ft}, 8 \mathrm{ft}$ and $10 \mathrm{ft}$ ) from the anemometer, corresponding to typical distances of a positive pressure ventilation fan from a structure. The magnitudes of the velocities are shown in Figures 2-16, 2-18 and 2-20. The average velocities of the three distances were $2.42 \mathrm{~m} / \mathrm{s}, 2.72 \mathrm{~m} / \mathrm{s}$ and $3.35 \mathrm{~m} / \mathrm{s}(7.9 \mathrm{ft} / \mathrm{s}, 8.9 \mathrm{ft} / \mathrm{s}$ and $11.0 \mathrm{ft} / \mathrm{s})$ respectively. Using NIST's FDS, many runs were performed examining the possibilities of creating a PPV fan that closely portrays the actual fan that was used for experimentation. The final version of the fan that was created and used in the FDS runs, Figure 2-15, yielded velocity measurements that are graphed in Figures 2-17, 2-19 and 2-21. The average velocities of the three distances were $2.65 \mathrm{~m} / \mathrm{s}, 3.19 \mathrm{~m} / \mathrm{s}$ and $3.25 \mathrm{~m} / \mathrm{s}$ (8.7 ft/s, $10.5 \mathrm{ft} / \mathrm{s}$ and $10.7 \mathrm{ft} / \mathrm{s})$ respectively. Average velocities were compared due to the fluctuations in flow across the measurement plane of interest. This comparison gives an average difference of slightly less than $10 \%$ (Table 1 ). The quality of the flow can be compared in Figures 2-17 and 2-18. 
Table 1. Comparison of Experimental and FDS Velocity Mapping Results

\begin{tabular}{|l|c|c|c|}
\hline & \multicolumn{3}{|c|}{ Average Velocities (m/s (ft/s)) } \\
\hline & $1830 \mathrm{~mm}(6 \mathrm{ft})$. & $2440 \mathrm{~mm}(8 \mathrm{ft})$. & $3050 \mathrm{~mm}(10 \mathrm{ft})$. \\
\hline Experimental & $2.42(7.9)$ & $2.72(8.9)$ & $3.35(11.0)$ \\
\hline $\begin{array}{l}\text { Fire Dynamic } \\
\text { Simulator }\end{array}$ & $2.65(8.7)$ & $3.19(10.5)$ & $3.25(10.7)$ \\
\hline Percent Difference (\%) & 8.7 & 14.7 & $(3.1)$ \\
\hline
\end{tabular}

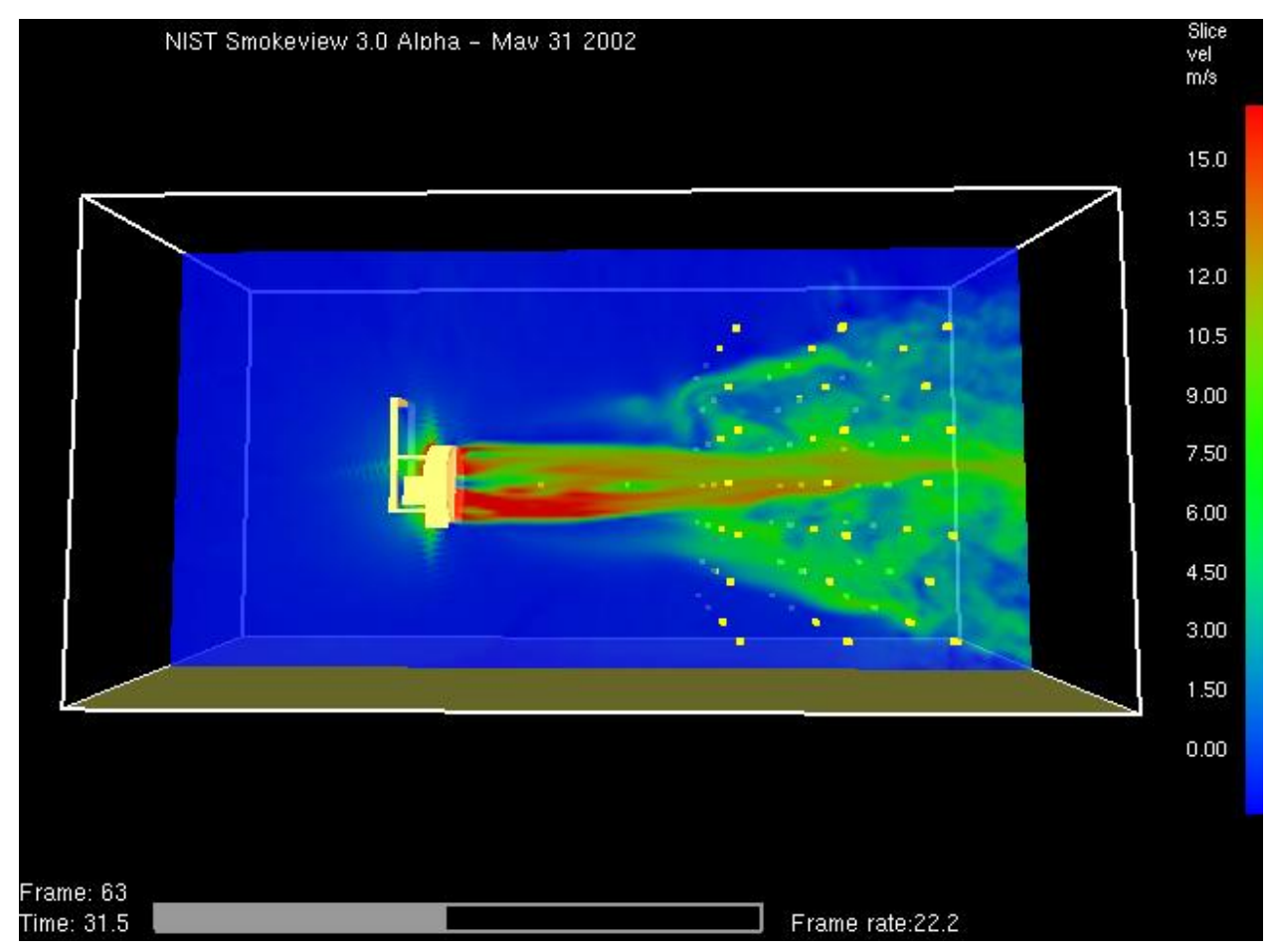

Figure 2-15. Smokeview Visualization of FDS PPV Flow Pattern 


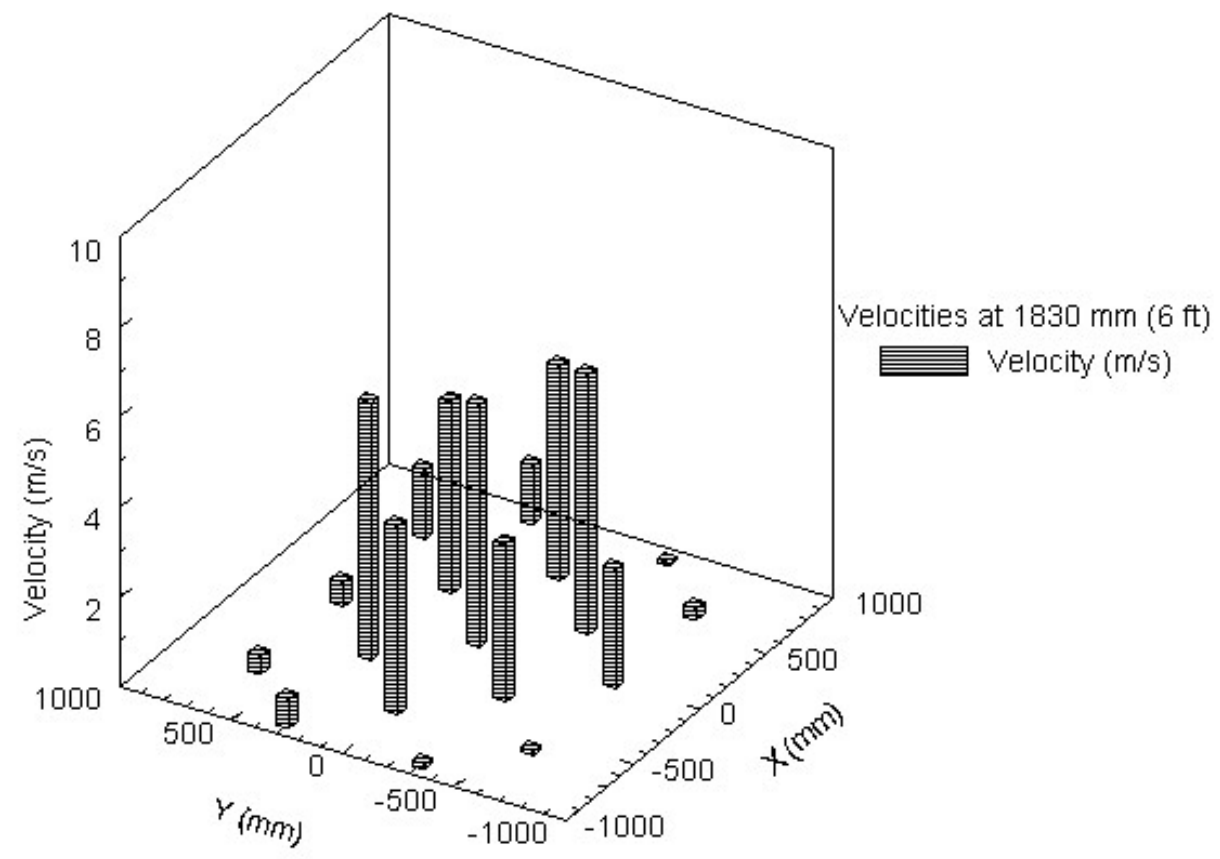

Figure 2-16. Experimental Velocities $1830 \mathrm{~mm}$ (6 ft) From the Fan

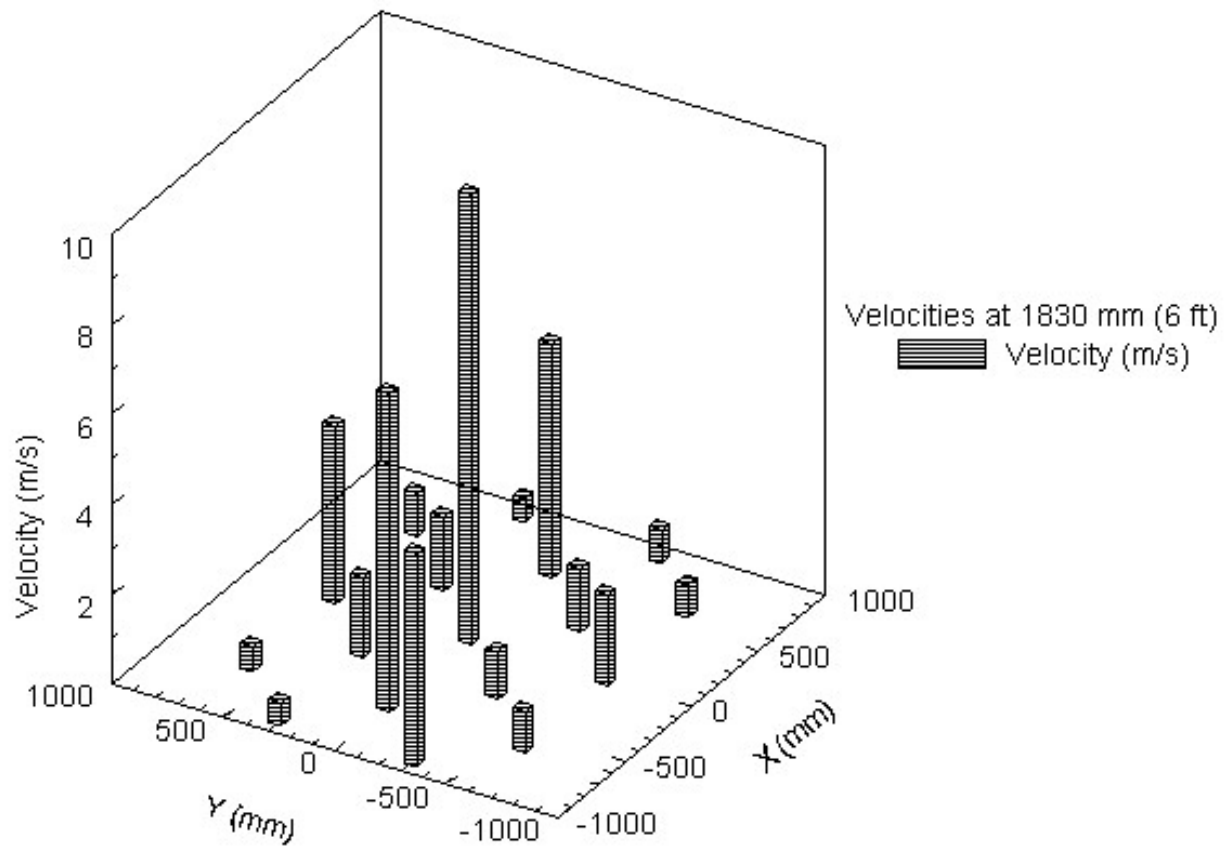

Figure 2-17. FDS Velocities $1830 \mathrm{~mm}(6 \mathrm{ft})$ From the Fan 


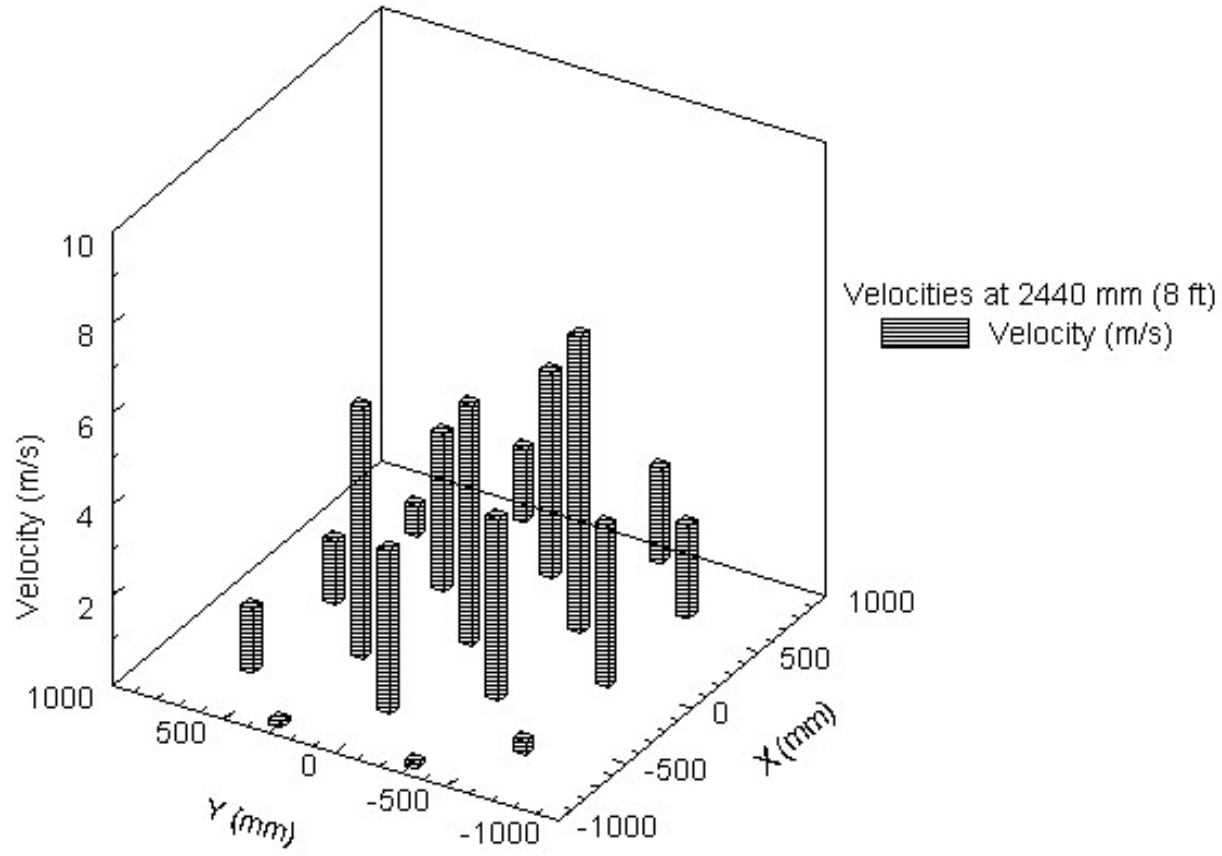

Figure 2-18. Experimental Velocities $2440 \mathrm{~mm}(8 \mathrm{ft})$ From the Fan

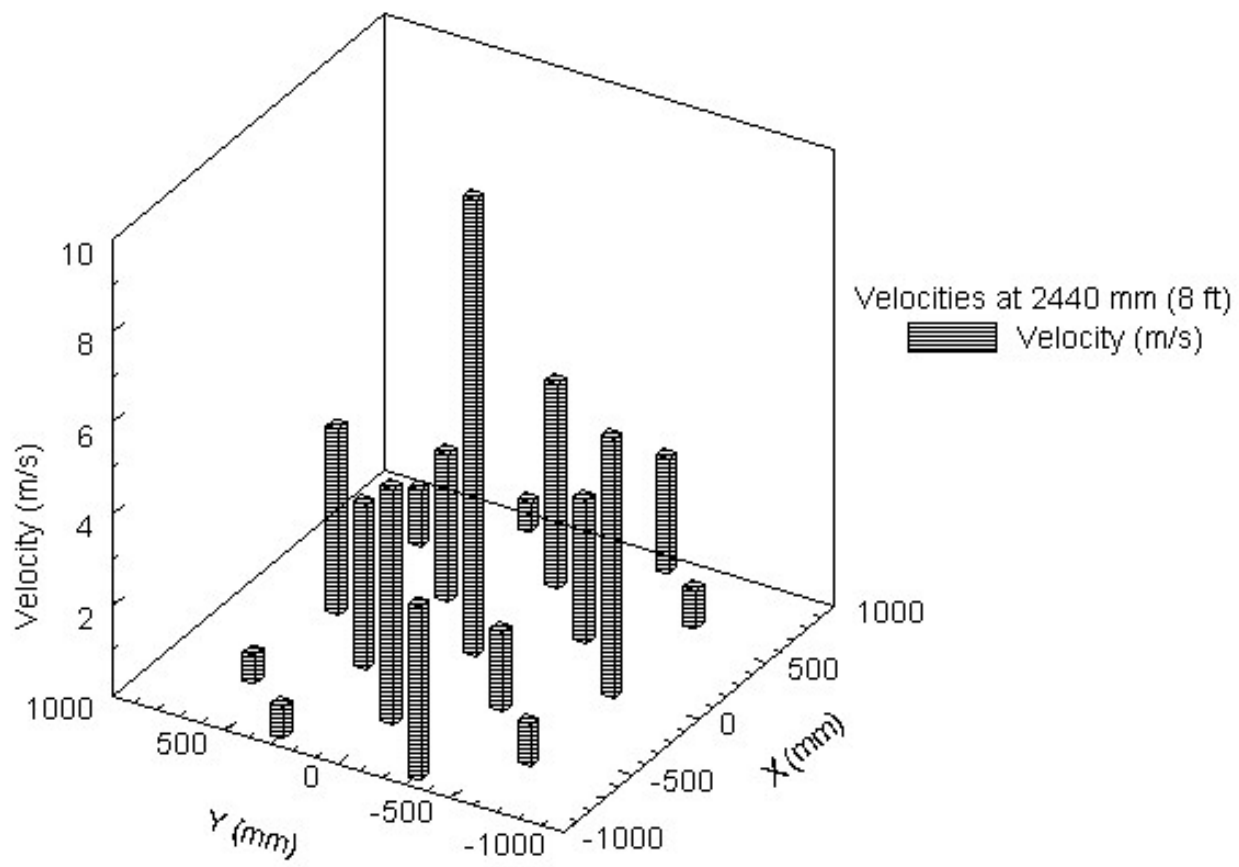

Figure 2-19. FDS Velocities $2440 \mathrm{~mm}(8 \mathrm{ft})$ From the Fan 


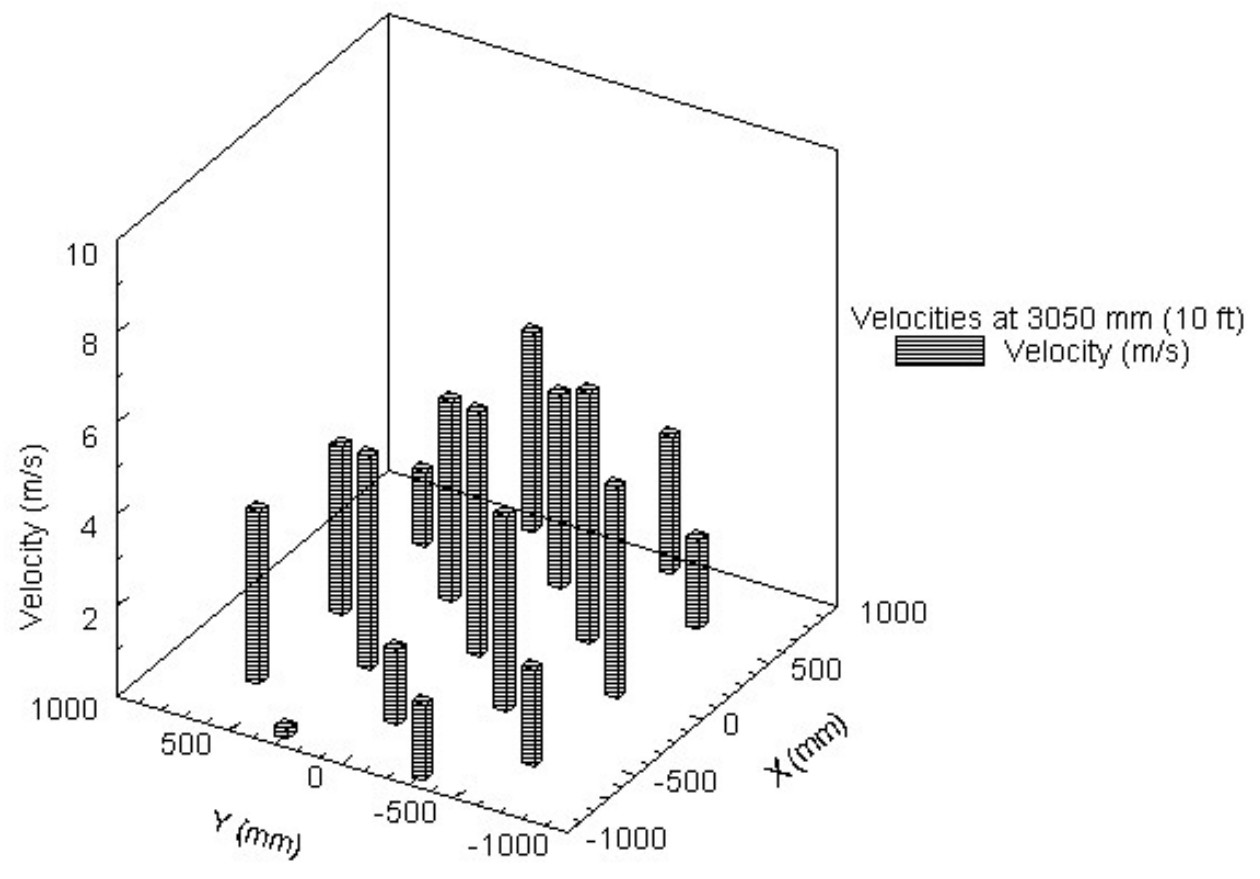

Figure 2-20. Experimental Velocities $3050 \mathrm{~mm}$ (10 ft) From the Fan

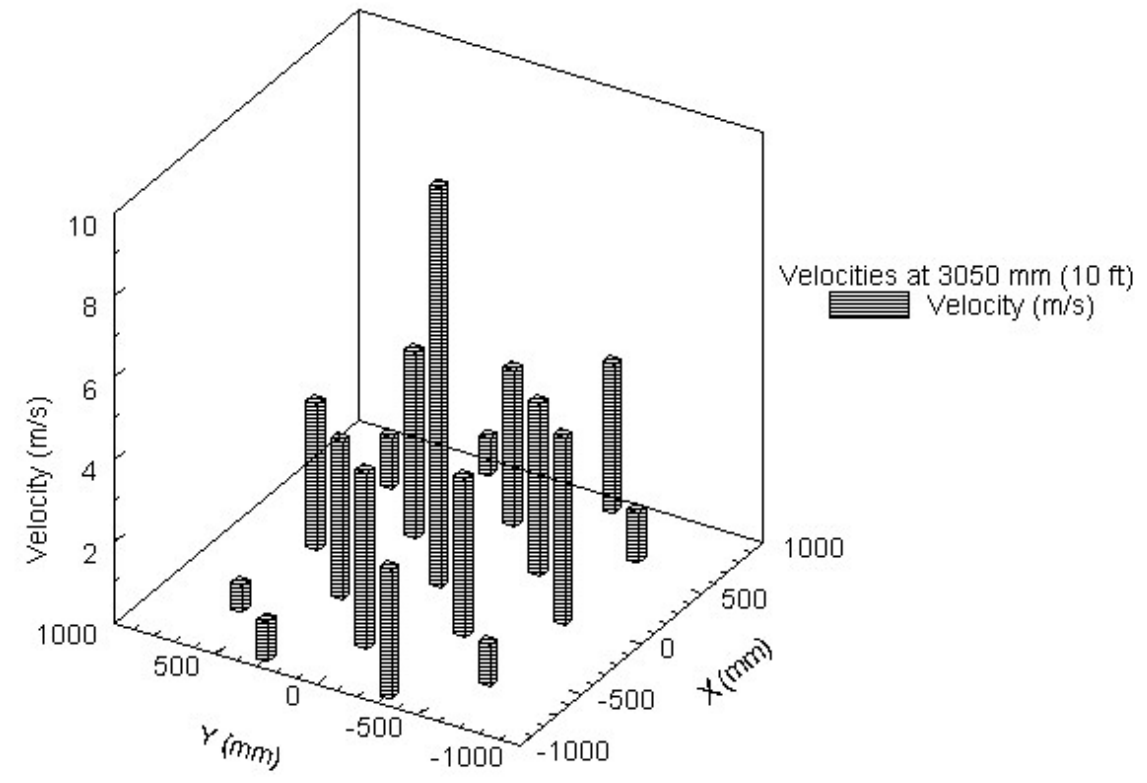

Figure 2-21. FDS Velocities $3050 \mathrm{~mm}(10 \mathrm{ft})$ From the Fan 


\section{Chapter 3: Simple Room Experiment}

\subsection{Experimental Description}

A series of experiments were conducted to determine the impact that basic room geometries have on the flow of PPV fans. The experimental results were compared to FDS simulations to see if FDS predicts the airflow accurately. Just as in chapter 2, the results will be both qualitative and quantitative.

\subsubsection{Experimental Facility}

These experiments were also conducted at NIST's Building and Fire Research Laboratory Large Fire Facility. The experiments were located in an area within the facility so that the airflow created by the PPV fan was not affected by external factors to the experiments. The facility has the following interior dimensions, 36.6 meters (120 ft) long, 18.3 meters (60 ft) wide and 7.6 meters ( $25 \mathrm{ft})$ high.

\subsubsection{Experiment Components}

\section{Fan and Anemometer}

The same fan and anemometer used in the chapter 2 experiments were used in this series of experiments. A complete description of the fan and the anemometer can be found in section 2.1.2 of this report. 


\section{Room}

The floor plan for the room is shown in Figure 3-1. The room was on a $0.2 \mathrm{~m}$ (8 in)

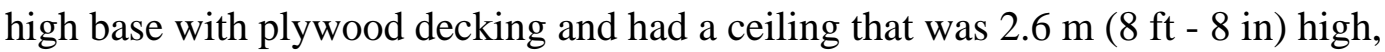
measured from the top of the base. The window on the left hand side of the room was located $0.45 \mathrm{~m}$ (18 in) off the floor and was $1.4 \mathrm{~m}$ (54 in) tall. The door centered in the front wall was $2.0 \mathrm{~m}$ (80 in) tall. All of the walls were finished with gypsum board. There was a $1.8 \mathrm{~m}(6 \mathrm{ft})$ overhang that extended over the front of the room (Figures 3-2, 3-3 and 3-4).

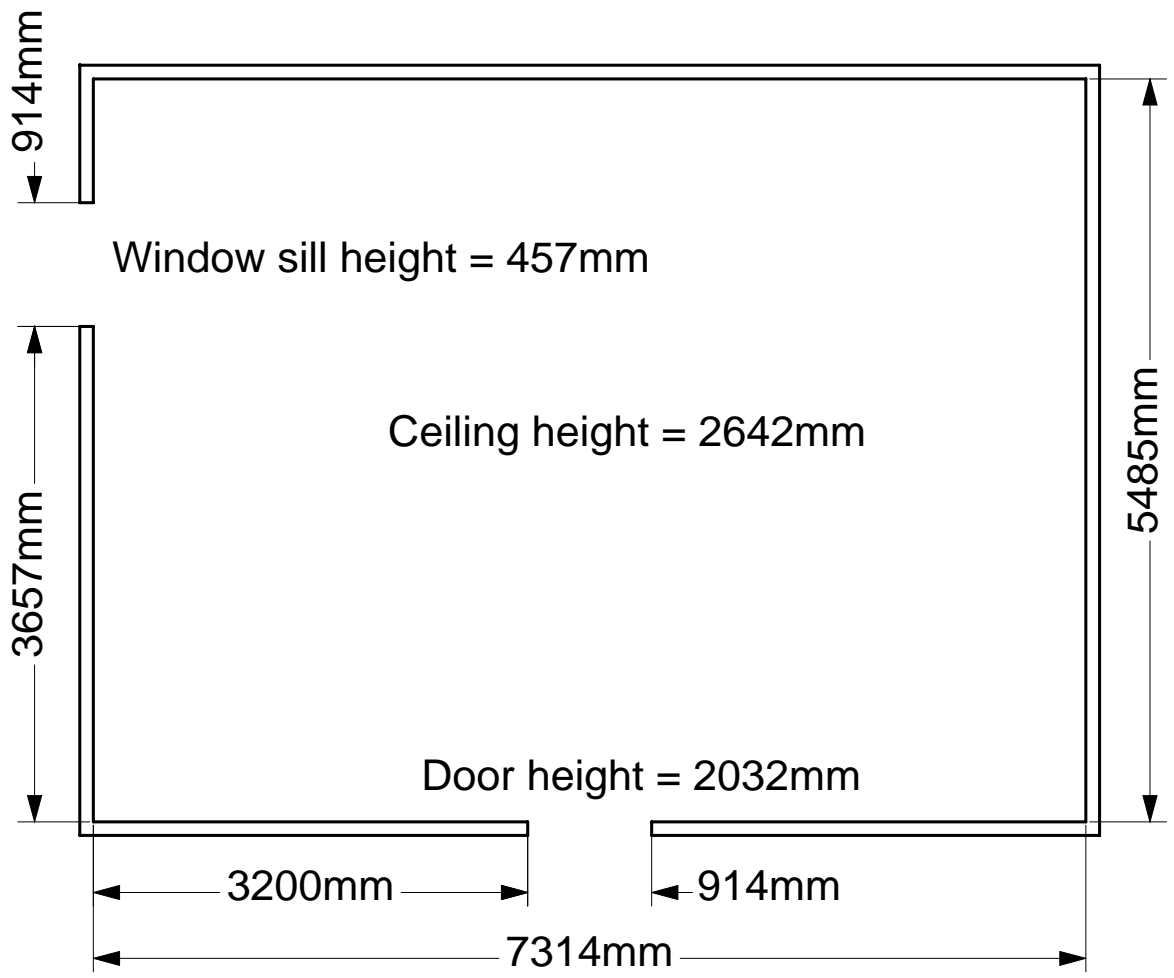

Figure 3-1. Floor Plan of Simple Room 


\subsubsection{Experiment Layout}

The fan was positioned in the center of the doorway and allowed to run at the maximum speed, 2200 RPM. The cone of air coming from the fan covered the doorway when the fan was $3.05 \mathrm{~m} \mathrm{(10} \mathrm{ft)} \mathrm{from} \mathrm{the} \mathrm{doorway} \mathrm{so} \mathrm{that} \mathrm{was} \mathrm{the} \mathrm{location}$ chosen for the tests. The doorway and window were marked with anemometer measurement locations. These locations are shown in Figures 3-5 and 3-6.

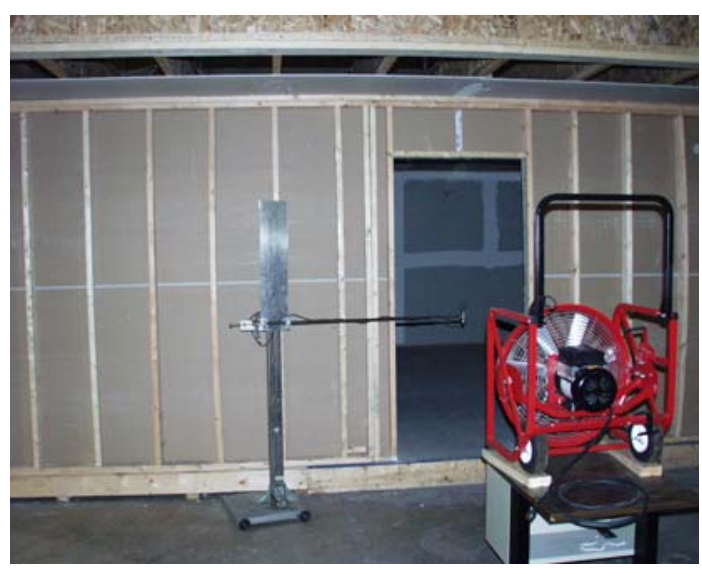

Figure 3-2. Simple Room Experimental Layout

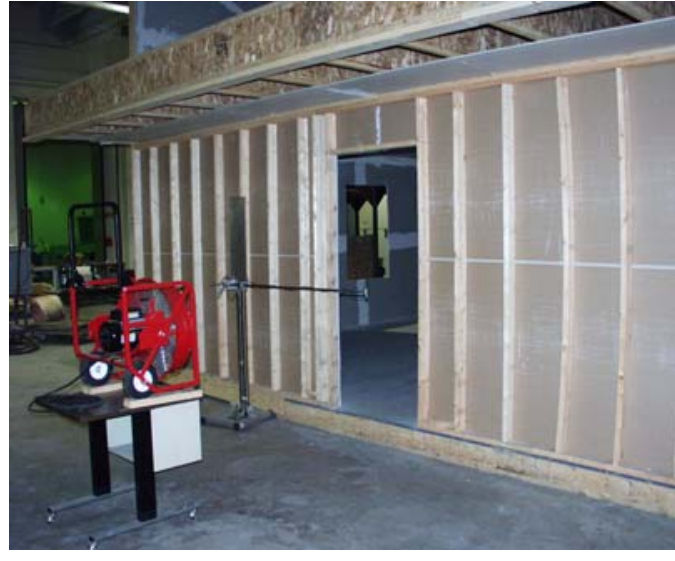

Figure 3-3. Experimental Layout Looking at Room Inlet and Outlet

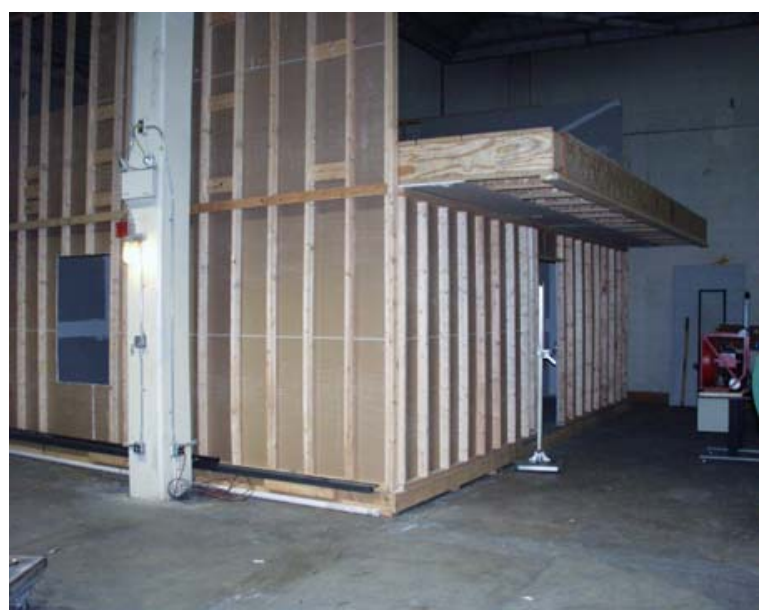

Figure 3-4. Inlet and Outlet From a Different Perspective 


\subsubsection{Experiment Procedure}

The fan was turned on and allowed to run for two minutes at the maximum speed setting, 2200 RPM. While the fan was running, the door was rechecked to make sure there was a cone of airflow around the door, and the window was checked to make sure there was a constant flow prior to measurement. Once the fan had been running for two minutes the data recording was started. Four minutes of readings were taken using sixteen second averaging with no rotation of the anemometer. Readings were recorded every two seconds and the output was an average of the previous eight readings. Air velocity readings were taken at specific points at the door and window as seen in Figures 3-5 and 3-6.

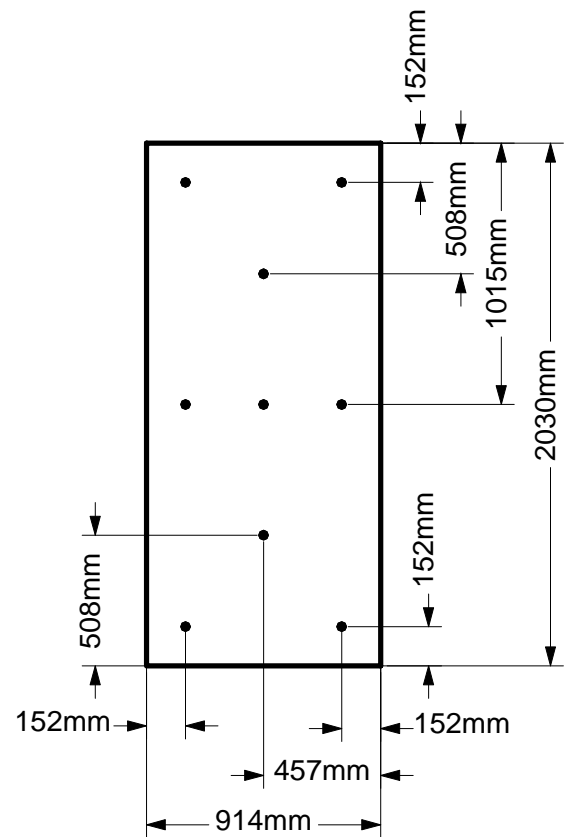

Figure 3-5. Doorway (Inlet) Measurements Points 


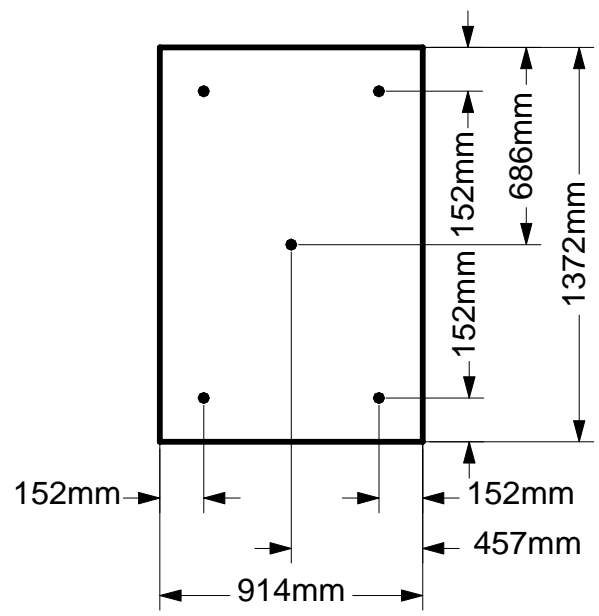

Figure 3-6. Window (Outlet) Measurement Points

\subsubsection{Flow Visualization Experiment}

In order to visualize and qualify the flow through the room a supplemental experiment was performed. A smoke generator was placed in the room and turned on to produce enough simulated smoke to fill the room. Cameras were set up and the fan was turned on to the maximum speed of 2200 RPM. Pictures were taken of the simulated smoke flow from the room on a black background to be compared to the FDS simulations. See Figures 3-7 and 3-8. 


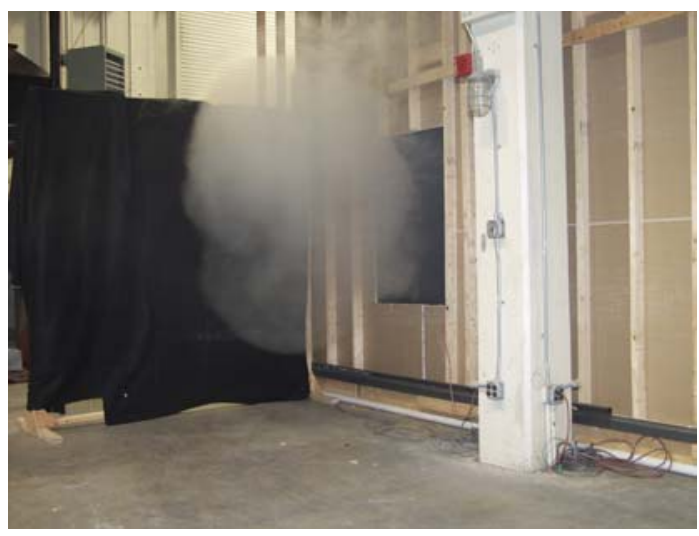

Figure 3-7. Visualization of Supplemental Experiment as Soon as Room is Pressurized

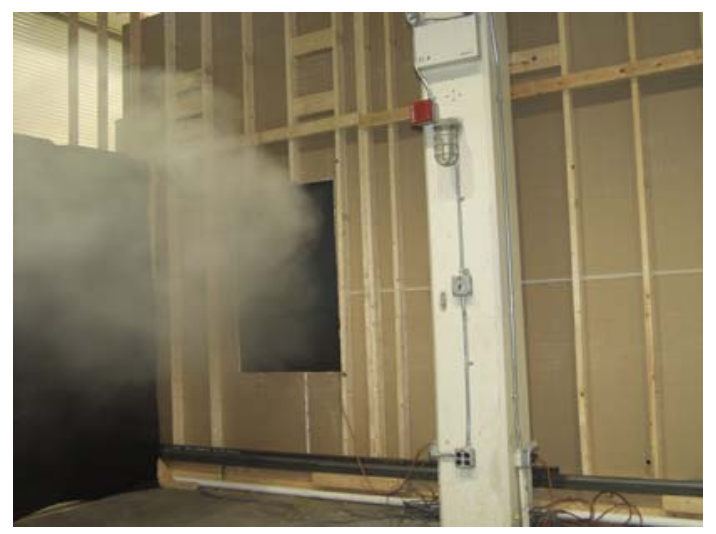

Figure 3-8. Visualization of Supplemental

Experiment Once Constant Flow is Achieved

\subsection{Computer Simulation}

The inputs required by FDS in order to model the PPV fan for this experiment were the same as those in chapter 2 . The difference was the addition of the room. The room required additional inputs such as the properties of the ceiling, walls and openings.

\subsubsection{Domain}

The main issue that arises with the use of both the fan and the room is computational cell size. As stated in chapter 2 the simulated fan required a computation cell size of $16400 \mathrm{~mm}^{3}\left(1 \mathrm{in}^{3}\right)$. If the domain containing the fan and room were completely $16400 \mathrm{~mm}^{3}\left(1 \mathrm{in}^{3}\right)$ cells then there would be in excess of 15 million cells. Past experience with FDS suggests that the number of cells should remain less than one 
million in order to keep computer computational time down. With 15 million cells one simulation would require over a month to complete.

In order to minimize the number of cells and still maximize the accuracy of the calculation FDS has a multiblocking feature. Multiblocking enables the user to save computational time by applying relatively fine grids in areas of interest and coarse grids elsewhere [6]. In this case, a fine grid is used for the domain surrounding the fan and a coarser grid is used for the room. There are many considerations that need to be taken into account when using multiblock, especially for these cases due to the large quantity of air movement. First, the finer grid containing the fan must be specified first in the input file. This allows FDS to give precedence to this domain and speed up calculation times. Second, the grids need to overlap by at least $1.0 \mathrm{~m}$. This helps speed up calculations because information is transferred from grid to grid via external boundaries. When the grids overlap they share the same information, which helps speed up calculations. Third, neither of the domain boundaries can be within one meter of the face of the fan. This allows for airflow in and out of the fan. Placing the end of a domain too close to the fan face causes a linear flow, which is not accurate. Next, the fan grid should not be completely imbedded within the room grid. When this is done information is not transferred between the grids and there will be no results for the fan. Finally, the cell size for the room domain should not be larger than $65,600 \mathrm{~mm}^{3}\left(4 \mathrm{in}^{3}\right)$. This allows for a small step between the grids sizes and sufficient amounts of data to be shared. 
Another issue that needs to be addressed is the positioning of the PPV fan. From the Smokeview animation, it appears that the fan is floating in mid air. The reason for this is the inability of FDS to portray angled geometry. Typically the fire service places the fan away from the door and adjusts the angle of the fan to achieve a cone surrounding the opening [9]. In order for FDS to achieve this angle there would have to be hundreds of pieces prescribed to create the shroud. In order to avoid this, the fan is placed in the center of the doorway above floor level. This placement allows for the flow from the fan to complete a cone around the opening just as done by the fire service, without using hundreds of additional inputs to the model.

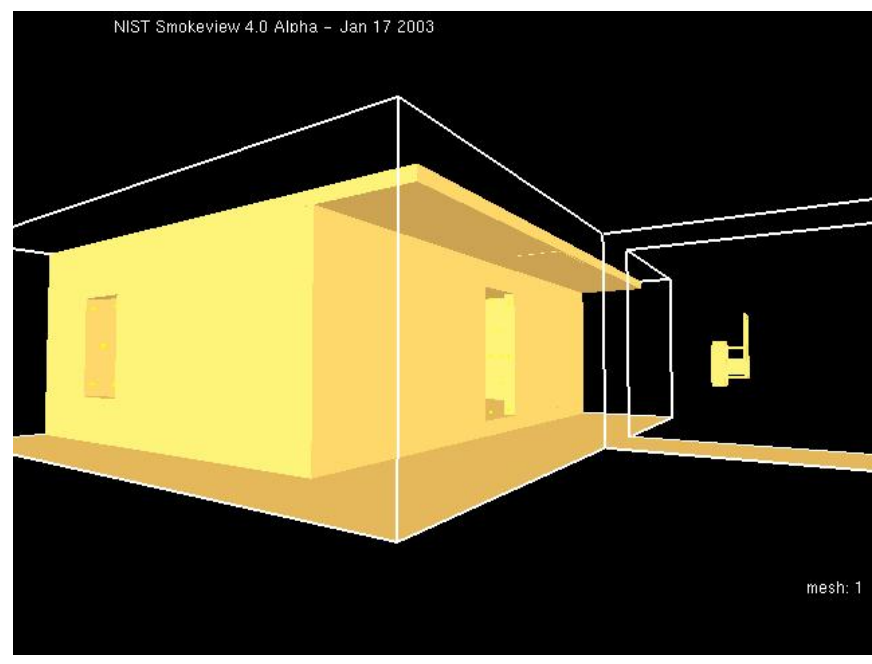

Figure 3-9. FDS Layout for Simple Room Experiement 


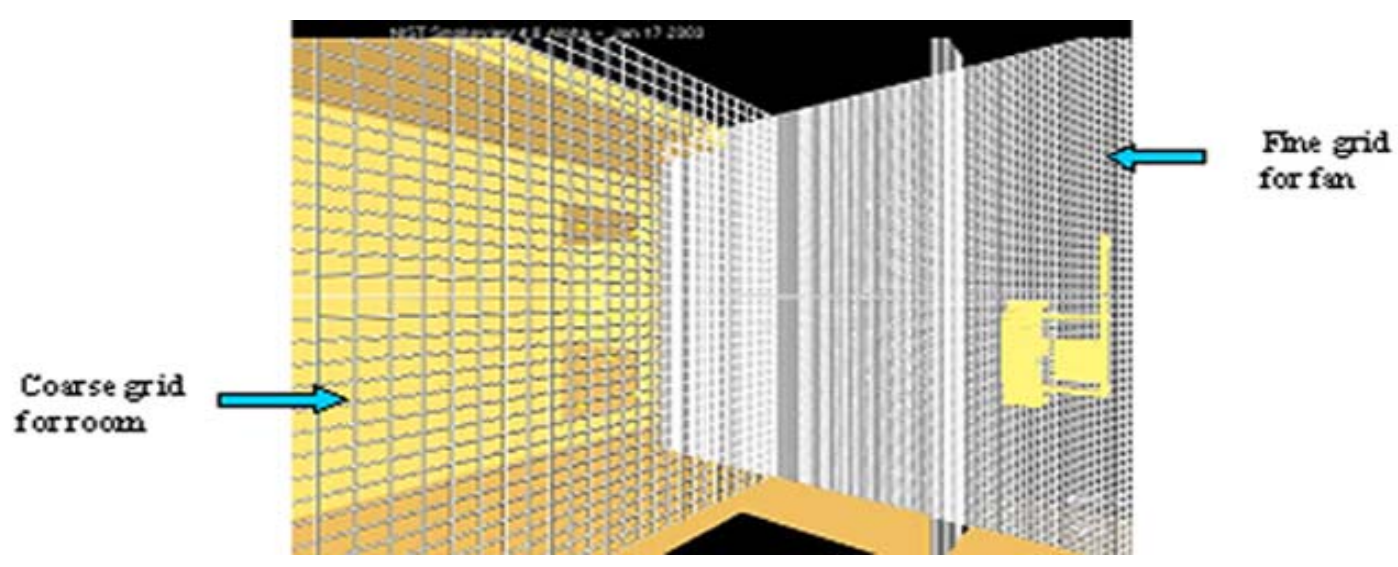

Figure 3-10. Grid Cell Visualization, Multiblocking

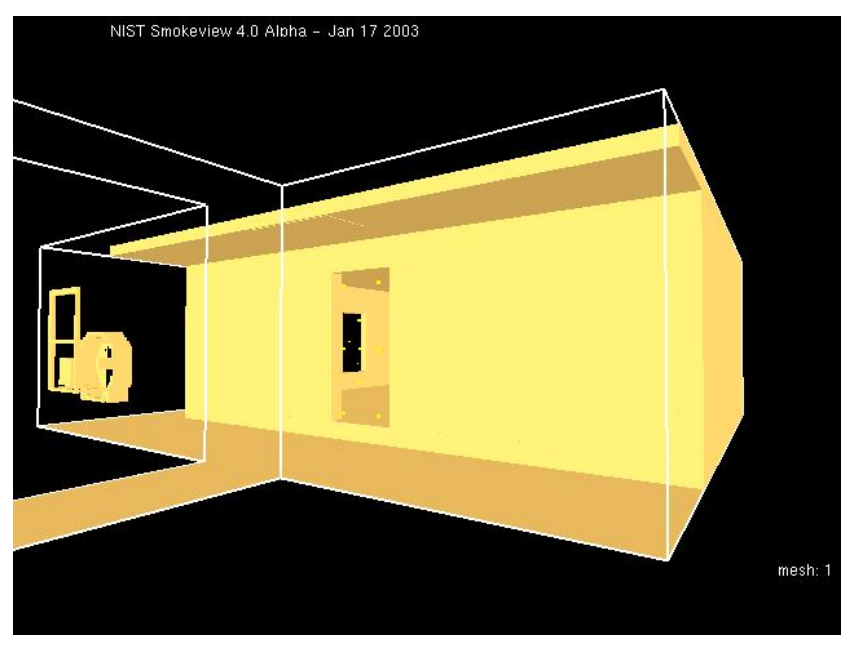

Figure 3-11. FDS Layout Looking at Room Inlet and Outlet

\subsubsection{Geometry and Vents}

The PPV fan used for these runs was the same fan created in chapter 2. See section 2.2.3 for details on fan geometry and vent considerations. Chapter 3 involved the addition of a room with dimensions of that in Figures 3-1 through 3-5. This room was prescribed in FDS as a series of blocks with characteristics of gypsum board. The dimensions and openings were the same as those in the experimental setup. All of the room boundaries, including the walls and ceiling were contained within the 
domain. None of the room envelope obstructions were formed by the use of a boundary.

\subsubsection{Output Files}

Vertical velocity slices were placed through the center of the doorway and window. Velocity measurement points were also prescribed at the same locations as in the experimental layout. A comparison of these output files with the experimental measurements are located in the results section.

\subsection{Results}

Velocity measurements were taken at the locations in the door shown in Figure 3-5, and in the window in Figure 3-6. These measurements were recorded with the fan $3.0 \mathrm{~m}$ (10 ft) from the front door of the room, just as in the chapter 2 experiments. Having the fan $3.0 \mathrm{~m}(10 \mathrm{ft})$ from the door provides a cone of air around the front door per International Fire Service Training Association recommendations [9]. The magnitudes of the velocities into the door are shown in Figure 3-13. The magnitudes

of the outlet velocities at the window are in Figure 3-15. The average inlet velocity at the door is $2.2 \mathrm{~m} / \mathrm{s}(7.2 \mathrm{ft} / \mathrm{s})$. The average outlet velocity at the window is $2.6 \mathrm{~m} / \mathrm{s}$ (8.5 ft/s). NIST’s Fire Dynamic Simulator was used to examine the use of the PPV fan from chapter 2 in the same configuration as in the experiment. FDS yielded an average inlet velocity at the door of $4.1 \mathrm{~m} / \mathrm{s}(13.5 \mathrm{ft} / \mathrm{s})$ and an average outlet velocity of $3.0 \mathrm{~m} / \mathrm{s}(9.8 \mathrm{ft} / \mathrm{s})$ measured at the window (Figures 3-14 and 3-16). These 
comparisons give a difference of 84 percent at the door and a difference of

16.5 percent at the window (Table 2). This yields a good comparison at the window, which is the important correlation. The air movement at the window is the result of the pressure change in the room, interaction of the geometry of the room and the airflow. The door point predictions are dependent upon the local turbulence that FDS creates from the fan simulation shown in Figure 3-12. Experimentally this turbulence is very complex and difficult to measure. Qualitatively, the flow can be compared in Figures 3-19 to 3-22.

Table 2. Comparison of Experimental and FDS Simple Room Results

\begin{tabular}{|l|c|c|}
\hline & \multicolumn{2}{|c|}{ Average Velocities (m/s (ft/s)) } \\
\hline & Door & Window \\
\hline Experimental & $2.2(7.2)$ & $2.6(8.5)$ \\
\hline Fire Dynamic Simulator & $4.1(13.5)$ & $3.0(9.8)$ \\
\hline Percent Difference & 84.0 & 16.5 \\
\hline
\end{tabular}

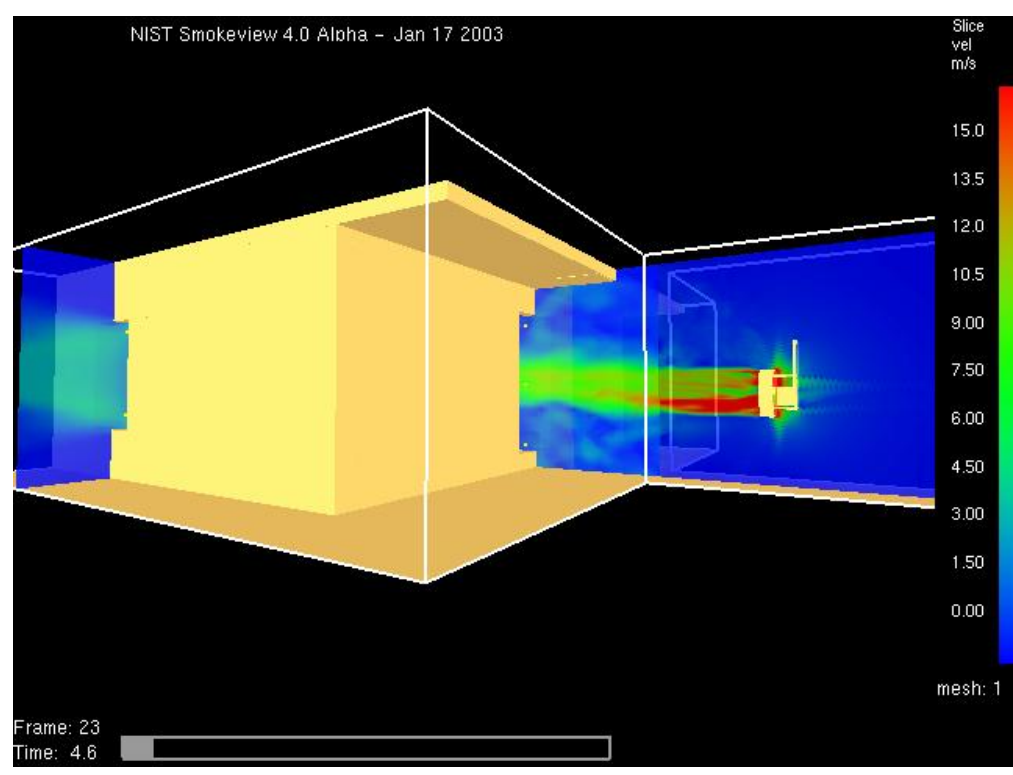

Figure 3-12. FDS Layout with Fan Operating 


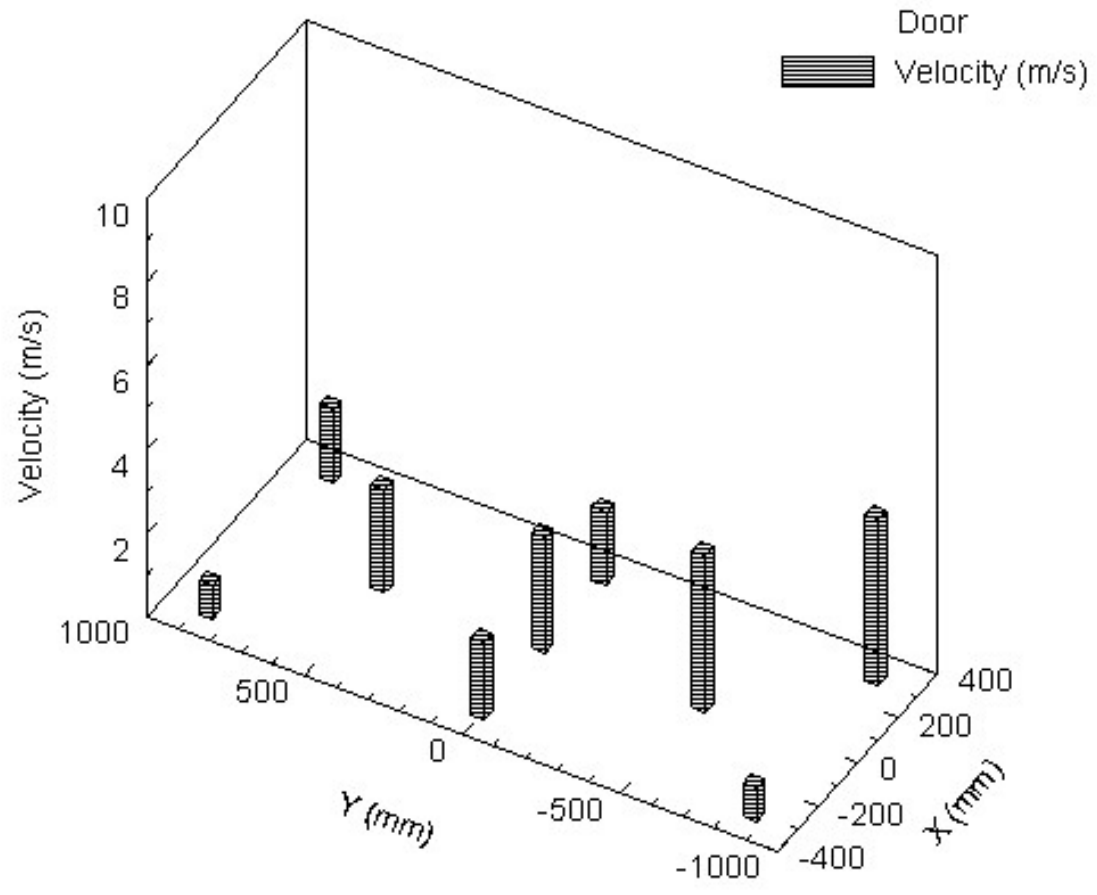

Figure 3-13. Experimental Velocity Measurements in the Doorway (Inlet)

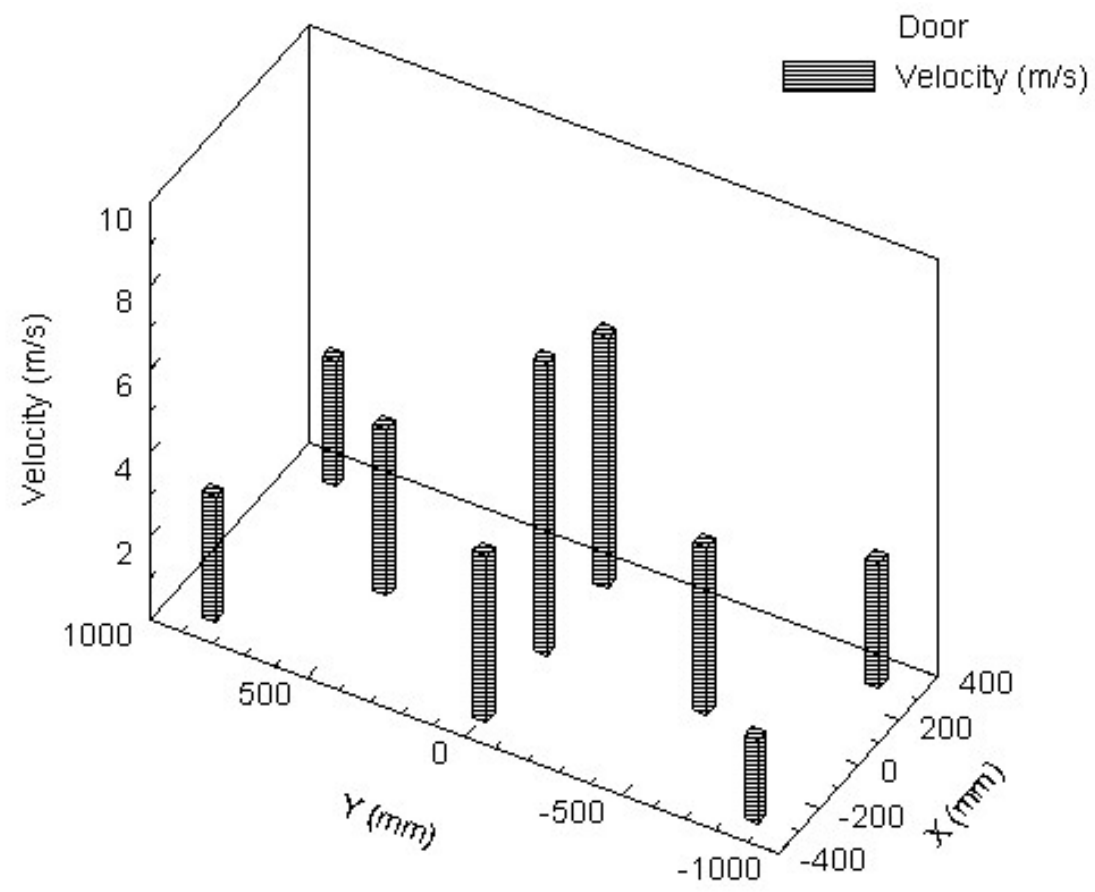

Figure 3-14. FDS Velocities in the Doorway (Inlet) 


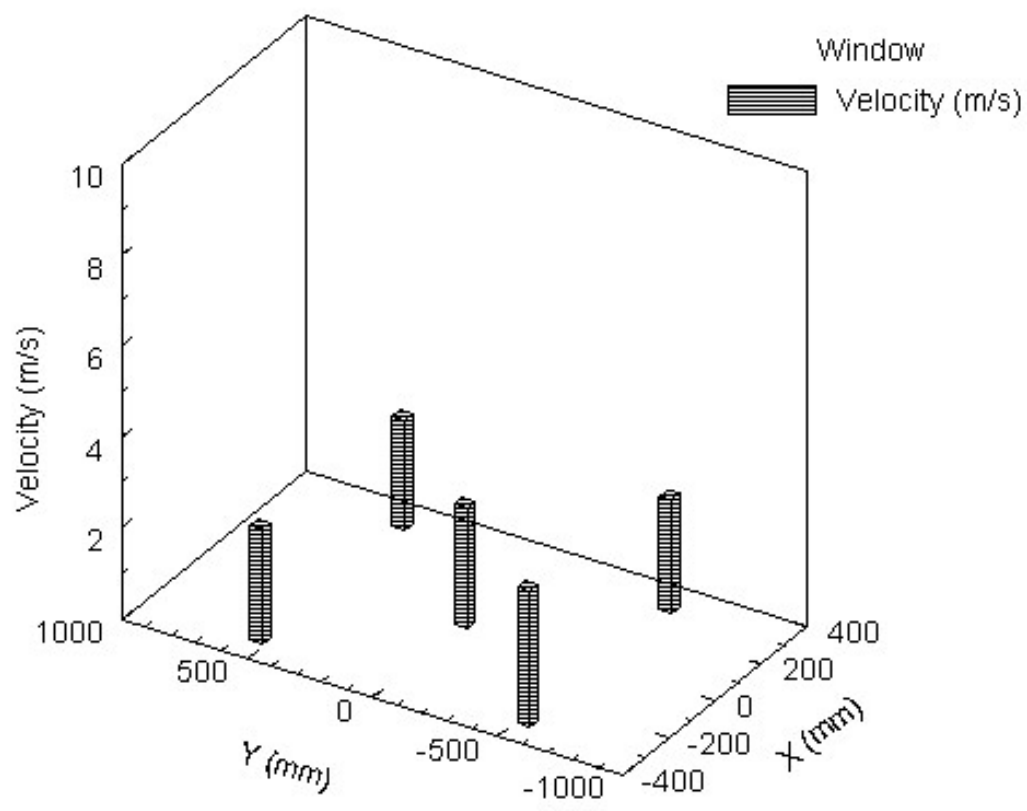

Figure 3-15. Experimental Measurements in the Window (Outlet)

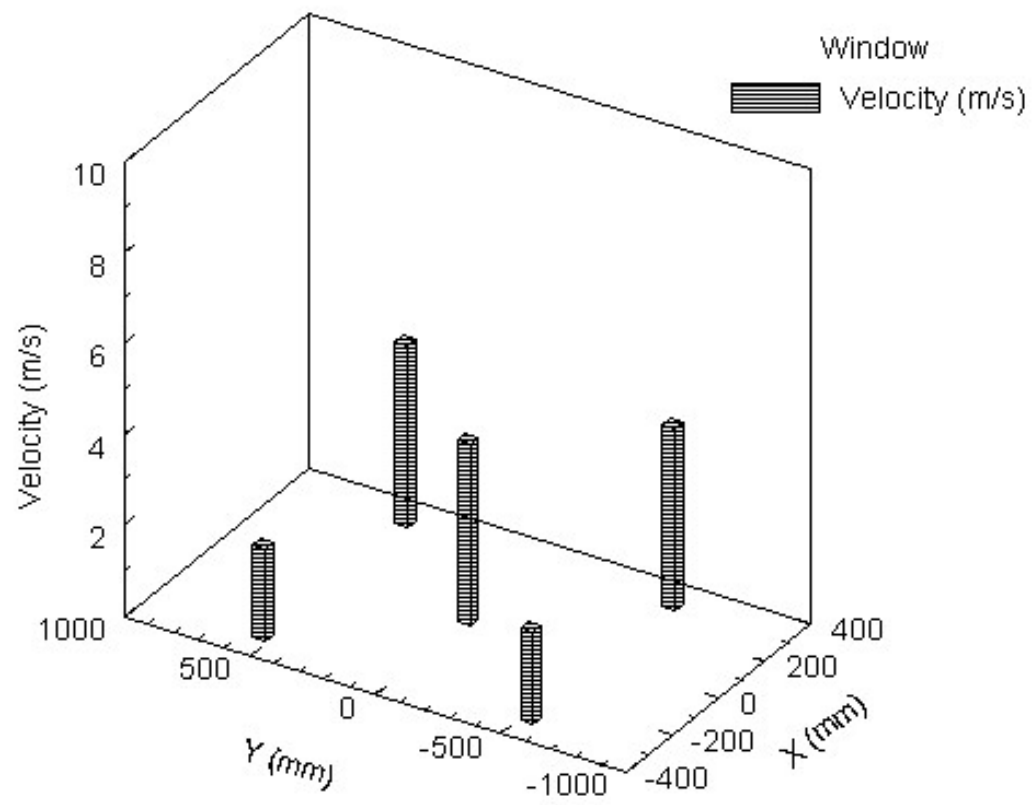

Figure 3-16. FDS Velocities in the Window (Outlet) 


\subsection{Mapping and Simple Room Summary}

A comparison of the computational fluid dynamic model Fire Dynamic Simulator (FDS) was made with data from two different sets of data collected from full-scale experiments. The full-scale experiments characterized a Positive Pressure Ventilation (PPV) fan in an open atmosphere, and with a simple room geometry. Both experimental data sets provide insight into the gas velocities, as well as providing the opportunity to validate the predictions of the Fire Dynamic Simulator.

The measurements for the fan in an open atmosphere compared favorably with the FDS predictions. With the correct geometry, vent placement and boundary location FDS predicted velocities that were within 10 percent of the experimental results (Table 3). FDS's visualization of the flow pattern also correlates well with the experimental visualization.

The measurements for the fan and a single room also compared favorably with the FDS predictions for the flow out the window. The flow that was created out of the window in FDS was within 20 percent of that measured experimentally. FDS's visualization of the flow out of the window using multiblocking also correlates well with that captured experimentally (Table 4).

The results from these two experiments are a good indicator that FDS is able to accurately portray the flow created by positive pressure ventilation fans. Future experiments need to be conducted to examine the flow in other structures such as 
multi-floor structures and structures with a more complex geometry. Further, the impact of the fan on other factors in the fire environment such as temperature, burning rate, and gas concentrations has not been examined here.

Table 3. Summary of FDS Fan Characteristics Needed to Create an Accurate Flow

\begin{tabular}{|l|l|}
\hline 1 & Computational cell size of less than or equal to 1 cubic inch \\
\hline 2 & At least 1 meter of domain to the rear of the fan \\
\hline 3 & Shroud must be cylindrical \\
\hline 4 & Vents must be located on the front face of the shroud \\
\hline 5 & A velocity must be prescribed for the vents (17.88 m/s for this fan) \\
\hline 6 & $\begin{array}{l}\text { A block must be added to the center of the shroud to simulate the blade center } \\
\text { (effects air movement) }\end{array}$ \\
\hline 7 & A motor must be added to the rear of the fan (effects air movement) \\
\hline
\end{tabular}

Table 4. Summary of Multiblock Characteristics Needed to Create and Accurate Flow

\begin{tabular}{|l|l|}
\hline 1 & Specify the fan grid (finer) first in the data file \\
\hline 2 & Overlap the grids by at least 1 meter \\
\hline 3 & Neither of the domain boundaries should be within 1 meter of the fan \\
\hline 4 & Do not imbed one grid completely within the other \\
\hline 5 & $\begin{array}{l}\text { Computational cell size for the non-fan grid should not be greater than } 4 \text { in on a } \\
\text { side. }\end{array}$ \\
\hline
\end{tabular}




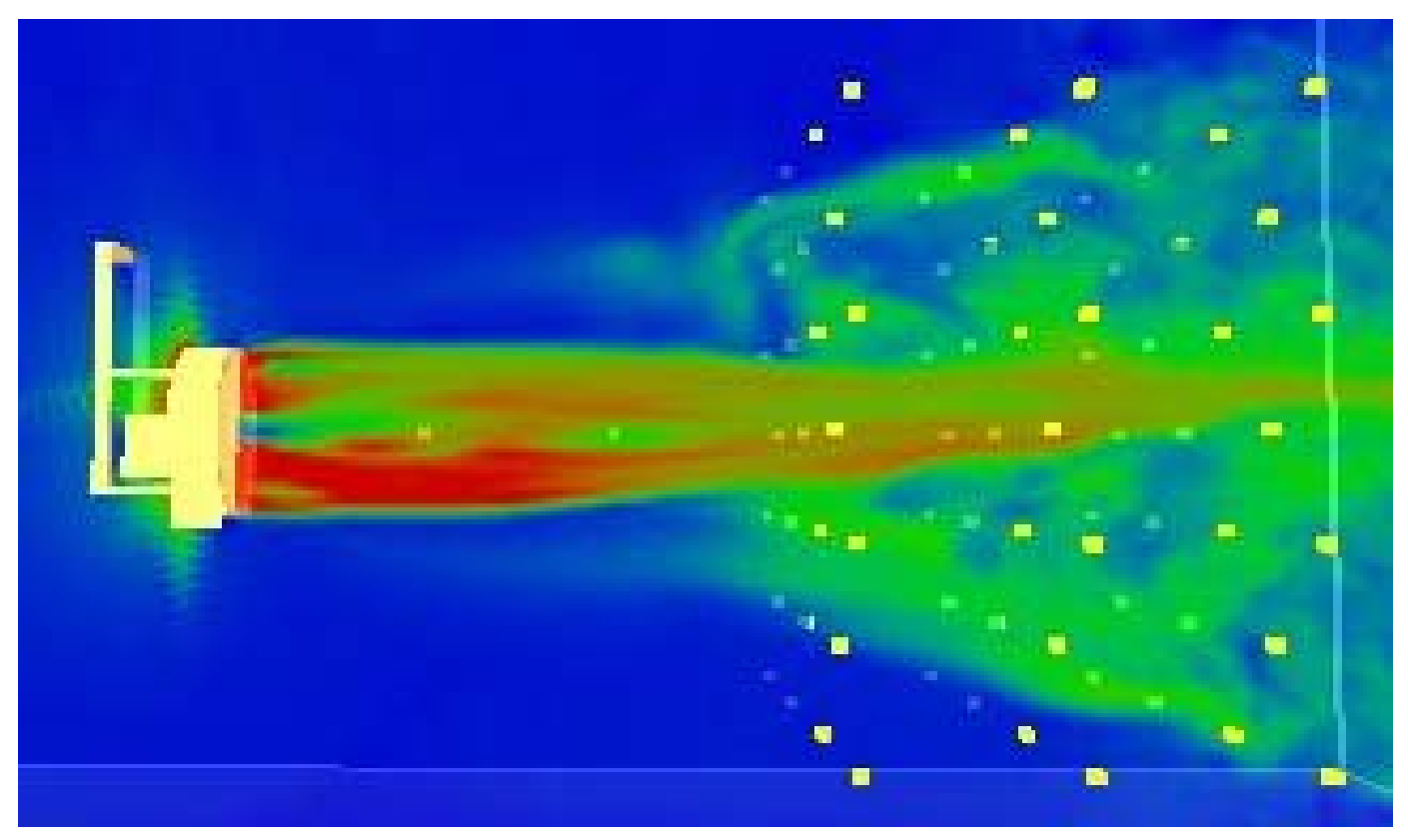

Figure 3-17. Smokeview Visualization of FDS PPV Flow Pattern

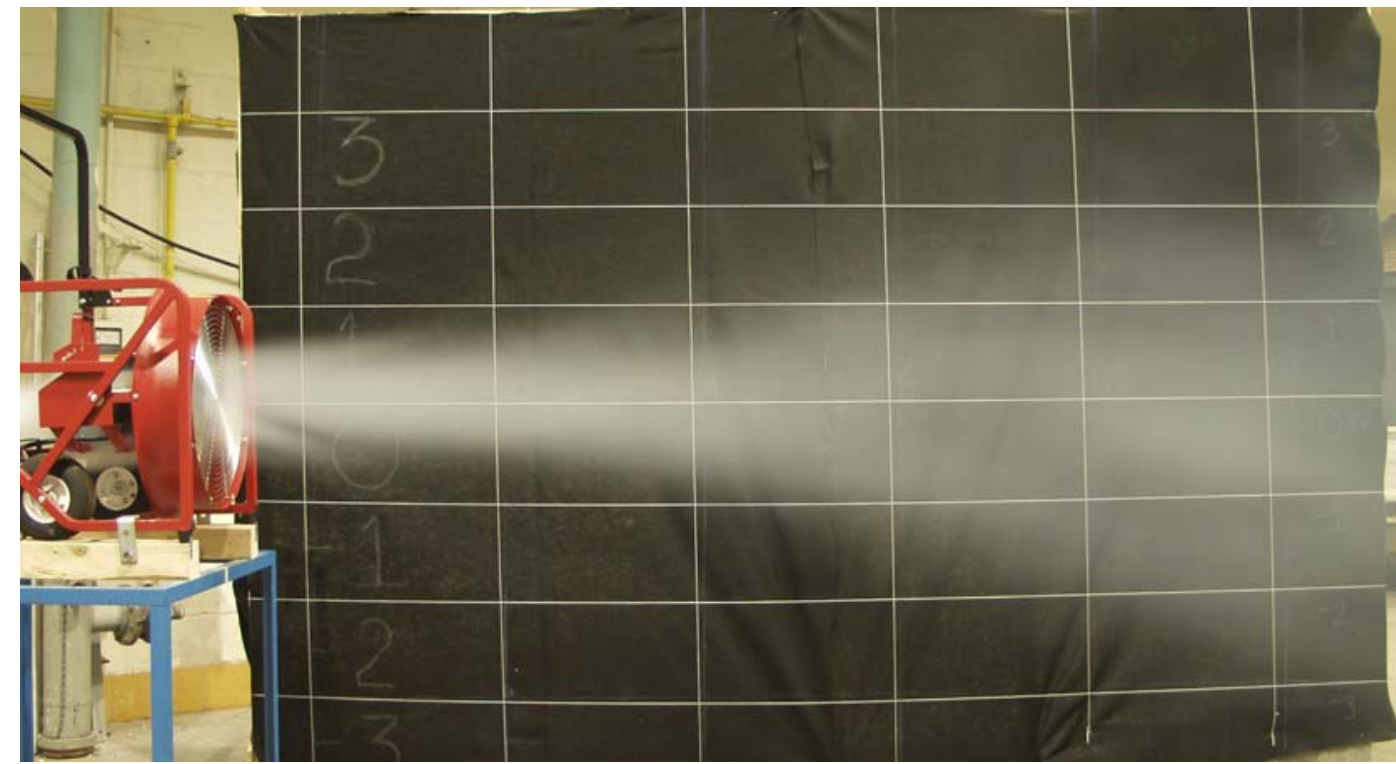

Figure 3-18. Experimental Visualization of the PPV Flow Pattern 


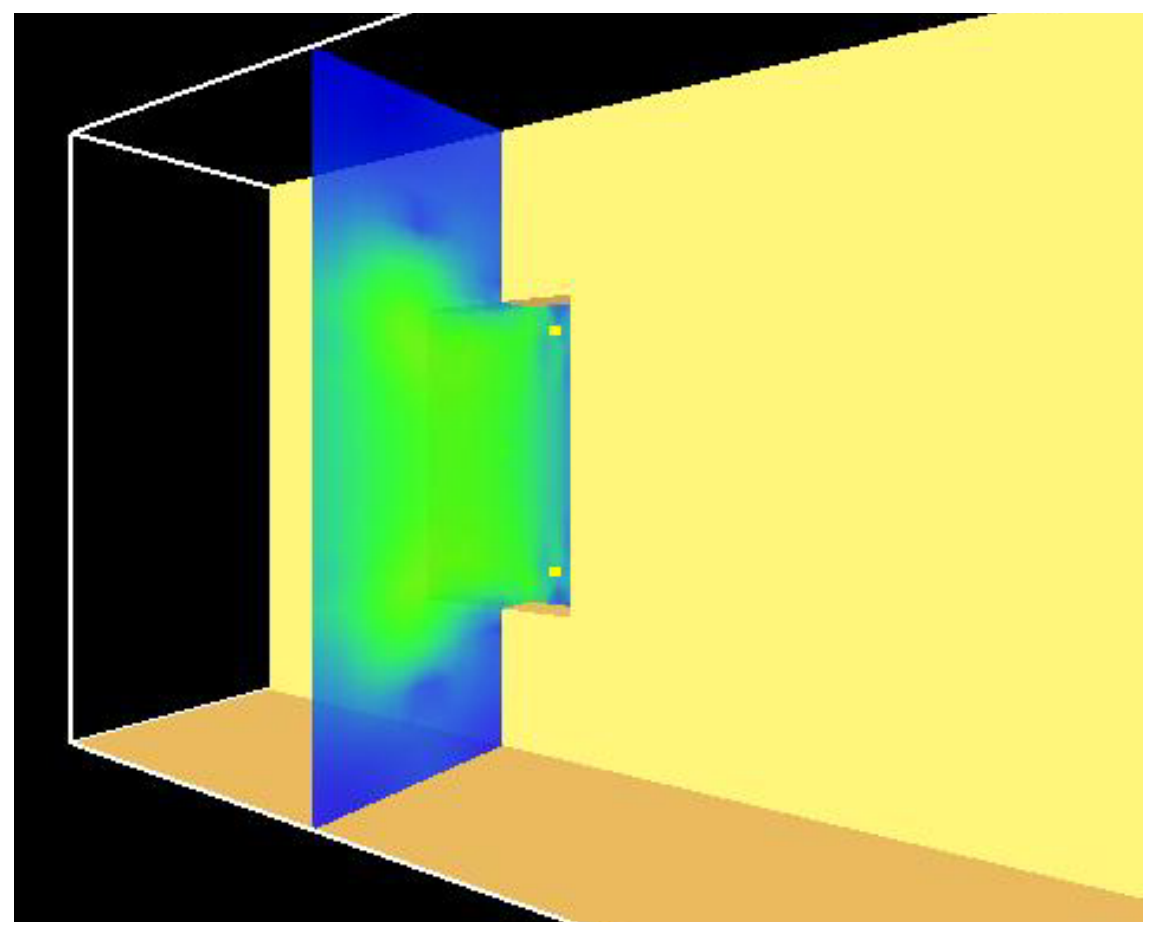

Figure 3-19. FDS Visualization of Supplemental Experiment as Soon as Room is Pressurized

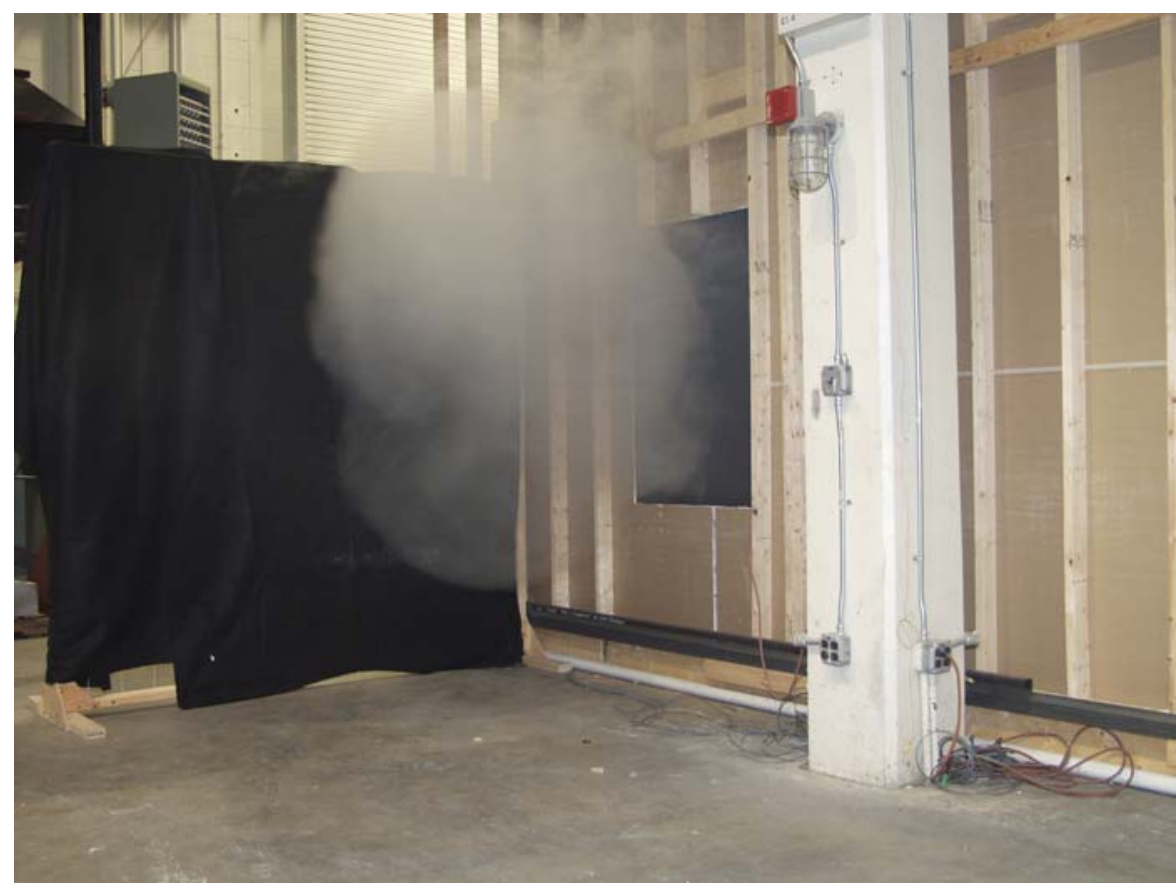

Figure 3-20. Visualization of Supplemental Experiment as Soon as Room is Pressurized 


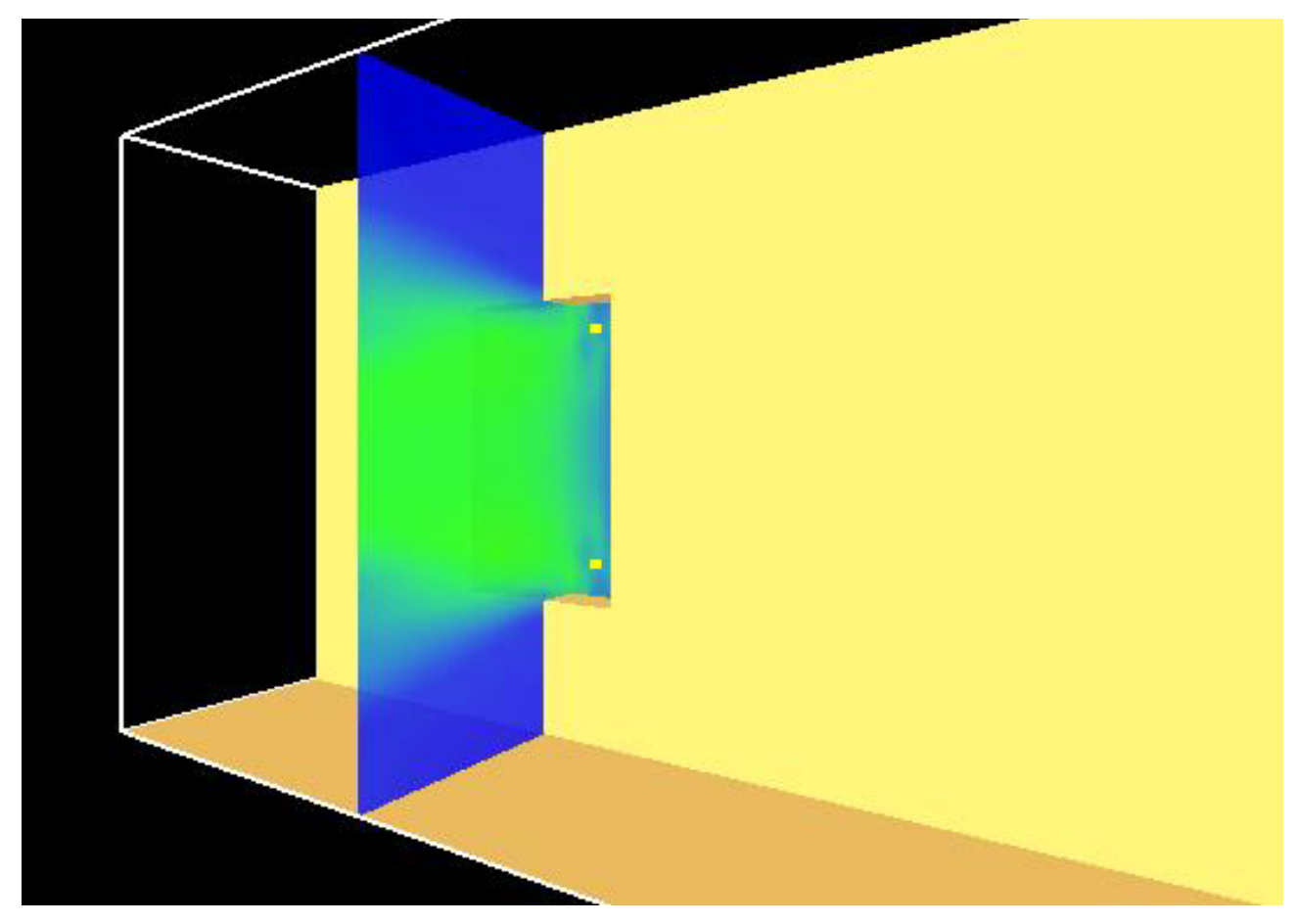

Figure 3-21. FDS Visualization of Supplemental Experiment Once Constant Flow is Achieved

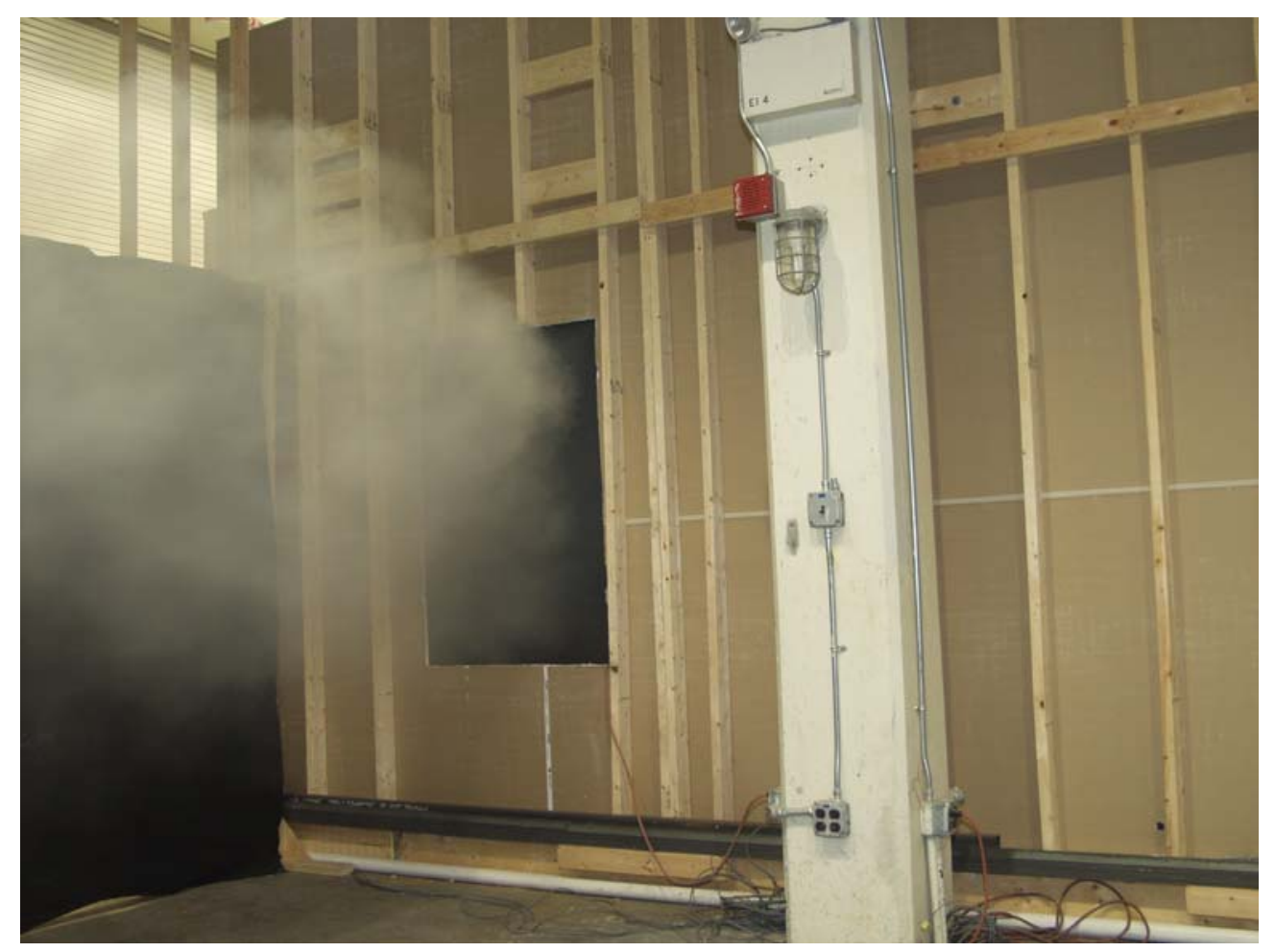

Figure 3-22. Visualization of Supplemental Experiment Once Constant Flow is Achieved 


\section{Chapter 4: Room Fire Experiments}

\subsection{Experimental Description}

A pair of full-scale experiments was performed at NIST’s Building and Fire Research Laboratory Large Fire Facility. The facility has interior dimensions, 36.6 m (120.0 ft) long, $18.3 \mathrm{~m}(60.0 \mathrm{ft})$ wide and $7.6 \mathrm{~m}(25.0 \mathrm{ft})$ high. A room was constructed within the facility under a $6 \mathrm{~m}$ × $6 \mathrm{~m}(20 \mathrm{ft}$ x $20 \mathrm{ft})$ hood which was instrumented to allow for oxygen depletion calorimetry to measure the heat release rate produced by the fire in the room. The room had interior dimensions of $3.66 \mathrm{~m} \mathrm{x} 4.27 \mathrm{~m}$ (12 ft x $14 \mathrm{ft})$ and a ceiling height of $2.44 \mathrm{~m}$ (8 ft) (Figure 4-1). A window was located in the center of one of the $4.27 \mathrm{~m}$ walls (Figure 4-2) and a doorway was located on the center of one of the 3.66 m walls. The doorway opened to a $1.22 \mathrm{~m}$ wide x $2.29 \mathrm{~m}$ long $(4.0 \mathrm{ft} \mathrm{x}$ $7.5 \mathrm{ft}$ ) corridor (Figure 4-3). Another doorway was located at the end of the corridor that was the same size as the doorway to the room. Both doorways were $2.06 \mathrm{~m}$ $(6.75 \mathrm{ft})$ tall and $0.91 \mathrm{~m}(3 \mathrm{ft})$ wide. The window was $1.2 \mathrm{~m}(3.9 \mathrm{ft})$ tall and $0.89 \mathrm{~m}$

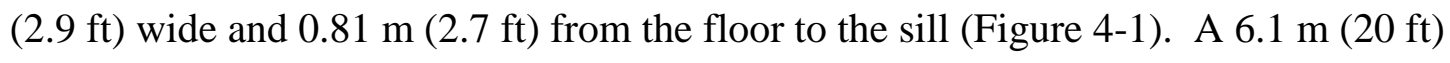
wall was constructed between the corridor doorway and room window to the exterior of the room in order to isolate the effects of the fan and not allow recirculation of smoke from the window back through the doorway. All of the walls and the ceiling were framed with $0.050 \mathrm{~m} \times 0.100 \mathrm{~m}$ (1.5 in $\times 3.5$ in) pine studs and sheathed with two layers of $0.0095 \mathrm{~m}$ (0.38 in) gypsum board. The room was furnished with a bunk bed, stuffed chair, book case and desk (Figure 4-4). The floor was covered with carpet and a computer monitor was placed on the desk. 
Two experiments were conducted with nearly identical fuel loads, examining the effect of the PPV fan on the room fire. The first experiment utilized a fan to forcibly ventilate the room just after the window was opened. The second experiment was similar to the first experiment except that it was naturally ventilated. The fan used was a $0.75 \mathrm{~m}$ (18 in), variable speed, electric positive pressure ventilator. The fan had a depth of $0.48 \mathrm{~m},(18.75 \mathrm{in})$, width of $0.62 \mathrm{~m}$ (24.5 in) and height of $0.62 \mathrm{~m}$ (24.5 in). It had a maximum speed of 2200 RPM, a power rating of $746 \mathrm{~W}$ (1 hp) and a volumetric flow rating of $6.64 \mathrm{~m}^{3} / \mathrm{s}\left(14,060 \mathrm{ft}^{3} / \mathrm{min}\right)$ [10]. The fan was positioned $2.44 \mathrm{~m}(8 \mathrm{ft}$ ) from the open doorway to the corridor at an angle of approximately 15 degrees from horizontal to create the cone of air around the doorway. 


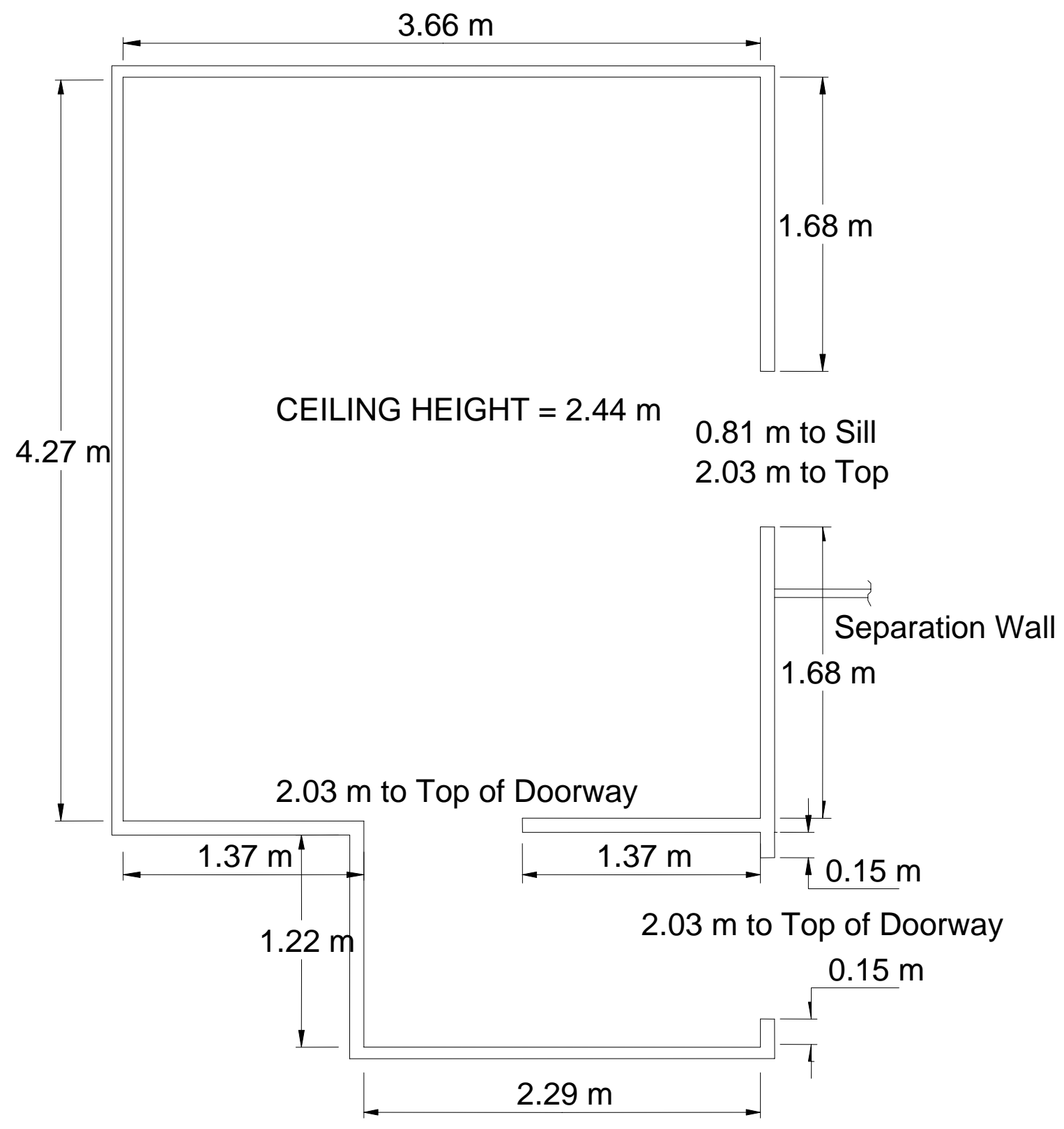

Figure 4-1. Experimental Floor Plan 


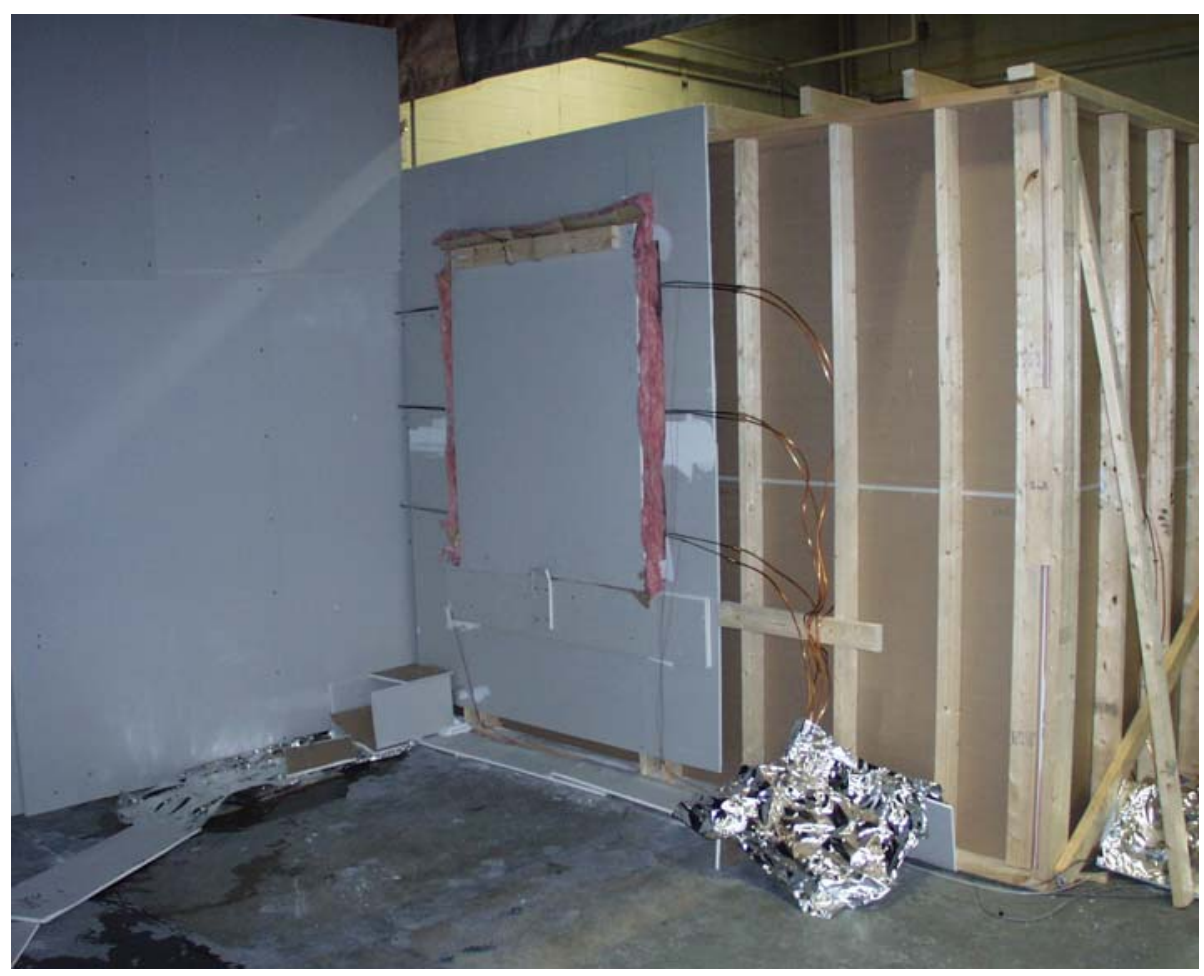

Figure 4-2. External View of Window in Closed Position

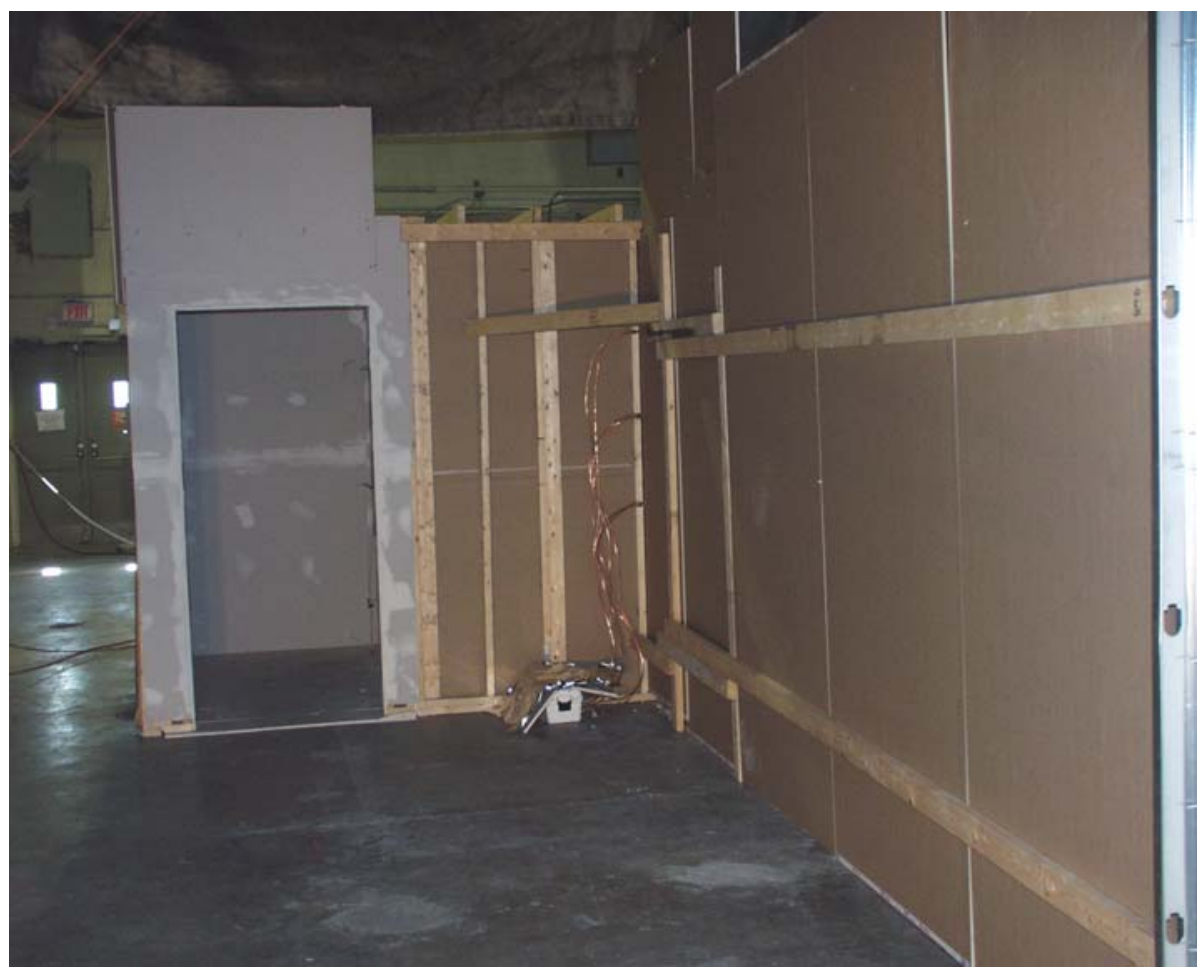

Figure 4-3. External View of Open Corridor Doorway 


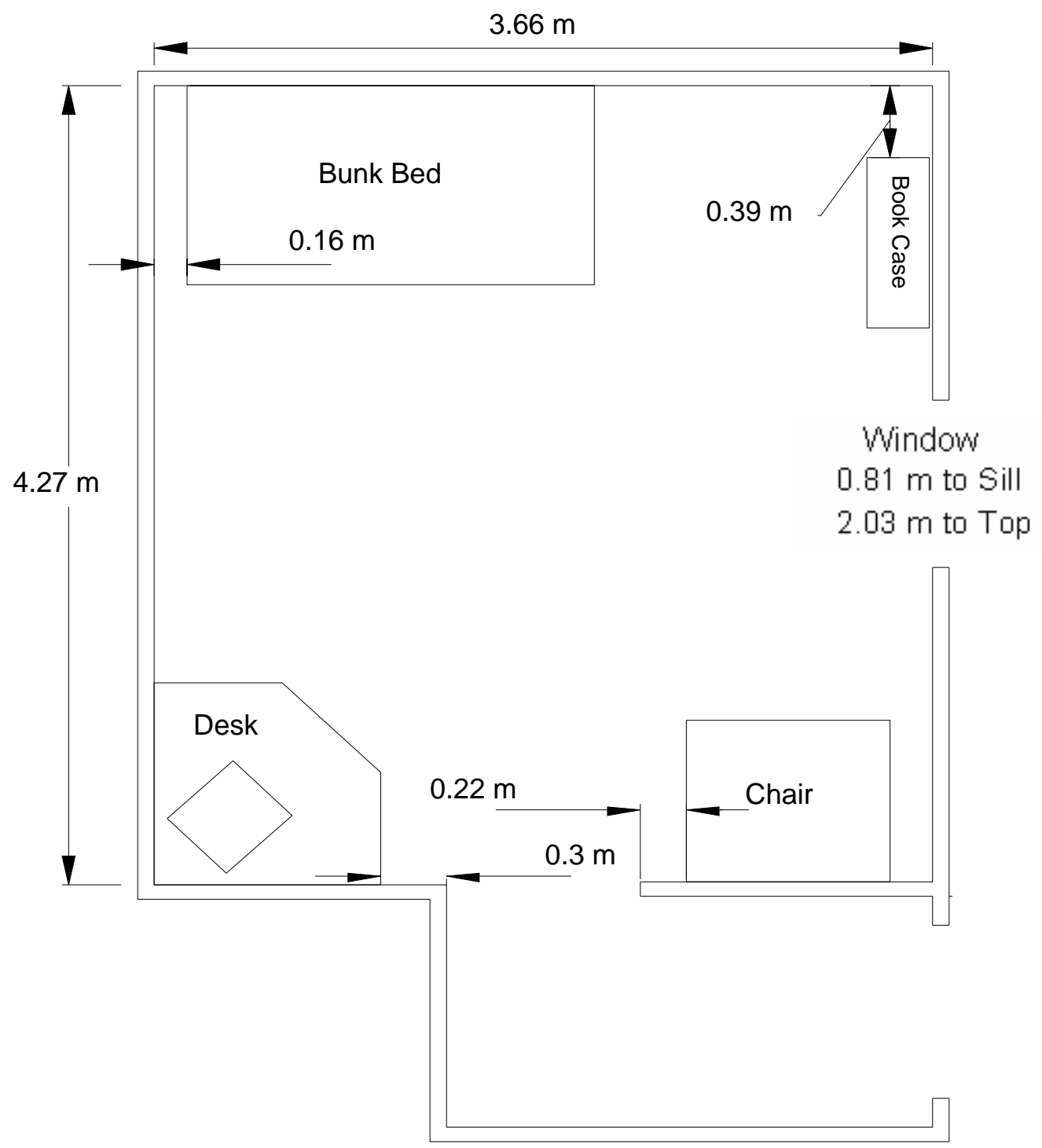

Figure 4-4. Furniture Floor Plan 


\subsubsection{Instrumentation}

Temperature measurements were made with $0.5 \mathrm{~mm}$ (0.02 in) nominal diameter type $\mathrm{K}$ bare bead thermocouples. A vertical thermocouple array was located in the center of the fire room with measurement locations of $0.025 \mathrm{~m}, 0.30 \mathrm{~m}, 0.61 \mathrm{~m}, 0.91 \mathrm{~m}$, $1.22 \mathrm{~m}, 1.52 \mathrm{~m}, 1.83 \mathrm{~m}$ and $2.13 \mathrm{~m}(1 \mathrm{in}, 1 \mathrm{ft}, 2 \mathrm{ft}, 3 \mathrm{ft}, 4 \mathrm{ft}, 5 \mathrm{ft}, 6 \mathrm{ft}$ and $7 \mathrm{ft}$ ) below the ceiling. The corridor doorway also had a vertical array with measurement locations of $0.025 \mathrm{~m}, 0.30 \mathrm{~m}, 0.61 \mathrm{~m}, 0.91 \mathrm{~m}, 1.22 \mathrm{~m}, 1.52 \mathrm{~m}, 1.83 \mathrm{~m}(1 \mathrm{in}, 1 \mathrm{ft}, 2 \mathrm{ft}$, $3 \mathrm{ft}, 4 \mathrm{ft}, 5 \mathrm{ft}$ and $6 \mathrm{ft}$ ) below the top of the doorway opening. Three thermocouples were located in the room doorway, $0.30 \mathrm{~m}(1 \mathrm{ft})$ from the top of the doorway, $0.30 \mathrm{~m}$ (1 $\mathrm{ft}$ ) from the bottom of the doorway and the midpoint of the doorway at $1.02 \mathrm{~m}$ (Figure 4-5). Six additional thermocouples were placed in the ventilation window.

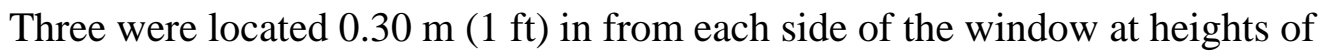
$0.15 \mathrm{~m}, 0.61 \mathrm{~m}$ and $1.07 \mathrm{~m}(0.5 \mathrm{ft}, 2 \mathrm{ft}$ and $3.5 \mathrm{ft})$ from the bottom of the window (Figures 4-6 and 4-7).

Gas velocity measurements were recorded in the window and in the fire room doorway using bi-directional probes (Figure 4-8). The doorway had measurement

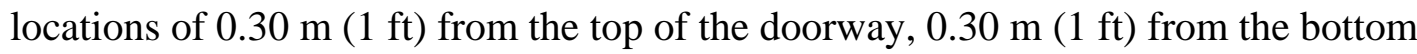
of the doorway and the midpoint of the doorway. The ventilation window had six bidirectional probes in the same locations as the thermocouple locations shown in Figure 4-6. Probes were connected to Setra Systems Model 264 differential pressure transducers. Since both in and outflow was expected, each transducer had the capacity to monitor positive and negative pressure differentials. Bi-directional high 
pressure ranges up to $62 \mathrm{~Pa}(0.01 \mathrm{PSI})$ were utilized because of the flow that was expected in the two openings. A set of pressure transducers was also positioned in the rear corner of the room adjacent to the bookcase to examine the differential

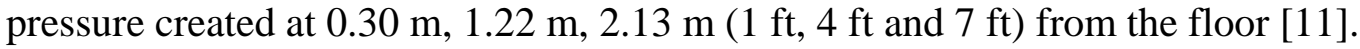

Video recordings were made of each experiment. Two cameras were positioned on the exterior of the room. One had the view of the ventilation window and the other the open doorway to the corridor. Two water cooled cameras were positioned inside the room (Figure 4-9). One camera was placed just above the floor near the bunk beds viewing the gas flow between the window and doorway. The second interior camera was positioned near the floor viewing the ignition location and flame spread across the bunk beds.

The combustion products were captured by a $6 \mathrm{~m} \mathrm{x} 6 \mathrm{~m}$ (20 ft x $20 \mathrm{ft}$ ) hood which was instrumented for oxygen consumption calorimetry. Oxygen depletion, temperature and pressure readings were continuously monitored in order to calculate the total heat release rate of the fire room [12]. 


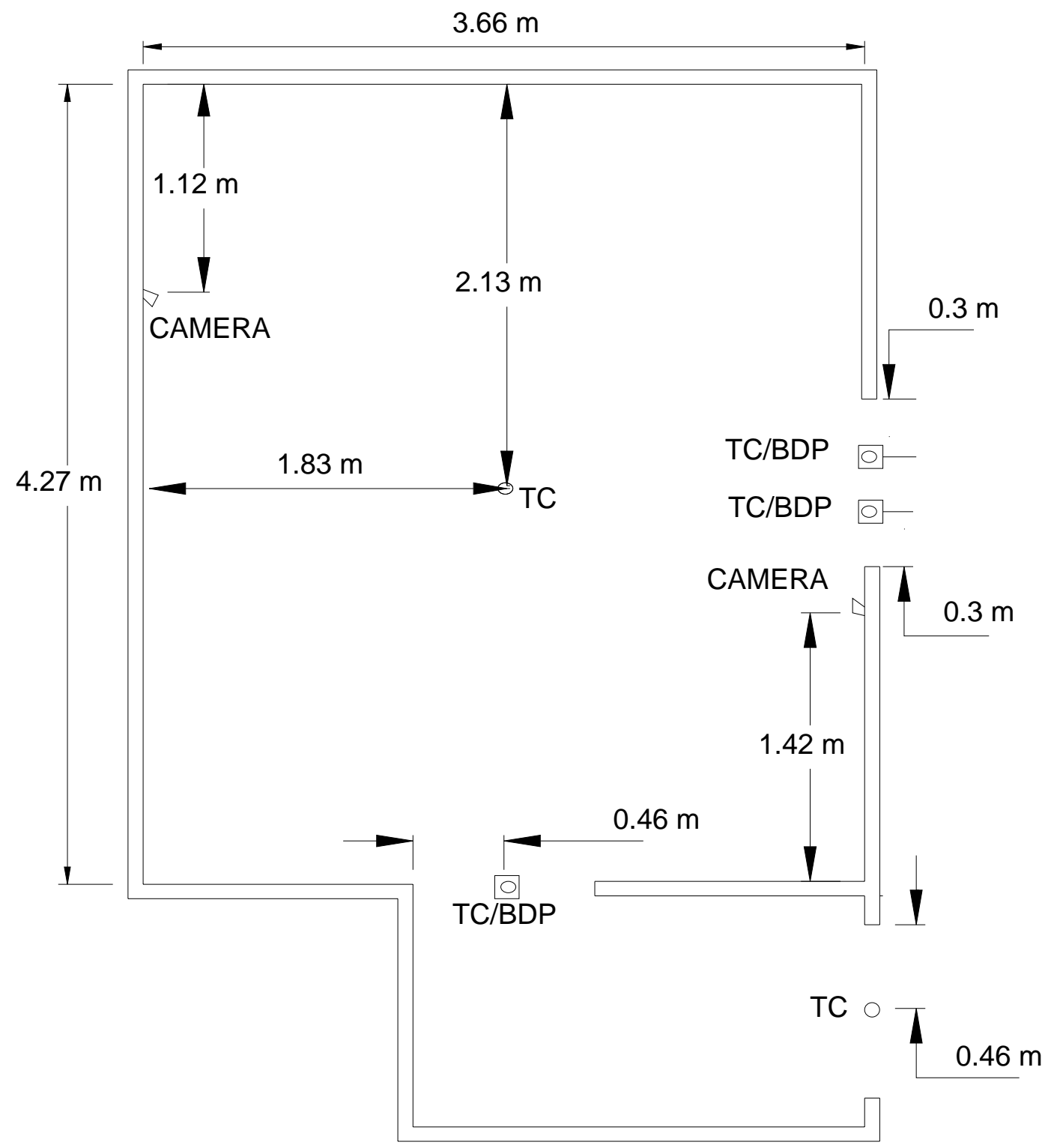

Figure 4-5. Instrumentation Floor Plan 

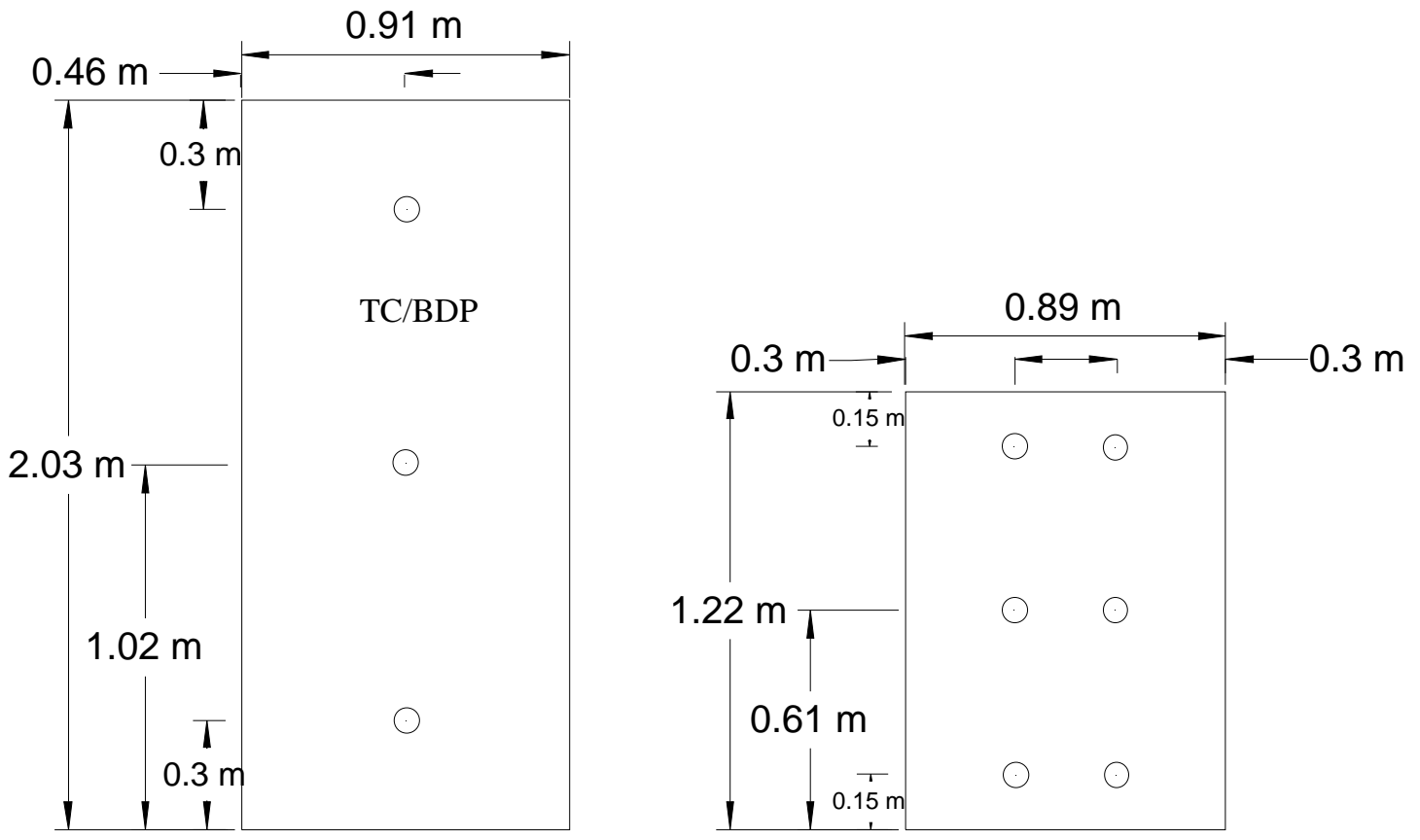

Figure 4-6. Doorway and Window Probe and Thermocouple Combination
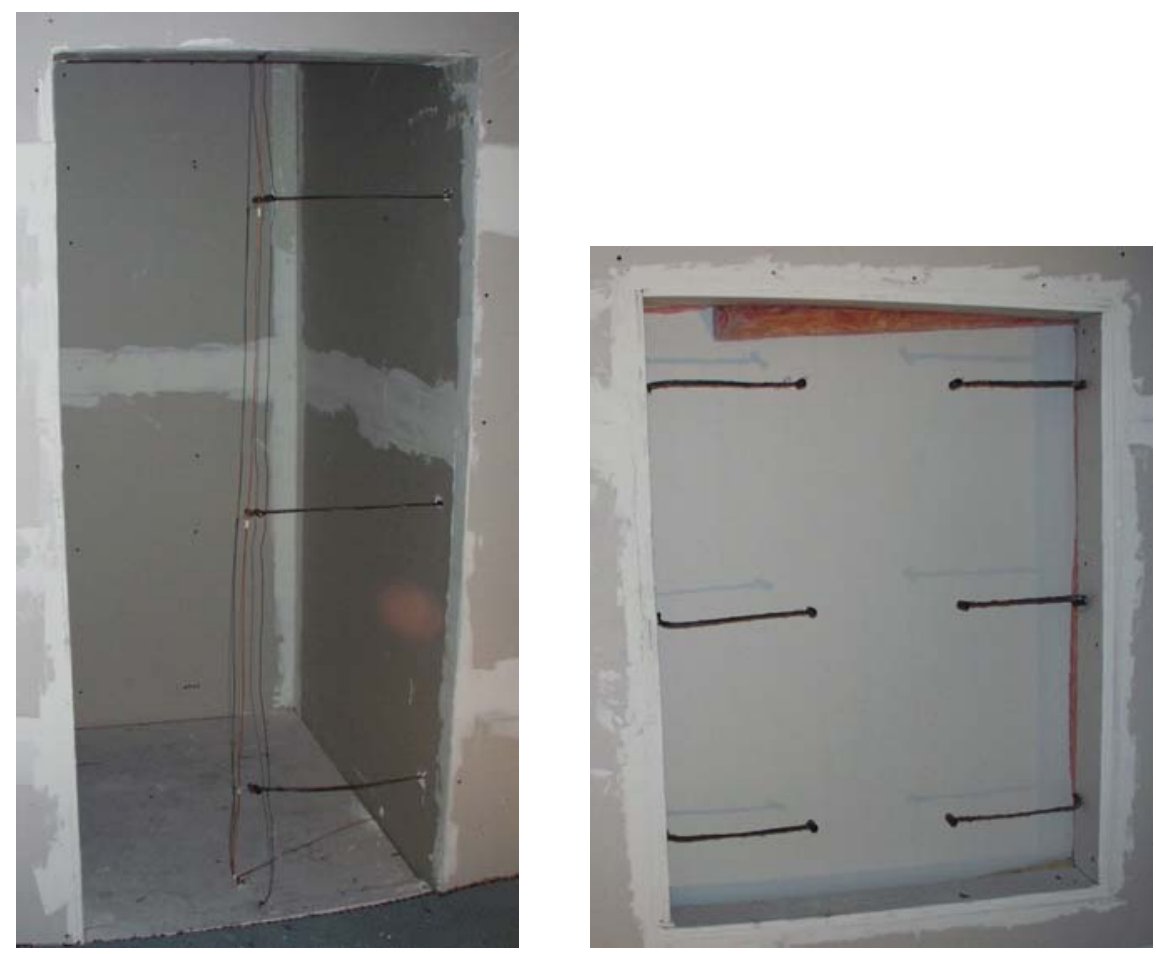

Figure 4-7. View of Doorway From Inside the Room into Corridor and Window with Instrumentation 


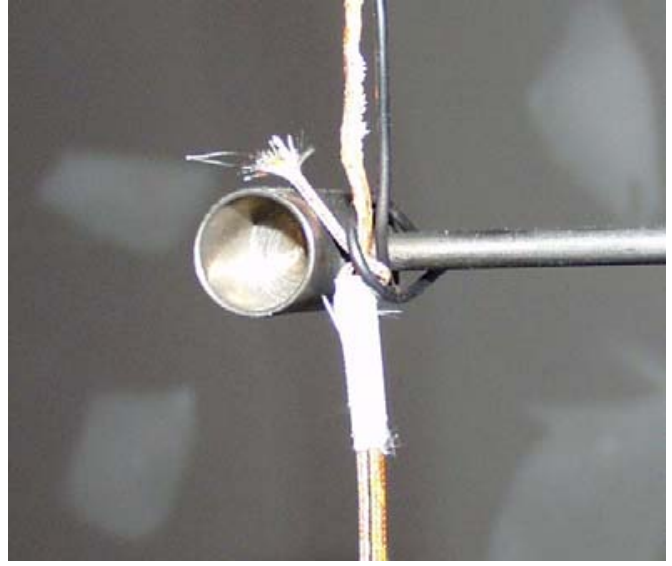

Figure 4-8. Bidirectional Probe and Thermocouple Combination

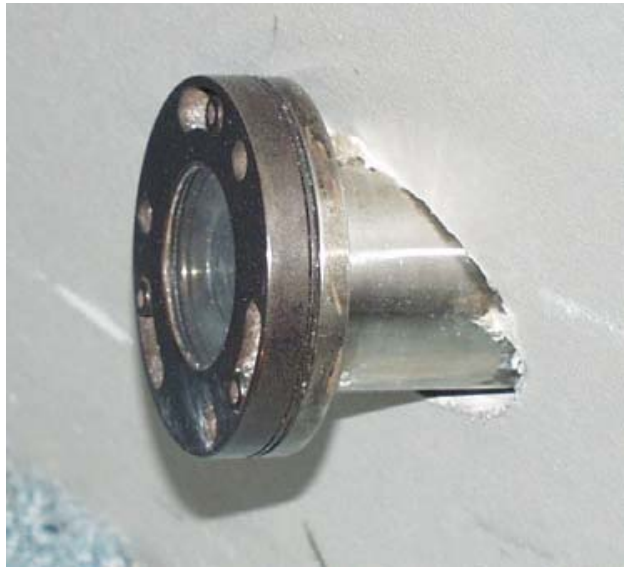

Figure 4-9. Water Cooled Camera

\subsubsection{Fuel Load}

The fuel load was selected to represent a typical bedroom configuration. It was also intended to create a fuel rich atmosphere to make burning dependent on the available oxygen. Both experiments had similar furniture and a total fuel mass that was $250.6 \mathrm{~kg}$ and $251.6 \mathrm{~kg}$ for experiment 1 and 2, respectively (Table 5). The book case was made of $0.013 \mathrm{~m}$ (0.5 in) thick compressed particle board covered with a plastic laminate top (Figures 4-10 and 4-11). The desk was also made of compressed particle board with a laminate top, but was $0.038 \mathrm{~m}$ (1.5 in) thick (Figures 4-12 and 4-13). The $0.38 \mathrm{~m}$ (15 in) nominal size computer monitor on the desk had a plastic shell and a glass face (Figures 4-14 and 4-15). The chair located in the corner had a wood frame, polyurethane cushions and cotton cover (Figures 4-16 and 4-17).

Finally, the bunk beds were framed out with $0.050 \mathrm{~m}$ x $0.100 \mathrm{~m}$ (2 in x 4 in) nominal pine lumber (Figures 4-18 and 4-19). All of the mattresses were placed on box 
springs and were covered with cotton bedding consisting of fitted sheets, blankets, comforters, pillows and pillow cases. The mattresses consisted of a polyester cover, twin innersprings, and polyurethane foam. The carpet was polypropylene based and covered the floor wall to wall. It did not extend into the corridor. There was no padding under the carpet, but a $0.01 \mathrm{~m}$ (0.375 in) thick sheet of gypsum board was placed under the carpet.

Table 5. Fire Load Weights

\begin{tabular}{|c|c|c|}
\hline Item & $\begin{array}{c}\text { Mass (PPV Experiment) } \\
(\mathrm{kg})\end{array}$ & $\begin{array}{c}\text { Mass (Natural Experiment) } \\
(\mathrm{kg})\end{array}$ \\
\hline Bunk Bed Frame & 19.15 & 20.13 \\
\hline Top Mattress & 14.60 & 17.14 \\
\hline Top Box Spring & 12.63 & 13.06 \\
\hline Bottom Mattress & 14.98 & 14.44 \\
\hline Bottom Box Spring & 14.21 & 12.94 \\
\hline \multirow{2}{*}{ Pillows } & 0.57 & 0.56 \\
\hline & 0.58 & 0.56 \\
\hline \multirow{2}{*}{ Pillow Cases } & 0.11 & 0.10 \\
\hline & 0.11 & 0.10 \\
\hline \multirow[t]{2}{*}{ Fitted Sheets } & 0.40 & 0.34 \\
\hline & 0.39 & 0.37 \\
\hline \multirow[t]{2}{*}{ Blankets } & 1.15 & 1.19 \\
\hline & 1.18 & 1.22 \\
\hline \multirow[t]{2}{*}{ Comforters } & 1.54 & 1.55 \\
\hline & 1.59 & 1.56 \\
\hline Chair & 27.13 & 27.80 \\
\hline Book Case & 27.08 & 26.17 \\
\hline Desk & 55.48 & 55.48 \\
\hline Computer Monitor & 17.09 & 17.90 \\
\hline Carpet & 40.66 & 39.00 \\
\hline Total Weight & 250.63 & 251.61 \\
\hline
\end{tabular}




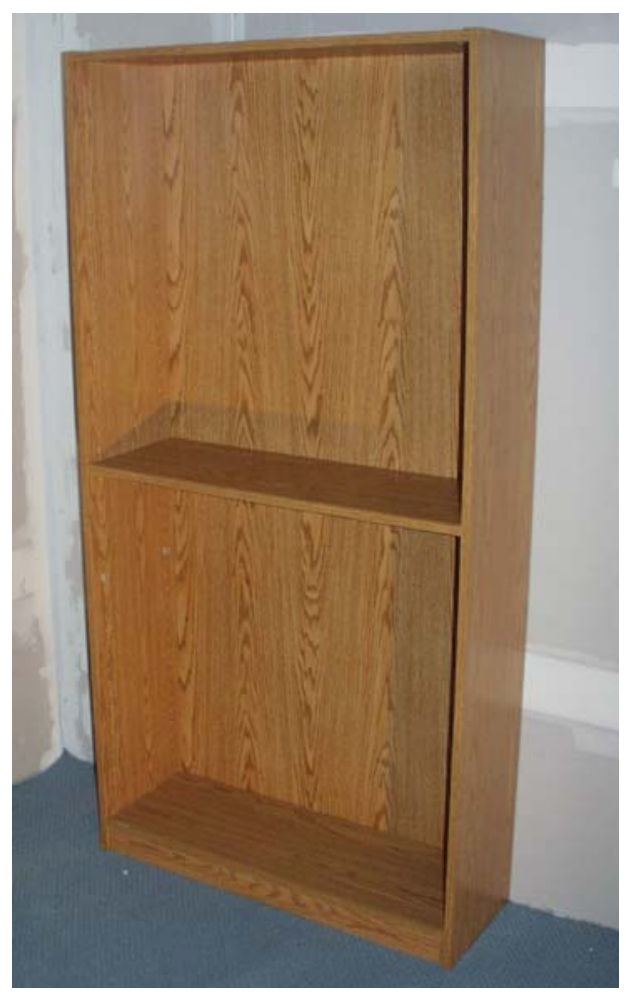

Figure 4-10 - Book Case

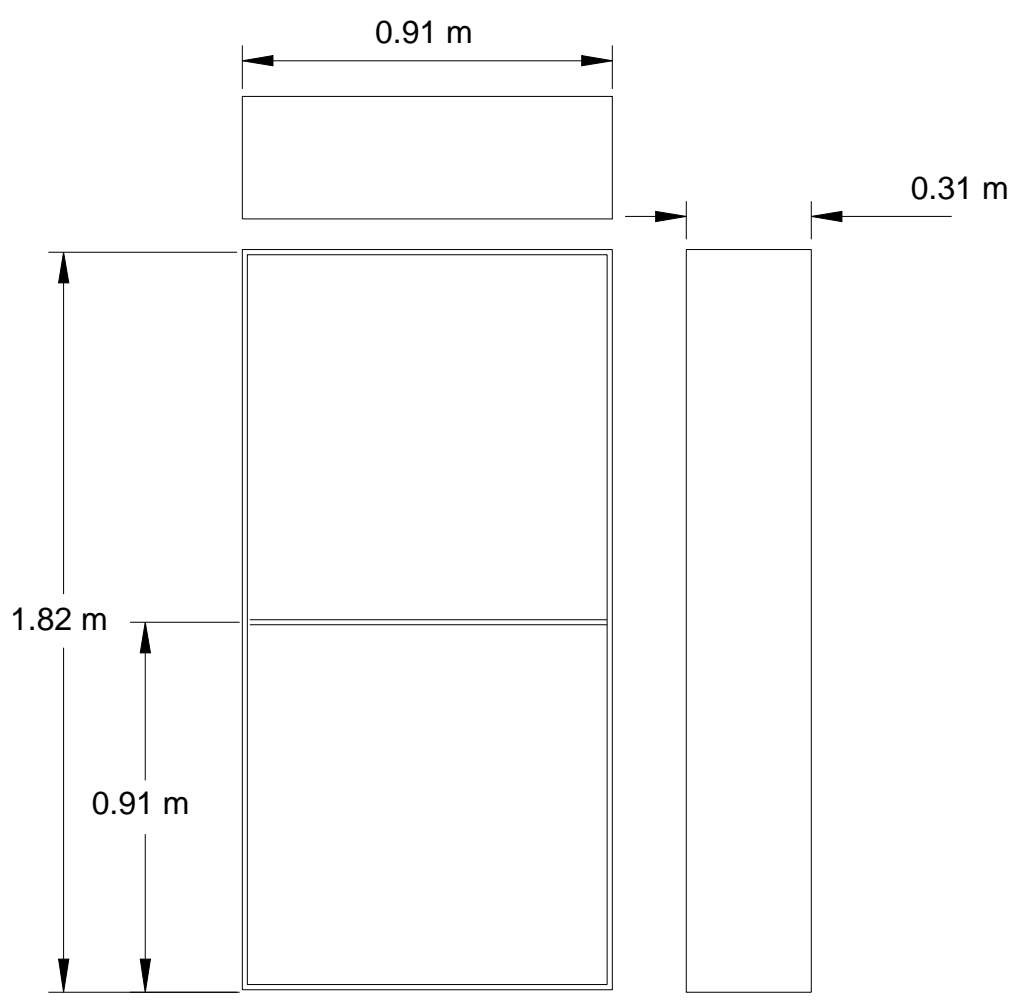

Figure 4-11 - Book Case Dimensions 


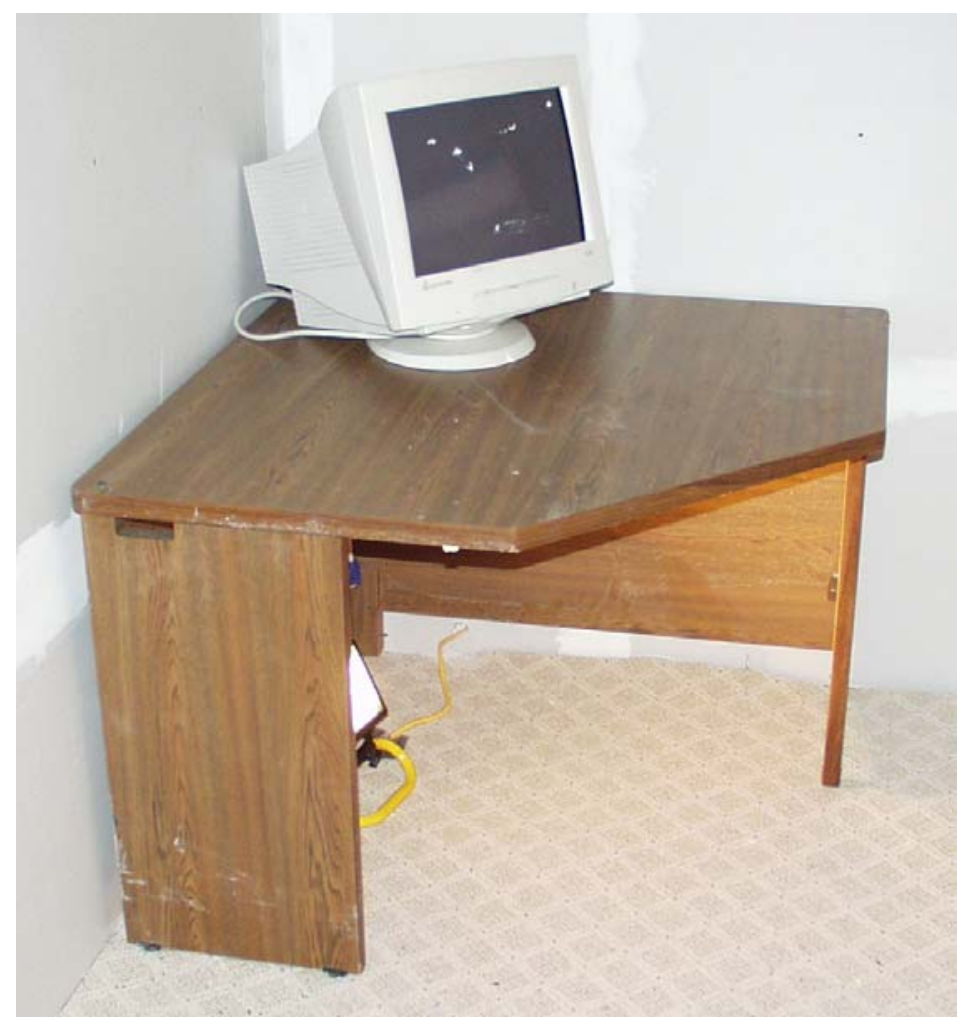

Figure 4-12 - Desk and Monitor
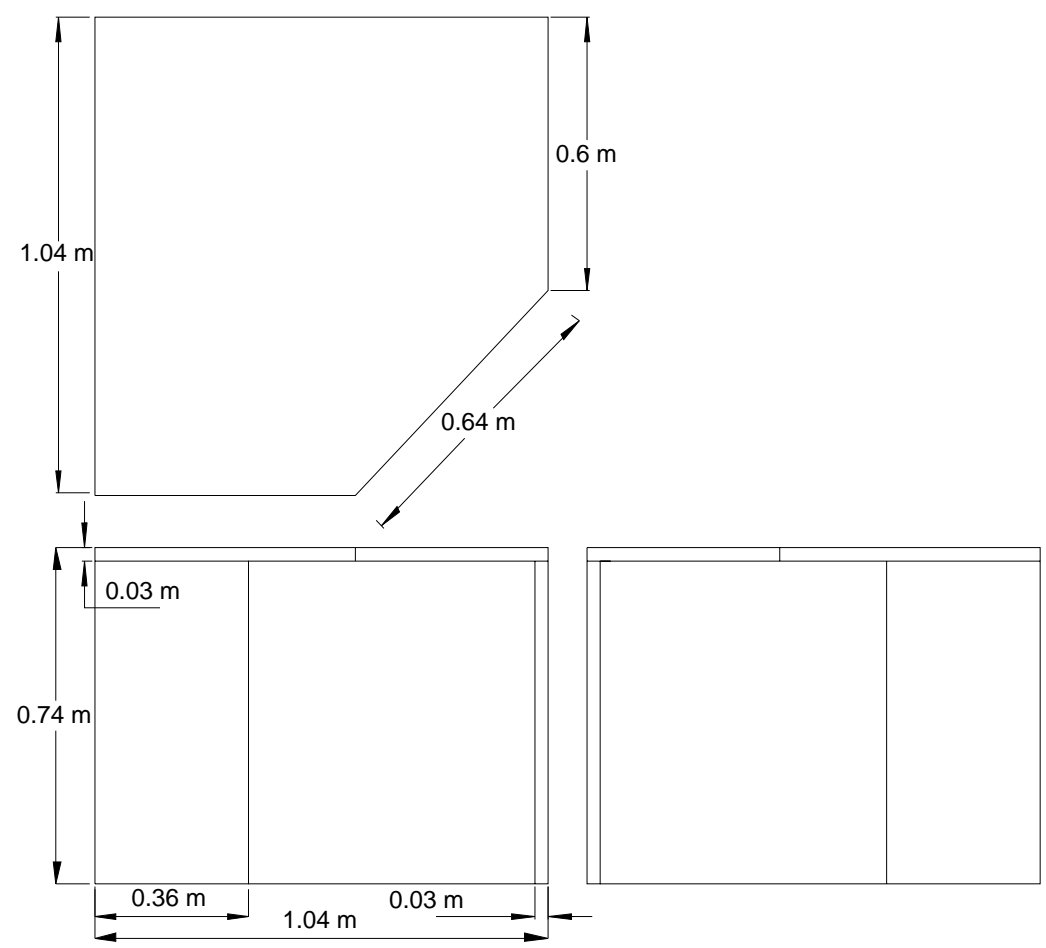

Figure 4-13 - Desk Dimensions 


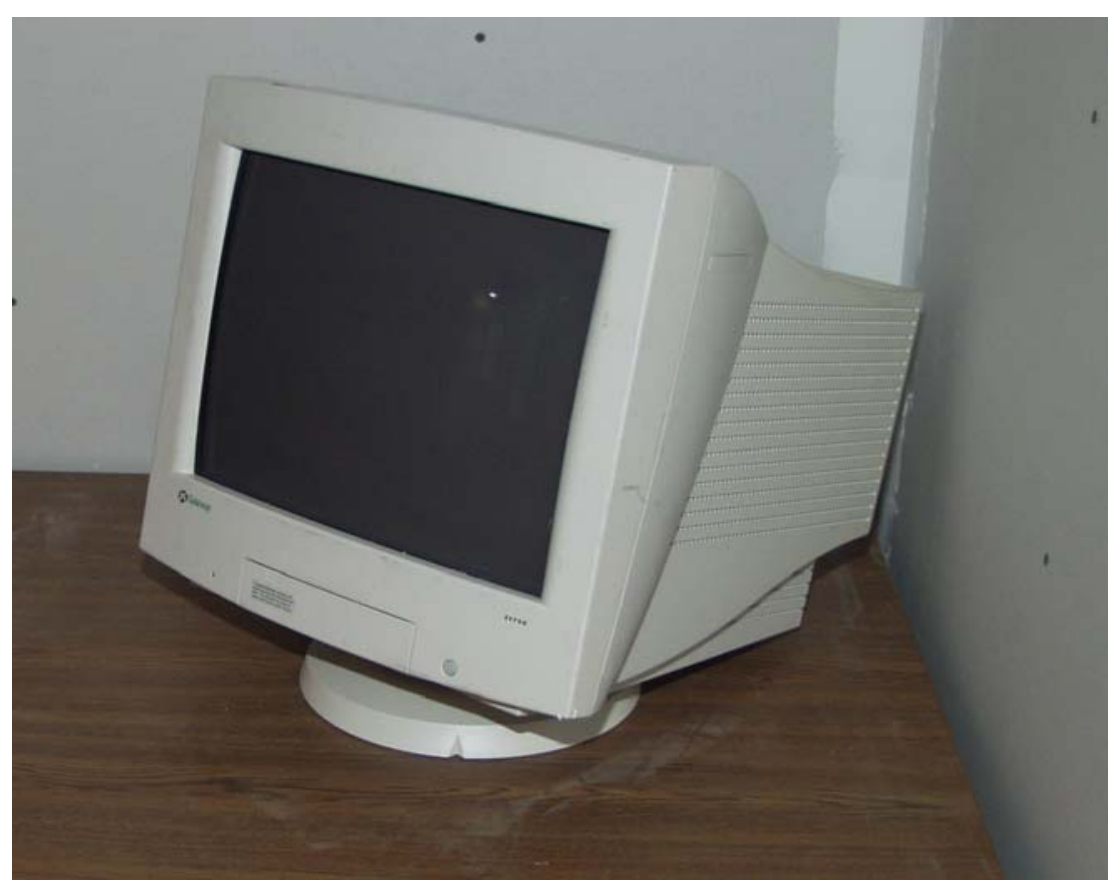

Figure 4-14 - Monitor

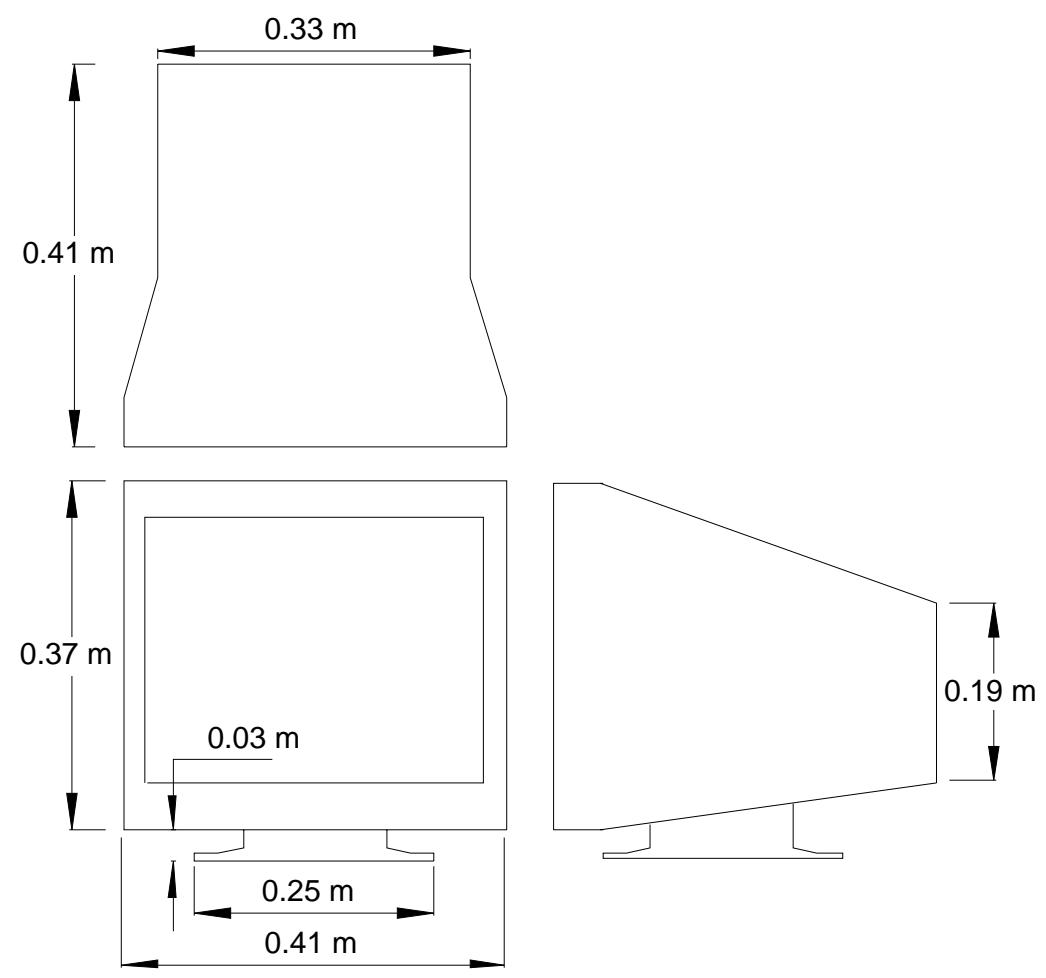

Figure 4-15 - Monitor Dimensions 


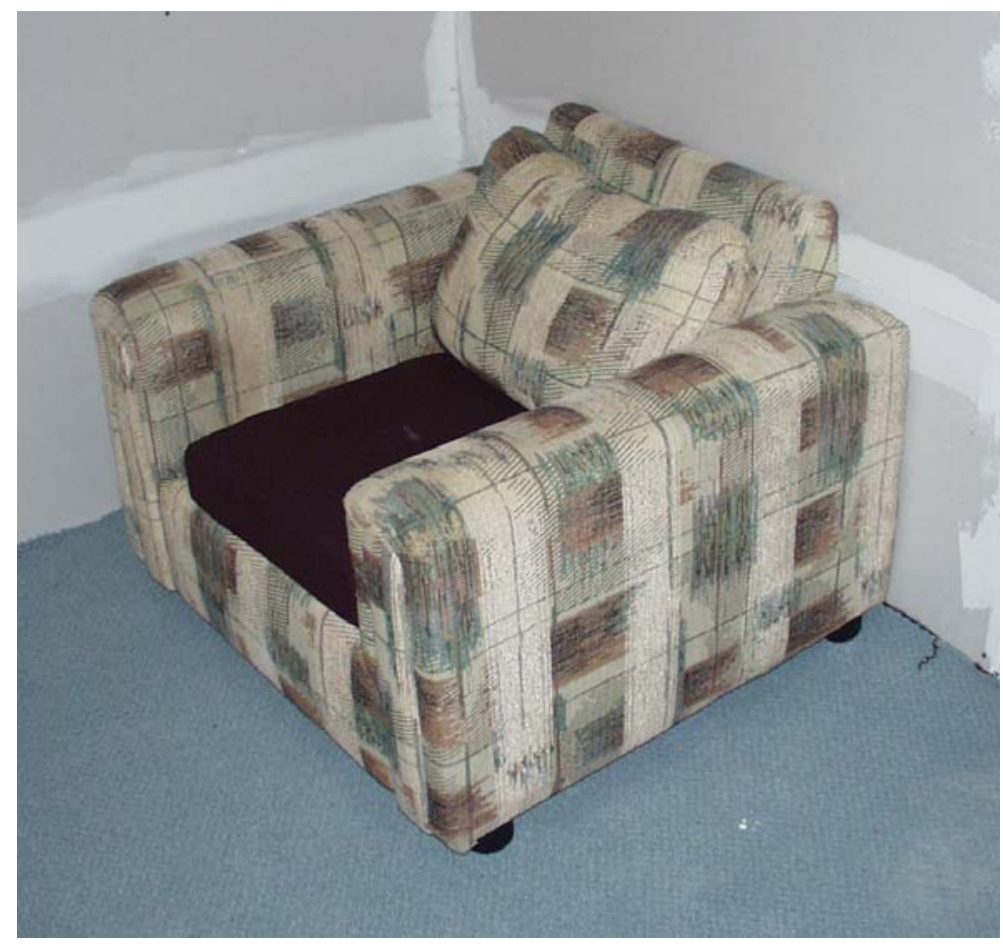

Figure 4-16 - Chair

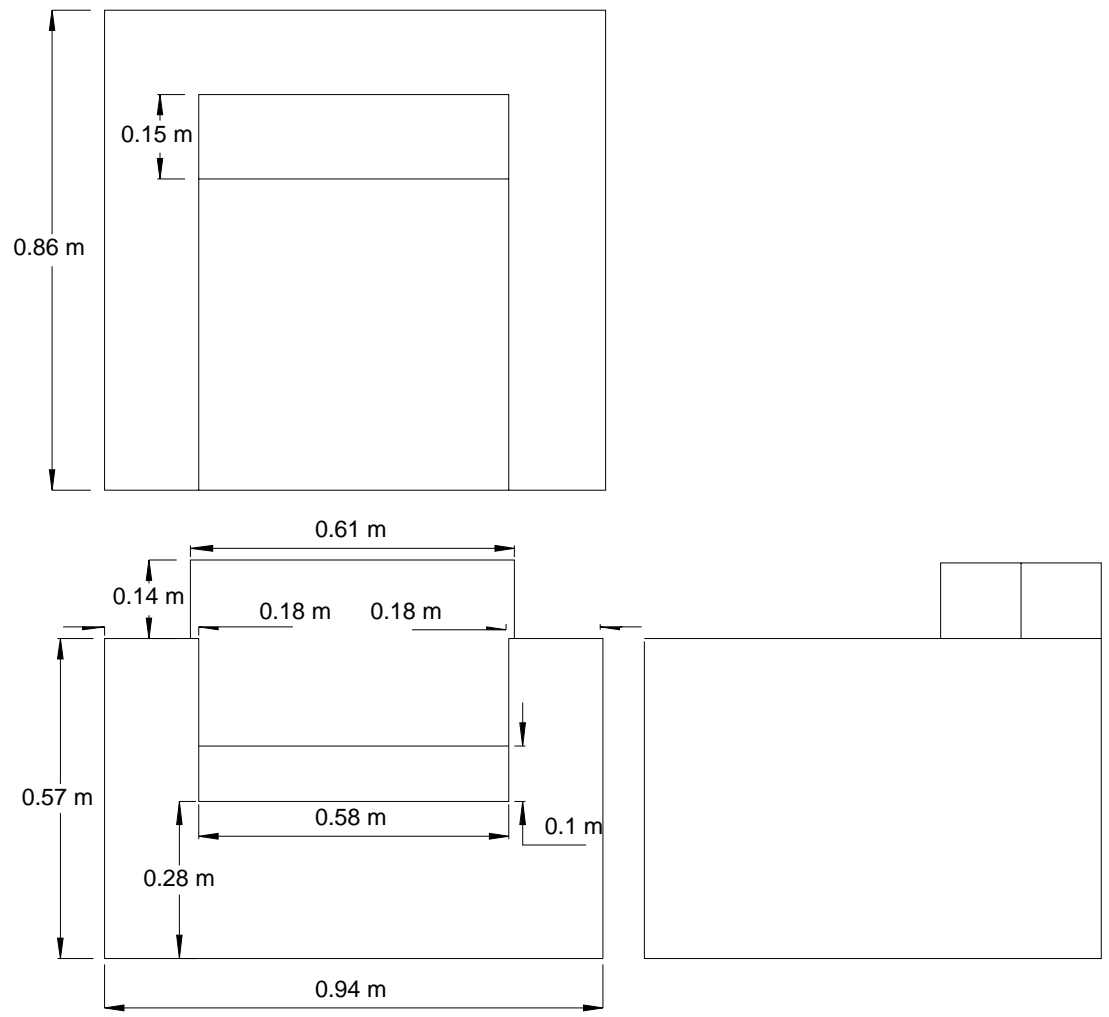

Figure 4-17 - Chair Dimensions 


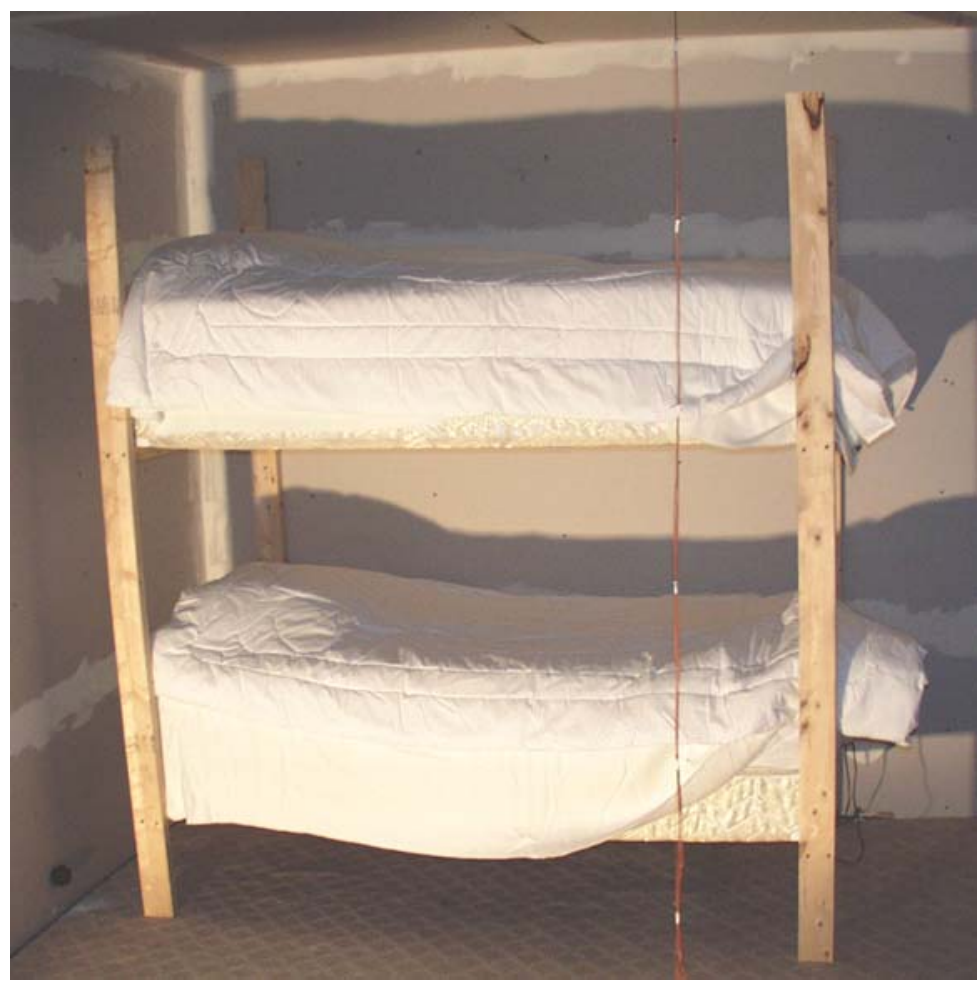

Figure 4-18 - Bunk Bed

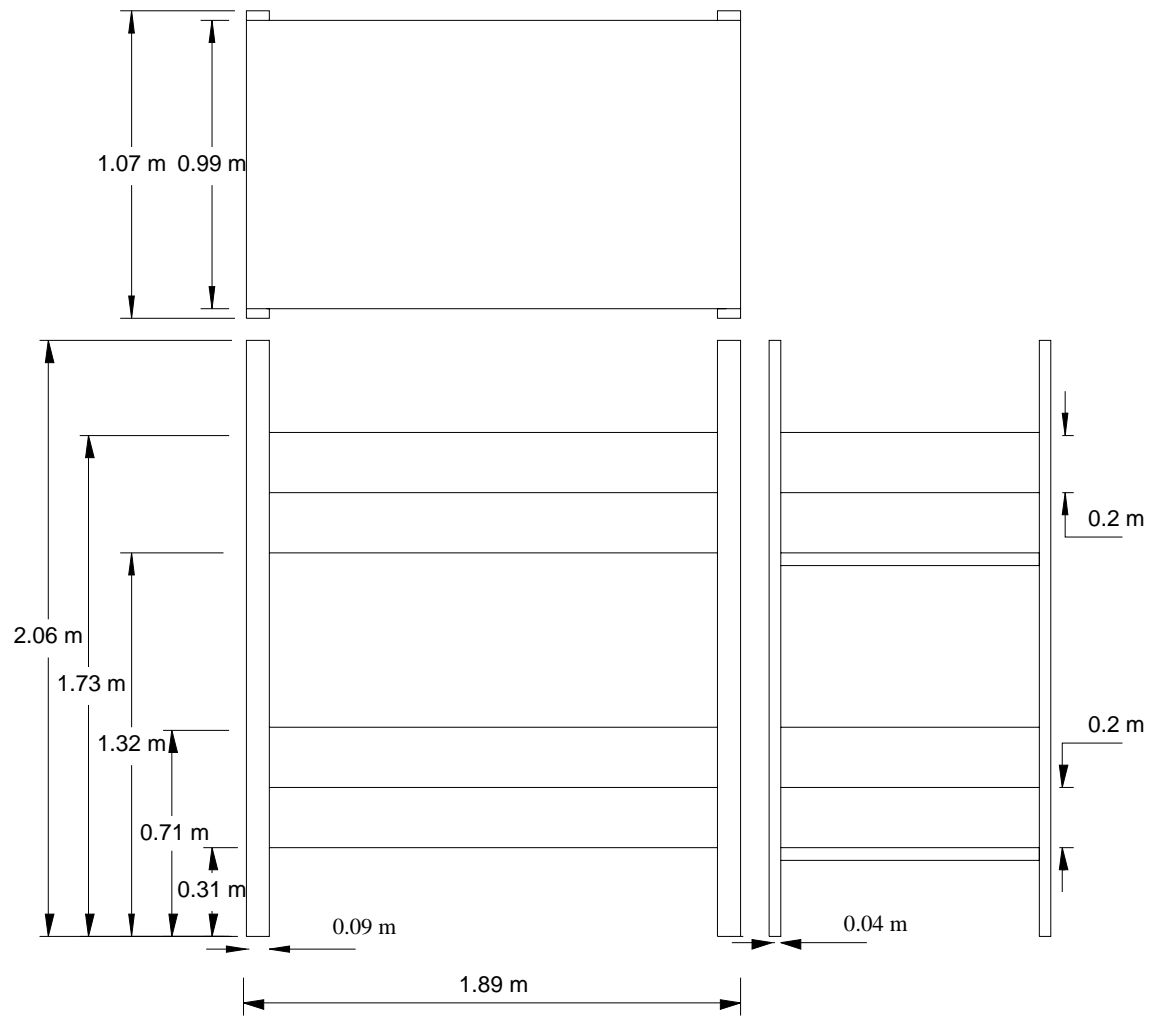

Figure 4-19 - Bunk Bed Dimensions 


\subsubsection{Procedure}

The fire was ignited using two electrically activated matches located in the mattress of the lower bunk, in the corner nearest the center of the room (Figure 4-20). The electric matches consisted of a match book with the cover placed behind the matches, exposing the match heads. Nickel-Chromium wire was spiraled through the match heads and taped to the bottom corners of the match book. A copper wire was connected to each end of the nickel-chromium wire with alligator clips and run to the exterior of the room where they were connected to an igniter box. The igniter box sent current through the wire, heating the wire and, in turn, igniting the matches providing ignition. One of the match books was cut into the mattress and the second was placed under the bedding, directly on top of the mattress to ensure a strong ignition (Figure 4-21).

At the time of ignition, the window was closed and the fire's only source of oxygen beyond the room was through the open room doorway which connected to the corridor via a doorway. The fire was allowed to grow until flashover conditions were reached and the fire became oxygen limited. This was determined by the internal video. Once the fire was oxygen limited for a short period of time, the window was opened from the outside of the room to ventilate the fire. Both of the experiments were ventilated 345 seconds after ignition. In the PPV experiment, the window was opened and 5 seconds later the fan was turned on to full speed until $1380 \mathrm{~s}$ after ignition, when the fan was turned off to assess the structure and begin extinguishment. In the naturally ventilated experiment, the window and doorway 
provided ventilation until the fuel in the room burned to completion. Table 6 provides the timeline of events.

Table 6. Experimental Procedure

\begin{tabular}{|c|c|c|}
\hline Time (s) & Natural Ventilation & Positive Pressure Ventilation \\
\hline 0 & Ignition & Ignition \\
\hline 345 & Window Open & Window Open \\
\hline 350 & - & PPV Fan On \\
\hline \multicolumn{2}{|c|}{ * Fire burned until all fuel was exhausted } \\
\hline
\end{tabular}

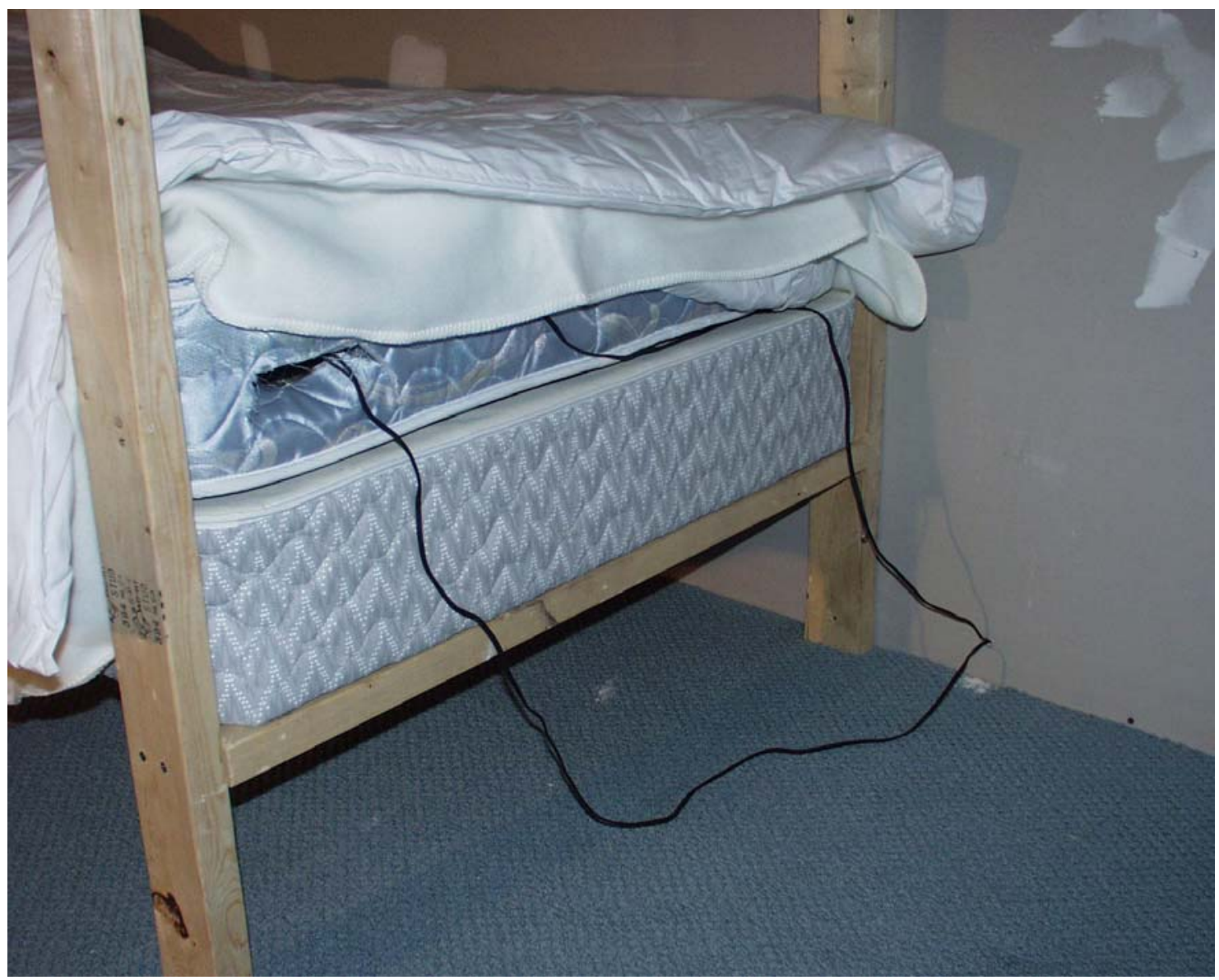

Figure 4-20. Ignition Setup 


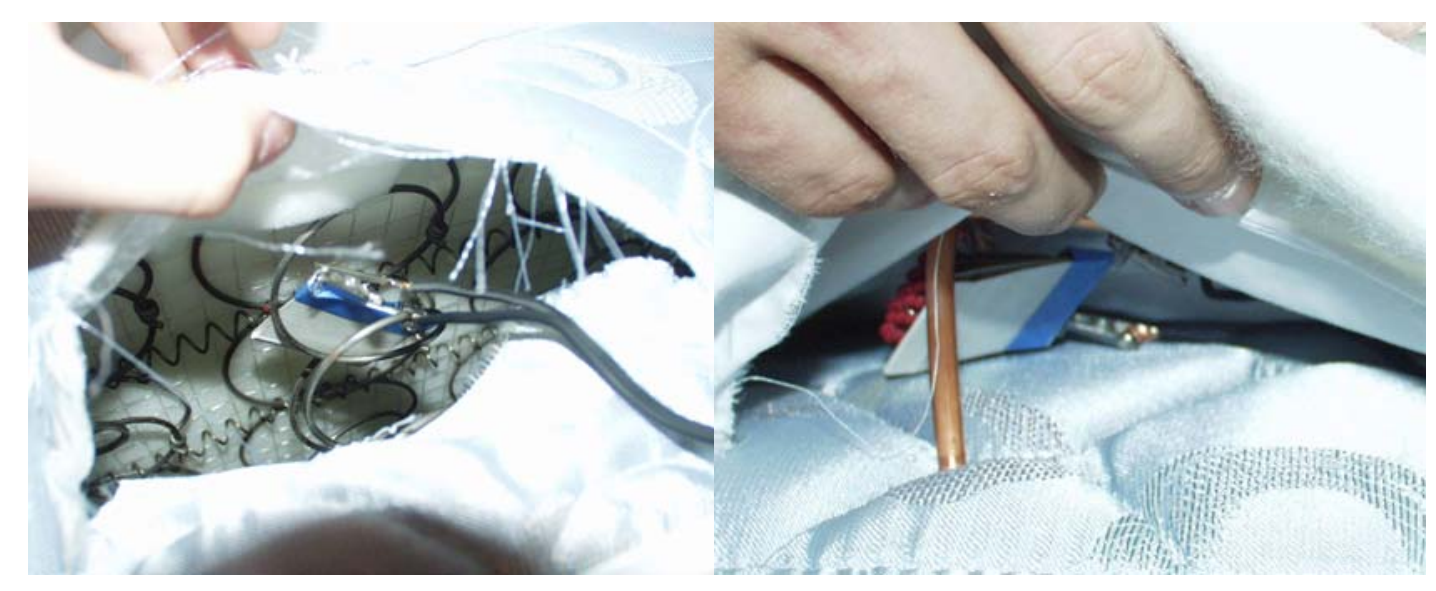

Figure 4-21. Electrically Activated Matchbook Locations

\subsection{Experimental Results}

Cameras at four locations allowed for the visualization of most of the fire growth and the combustion gas flow out of the furnished room. Both experiments experienced very similar fire growth up until the time that the window was opened. In the PPV ventilated experiment, flashover occurred at 275 seconds and near zero visibility at 278 seconds. In the natural ventilation experiment, flashover occurred at approximately 285 seconds and near zero visibility at 298 seconds. While the growth was very similar in both experiments, visibility returned more rapidly in the PPV experiment. The view from the water cooled camera focused on the corner of the room with the bunk beds. The camera showed visibility began to return 181 seconds after the ventilation in the PPV experiment and 395 seconds after the ventilation of the naturally ventilated case. Clear visibility inside the room returned to the PPV ventilated experiment 120 seconds prior to that of the naturally ventilated experiment. 
In both experiments, a black smoke flow was observed in the corridor prior to 300 seconds and flames were not observed in the corridor doorway until the window was ventilated. Within 10 seconds of opening the window, flames extended out of the corridor doorway. Once the fan was activated, it took 130 seconds to completely reverse the flow back into the room. The PPV fan forced all burning out of the corridor and back into the room by 516 seconds after ignition. At that point, little or no smoke was seen coming out of the room doorway. Flames were observed in the corridor of the naturally ventilated experiment until 1200 seconds (Figures 4-22 and $4-24)$.

The exterior view of the window showed that it took less than 5 seconds for flames to come out of the window after ventilation in both experiments. The flames in the PPV ventilated experiment extended approximately $1.83 \mathrm{~m}(6 \mathrm{ft})$ from the window. This length was referenced by the known width of the gypsum board sheets in the background. The flames from the naturally ventilated experiment extended

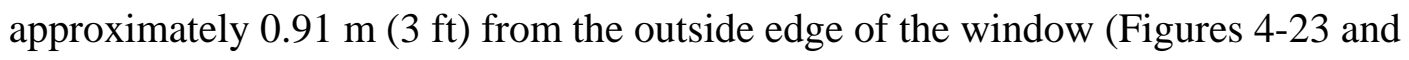
4-25). Detailed observations of both experiments are tabulated in Table 7. 
Table 7. Observations

\begin{tabular}{|c|c|l|}
\hline $\begin{array}{c}\text { PPV } \\
\text { Ventilated } \\
\text { Experiment } \\
\text { Time (s) }\end{array}$ & $\begin{array}{c}\text { Natural } \\
\text { Ventilation } \\
\text { Experiment } \\
\text { Time (s) }\end{array}$ & \\
\hline 0 & 0 & Ignition \\
\hline 86 & 120 & Flames touch top bunk box spring \\
\hline 105 & 120 & Black smoke out of corridor \\
\hline 156 & 180 & Flames extend to top bunk \\
\hline 190 & 220 & Top bunk fully involved in flames \\
\hline 190 & 225 & Smoke layer drops to bottom of window \\
\hline 210 & 240 & Bunk bed fully involved in flames \\
\hline 275 & 285 & Flashover \\
\hline 278 & 298 & Zero visibility \\
\hline 270 & 300 & Smoke down to 0.30 m (1 ft) above corridor floor \\
\hline 345 & 345 & Window Open \\
\hline 350 & 350 & Flames out of window \\
\hline 420 & 460 & Flames on corridor floor \\
\hline- & 650 & Reduction in smoke out of corridor, increase in flames \\
\hline 480 & - & Little - no smoke out of corridor \\
\hline 526 & 740 & Limited visibility returned \\
\hline 645 & 765 & Room clear, everything burning \\
\hline- & 900 & Flames out of room but not out of corridor \\
\hline NA & 960 & Flames no longer extend out of window \\
\hline 1200 & - & Bunk bed falls against thermocouple tree \\
\hline 1230 & 1230 & Burnout \\
\hline 1380 & - & Fan is turned off \\
\hline Note: Times were estimated from the four video camera views \\
\hline
\end{tabular}




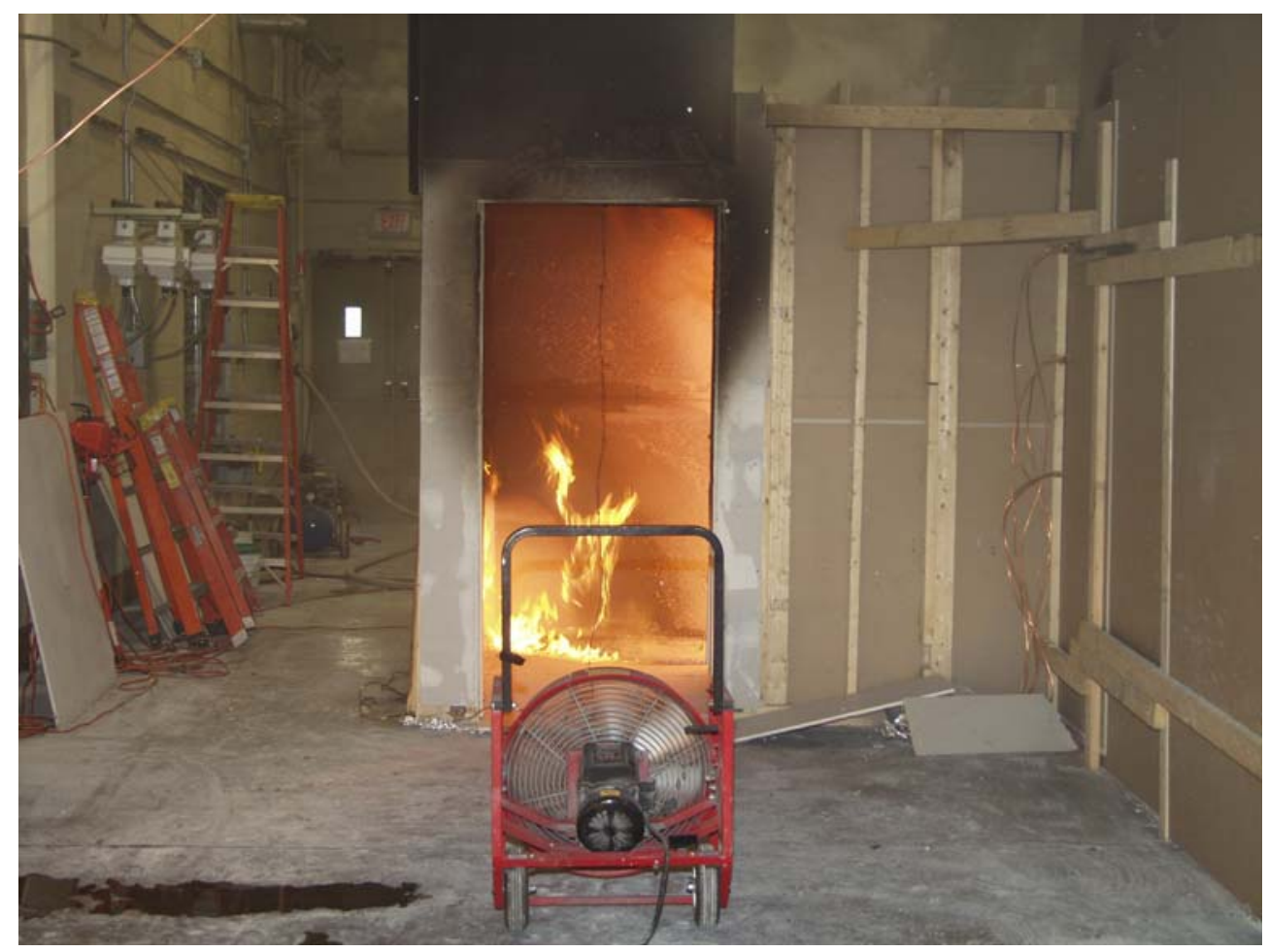

Figure 4-22. Exterior View of Doorway to Corridor After the Start of Forced Ventilation (470 s)

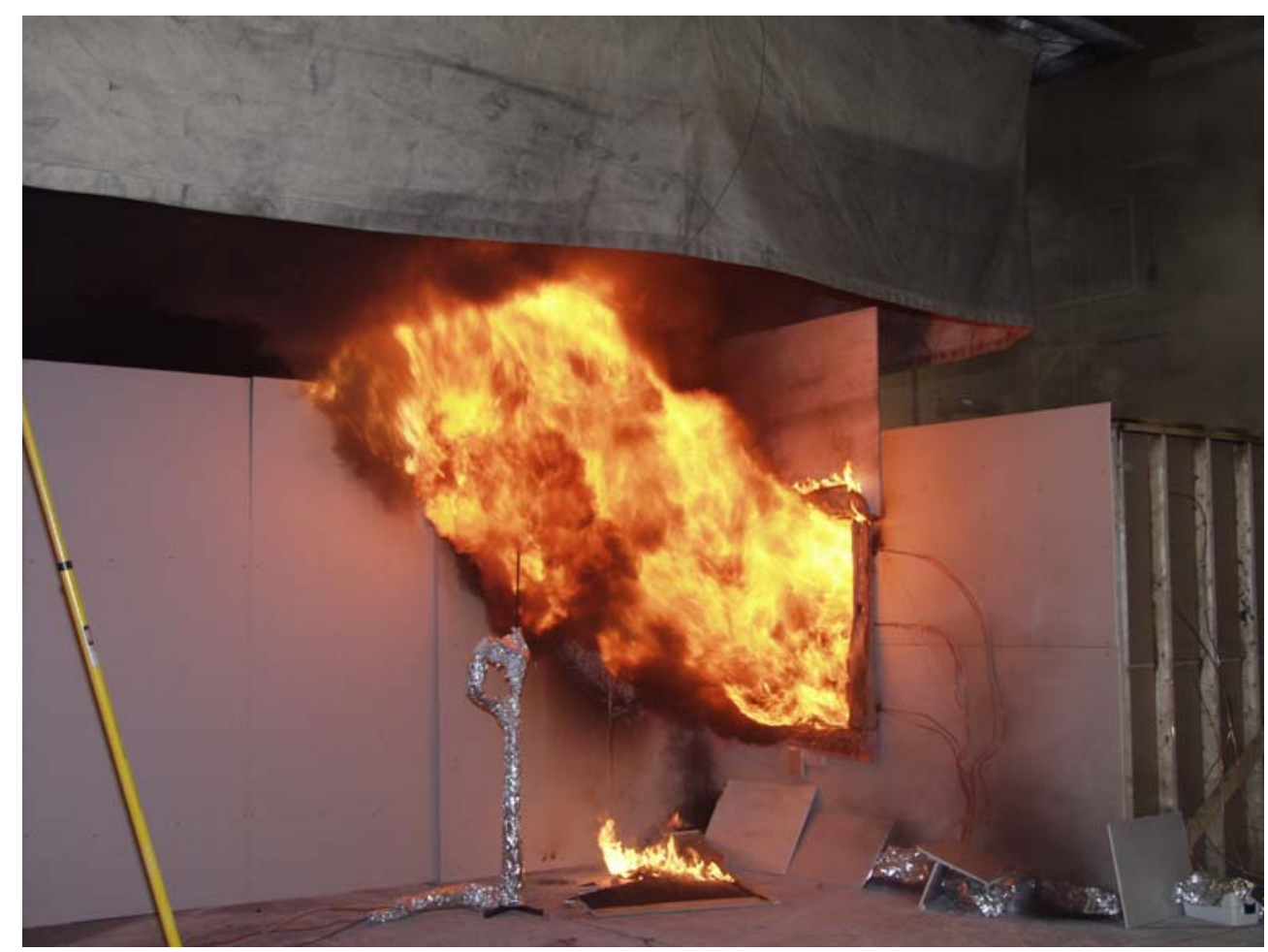

Figure 4-23. Exterior View of Window After the Start of Forced Ventilation (380 s) 


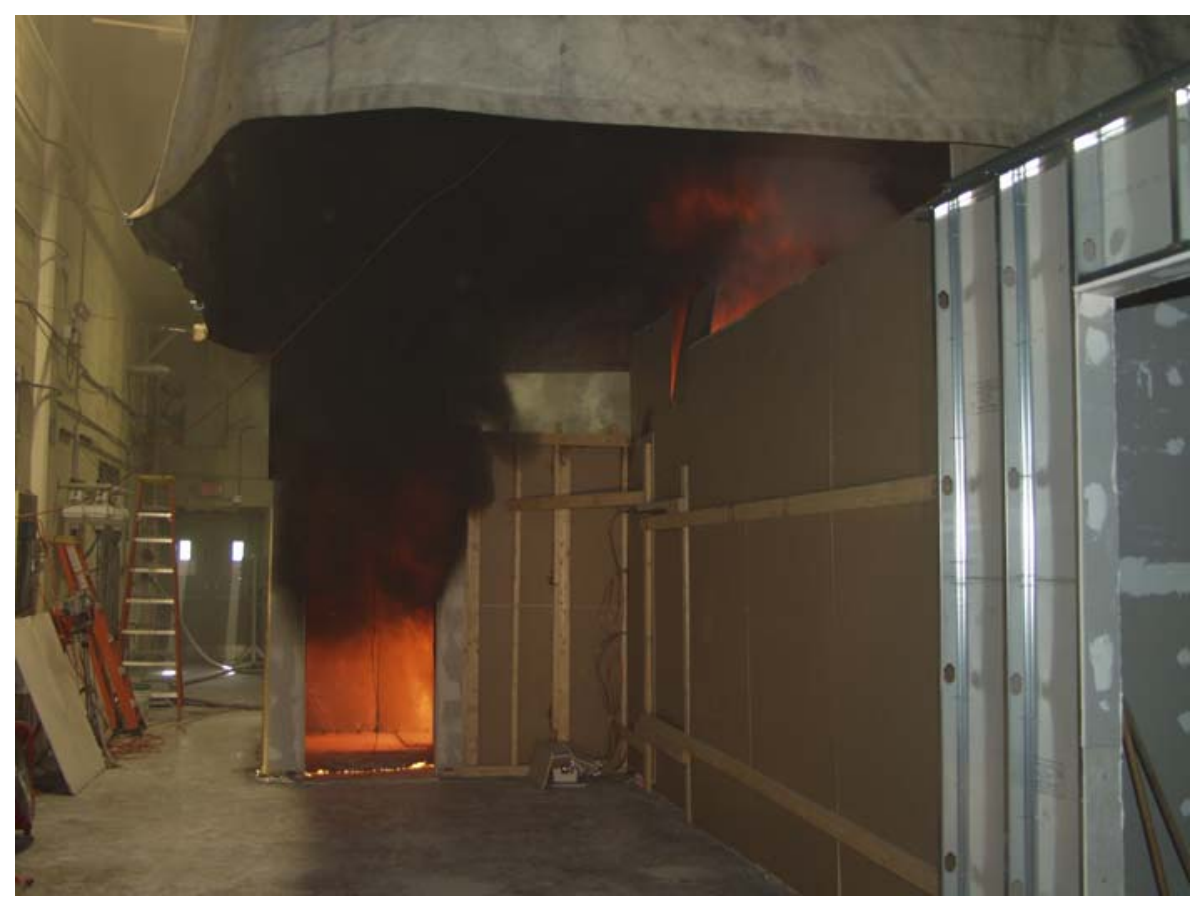

Figure 4-24. Doorway During Natural Ventilation Experiment (645 s)

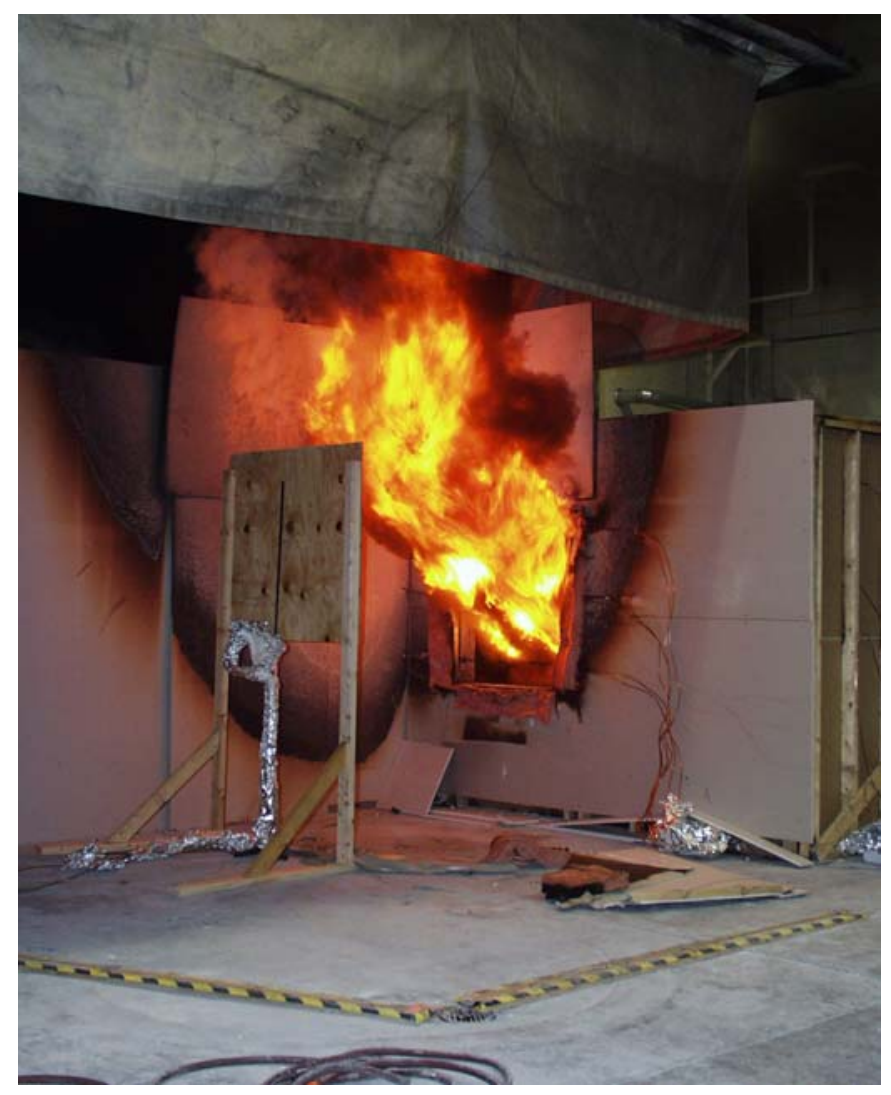

Figure 4-25. Window During Natural Ventilation Experiment (470 s) 


\subsubsection{Heat Release Rate}

The peak measured heat release rate was $14 \mathrm{MW}$ for the PPV ventilated fire and approximately12 MW for the naturally ventilated fire. Peak heat release rates of both fires occurred approximately 40 seconds after window ventilation with a spike to their respective maximum. The peak of the PPV experiment occurred 5 seconds after that of the natural experiment. This corresponded to the 5 seconds period before the PPV fan was started. Comparing the heat release rate between the time of peak and the time where the two curves intersect showed that the PPV created a greater burning rate by approximately $60 \%$ for about 200 seconds after the fire reached its maximum output. After the heat release rate spiked, the PPV output remained $4 \mathrm{MW}$ above that of the naturally ventilated experiment for 70 seconds. At the end of those $70 \mathrm{~s}$, the rates converged until 590 seconds when the naturally ventilated fire had the higher heat release rate. The naturally ventilated fire remained roughly $1 \mathrm{MW}$ above the output of the PPV ventilated fire until the end of the experiment (Figures 4-26 and 4-27). The integral of the heat release rate curve in Figure 4-28 provided the total heat released over the duration of both experiments. The PPV ventilated experiment released 3.7 GJ and the naturally ventilated experiment released 3.4 GJ. The fan caused heat to be released quicker in the PPV experiment, but ultimately both experiments released approximately the same amount of heat.

For fires burning in the open under the laboratory hood, the chemical power measured by the oxygen depletion calorimeter is equal to the heat release rate from the fire as a function of time. However, for a fire within a room, the effluent from the enclosure is 
a mixed average of the upper layer gases, and does not represent the instantaneous heat release rate of the fire. Prior to ventilation there was a delay in the heat release rate measured due to the room configuration and the time needed for combustion products to travel out of corridor doorway. After the window was opened a majority of the burning took place on the exterior of the room which allowed for a faster and more accurate measure of heat release rate.

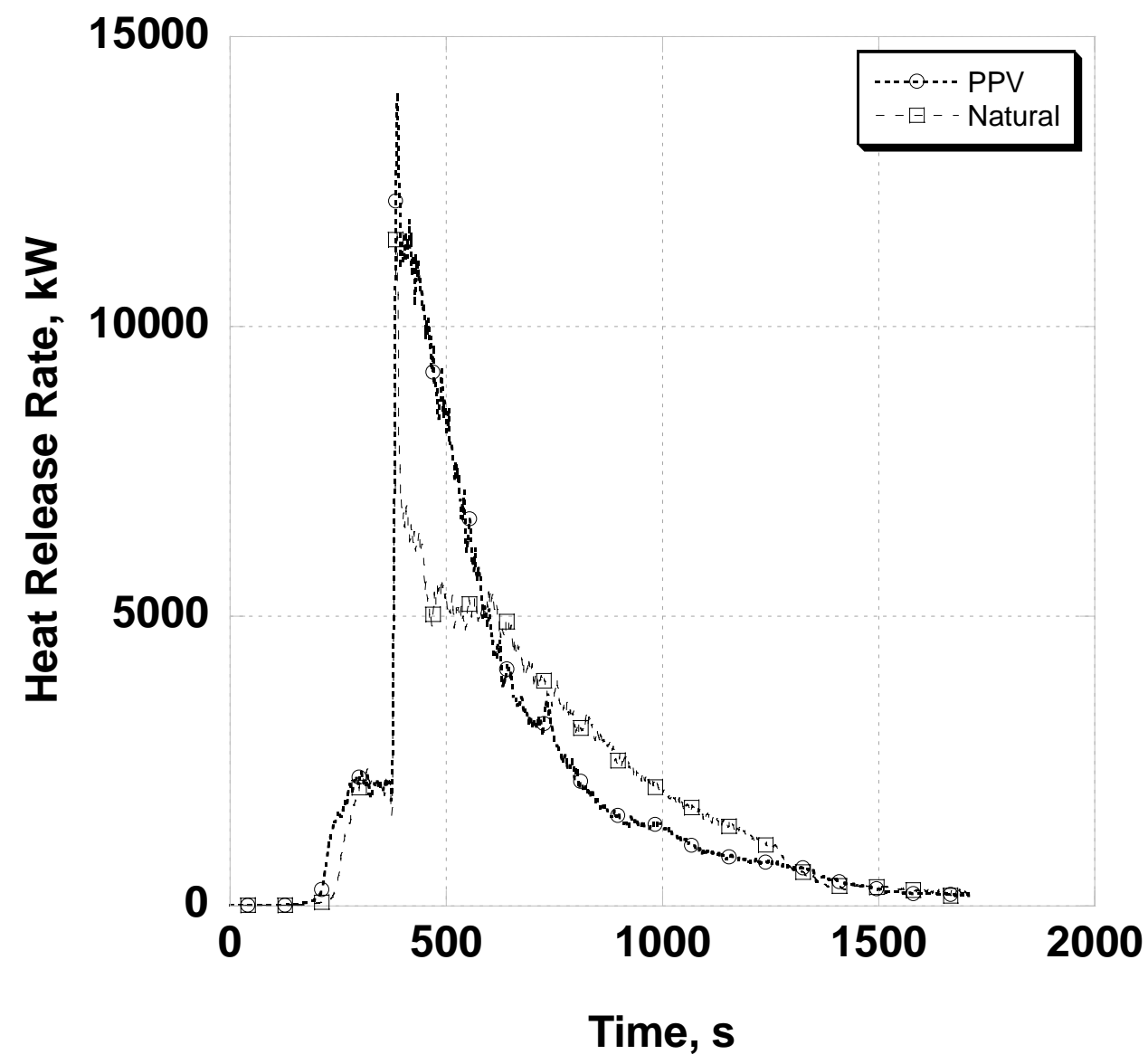

Figure 4-26. Heat Release Rate 


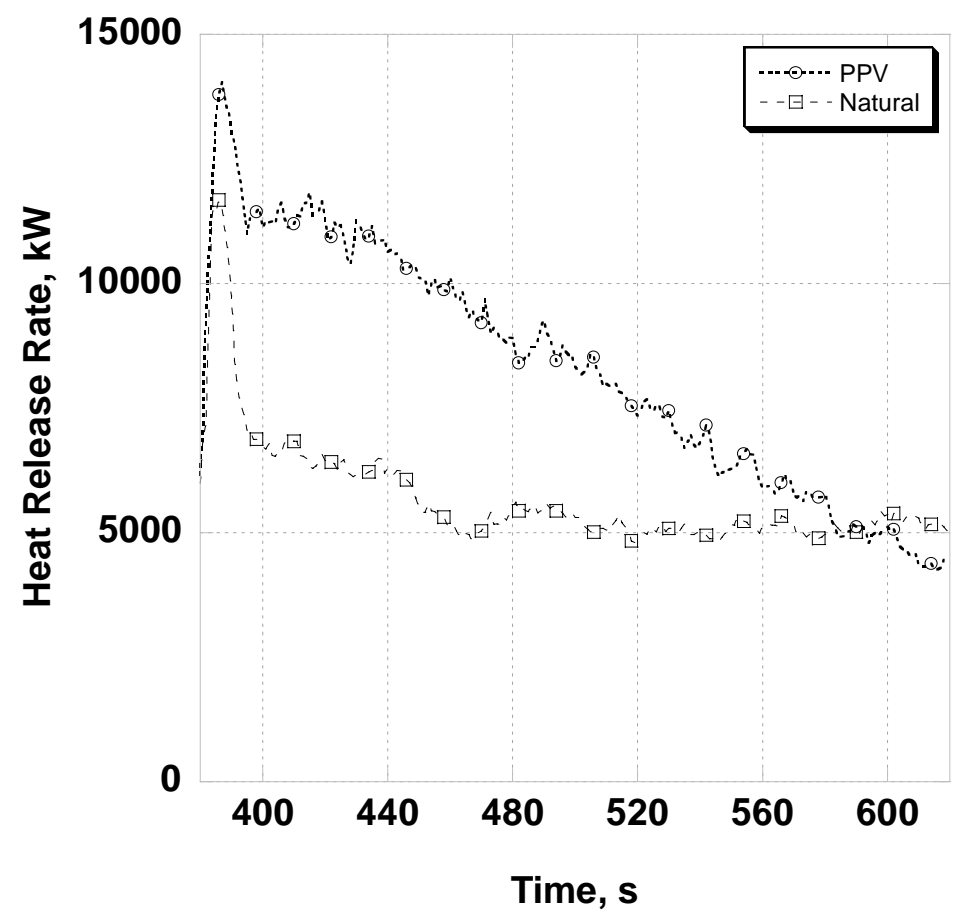

Figure 4-27. Heat Release Rate Detail For 200 seconds Following Peak Output

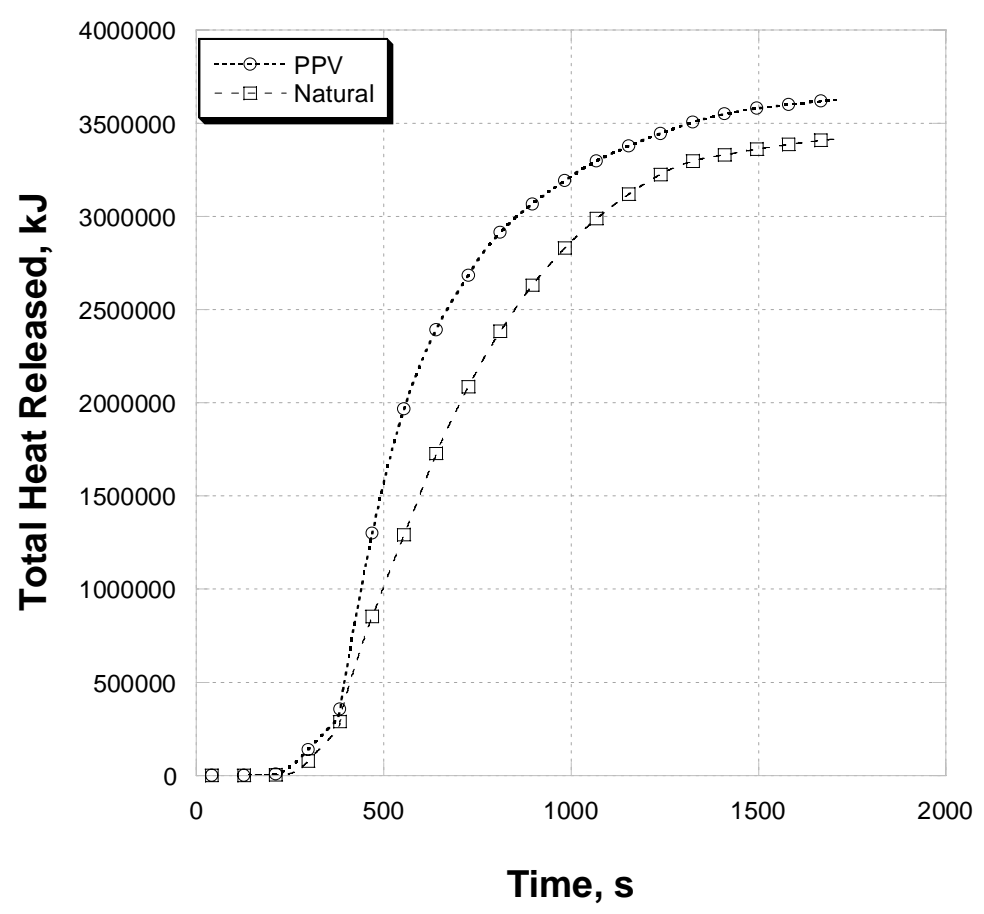

Figure 4-28. Total Heat Released 


\subsubsection{Room Gas Temperature}

The gas temperatures measured in the room were similar for both experiments prior to ventilation as each fire grew to an initial peak of approximately $800{ }^{\circ} \mathrm{C}\left(1470{ }^{\circ} \mathrm{F}\right)$ (Figure 4-29). Flashover occurred approximately 270 seconds (s) after ignition and both fires became ventilation limited. Once the fires were ventilation limited, the upper layer temperatures decreased to $700{ }^{\circ} \mathrm{C}\left(1290{ }^{\circ} \mathrm{F}\right)$. When ventilation was started in the experiment with a PPV fan, the upper layer temperature increased temporarily to $800{ }^{\circ} \mathrm{C}\left(1470{ }^{\circ} \mathrm{F}\right)$, quickly dropped to $550{ }^{\circ} \mathrm{C}\left(1020^{\circ} \mathrm{F}\right)$ and then rapidly increased to the maximum temperature of approximately $980{ }^{\circ} \mathrm{C}\left(1800{ }^{\circ} \mathrm{F}\right)$. The maximum temperature was maintained for a short period of time and then the temperatures in the room steadily decreased to $400{ }^{\circ} \mathrm{C}\left(750{ }^{\circ} \mathrm{F}\right)$ at a rate of $0.8^{\circ} \mathrm{C} / \mathrm{s}$. At 1200 seconds into the experiment a piece of the burning bunk bed fell onto the thermocouple leads and caused an artificial room temperature increase. The room gas temperatures shown in Figure 4-29 are inaccurate after this point.

The naturally ventilated fire produced a much smoother time evolution of room temperatures. After ventilation, the temperatures rapidly increased to the maximum temperature of $1050^{\circ} \mathrm{C}\left(1890{ }^{\circ} \mathrm{F}\right)$. The temperatures remained approximately $1000{ }^{\circ} \mathrm{C}\left(1830{ }^{\circ} \mathrm{F}\right)$ for approximately 300 seconds. Once the temperatures began to decrease the values did so steadily to $500{ }^{\circ} \mathrm{C}\left(932{ }^{\circ} \mathrm{F}\right)$ at a rate of $0.8{ }^{\circ} \mathrm{C} / \mathrm{s}$. At 1430 seconds there was a rapid decrease in temperature to $100{ }^{\circ} \mathrm{C}\left(210^{\circ} \mathrm{F}\right)$ as the fuel in the room was consumed (Figure 4-30). 


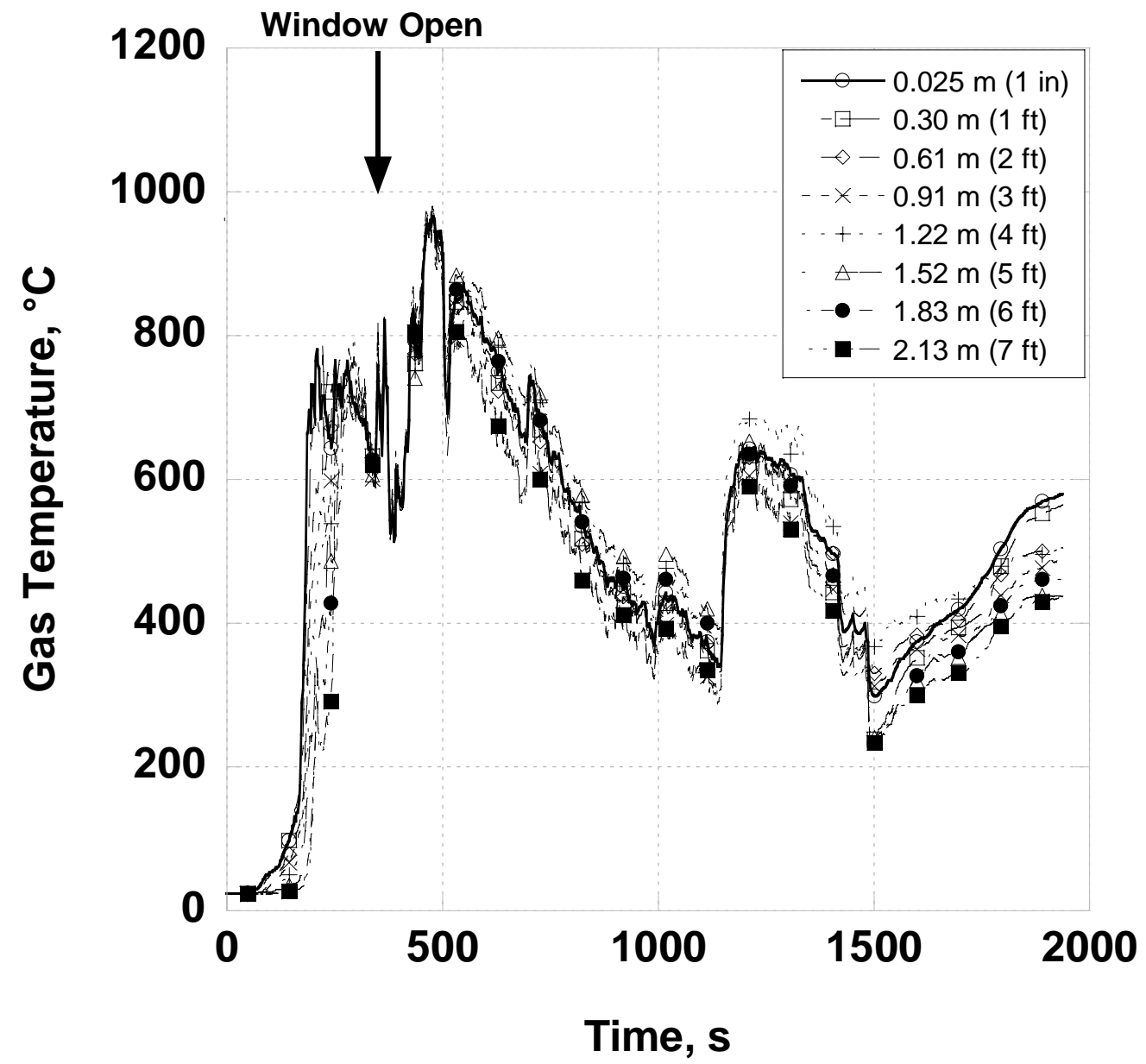

Figure 4-29. PPV Room Temperatures, Distances Measured From Ceiling 


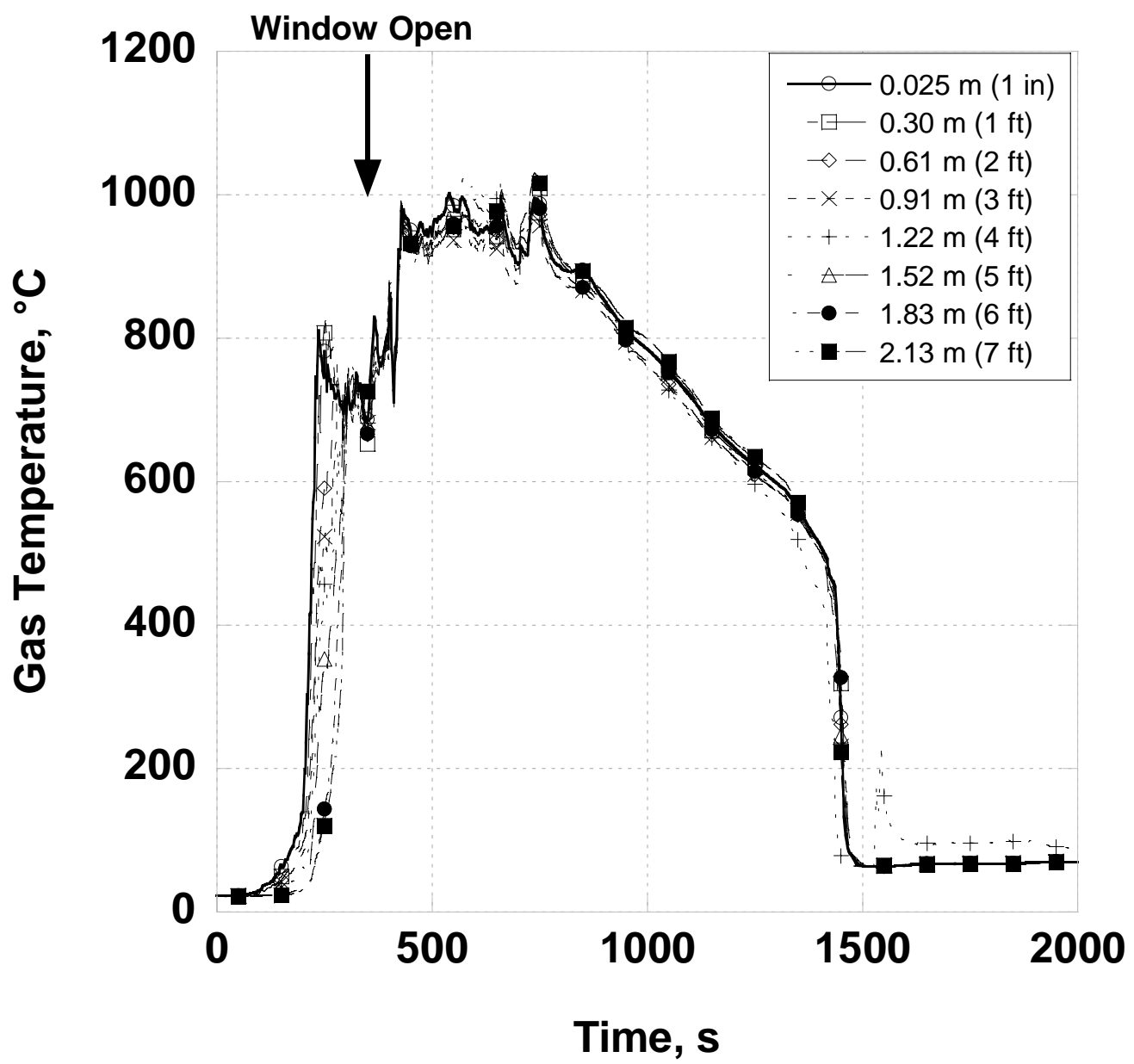

Figure 4-30. Natural Ventilation Room Temperatures

\subsubsection{Doorway Gas Temperature}

The temperatures recorded in the upper portion of the doorway to the room were comparable to those within the room. For both experiments the temperatures at the top and middle of the doorway were around $600{ }^{\circ} \mathrm{C}\left(1110{ }^{\circ} \mathrm{F}\right)$ while the lower portion of the doorway remained less than $100{ }^{\circ} \mathrm{C}\left(212^{\circ} \mathrm{F}\right)$ prior to window ventilation. This was consistent with the fire drawing ambient air into the room through the lower section of the doorway. 
After positive pressure ventilation was started, the gas temperatures increased quickly to the peak temperatures of $1000{ }^{\circ} \mathrm{C}\left(1830{ }^{\circ} \mathrm{F}\right)$ at the top, $800{ }^{\circ} \mathrm{C}\left(1470{ }^{\circ} \mathrm{F}\right)$ in the center and $550{ }^{\circ} \mathrm{C}\left(1020^{\circ} \mathrm{F}\right)$ at the bottom of the doorway. Once the fan forced the air into the room, the doorway temperatures began to decline and continued to decrease until the end of the experiment (Figure 4-31). A small increase in temperature occurred at approximately 1380 seconds which was consistent with the turning off of the fan. The increase is further evidence of the cooling effects of the fan.

The doorway temperatures for the naturally ventilated experiment were higher than those of the PPV experiment for a longer time period. It took approximately 300 seconds for the maximum temperatures to be reached at the top of the doorway. Both the top and center of the doorway reached a maximum of $1000{ }^{\circ} \mathrm{C}\left(1830{ }^{\circ} \mathrm{F}\right)$. The bottom of the doorway briefly peaked at $700{ }^{\circ} \mathrm{C}\left(1290{ }^{\circ} \mathrm{F}\right)$ before dropping to $200{ }^{\circ} \mathrm{C}\left(390{ }^{\circ} \mathrm{F}\right)$ as the fire continued to burn. Temperatures slowly declined to $100{ }^{\circ} \mathrm{C}\left(212^{\circ} \mathrm{F}\right)$ over the 700 seconds after the peak (Figure 4-32). 


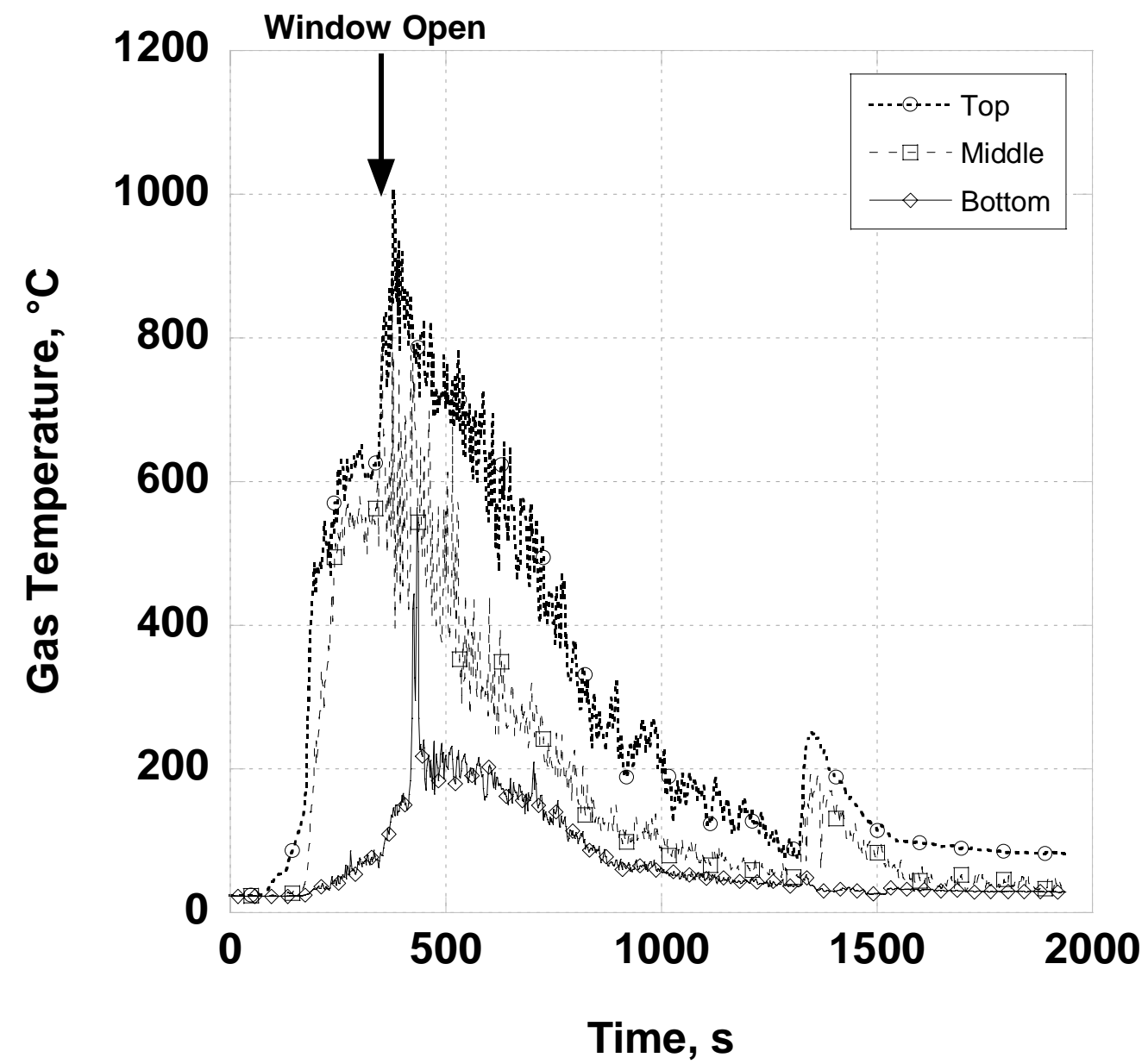

Figure 4-31. PPV Doorway Temperatures 


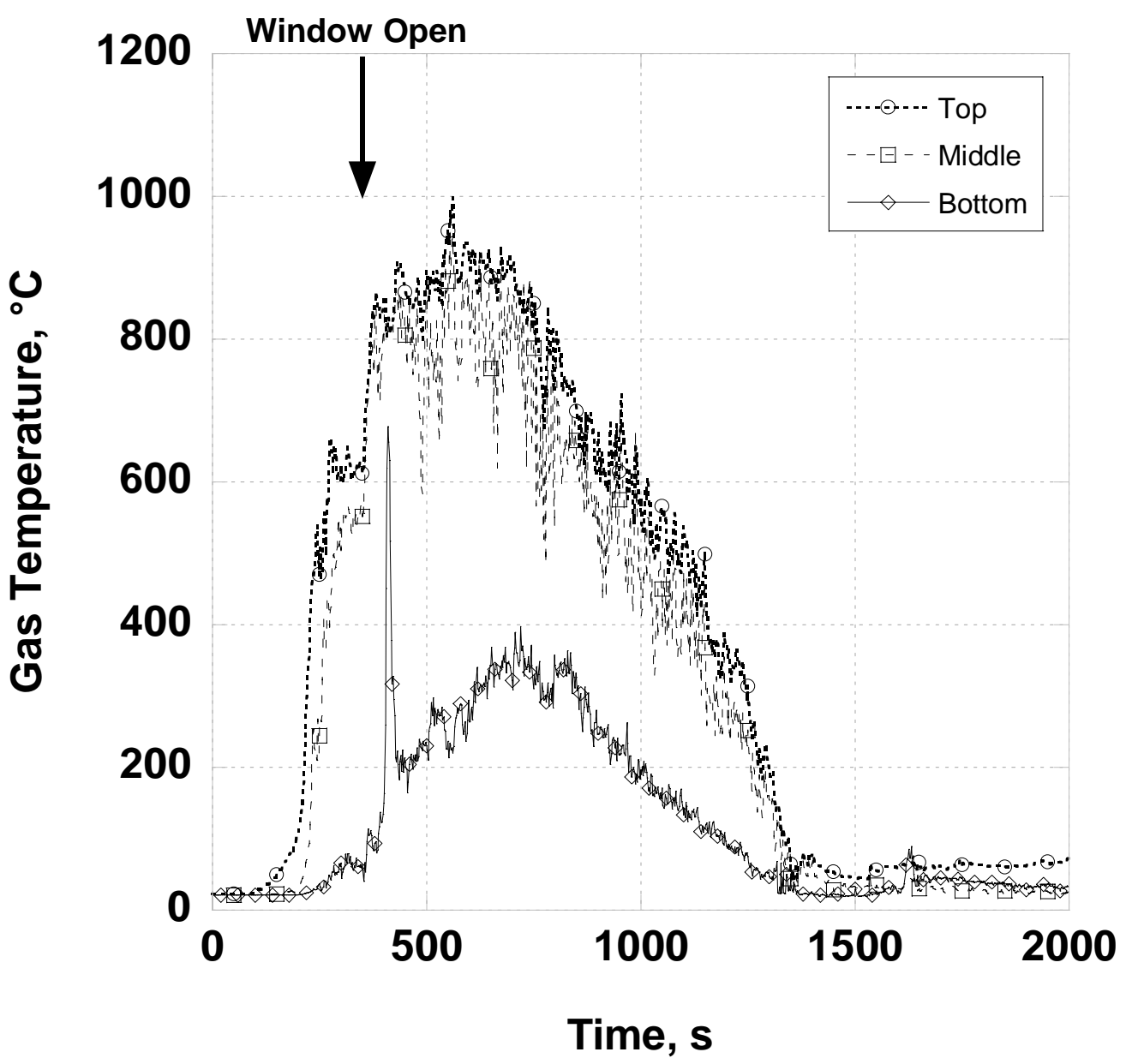

Figure 4-32. Natural Ventilation Doorway Temperatures

\subsubsection{Window Gas Temperature}

The gas temperatures monitored at the window were significantly different depending on the method of ventilation. The PPV experiment created more uniform gas temperatures in the window due to the unidirectional flow out of the window. Flames and hot gases could be observed coming out of the entire cross sectional area of the window. A bidirectional flow pattern existed in the naturally ventilated fire experiment. Flames could be seen in the entire window for a short period of time and 
then air entered the lower third of the window for the remainder of the experiment.

The gas temperatures in the PPV experiment were entirely between $900{ }^{\circ} \mathrm{C}\left(1650{ }^{\circ} \mathrm{F}\right)$ and $1100{ }^{\circ} \mathrm{C}\left(2010{ }^{\circ} \mathrm{F}\right)$ while the naturally ventilated experiment had temperatures of $1000{ }^{\circ} \mathrm{C}\left(1832{ }^{\circ} \mathrm{F}\right)$ at the top and $600{ }^{\circ} \mathrm{C}\left(1110{ }^{\circ} \mathrm{F}\right)$ at the bottom of the window. The PPV experiment required 200 seconds to reach these temperatures while the naturally ventilated experiment took approximately 400 seconds (Figures 4-33 and 4-34).

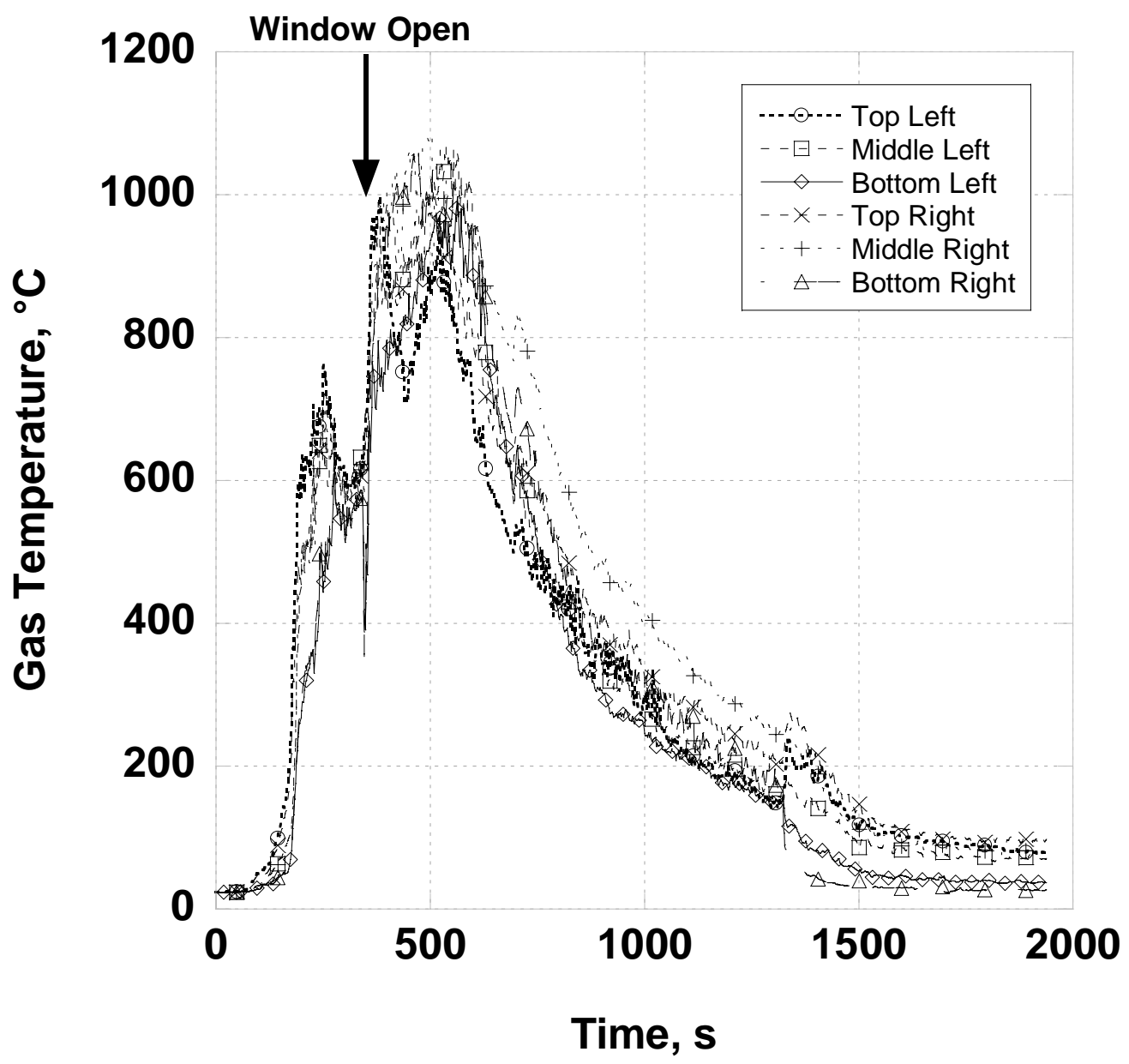

Figure 4-33. PPV Window Temperatures 


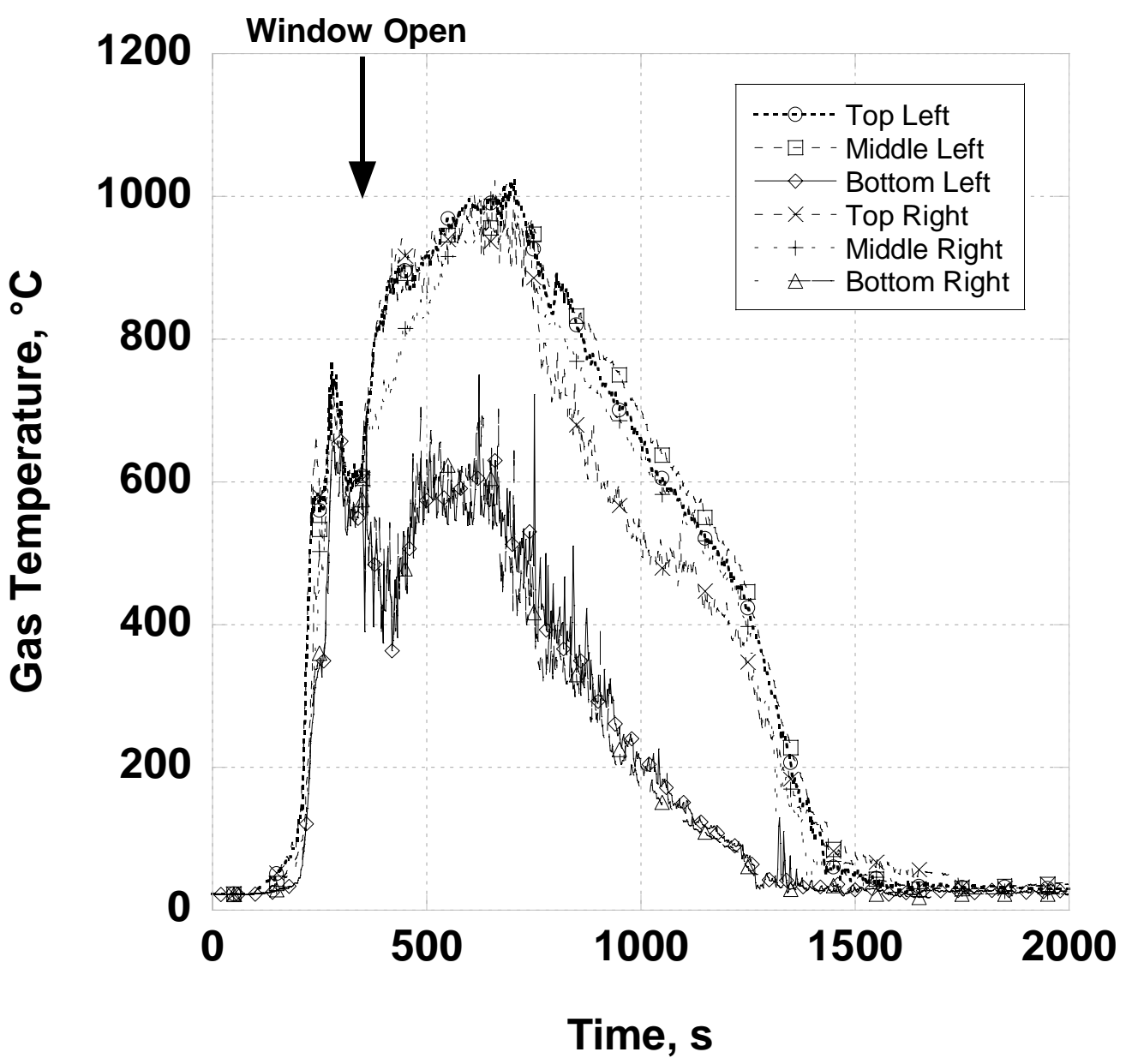

Figure 4-34. Natural Ventilation Window Temperatures

\subsubsection{Corridor Gas Temperature}

The corridor doorway gas temperatures also showed a significant difference between the two ventilation tactics. Approximately 120 seconds after the fan was started; the fan was able to reverse the natural tendency for the gas to flow back into the room. This created a unidirectional flow. After ventilation started in the PPV experiment, the gas temperature reached nearly $700{ }^{\circ} \mathrm{C}\left(1290{ }^{\circ} \mathrm{F}\right)$ at the very top of the doorway. Once the fan was turned on, the upper doorway temperatures never increased above 
$200{ }^{\circ} \mathrm{C}\left(390{ }^{\circ} \mathrm{F}\right)$. The bottom half of the doorway remained slightly above ambient temperatures of $25^{\circ} \mathrm{C}\left(77^{\circ} \mathrm{F}\right)$.

The naturally ventilated gas temperatures were different due to the flow of combustion gases and flames that ventilated out of the corridor doorway. Gas temperatures in the upper third of the doorway were between $600{ }^{\circ} \mathrm{C}\left(1110{ }^{\circ} \mathrm{F}\right)$ and $900{ }^{\circ} \mathrm{C}\left(1650{ }^{\circ} \mathrm{F}\right)$ after ventilation (window opened). The mid doorway temperature rose as high as $400{ }^{\circ} \mathrm{C}\left(750^{\circ} \mathrm{F}\right)$ while the temperature at the bottom remained approximately $100{ }^{\circ} \mathrm{C}\left(212{ }^{\circ} \mathrm{F}\right)$. The temperature trends in the corridor were very similar to those of the room doorway (Figures 4-35 and 4-36).

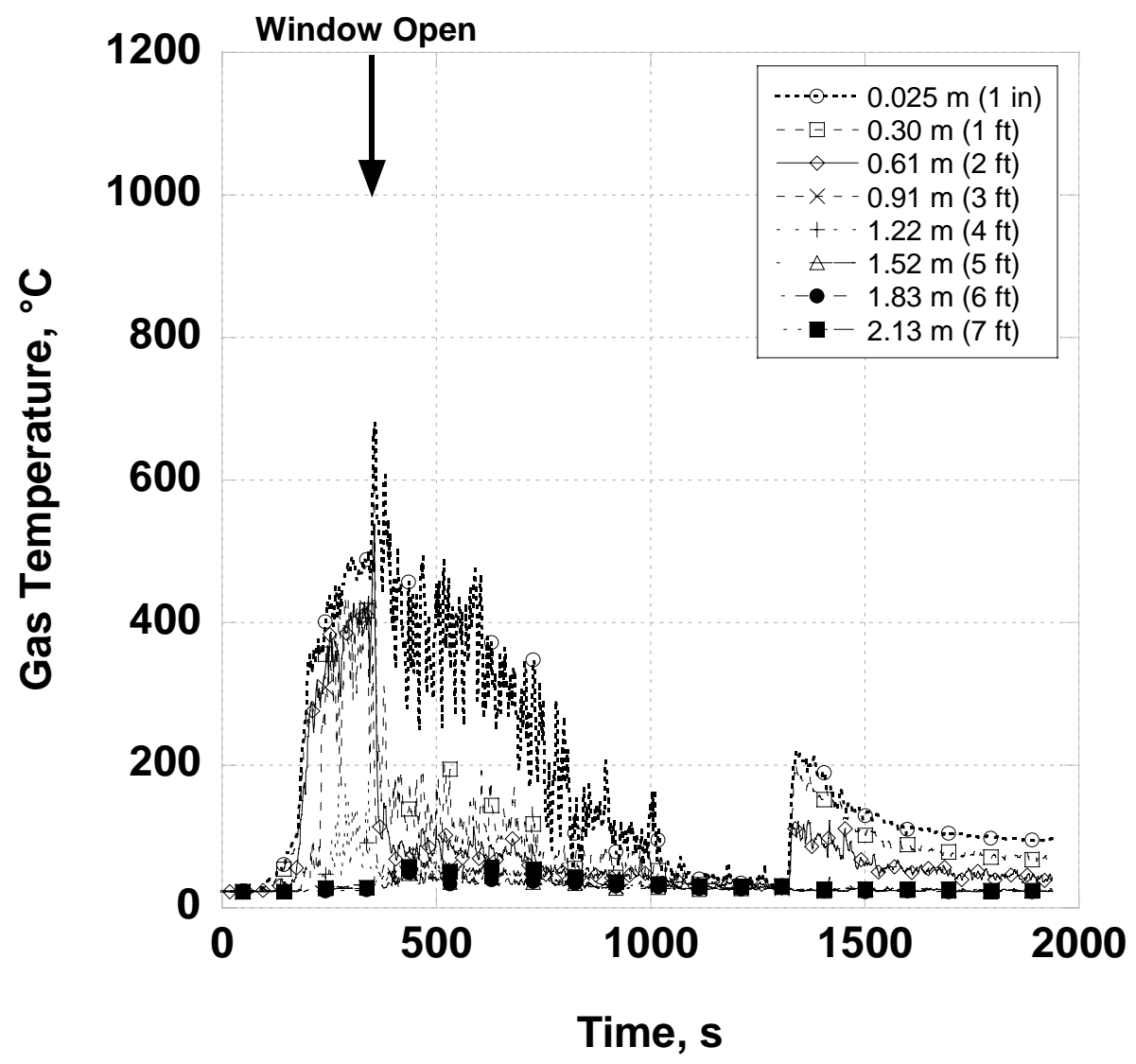

Figure 4-35. PPV Corridor Temperatures 


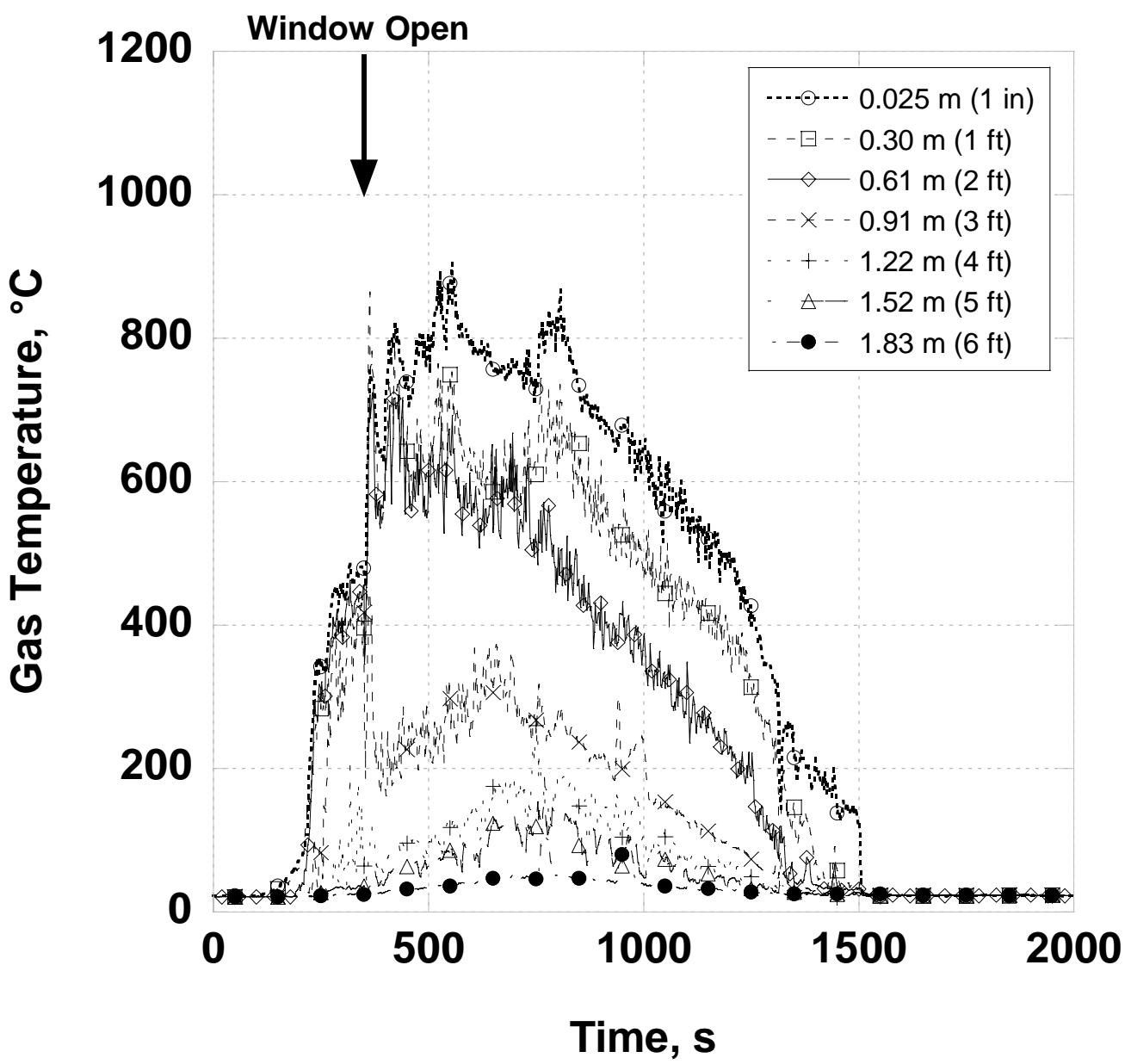

Figure 4-36. Natural Ventilation Corridor Temperatures

\subsubsection{Room Differential Pressure}

Differential pressure readings were taken to examine the static pressure in the room created by the fire and the impact of the PPV fan on this pressure. The interior pressure readings were referenced to the pressure at the same elevation on the outside of the room. Before ignition in the PPV experiment, the fan created uniform pressures at all three elevations of $21 \mathrm{~Pa}(0.003 \mathrm{PSI})$. After ignition, the fire created pressures of $34 \mathrm{~Pa}(0.005 \mathrm{PSI})$ at the top probe, $14 \mathrm{~Pa}(0.002 \mathrm{PSI})$ at the middle probe 
and $-14 \mathrm{~Pa}(-0.002 \mathrm{PSI})$ at the lower probe. Once the window was opened and the fan was turned on, these differential pressures became $62 \mathrm{~Pa}(0.009 \mathrm{PSI}), 41 \mathrm{~Pa}$ (0.006 PSI) and $21 \mathrm{~Pa}(0.003 \mathrm{PSI})$ respectively. These pressures held constant for a period of time when the fire was at peak and then declined steadily. The naturally ventilated fire created differential pressures of $28 \mathrm{~Pa}(0.004 \mathrm{PSI})$ at the top probe, $7 \mathrm{~Pa}(0.001 \mathrm{PSI})$ at the middle probe and $-14 \mathrm{~Pa}(-0.002 \mathrm{PSI})$ at the bottom probe. These differential pressures declined slightly until the fire diminished (Figures 4-37 and 4-39).

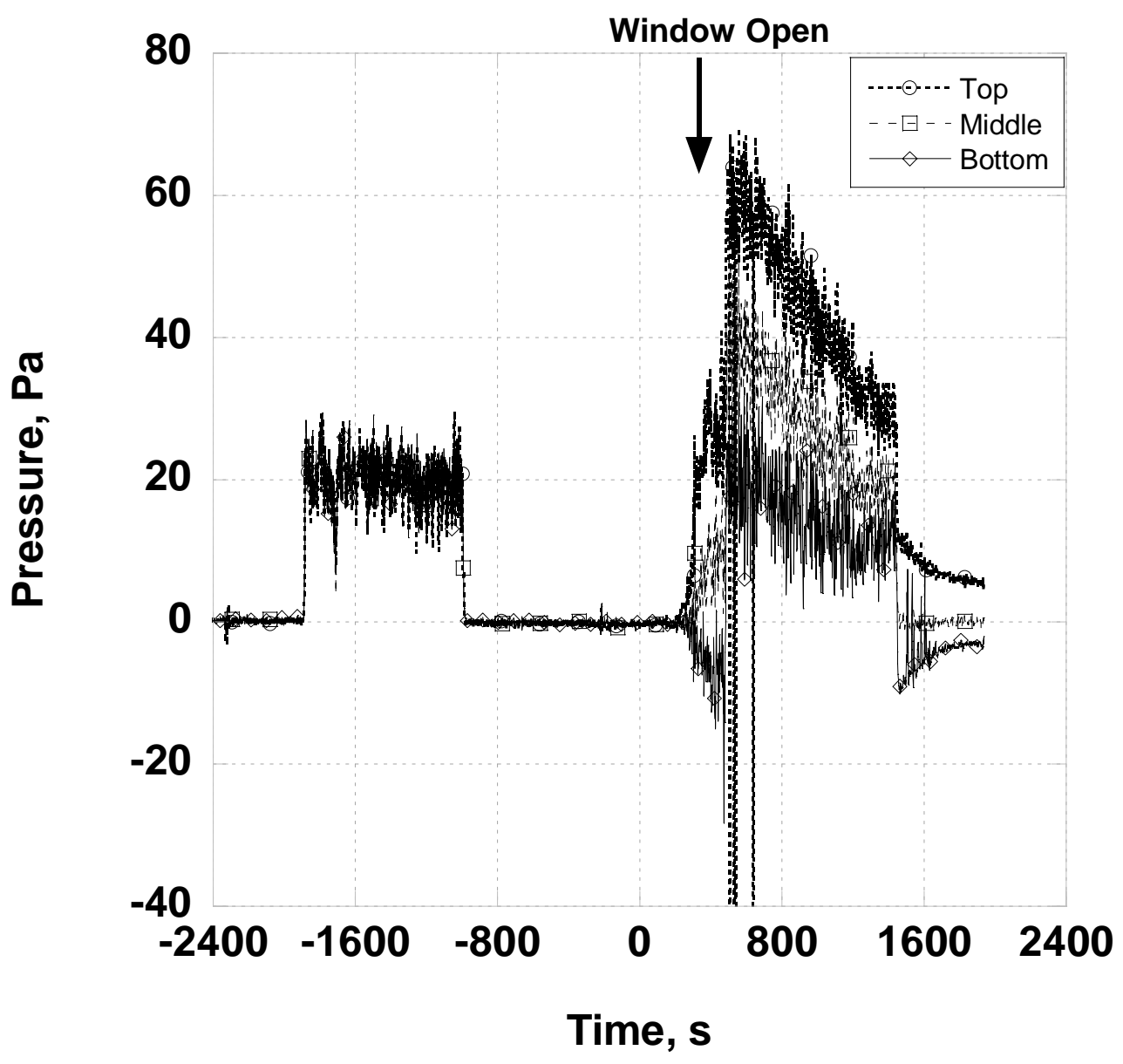

Figure 4-37. PPV Room Differential Pressure 


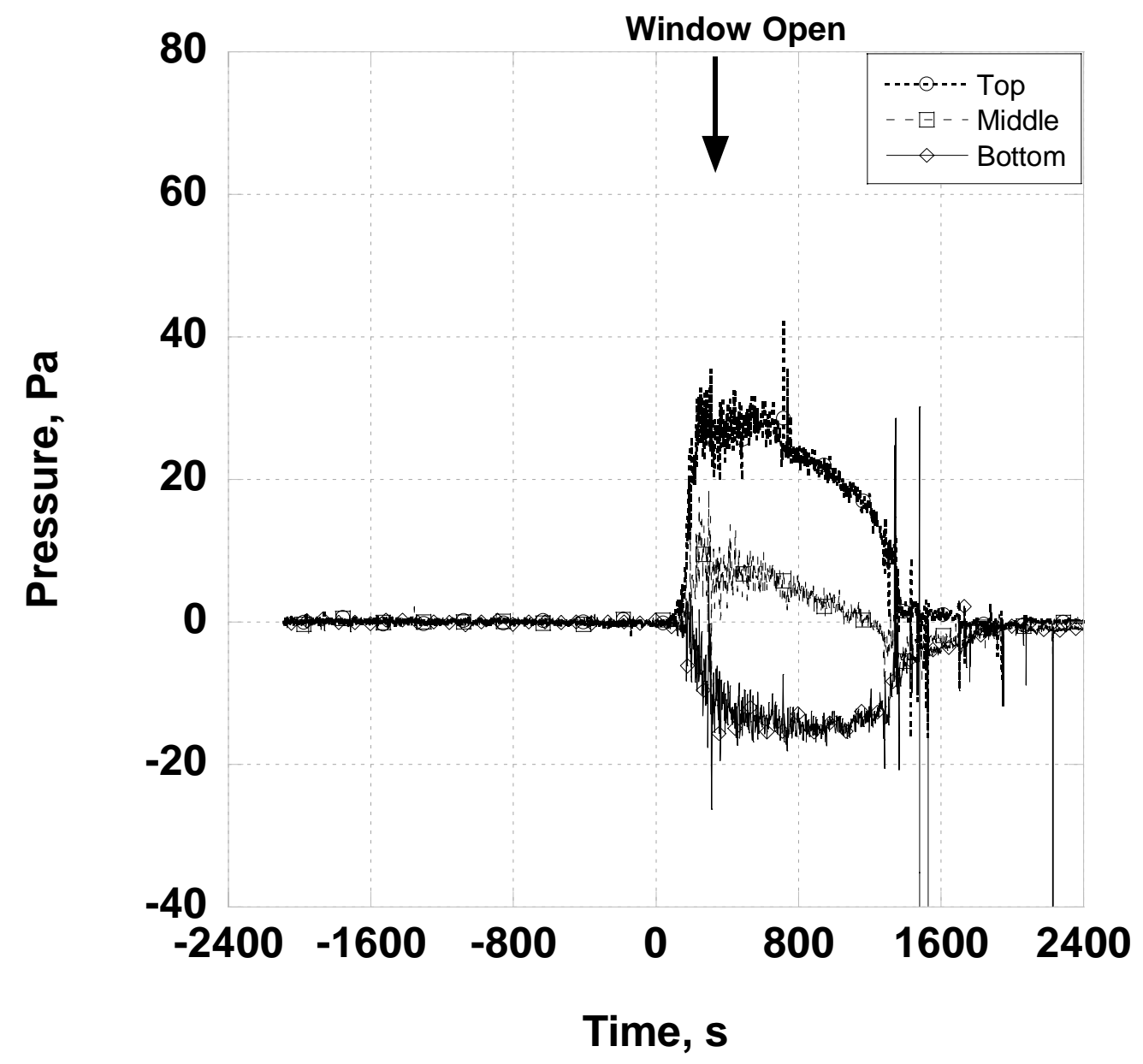

Figure 4-38. Natural Ventilation Room Differential Pressure

\subsubsection{Window Gas Velocity}

Before the PPV ventilated experiment, an ambient flow experiment (without a fire) of the fan through the room was conducted. The experiment produced an average velocity of $5 \mathrm{~m} / \mathrm{s}$ (16 ft/s) out of the window. For the PPV experiment, velocities on the order of $5 \mathrm{~m} / \mathrm{s}(16 \mathrm{ft} / \mathrm{s})$ to $20 \mathrm{~m} / \mathrm{s}(66 \mathrm{ft} / \mathrm{s})$ were measured. The highest velocity occurred just after the window was opened and the fan was turned on. With the fire growing, the velocity increased to $20 \mathrm{~m} / \mathrm{s}(66 \mathrm{ft} / \mathrm{s})$ and slowly decreased to the fan 
velocity of $5 \mathrm{~m} / \mathrm{s}(16 \mathrm{ft} / \mathrm{s})$ as the fire decreased. The naturally ventilated experiment had a bidirectional flow through the window with the highest velocities of $12 \mathrm{~m} / \mathrm{s}$ (39 ft/s) at the top of the window. The gas velocity in the middle of the window was about $7 \mathrm{~m} / \mathrm{s}(23 \mathrm{ft} / \mathrm{s})$ out of the room while the bottom of the window had a flow into the room of $2 \mathrm{~m} / \mathrm{s}(7 \mathrm{ft} / \mathrm{s})$. It took longer for the maximum velocities to be reached than in the PPV experiment but this was also directly proportional to the growth of the fire (Figures 4-39 and 4-40). In the three minutes following the window being opened, the average gas velocity produced by the PPV experiment was $14 \mathrm{~m} / \mathrm{s}$ (46 ft/s) while in the naturally ventilated experiment; the average gas velocity was $5.5 \mathrm{~m} / \mathrm{s}(18 \mathrm{ft} / \mathrm{s})$.

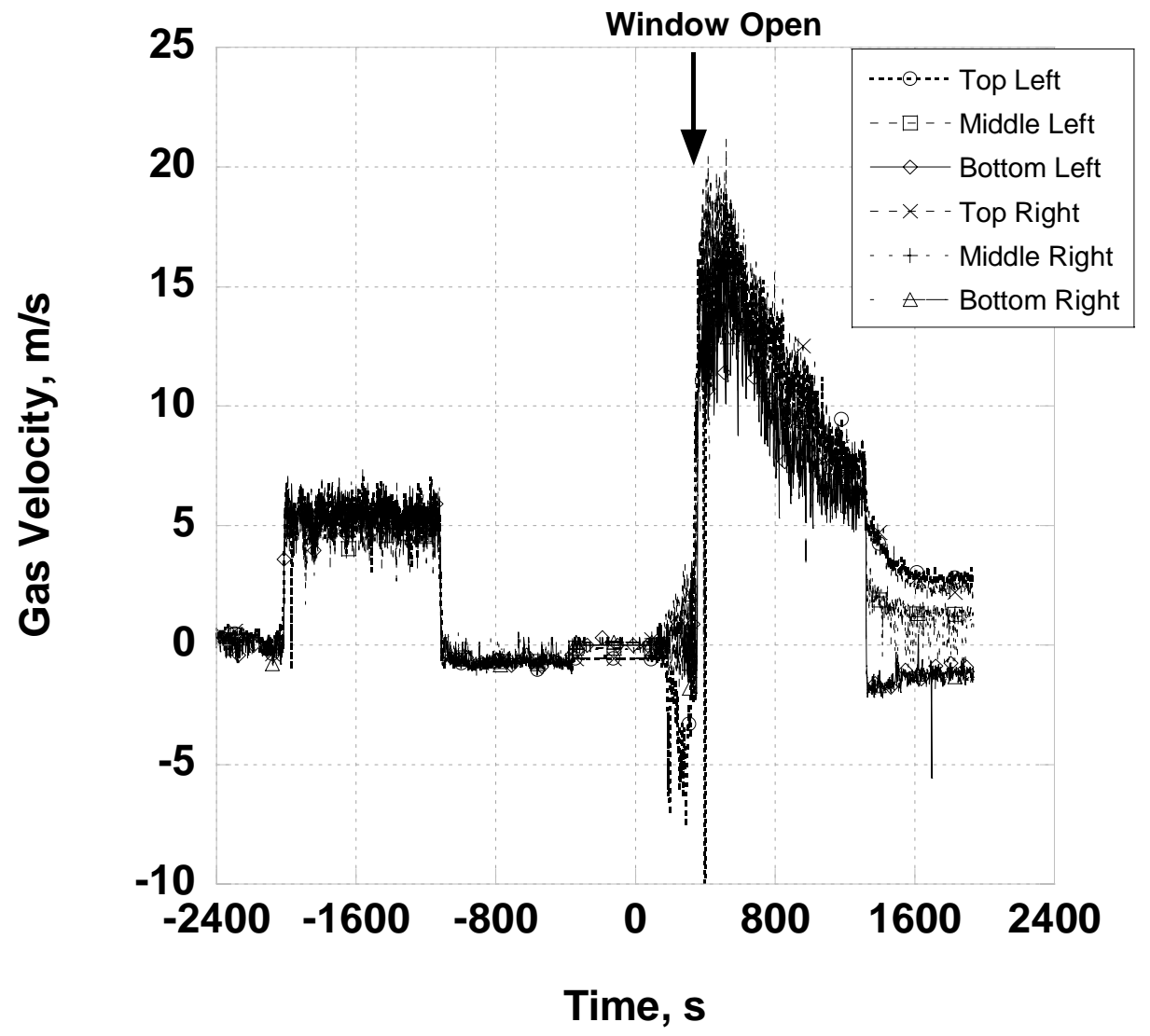

Figure 4-39. PPV Window Velocities 


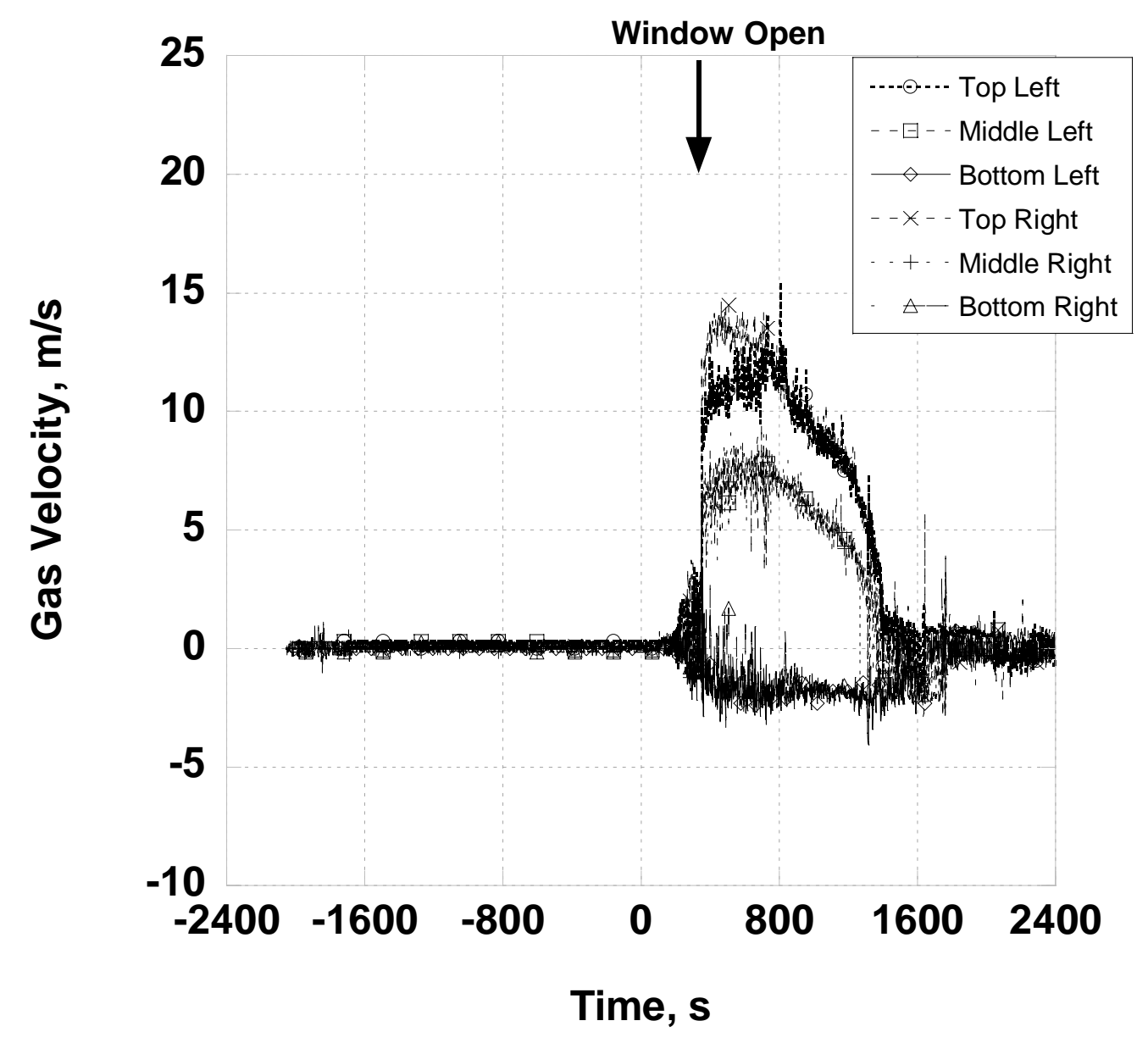

Figure 4-40. Natural Ventilation Window Velocities

\subsubsection{Doorway Gas Velocity}

The gas velocities into the room through the doorway were lower than those out through the window. The PPV fan alone created average flow velocities of $3 \mathrm{~m} / \mathrm{s}$ $(10 \mathrm{ft} / \mathrm{s})$ to $4 \mathrm{~m} / \mathrm{s}(13 \mathrm{ft} / \mathrm{s})$ as shown in Figure 4-41 for times of -2000 seconds to -1200 seconds. The negative time values represent times prior to ignition. Prior to ventilation, there was a $4 \mathrm{~m} / \mathrm{s}(13 \mathrm{ft} / \mathrm{s})$ to $6 \mathrm{~m} / \mathrm{s}(20 \mathrm{ft} / \mathrm{s})$ flow out of the top two-thirds of the doorway and a flow into the room in the bottom one-third of the doorway of 
$2 \mathrm{~m} / \mathrm{s}(7 \mathrm{ft} / \mathrm{s})$. After the fan was activated, the air flowed into the room via the bottom two-thirds of the doorway and the flow in the upper third of the doorway fluctuated between in and out of the room. Eventually, the fan was able to completely move air into the room over the entire doorway cross section. The naturally ventilated experiment began in the same manner as the PPV experiment with bidirectional flow through the doorway. Once ventilation was started, the gas velocities held rather steady until the fire began to decrease with the velocities decreasing as well.

The flows into the room may be underestimated due to the orientation of the bidirectional probes. The probes were faced into the room and perpendicular to the corridor which may not have measured the full magnitude of the velocity into the room but were accurate for the flows out of the room (Figures 4-41 and 4-42). The flow out of the room had to pass in the direction of the centerline of the probes yielding a more accurate differential pressure as opposed to the flow into the room that may have passed the bi-directional probe at an angle to the centerline of the probe causing lower differential pressure readings, which correspond to under estimation of the gas velocities. 


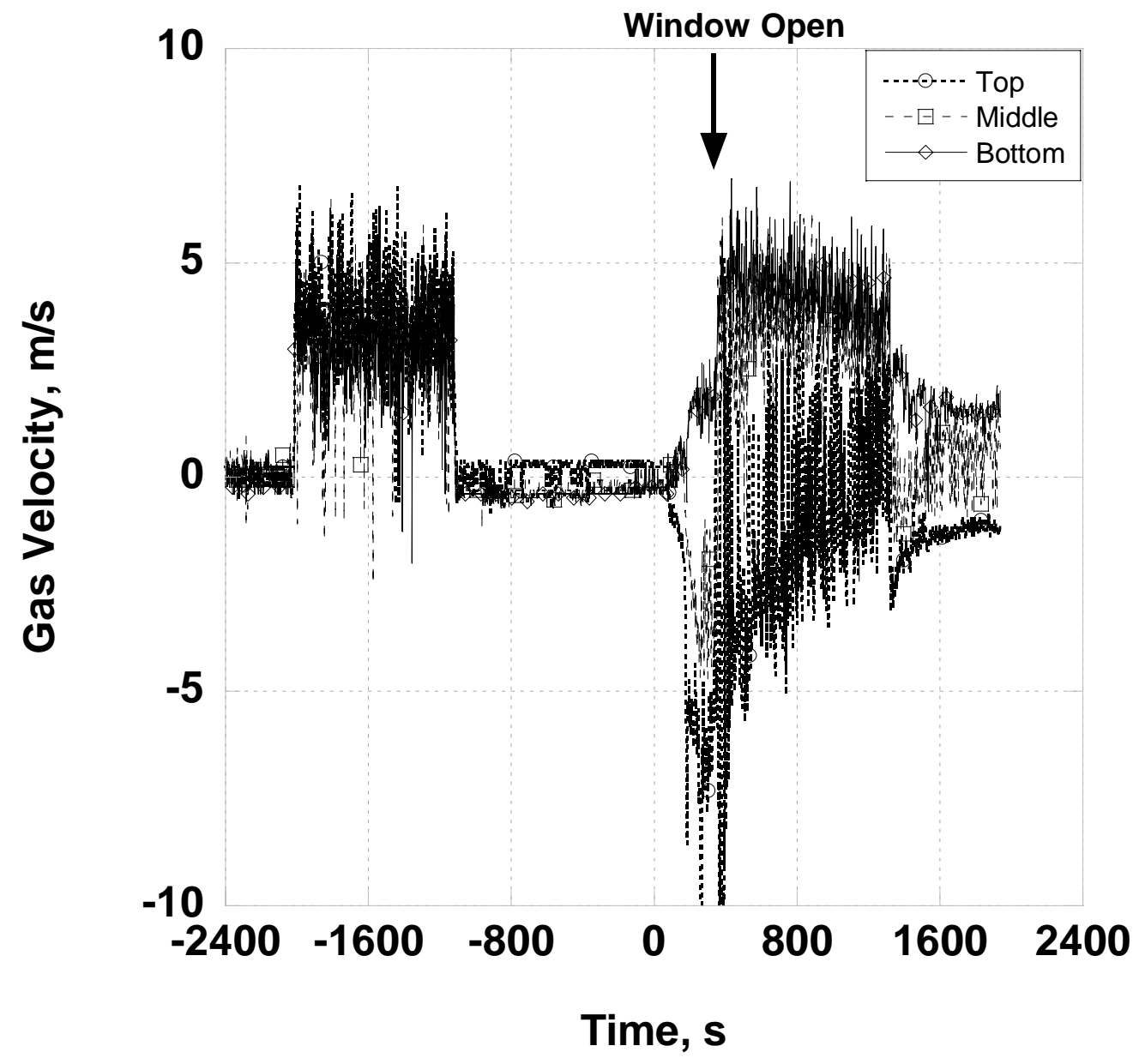

Figure 4-41. PPV Room Doorway Velocities 


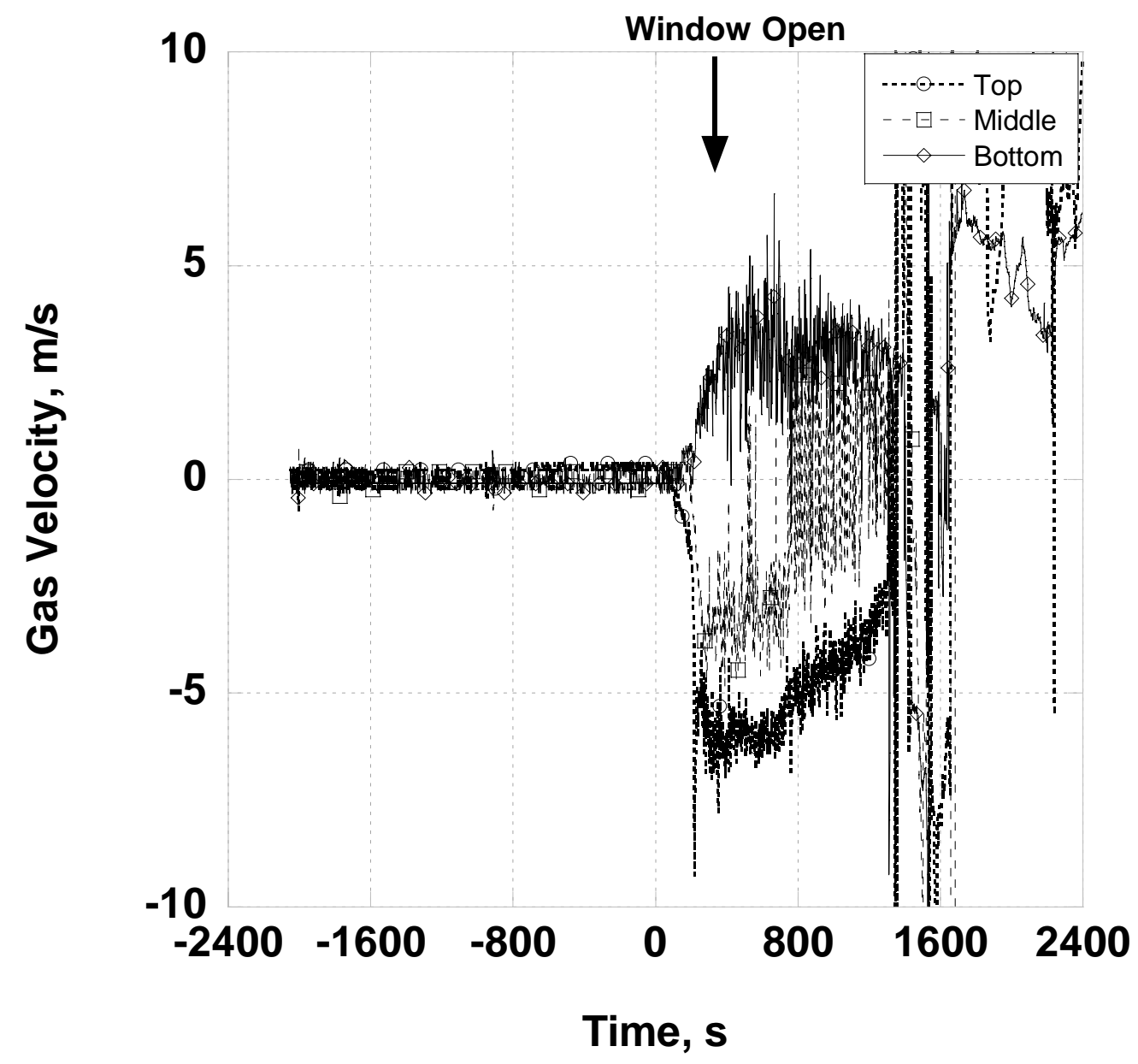

Figure 4-42. Natural Ventilation Room Doorway Velocities

\subsection{Computer Simulation}

The two experiments documented above were simulated using FDS in an attempt to visualize and accurately quantify the effects of a positive pressure ventilation fan on a post flashover room fire. The outputs of both simulations were then compared to the experimental data collected and analyzed. Although very complex, FDS was able to replicate the global effects of the PPV fan on the room fire. 


\subsubsection{Domain}

The domain used for the room fire calculation measured $6.0 \mathrm{~m}(19.7 \mathrm{ft}) \times 6.2 \mathrm{~m}$ (20.3 ft) x $3.0 \mathrm{~m}(9.8 \mathrm{ft})$ and was comprised of approximately 380,000 grid cells that measured $0.067 \mathrm{~m}$ (2.62 in) on a side (Figure 4-43). The domain was larger than the room in all directions to allow for more accurate pressure differences that would be created by the PPV fan. For the simulation with the PPV fan, the domain characteristics described in chapter 1 were utilized. The grid for the fan and the grid for the room were multiblocked together for a total of just over 1.6 million grid cells (Figure 4-44).

The grid cell size was selected in order to accurately resolve the furniture in the room and to minimize the difference in grid cell size between the room grid and the fan grid. Numerous variables existed such as fire growth rate and time to flashover that needed to correspond with the experiment without the fan. Therefore, numerous partial simulations were run in order to accurately replicate the variables that took place in the first 345 seconds. The grid cell size chosen allowed this fire development time to be simulated in approximately 40 hours. The final simulation was allowed to run for 1500 seconds until the fire was only smoldering as compared to the experimental data. This run required 15 days of computational time to complete. Preliminary runs were completed with grid cell sizes that varied from half to twice the size of the $0.067 \mathrm{~m}$ (2.62 in) on a side (Figure 4-45). The runs with larger grid cells developed much slower as compared to the experiment and the smaller grid took too long to complete so grid cell independency can not be claimed for this analysis. The 
final simulation with the fan was allowed to run for 33 days and produced 588 seconds of simulation prior to an unexpected power outage. The simulation time was into the decay stage of the fire so it was of sufficient duration to use for comparison although the actual PPV experiment was allowed to run the same 2000 seconds as the experiment without the fan.

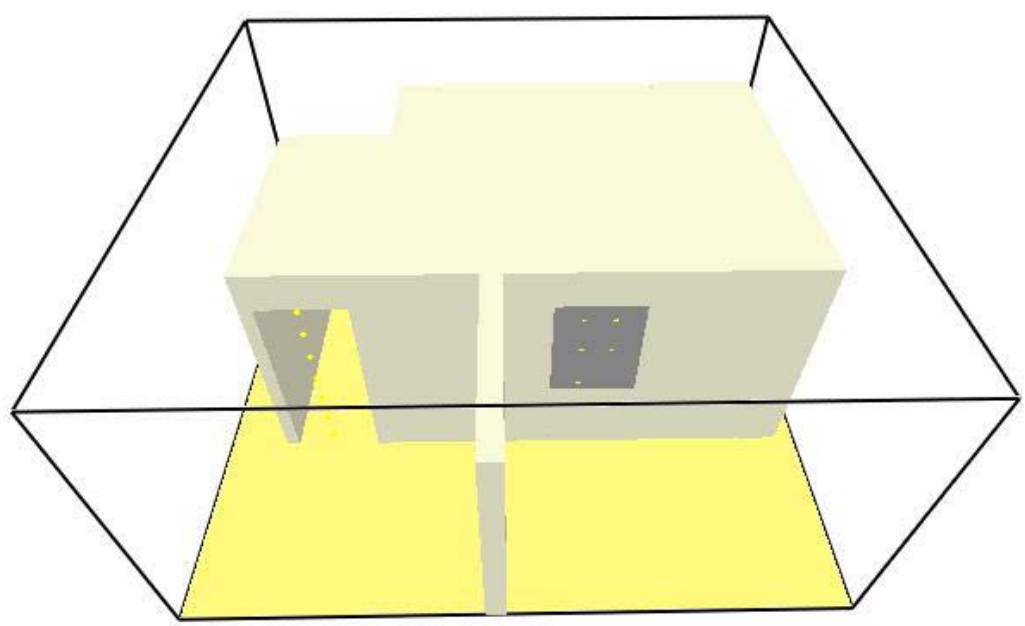

Figure 4-43. FDS Naturally Ventilated Domain

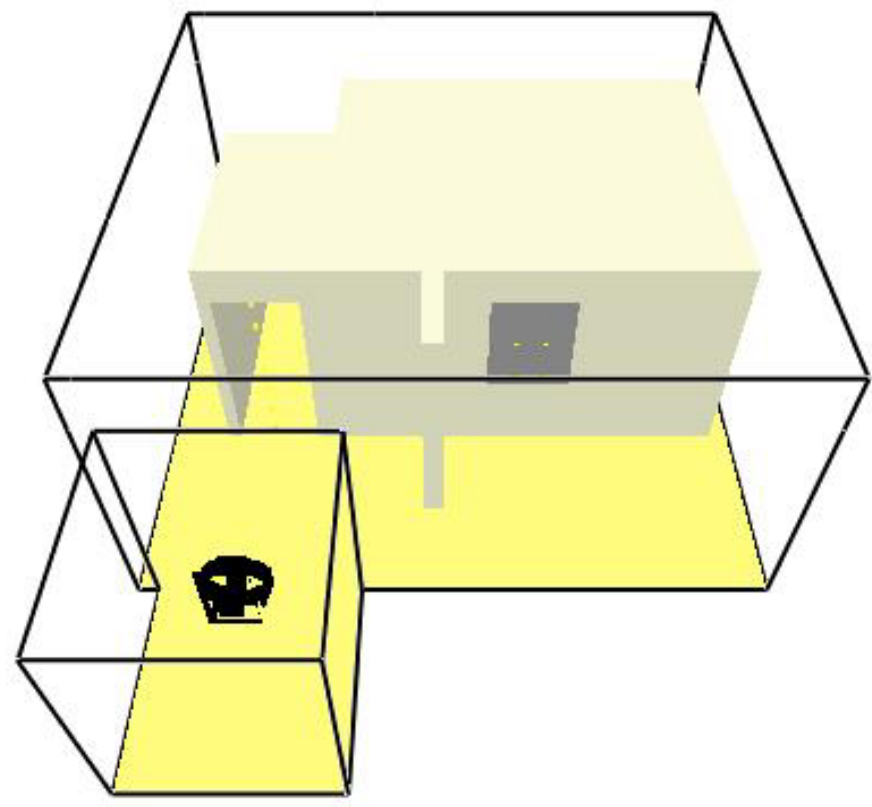

Figure 4-44. FDS PPV Ventilated Domain 


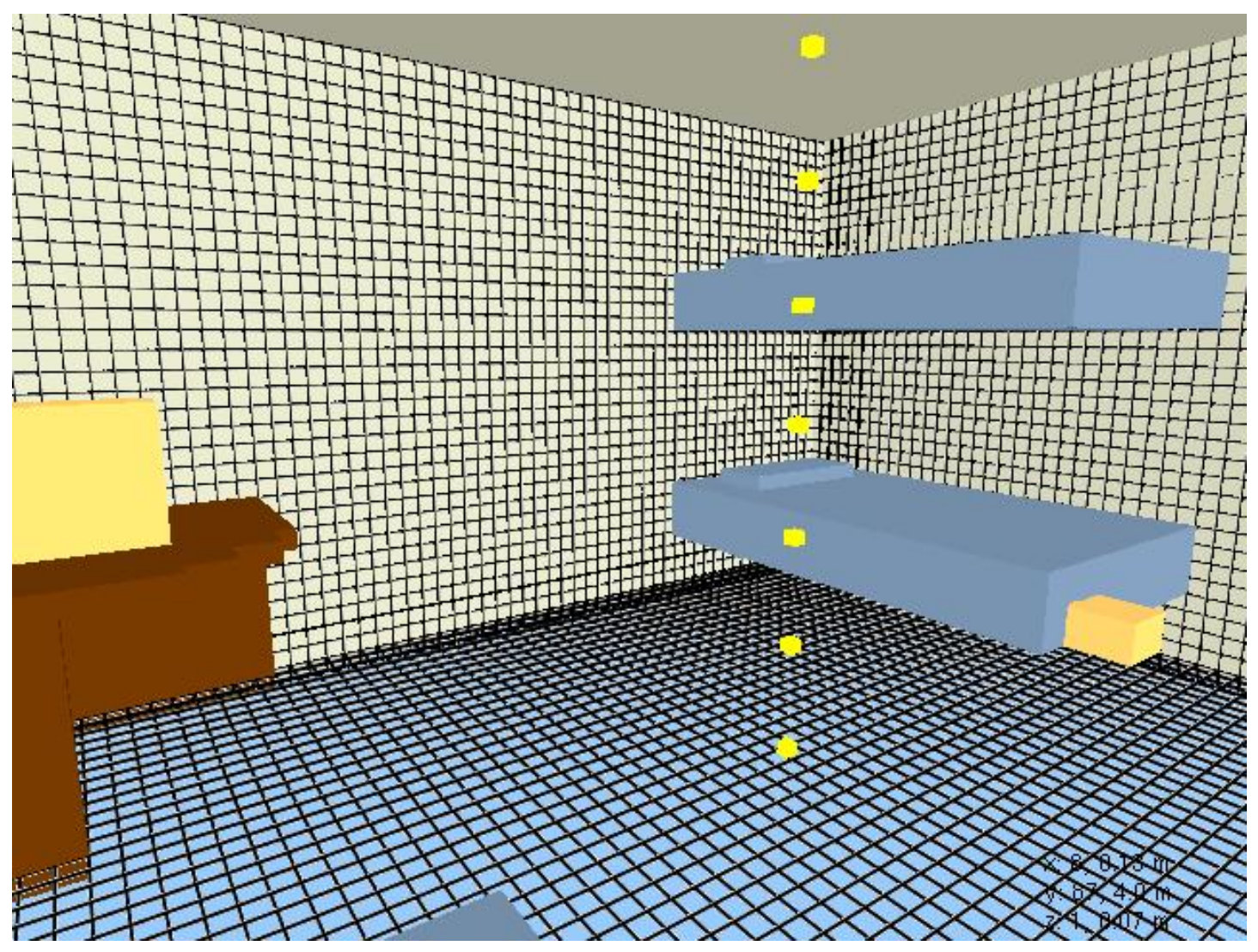

Figure 4-45. Grid Cell Visualization

\subsubsection{Geometry}

The simulation geometry was input into the model using the dimensions from the experimental floor plan. All of the geometry was prescribed using rectangular obstructions that are forced to conform to the rectilinear grid described in the previous domain description. For this reason the walls and furniture items are not the exact dimensions or in the exact location as they were in the experiment. These slight variations typically should have little impact on the calculation and will be analyzed to determine the impact of grid cell dependency. Obstructions are also not able to be entered diagonally. For example the computer monitor will appear sideways in the 
calculation but should contain a similar amount of fuel. The front of the desk also appears stepped for this same reason (Figure 4-46). Subtle differences also exist as the round edges of the chair cushions or mattresses are not able to be exactly captured, but are approximated.

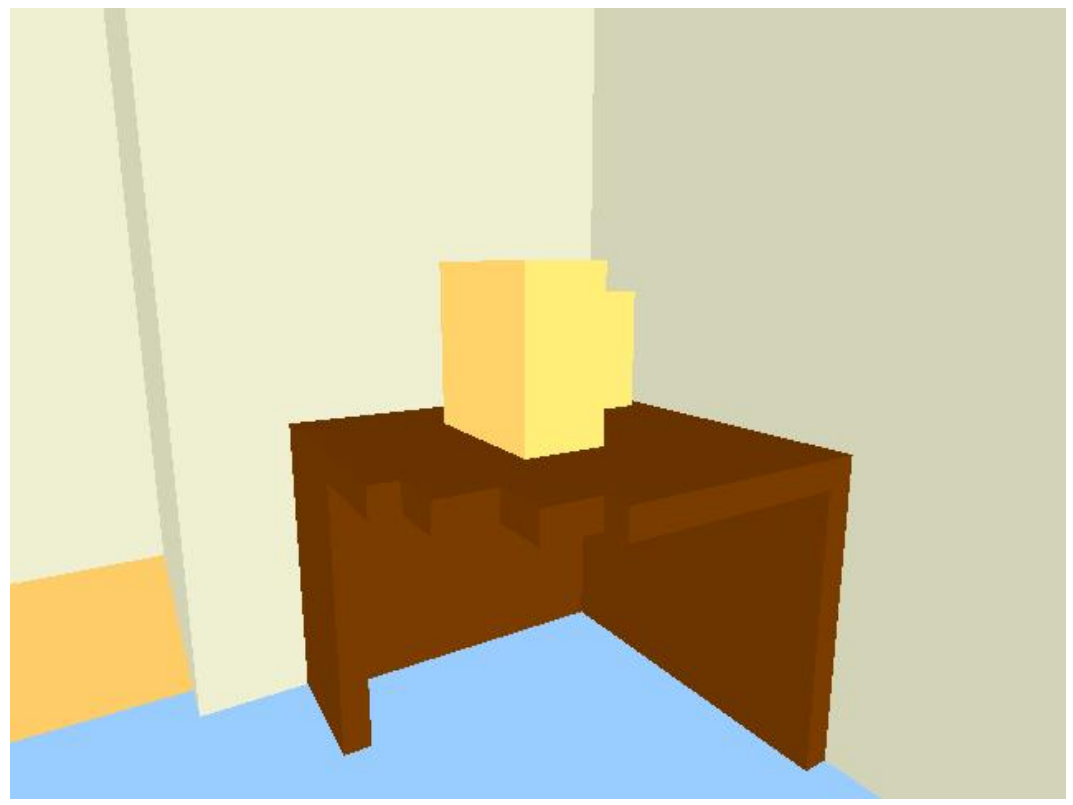

Figure 4-46. Rectangular Geometries

\subsubsection{Materials}

Each obstruction in the domain was given a set of physical and thermal properties that were used in the calculation. Each wall, ceiling, floor and piece of furniture is defined with properties such as thermal diffusivity, heat of vaporization, density and thickness. A table of these values is located in Table 8. All of the walls and the ceiling of the room were gypsum board and the floor was covered in carpet, as in the experiments. The primary fuels in the room were upholstery and oak. The chair and 
mattresses were prescribed as upholstery and the bookcase and desk were both oak.

All of the material properties were derived from standard reference literature.

Table 8. Room Fire FDS Input Material Properties

\begin{tabular}{|l|c|c|c|c|}
\hline Material & $\begin{array}{c}\text { Ignition } \\
\text { Temperature } \\
\left({ }^{\circ} \mathrm{C}\right)\end{array}$ & $\begin{array}{c}\text { Thickness } \\
(\mathrm{m})\end{array}$ & $\begin{array}{c}\text { Heat Release Rate } \\
\text { Per Unit Area } \\
\left(\mathrm{kW} / \mathrm{m}^{2}\right)\end{array}$ & $\begin{array}{c}\text { Heat of } \\
\text { Vaporization } \\
(\mathrm{kJ} / \mathrm{kg})\end{array}$ \\
\hline Upholstery & 280 & $\mathrm{n} / \mathrm{a}$ & $\mathrm{n} / \mathrm{a}$ & 1700 \\
\hline Oak & 340 & 0.02 & $\mathrm{n} / \mathrm{a}$ & 4000 \\
\hline Plastic & 370 & $\mathrm{n} / \mathrm{a}$ & 500 & $\mathrm{n} / \mathrm{a}$ \\
\hline Carpet & 280 & $\mathrm{n} / \mathrm{a}$ & $\mathrm{n} / \mathrm{a}$ & 3000 \\
\hline Gypsum Board & 400 & 0.013 & 100 & $\mathrm{n} / \mathrm{a}$ \\
\hline
\end{tabular}

\subsubsection{Vents and Ignition Source}

All of the external domain boundaries were prescribed as open with the exception of the floor outside the room. This floor was treated as an inert, adiabatic solid. Another small vent measuring $0.067 \mathrm{~m}(0.2 \mathrm{ft})$ by $0.13 \mathrm{~m}(0.4 \mathrm{ft})$ used for ignition was located at the corner of the bottom mattress (Figure 4-47). The vent had a constant heat release rate per unit area of $2500 \mathrm{~kW} / \mathrm{m}^{2}$. This vent produced heat for the duration of the simulation. The location of the vent corresponded with the location of the electric match in the experiments.

Initially the only openings within the domain were the door to the corridor and the door to the room. The doorways both measured $0.9 \mathrm{~m}(3.0 \mathrm{ft})$ wide and $2.0 \mathrm{~m}(6.6 \mathrm{ft})$ high. At 345 seconds the room window is opened as it was in the experiments. The 
domain extended outside the door and window to allow for the combustion products to flow out of the room. When the fan was added for the PPV simulation the boundaries to its domain were also open and the vents for the fan were located as described in chapter 1.

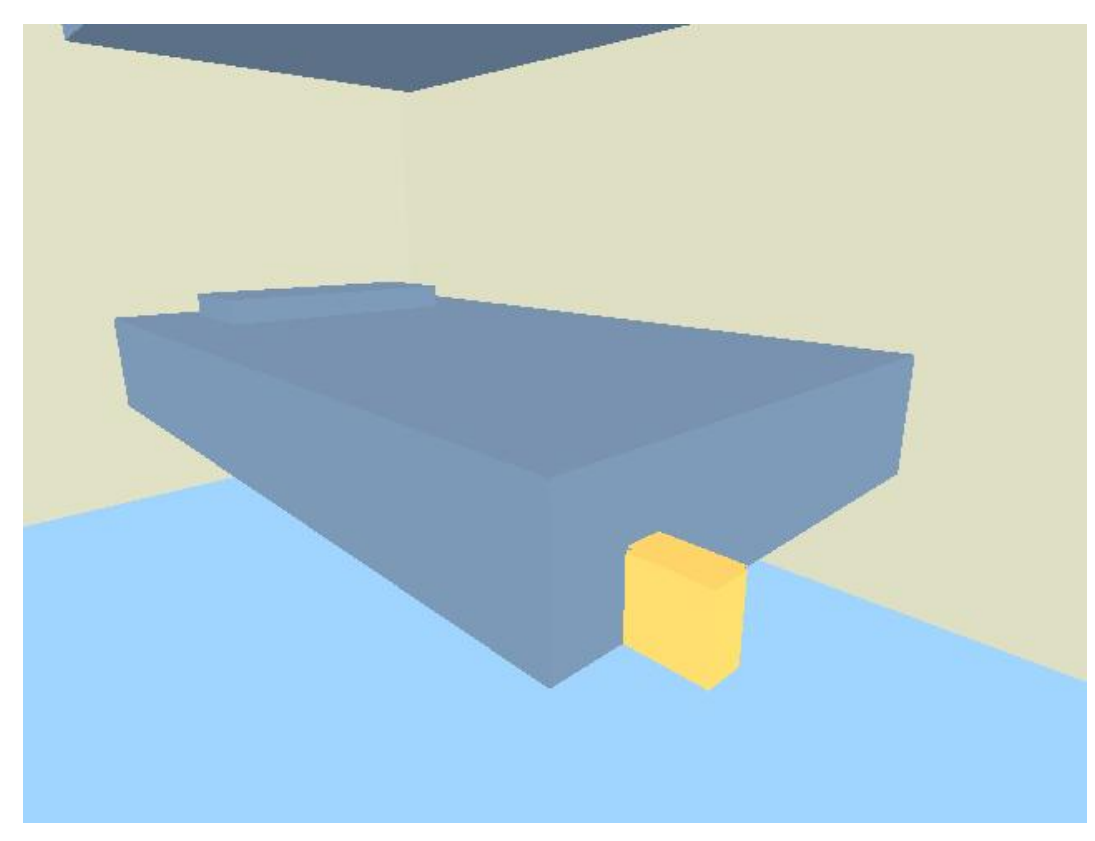

Figure 4-47. Location of Ignition Source

\subsubsection{Output Files}

Output files were prescribed to best replicate the measurements taken during the experiments. Vertical and horizontal temperature and velocity slices were placed through the center of the room, corridor, each doorway and the window. Velocity and temperature measurement points were also prescribed at the same locations as in the experiment layout using FDS's thermocouple input. Heat release rate was continually recorded in the domain as well as the flame isosurface locations. A three 
dimensional smoke was also used for comparisons of smoke movement and visibility. Comparisons of these output files with the experimental measurements are located in section 4.4.

\subsection{Simulation Results}

\subsubsection{Naturally Ventilated Simulation}

The results of the naturally ventilated simulation are compared with the video record of the experiment and the measurements of gas temperature, gas velocity and heat release rate. Visual comparisons of the experiment and simulation are shown in Figures 4-48 through 4-59. Quantitative comparisons between the experimental data and the model predictions are given in Figures 4-60 through 4-66.

\subsubsection{Visual Comparisons}

Figures 4-48 through 4-59 are composed of pairs of images. The still frames captured from experimental video tape appear on the left. The frames were not all taken from the same camera view. The camera view is included in the figure caption because some of the views are obstructed by smoke and or flames. The images on the right were rendered in Smokeview. Both images represent the same time after ignition. The images shown are at times 0, 90, 230, 275, 300, 330, 360, 430, 540 and 720 seconds. 

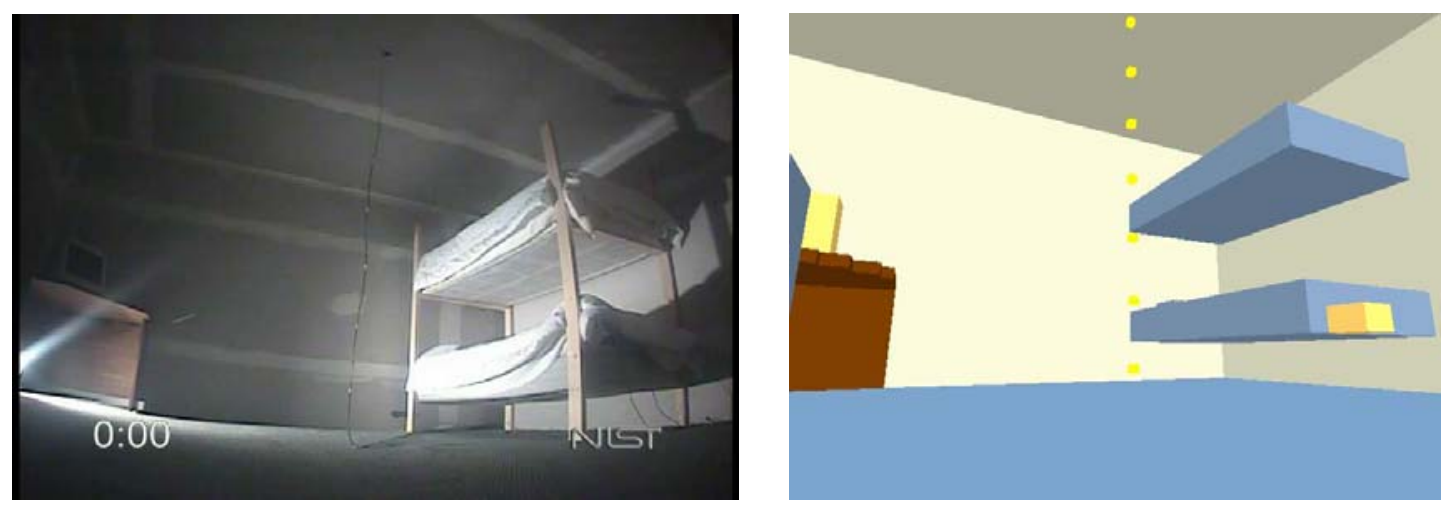

Figure 4-48. Bunkbed View at Time of Ignition (0 seconds)
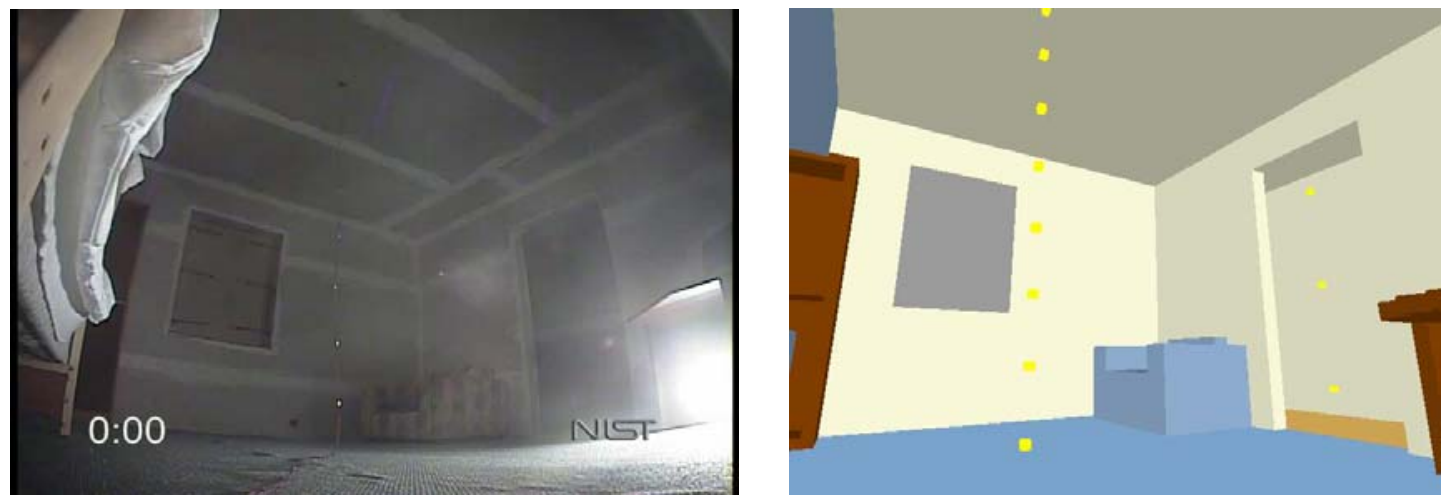

Figure 4-49. Doorway and Window View at Time of Ignition (0 seconds)

Figures 4-48 and 4-49 show the two interior camera views just before ignition.

Figure 4-48 shows the gypsum board walls and ceiling, carpeted floor, bunk bed covered with linens on the right, and the desk and computer monitor on the left. The thermocouple tree in the center can also be seen. The image from the simulation, on the right, the comparable finishes and fuel items can be seen. The yellow cubes represent the locations of the thermocouples. 
Figure 4-49 shows the opposite corner of the room comprised of the wall with the room door and the wall with the window. The chair is located in the corner with some of the bunk bed and desk visible on the edges of the image. The room thermocouple tree is also located in this view. The image from the simulation shows the same items. The white stripes that appear in the experimental video images are the locations of the gypsum board joints that have been spackled.
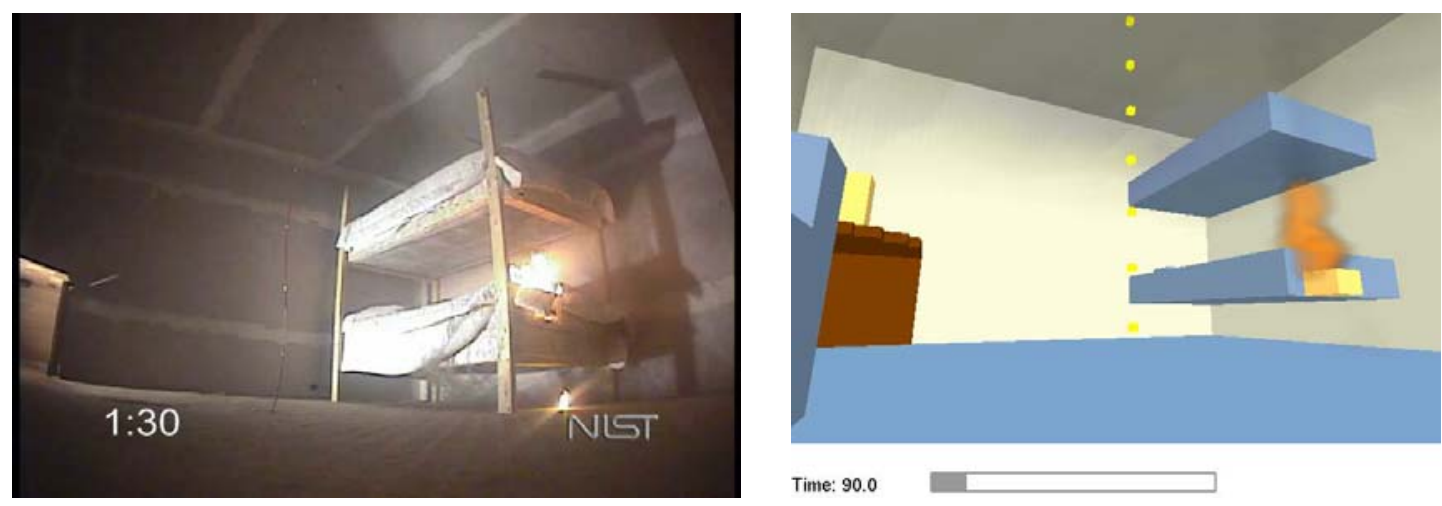

Figure 4-50. Fire Starting on Corner of Mattress (90 seconds)

Figure 4-50 compares the fire development at 90 seconds after ignition. A flame is located on the corner of the bottom mattress. In the case of FDS, the yellow block is the simulated ignition source. The area that appears to be involved with flames is based on the stoichiometric mixture fraction, where there is the ideal mixture of fuel and oxygen for a robust flame to exist. The heat release rate per unit volume represented by the simulated flames is $428.6 \mathrm{~kW} / \mathrm{m}^{3}$. The simulation is not able to account for the drop down of flaming material that takes place in the experiment. 

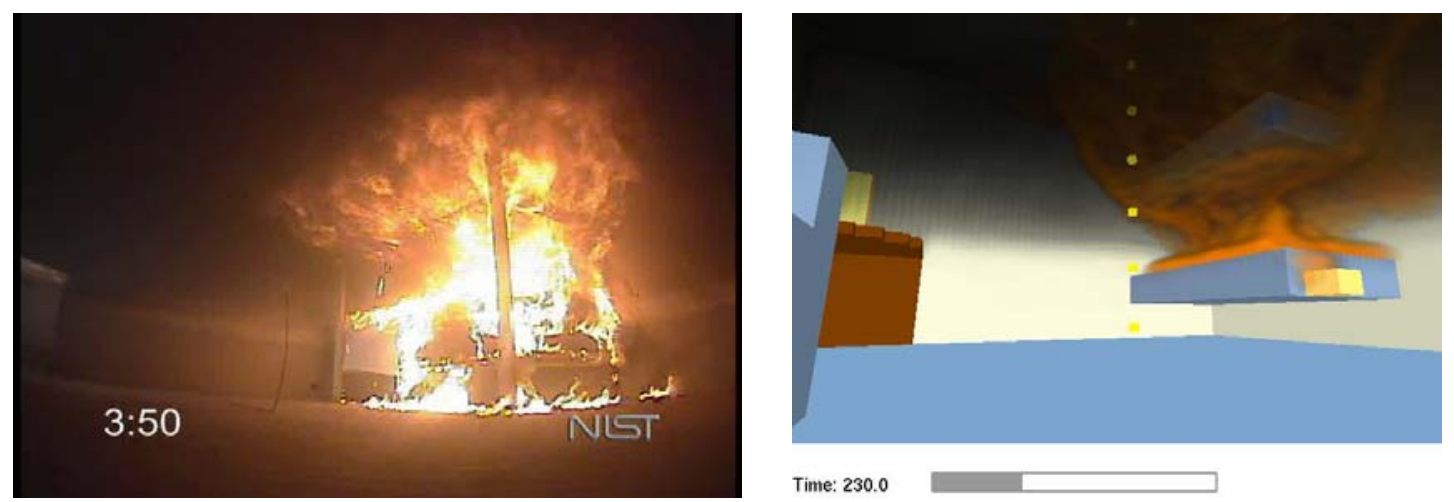

Figure 4-51. Flames Involving Bunkbed (230 seconds)

The experimental video frame to the left in Figure 4-51 shows fire development 230 seconds after ignition. The flames have spread across the bottom mattress and have involved the top box spring and mattress. The amount of drop down material has increased due to the burning, melting and falling of the bedding materials and foam mattress. A smoke layer has developed and has begun to descend. To the right the FDS simulation is behaving similarly with a slightly less amount of flaming materials. The smoke in the simulation appears to compare well qualitatively with the experimental video frame.
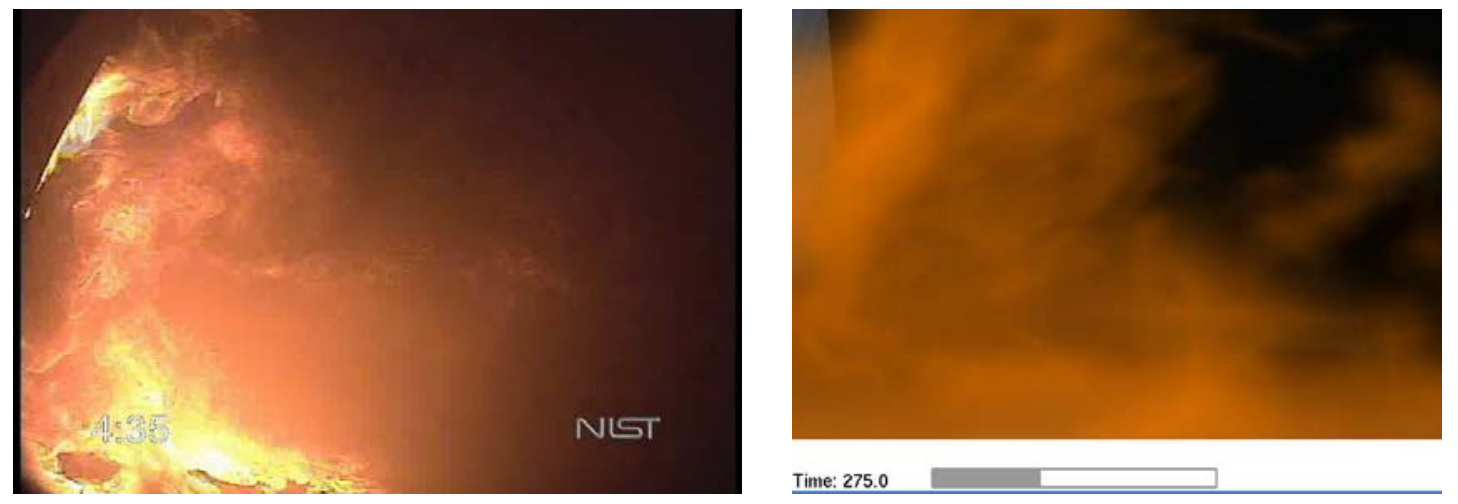

Figure 4-52. Onset of Flashover (275 seconds) 

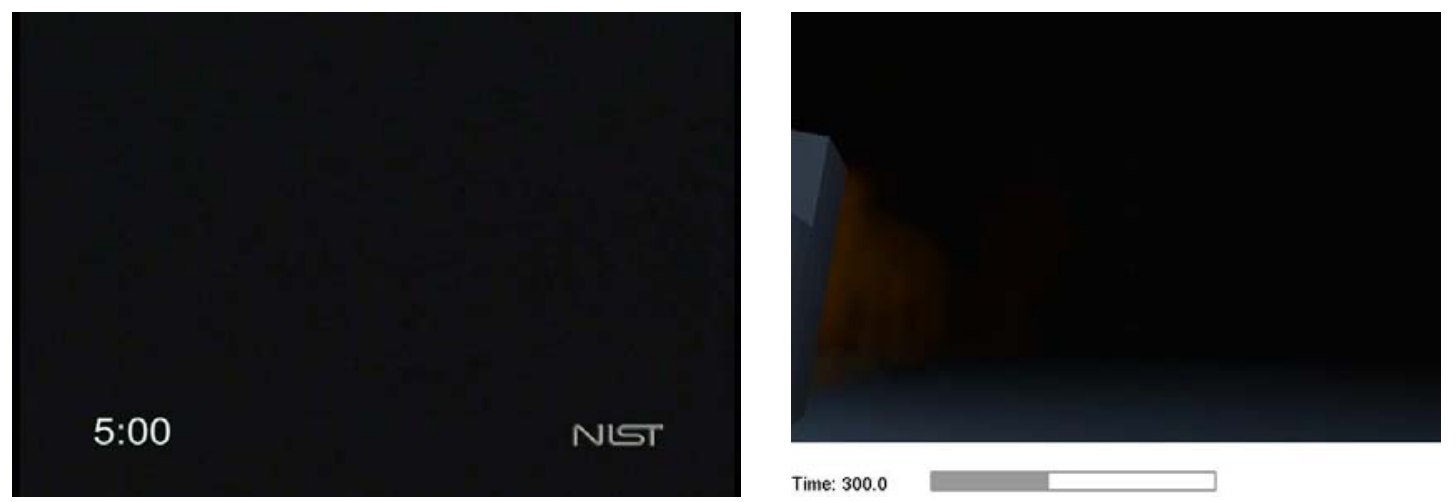

Figure 4-53. Visibility Lost in Bunk Bed View (300 seconds)

At 275 seconds after ignition the room has gone to flashover as can be seen in Figure 4-52. In the experiment, the flames are burning the carpet and the bunk bed to the left. The smoke has thickened and the layer lowered to the floor as the fire transitioned to an oxygen deficient state. The FDS simulation on the right has also gone to flashover and shows similar flaming and smoke levels as the experimental video frame.

Figure 4-53 has images captured at 300 seconds after ignition. In both the experiment and the FDS simulation, visibility has decreased to almost zero due to smoke filling. The experimental video is completely black while some of the chair can be seen in the left portion of the FDS simulation frame. Even though the door to the room is open to the corridor the camera view suggests that there is little if any fresh air being drawn into the room. 

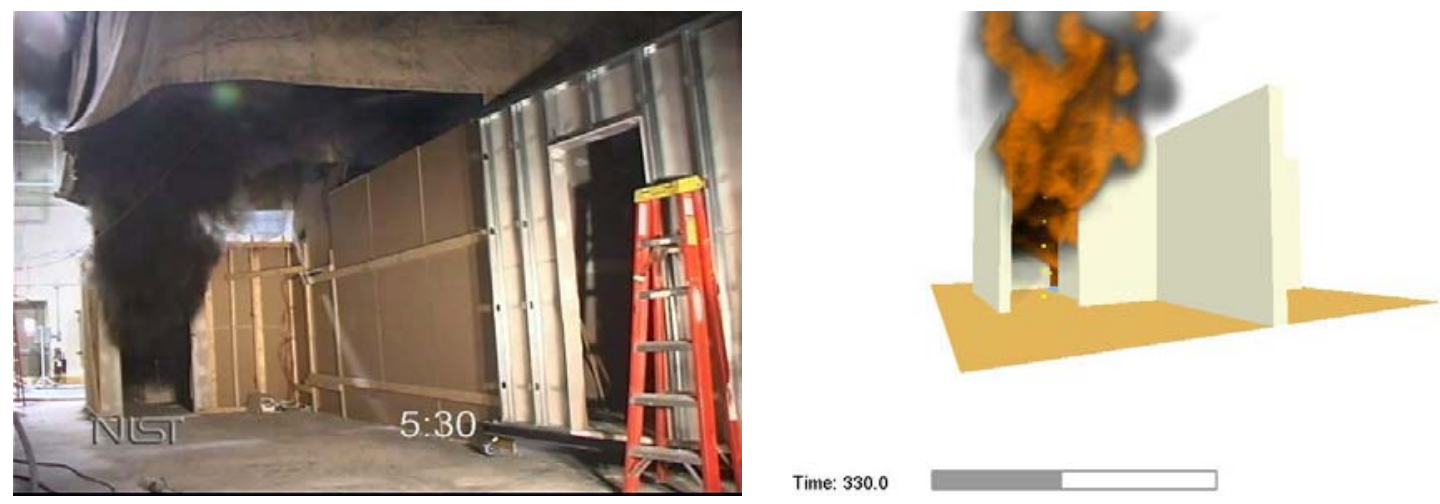

Figure 4-54. Combustion Products Flow From Corridor Doorway (330 seconds)

While visibility is lost in the room, the external door view in Figure 4-54, at 330 seconds, shows thick black smoke pouring from the top two thirds of the corridor doorway. There does not appear to be flames coming from the corridor door in the experiment but the FDS simulation is representing flames in this region. This could be due to the difficulty that FDS has when simulating oxygen limited scenarios. By representing the flames in that region FDS predicts that there is enough fuel and oxygen to have combustion but the temperature may not be high enough to actually have combustion.
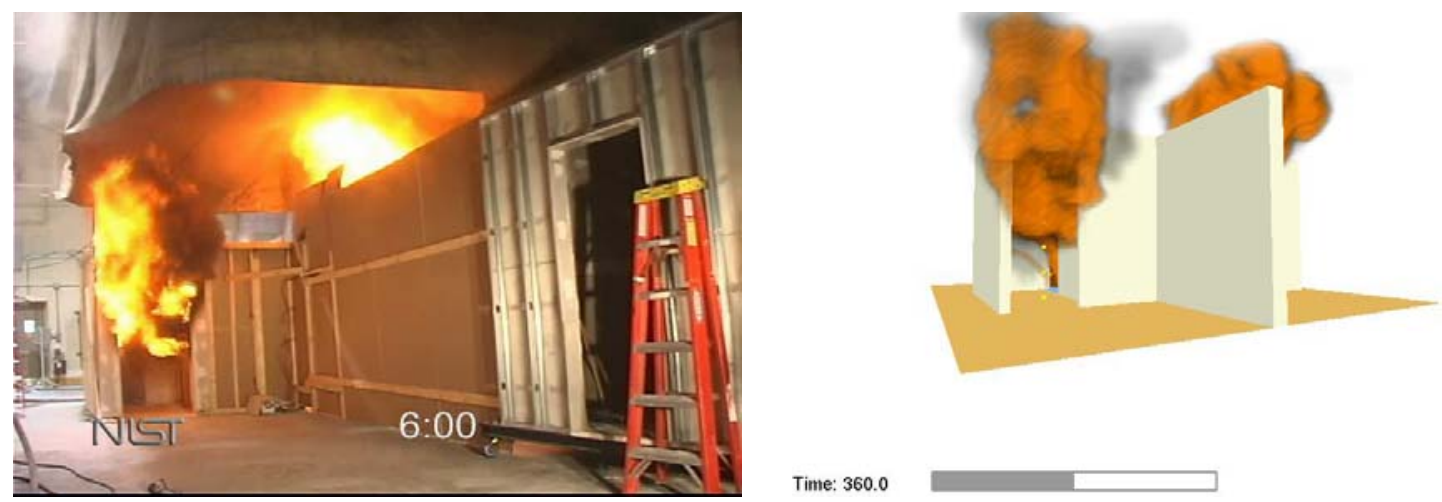

Figure 4-55. Flames Extend From Corridor Doorway Once Window is Opened (360 seconds) 
The images in Figure 4-55 show the corridor doorway view after the window is opened. Flames begin to extend out of the corridor doorway and the amount of smoke decreases as the fire transitions to a fuel limited stage with the additional oxygen provided by the open window. The flames can also be seen over the separation wall coming from the open window. The FDS simulation also shows flames coming from both openings and a decrease in smoke production.
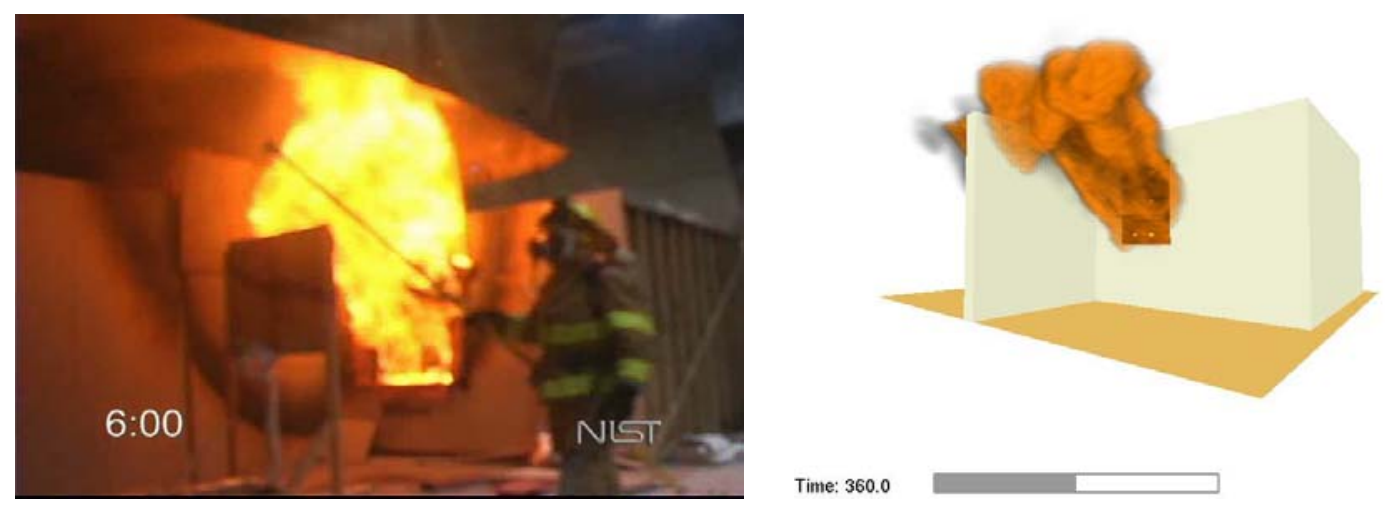

Figure 4-56. Flames From Window (360 seconds)
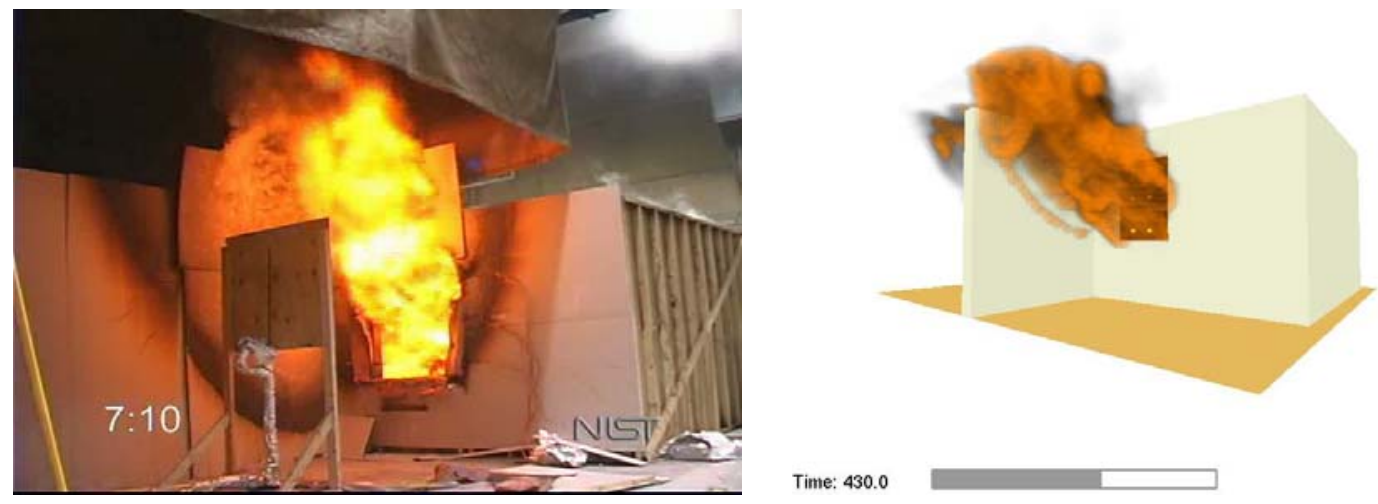

Figure 4-57. Flames Continue From Window (430 seconds) 
Figure 4-56 has images taken from the window side of the separation wall at 360 seconds after ignition. This is 15 seconds after the window was opened. Both images show flames filling the entire cross section of the window and extending above the height of the room. The square piece of plywood that can be seen outside the window was used in support of another project and was far enough away from the window to have no effect on the fire flows.

The same window view is shown in Figure 4-57. Seventy seconds after the previous Figure, there are still flames coming from the entire cross section of the window in both the experimental video frame and the FDS simulation.
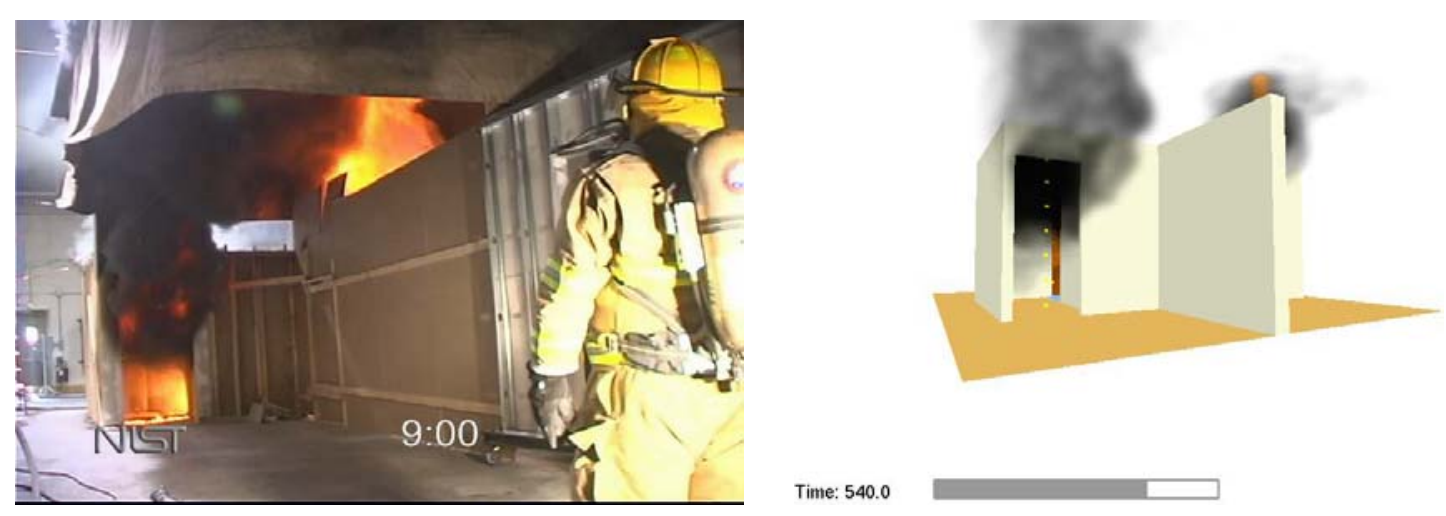

Figure 4-58. Fire in Decay Stage (540 seconds) 

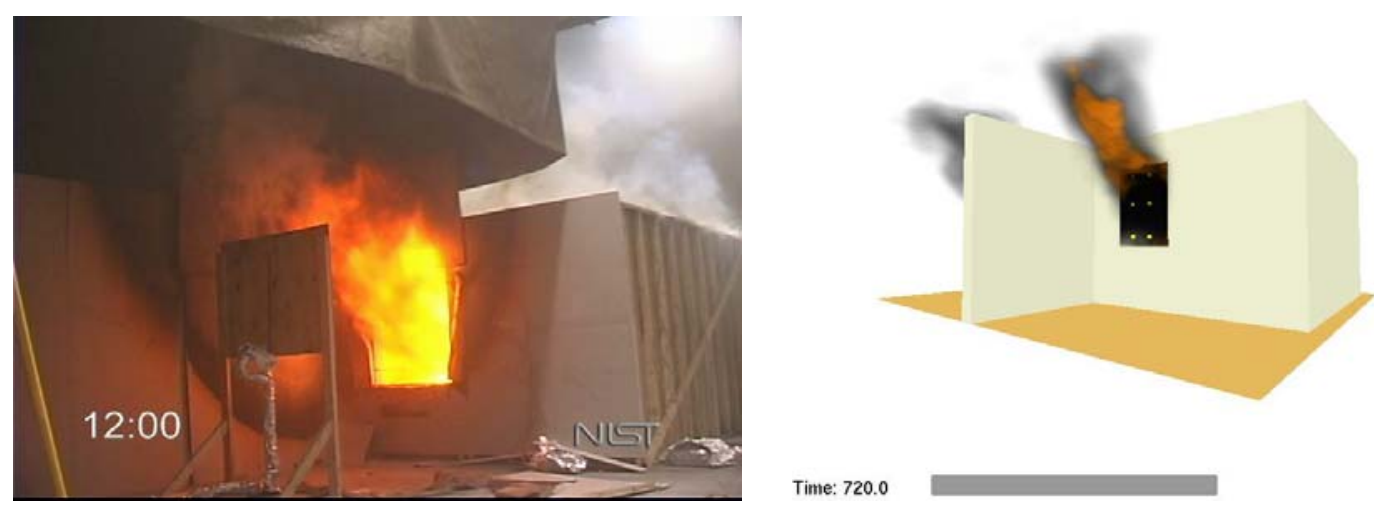

Figure 4-59. Room Continues to Burn (720 seconds)

The fire begins to decay in both the experiment and the simulation as shown in Figure 4-58. The experiment has thick black smoke and some flames coming from the doorway. Flames can also be seen coming from the window in the experiment video frame in Figure 4-59. The FDS simulation under predicts both the amount of smoke and flames present in both figures. The smoke is thinner and the flames pulled into the room from the corridor. Flames are still coming from the window in the FDS simulation but not at the same magnitude and intensity of that in the experiment. The FDS simulation appears to run out of fuel before the actual experiment.

\subsubsection{Numerical Comparisons}

In this section, values of heat release rate, gas temperatures and gas velocities generated by the naturally ventilated FDS simulation will be compared to measurements from the full-scale experiments described in Section 4.2.

Figure 4-60 compares the measured heat release rate from the experiment and the heat release rate predicted by FDS. The experimental peak is $12 \mathrm{MW}$ shortly after the 
window was opened and the FDS value is approximately 11 MW. The FDS peak occurs within 30 seconds of the experimental peak. The FDS heat release rate increases more quickly than the experimental values but this can be expected because the fire is in an enclosure. In FDS the heat release rate is measured immediately throughout the domain while the actual experiment does not record any measurable heat release rate until the combustion products leave the room and travel through the calorimetry hood. Both cases show a large increase once the window is opened and a quick decline from the maximum values once post flashover conditions occur. The FDS simulation holds its peak value for a longer duration than the actual experiment and declines at a faster rate but both cases seem to burn for a similar duration according to the total amount of heat released (Figure 4-61). 


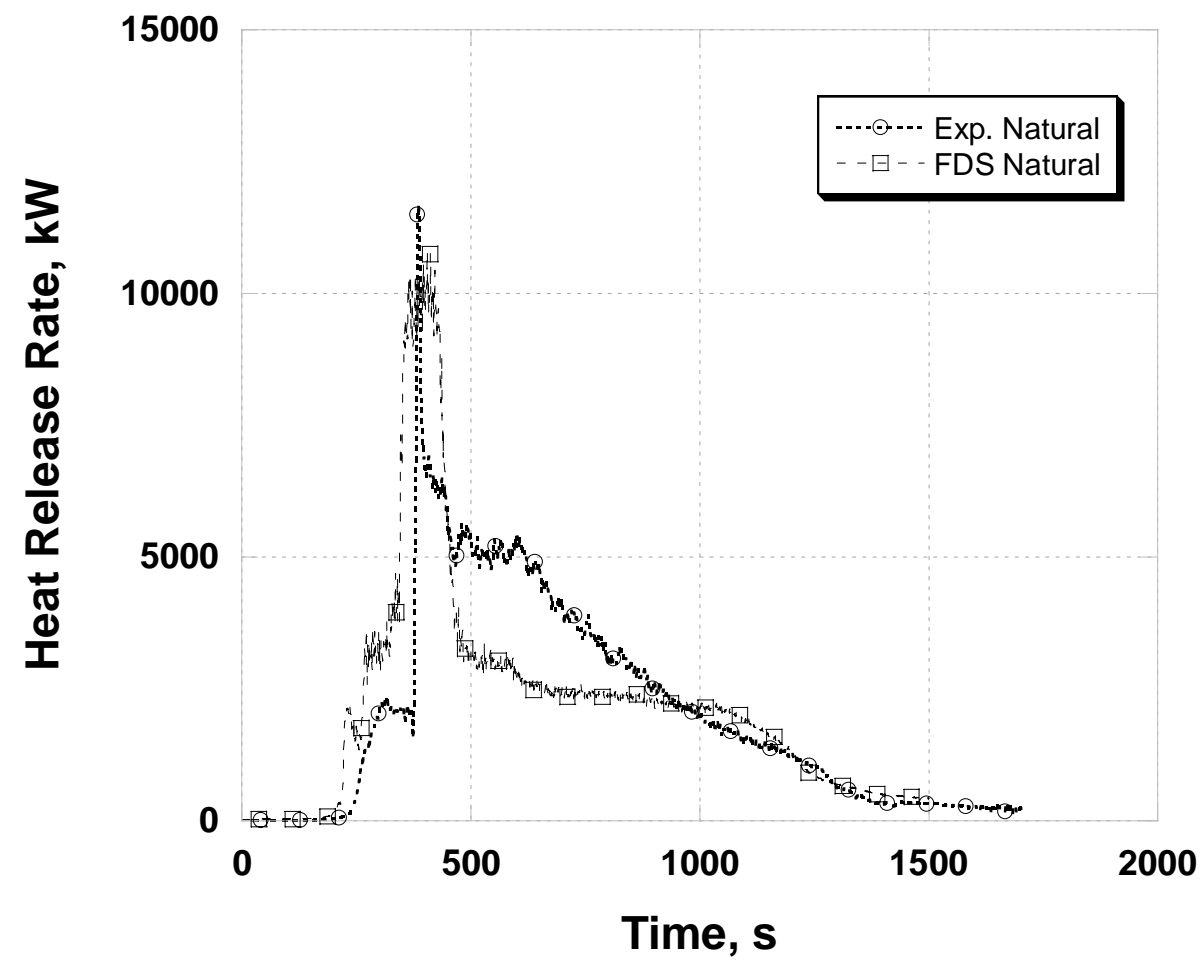

Figure 4-60. FDS and Experimental Naturally Ventilated Heat Release Rate 


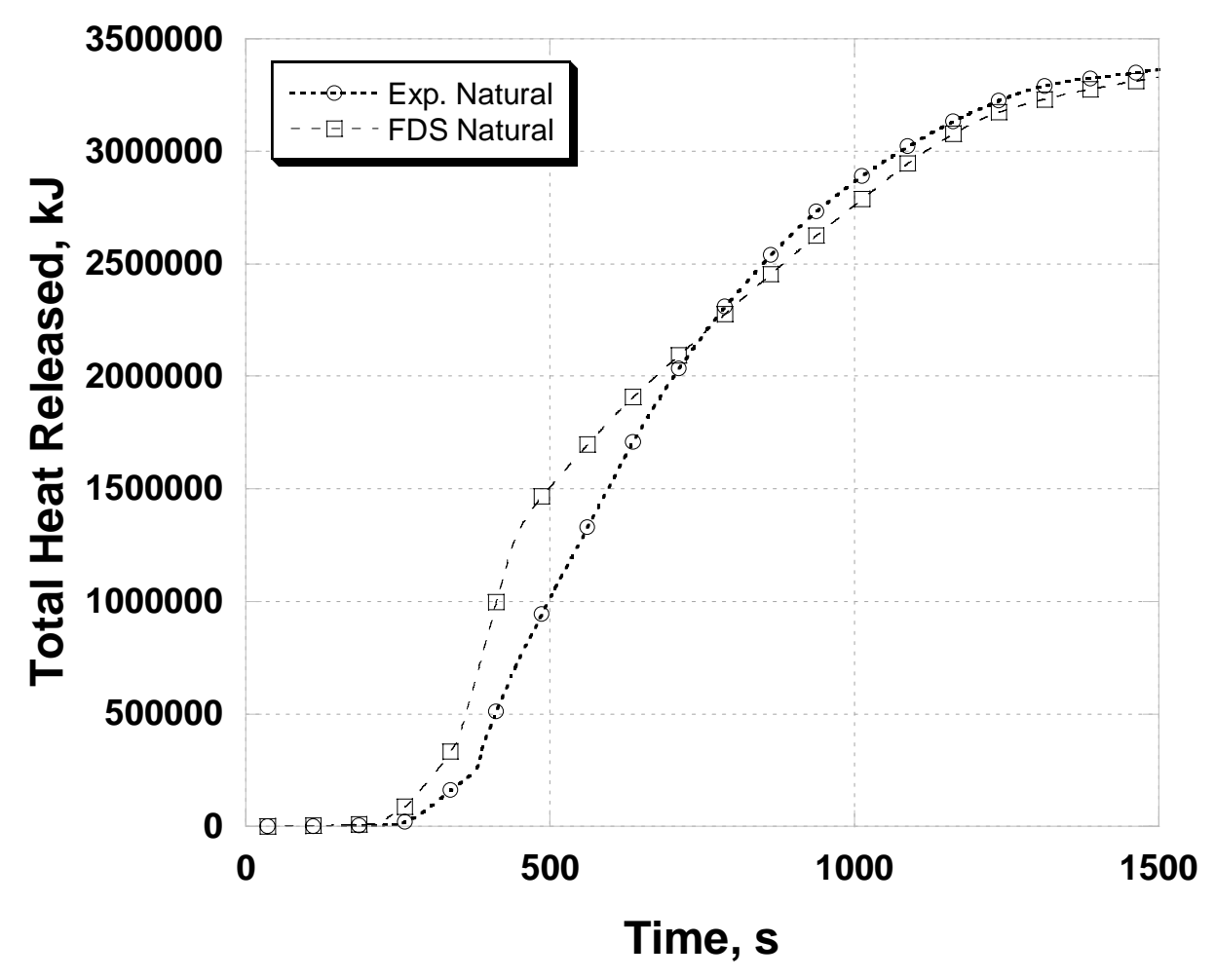

Figure 4-61. FDS and Experimental Naturally Ventilated Total Heat Released

Gas temperatures measured and predicted increased rapidly both before and after ventilation (Figure 4-30 on page 67 and 4-62). In both the experiment and the FDS simulation, gas temperatures rose to approximately $800{ }^{\circ} \mathrm{C}\left(1470{ }^{\circ} \mathrm{F}\right)$ prior to ventilation and began to decrease as the room became oxygen limited. Immediately after the window was opened, the room temperatures increased to a peak of $1000{ }^{\circ} \mathrm{C}$ $\left(1830{ }^{\circ} \mathrm{F}\right)$ in the experiment and $1100^{\circ} \mathrm{C}\left(2000{ }^{\circ} \mathrm{F}\right)$ in the FDS simulation. There was a difference after ventilation in the lower level temperatures. The experiment maintained a uniform temperature throughout the room while the FDS simulation yielded a temperature gradient. The reason for the under-predicted gas temperatures 
is due to the fresh air being pulled into the lower portion of the room and being mixed with the hot gases. The FDS values are true gas temperatures with no radiative effects. The experimental bare bead thermocouple temperatures are impacted by the exchange of radiation with room walls, hot flame gases, soot and the ambient environment that exists through the doors and the window. This temperature difference has been documented well and has been verified and well documented at NIST $[13,14]$. The under-predicted temperatures in the lower layers will be consistent throughout the results.

After the simulation reaches its peak temperature and transitions to a free burn stage the temperature at the ceiling $(0.025 \mathrm{~m}(0.08 \mathrm{ft}))$ is slightly over-predicted, the

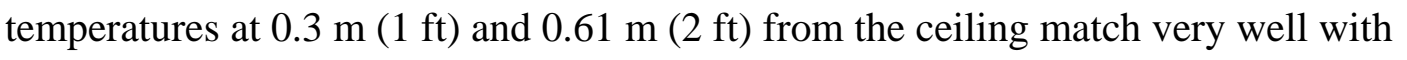
the experimental room temperatures. At $0.91 \mathrm{~m}$ ( $3 \mathrm{ft}$ ) from the ceiling FDS slightly under-predicts the experimental temperature. The three lowest temperature measurements are under-predicted by $400{ }^{\circ} \mathrm{C}\left(750^{\circ} \mathrm{F}\right)$, most likely due to radiation effects. 


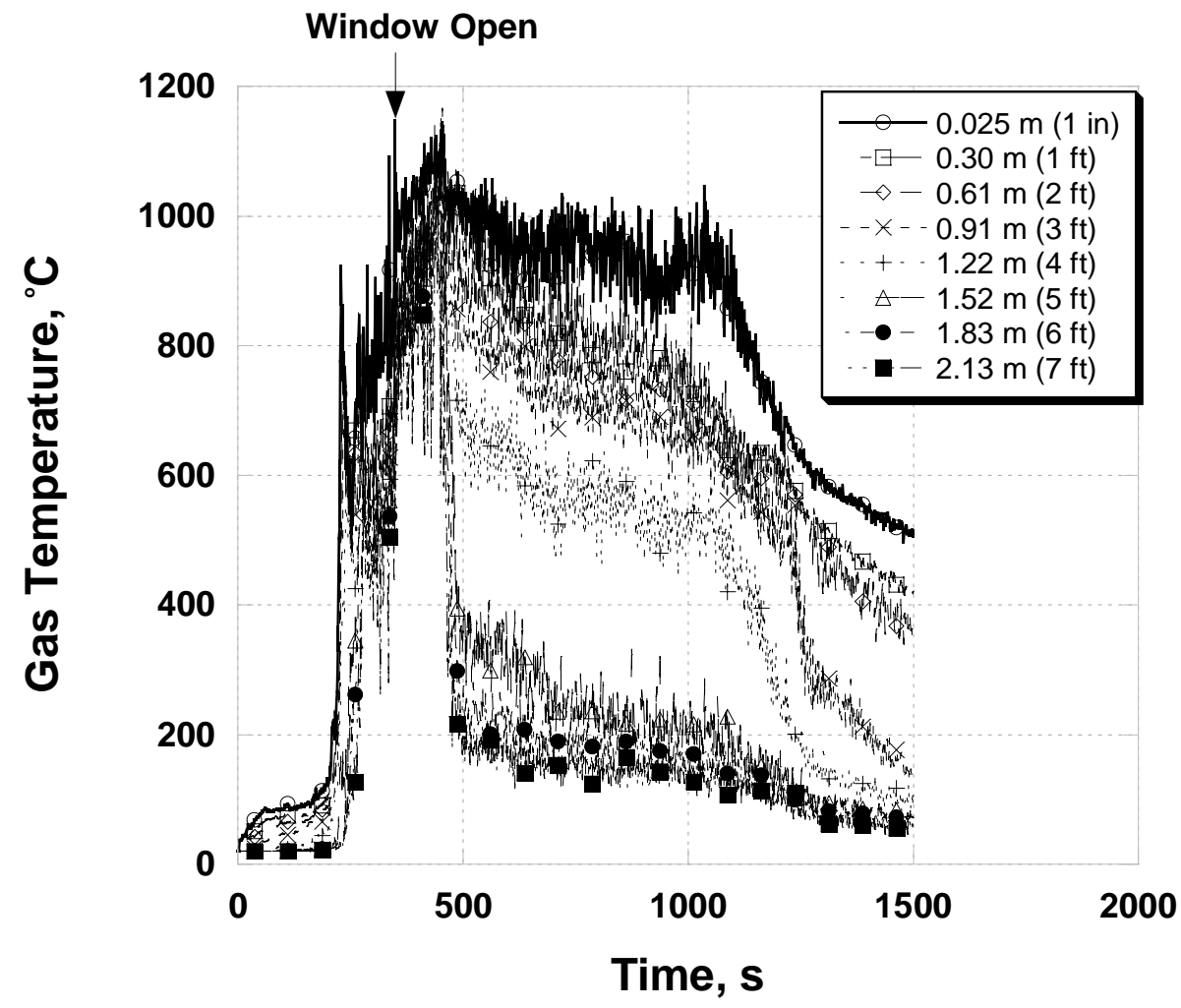

Figure 4-62. FDS Naturally Ventilated Room Temperatures

Figure 4-63 displays the FDS simulation fire room door temperatures. In both the simulation and the experiment, the top and middle measurement points increase to approximately $800{ }^{\circ} \mathrm{C}\left(1470{ }^{\circ} \mathrm{F}\right)$ prior to ventilation. After ventilation the experimental fire room door temperatures peak at $1000{ }^{\circ} \mathrm{C}\left(1830{ }^{\circ} \mathrm{F}\right)$ (Figure 4-32 on page 70 ) while the simulation predicted temperature peaks at $1100{ }^{\circ} \mathrm{C}\left(2000{ }^{\circ} \mathrm{F}\right)$. Similar to the lower level room temperatures the simulation middle temperature in the doorway is significantly lower than in the experiment. The bottom measurement point in both the experiment and the simulation remain low with a peak at the time of ventilation. The FDS simulation also under-predicts this temperature as compared to the experiment. 


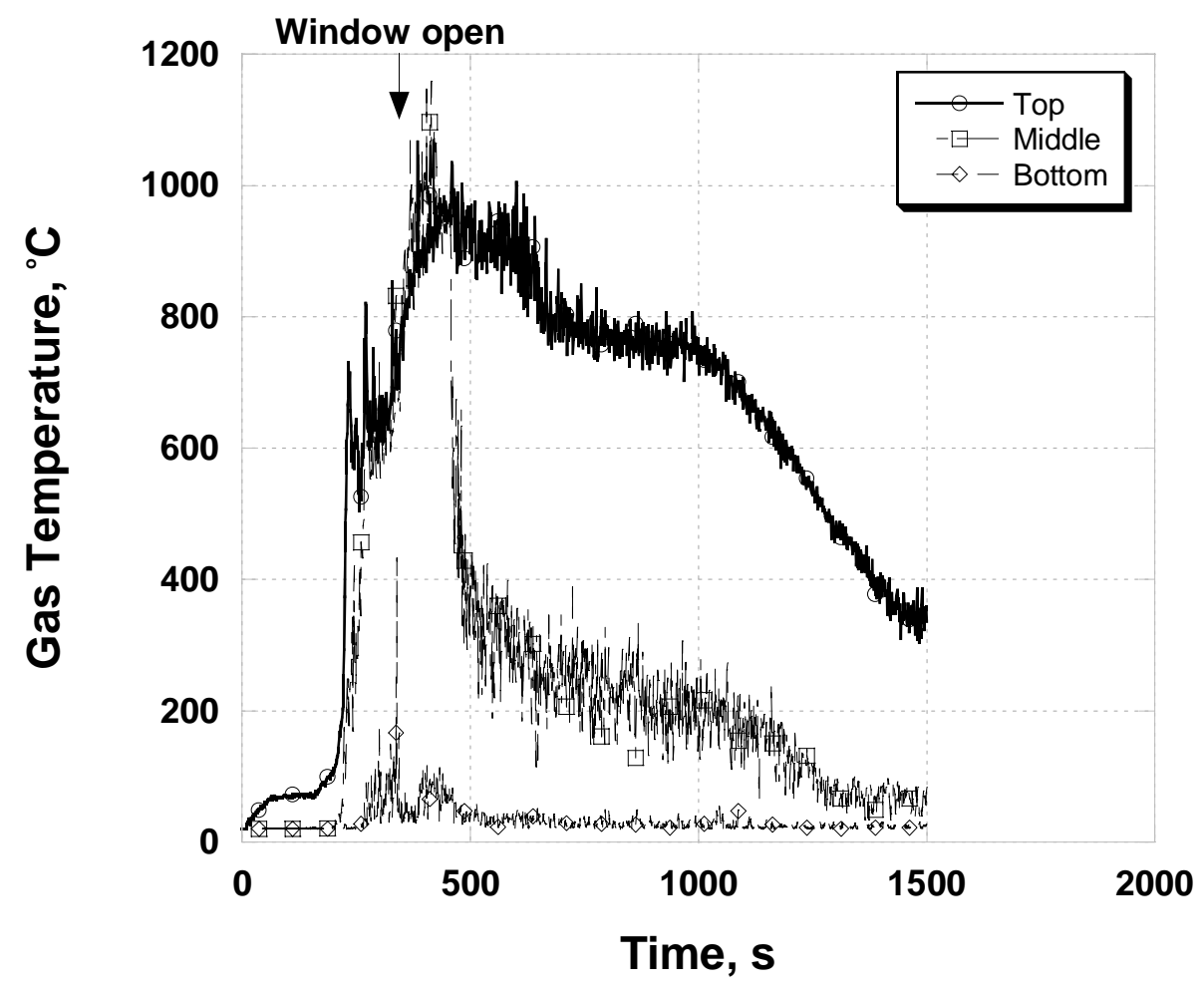

Figure 4-63. FDS Naturally Ventilated Room Doorway Temperatures

Experimental gas temperatures in the upper third of the corridor doorway were between $600{ }^{\circ} \mathrm{C}\left(1110{ }^{\circ} \mathrm{F}\right)$ and $900{ }^{\circ} \mathrm{C}\left(1650{ }^{\circ} \mathrm{F}\right)$ after ventilation (window opened) (Figure 4-35 on page 72). Simulation gas temperatures at the top of the doorway were higher, peaking at $1300{ }^{\circ} \mathrm{C}\left(2370{ }^{\circ} \mathrm{F}\right)$ (Figure 4-64). After the peak the top three temperature measurements in both cases progressed similarly. The experimental middoorway temperature rose as high as $400{ }^{\circ} \mathrm{C}\left(750^{\circ} \mathrm{F}\right)$ while the bottom remained approximately $100{ }^{\circ} \mathrm{C}\left(212^{\circ} \mathrm{F}\right)$. The simulation predicted temperatures at the low level were under-predicted just as they were in the room doorway and in the center of the room. The temperature trends in the corridor were very similar to those of the room doorway. 


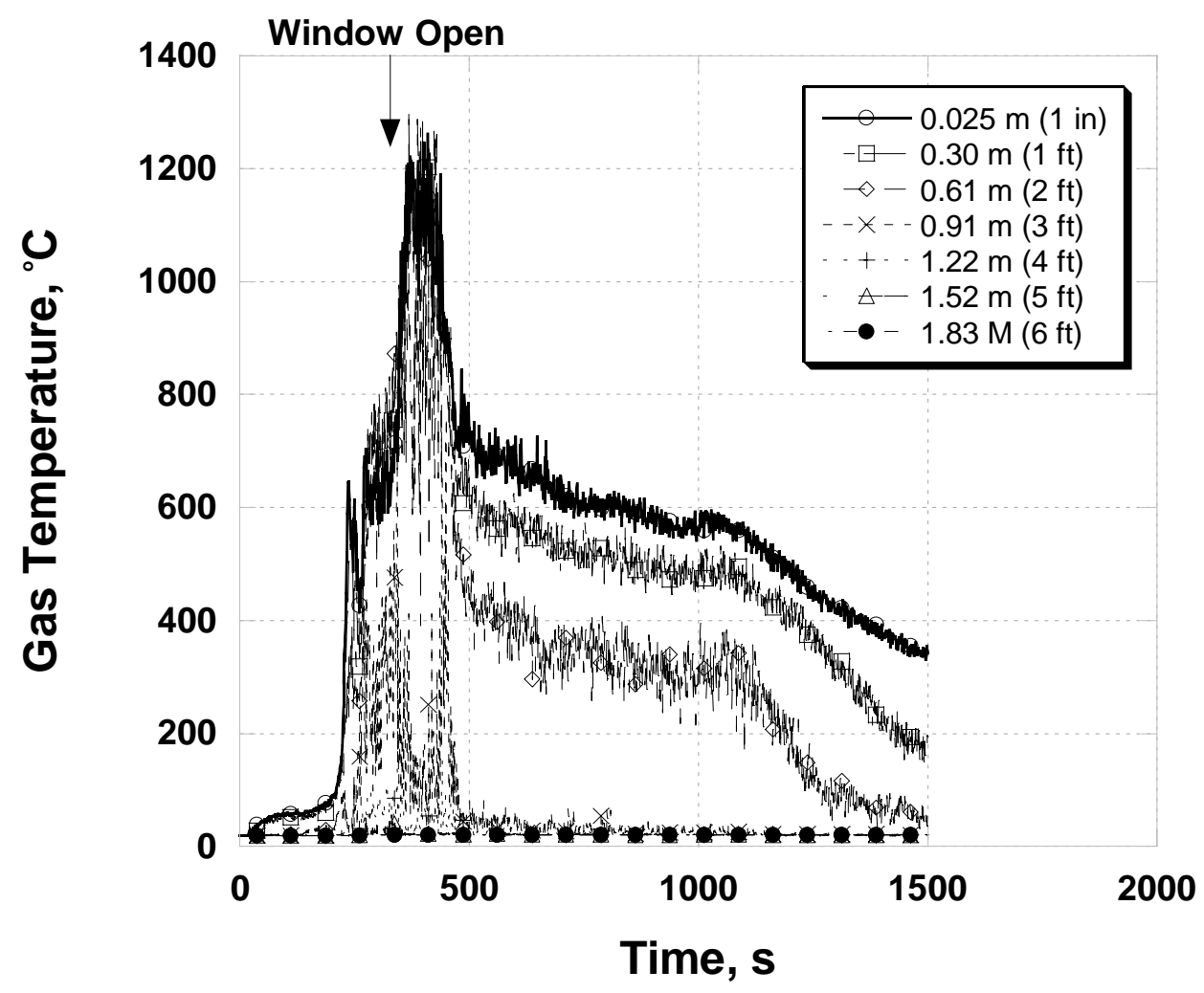

Figure 4-64. FDS Naturally Ventilated Corridor Doorway Temperatures

The naturally ventilated experiment had a bidirectional flow through the window with the highest velocities of $12 \mathrm{~m} / \mathrm{s}$ (39 ft/s) at the top of the window (Figure 4-40 on page 78). The simulation window velocity peaked at $10 \mathrm{~m} / \mathrm{s}$ (33 ft/s) at the top of the window (Figure 4-65). Velocities at the top of the window decreased linearly to $5 \mathrm{~m} / \mathrm{s}(16 \mathrm{ft} / \mathrm{s})$ at 1000 seconds in both the experiment and the simulation. The experimental gas velocity in the middle of the window was about $7 \mathrm{~m} / \mathrm{s}(23 \mathrm{ft} / \mathrm{s})$ out of the room while the bottom of the window had flow into the room of $2 \mathrm{~m} / \mathrm{s}(7 \mathrm{ft} / \mathrm{s})$. The lower window velocities in the simulation were lower in magnitude but were in the same direction. The simulation's mid-window velocities were approximately 
$5 \mathrm{~m} / \mathrm{s}(16 \mathrm{ft} / \mathrm{s})$ and the lower window velocities were approximately $1 \mathrm{~m} / \mathrm{s}(3 \mathrm{ft} / \mathrm{s})$ out into the window. In both the experiment and the simulation there is a brief time just after the window is opened where the lower window flow is out of the room. Shortly after this the flow switches into the room as the fire draws air.

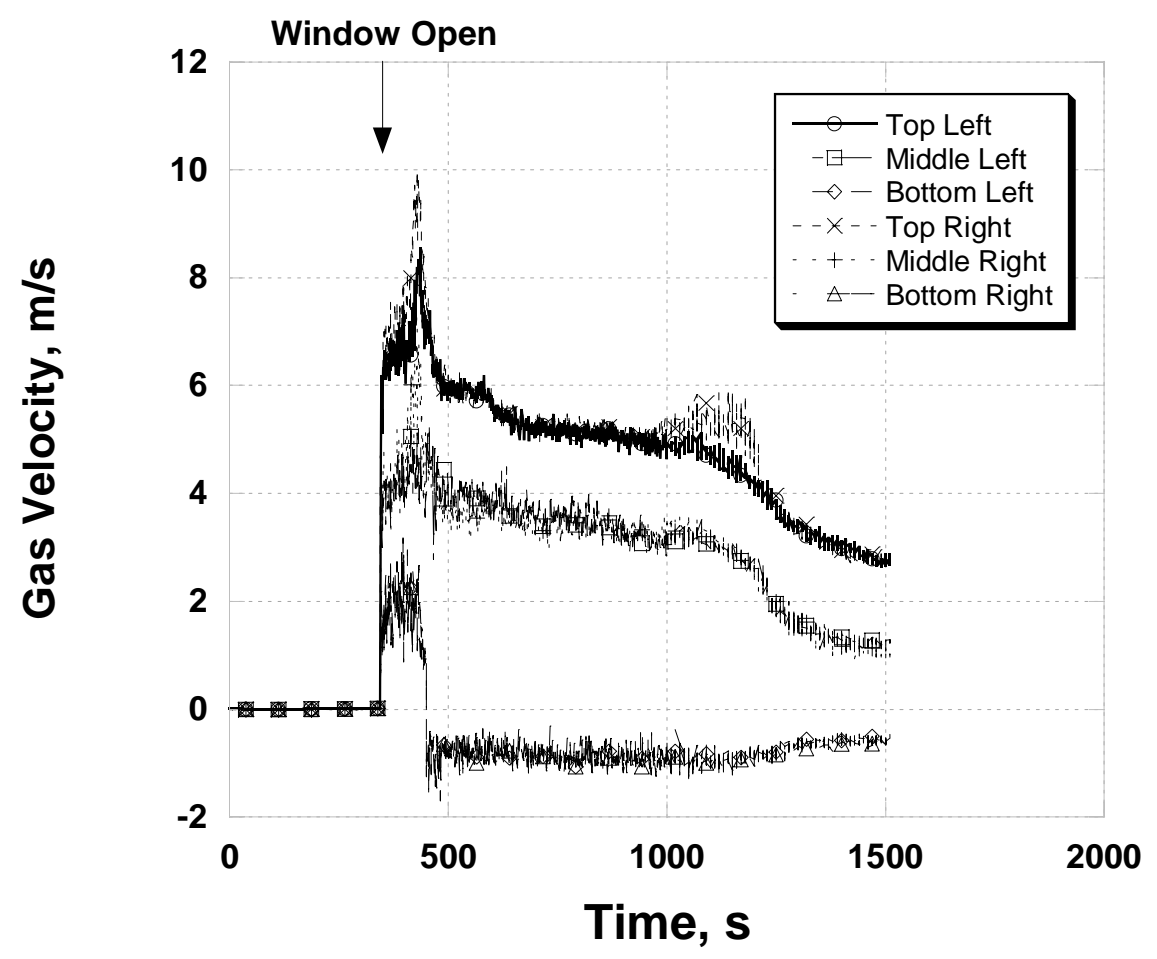

Figure 4-65. FDS Naturally Ventilated Window Velocities

Experimental and simulation fire room doorway velocities are shown in Figures 4-42 (on page 81) and 4-66. Both cases have flow out of the top of the doorway and flow into the bottom two-thirds of the doorway. The experimental flow out of the top of the door fluctuated between $3 \mathrm{~m} / \mathrm{s}(10 \mathrm{ft} / \mathrm{s})$ and $4 \mathrm{~m} / \mathrm{s}(13 \mathrm{ft} / \mathrm{s})$ and the simulation flow ranged between $2 \mathrm{~m} / \mathrm{s}(7 \mathrm{ft} / \mathrm{s})$ and $3 \mathrm{~m} / \mathrm{s}(10 \mathrm{ft} / \mathrm{s})$. Flows into the room in the lower 
portions of the door were between $3 \mathrm{~m} / \mathrm{s}(10 \mathrm{ft} / \mathrm{s})$ and $6 \mathrm{~m} / \mathrm{s}(20 \mathrm{ft} / \mathrm{s})$ in both the experiment and the simulation.

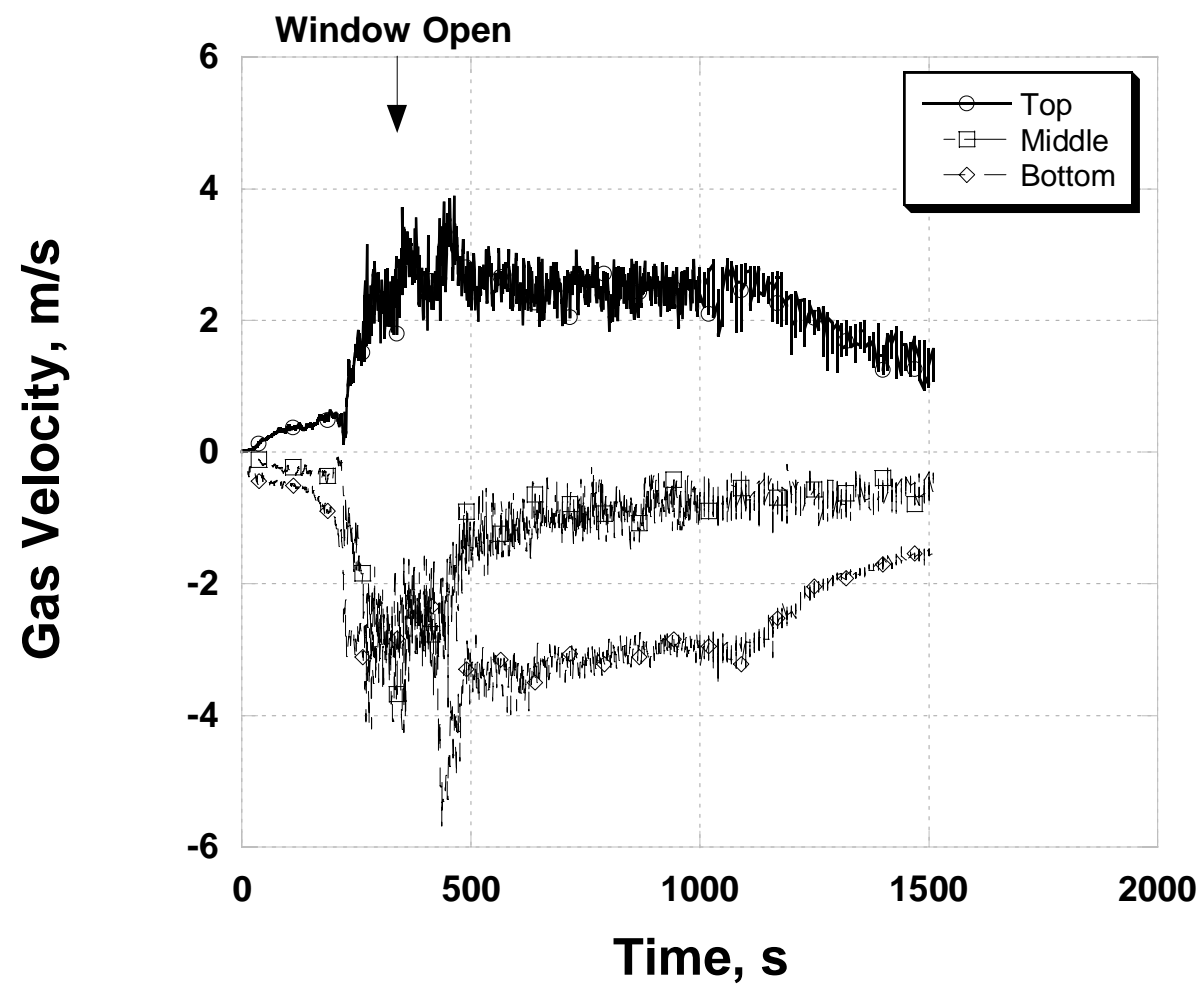

Figure 4-66. FDS Naturally Ventilated Room Doorway Velocities

\subsubsection{Positive Pressure Ventilated Simulation}

The results of the positive pressure ventilated simulation are compared with the video record of the experiment and the measurements of gas temperature, gas velocity and heat release rate. Visual comparisons of the experiment and simulation are shown in Figures 4-67 through 4-79. Quantitative comparisons between the experimental data and the model predictions are given in Figures 4-80 through 4-86. 


\subsubsection{Visual Comparisons}

Figures 4-67 through 4-79 are composed of pairs of images. The still frames captured from experimental video tape appear on the left. The frames were not all taken from the same camera view. The camera view is included in the figure caption because some of the views are obstructed by smoke and or flames. The images on the right were rendered in Smokeview. Both images represent the same time after ignition. The images shown are at times 0, 60, 170, 240, 300, 360, 400, 410, 445 and 500 seconds.
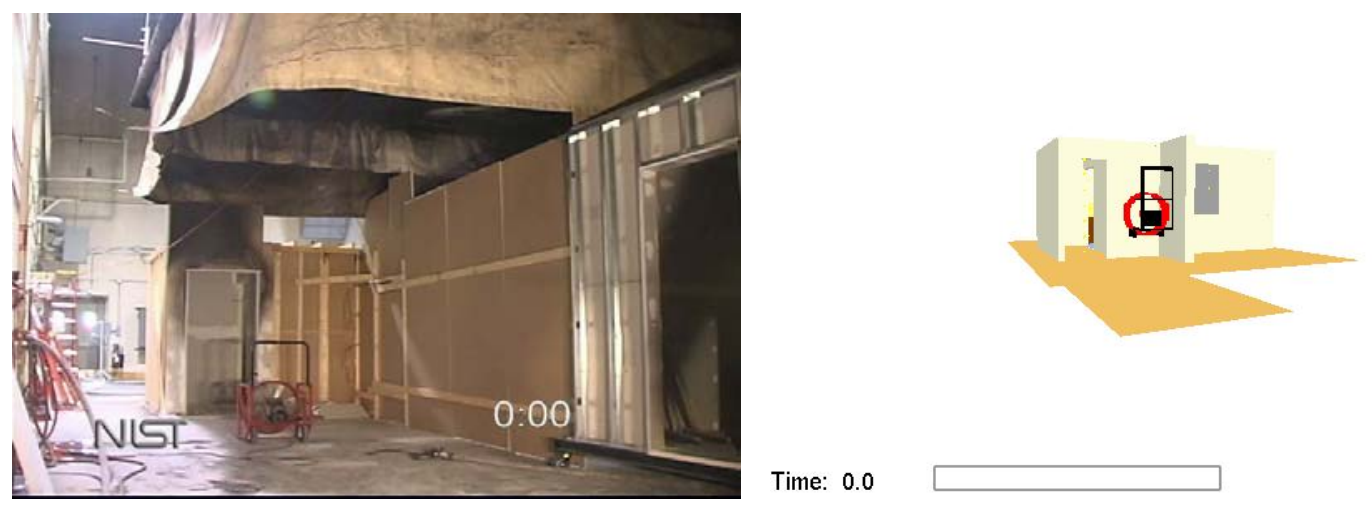

Figure 4-67. External Door View With Fan Prior to Ignition (0 seconds)

Figure 4-67 shows the external corridor doorway view prior to ignition. This is the only view that differs from the natural ventilation test due to the addition of the positive pressure ventilation fan. The difference can also be seen in the placement of the fan as explained in chapter one. The fan in the experiment is angled upward to cover the doorway. The fan in FDS was translated upward to cover the doorway as described in chapter 3. 

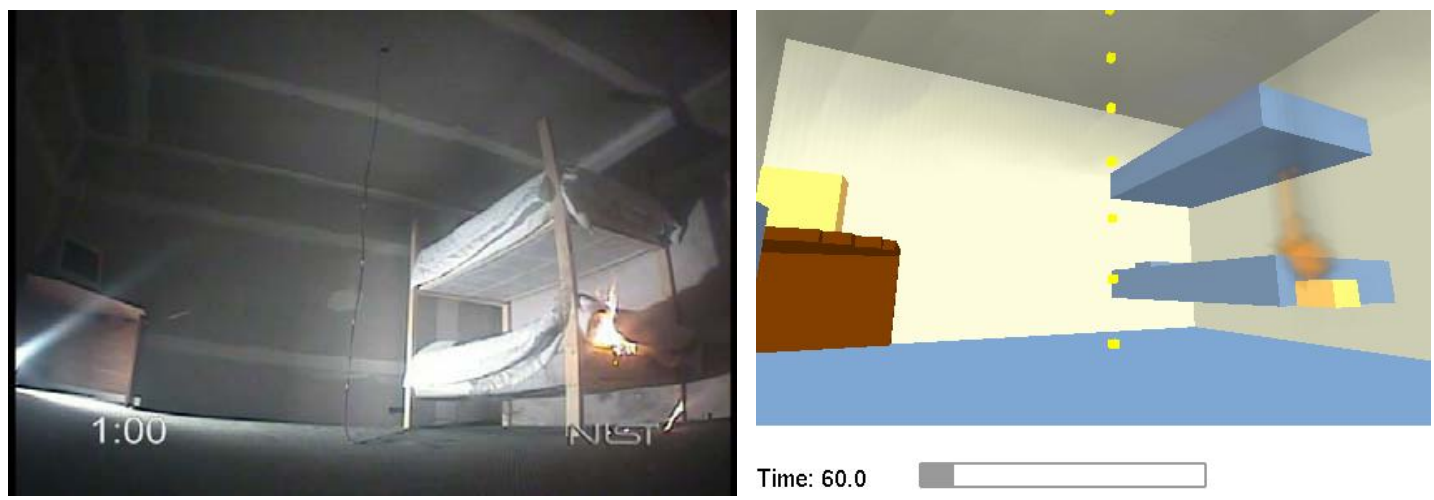

Figure 4-68. Bunkbed View as Flames Involve Corner of Mattress (60 seconds)
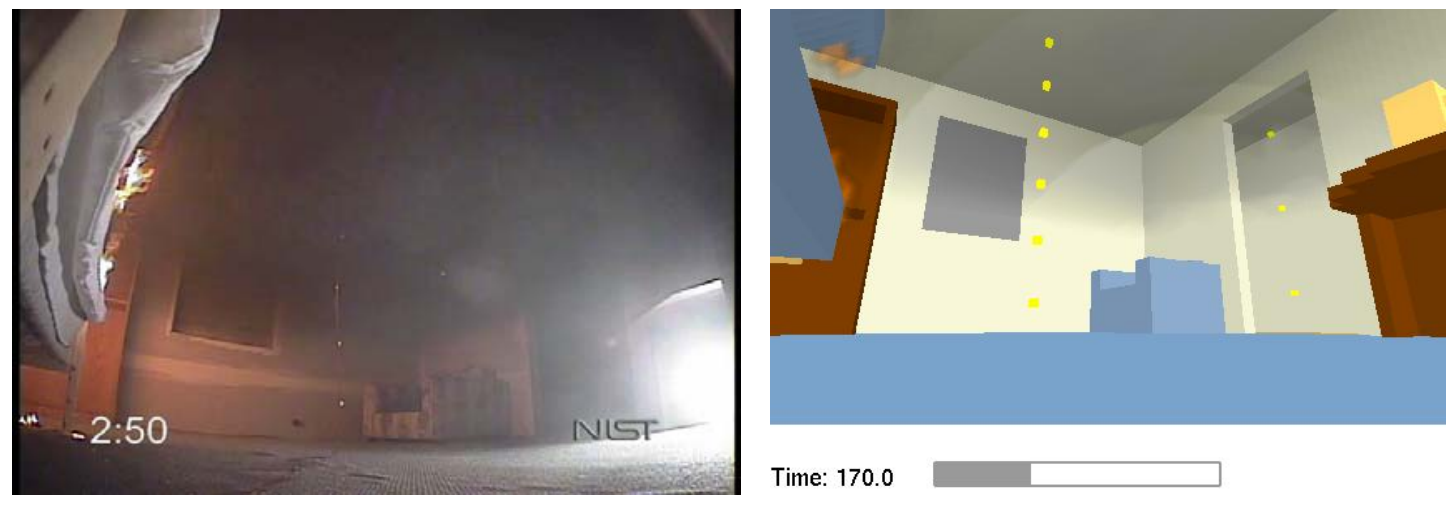

Figure 4-69. Doorway and Window View as Flames Spread to Top Mattress (170 seconds)

Figures 4-68 and 4-69 show two camera views during the growth stage of the fire.

The bunk bed view shows the fire beginning and spreading on the corner of the mattress. The doorway and window view show the fire as it begins to extend to the top bunk at 170 seconds. Some drop down of burning materials can be seen in the experimental frame of Figure 4-69, this is not easily repeatable in FDS and therefore increases the uncertainty of the simulation. The fire growth in this experiment is very comparable to the growth in the naturally ventilated experiment. 

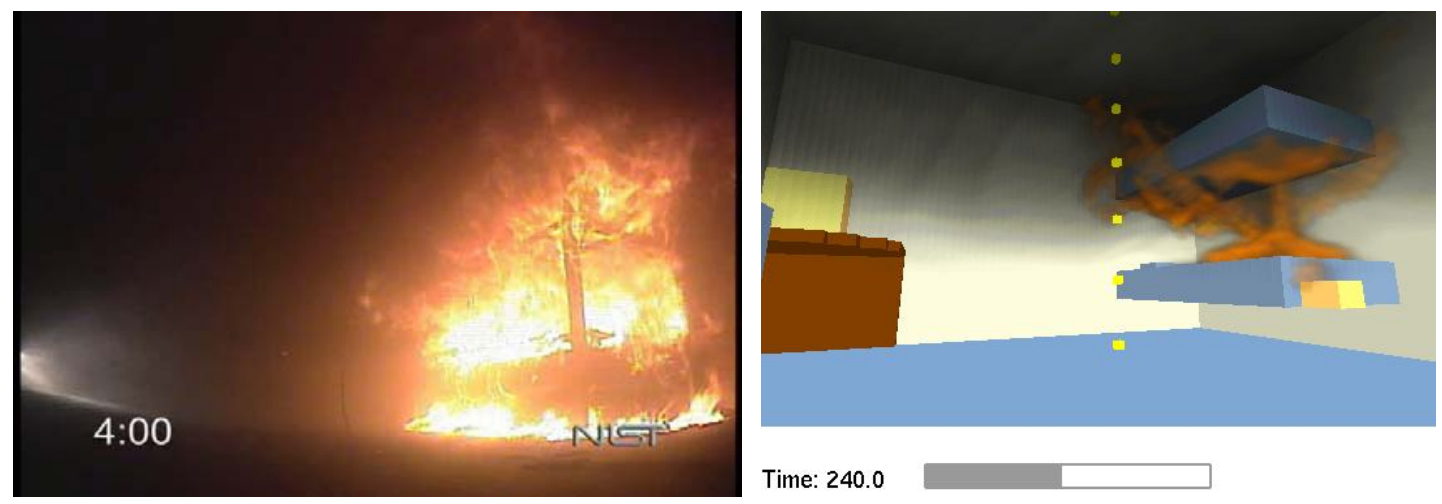

Figure 4-70. Flames Involving Bunk Bed (240 seconds)
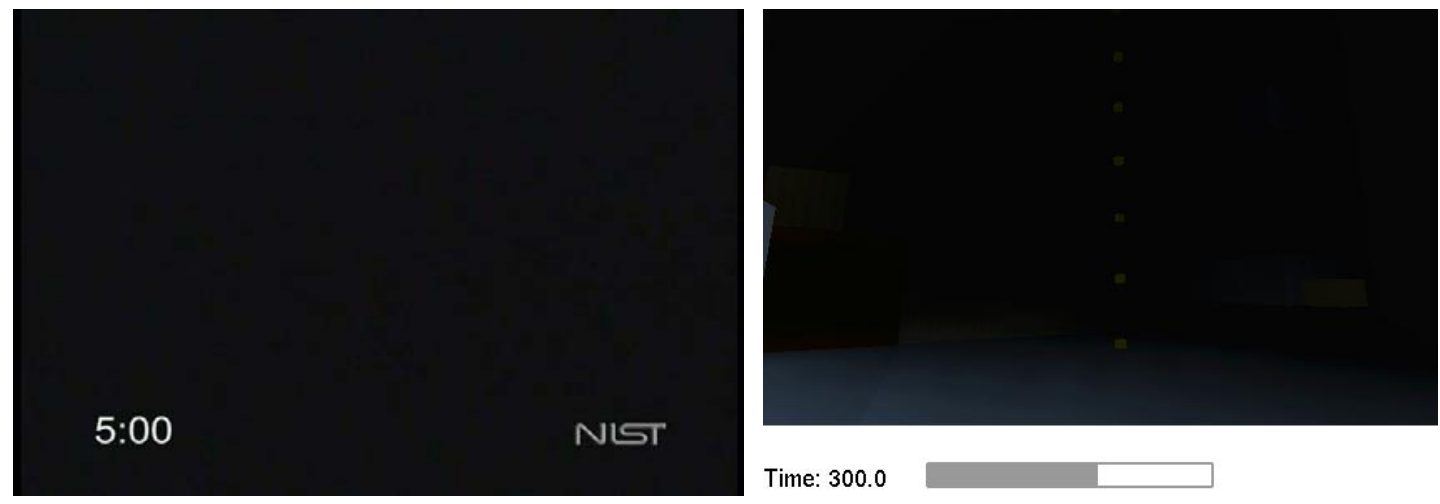

Figure 4-71. Visibility Lost in Bunk Bed View (300 seconds)

Figure 4-70 compares the fire development at 240 seconds after ignition. In both frames the fire is involving both mattresses that make up the bunk bed. The experimental growth is slightly ahead of that of the simulation. One reason for this could be the melted materials that have pooled below the bottom mattress in the experiment allowing for the bottom of the lower mattress to become involved in flames. The smoke is also denser in the experimental frame for the same reason not allowing for the visualization of burning that may be occurring on the top of the upper mattress. 
Figure 4-71 has images captured 300 seconds after ignition. In both the experiment and the FDS simulation visibility has decreased greatly due to smoke filling and the bunk bed can no longer be seen. The naturally ventilated experiment lost visibility at approximately the same time.
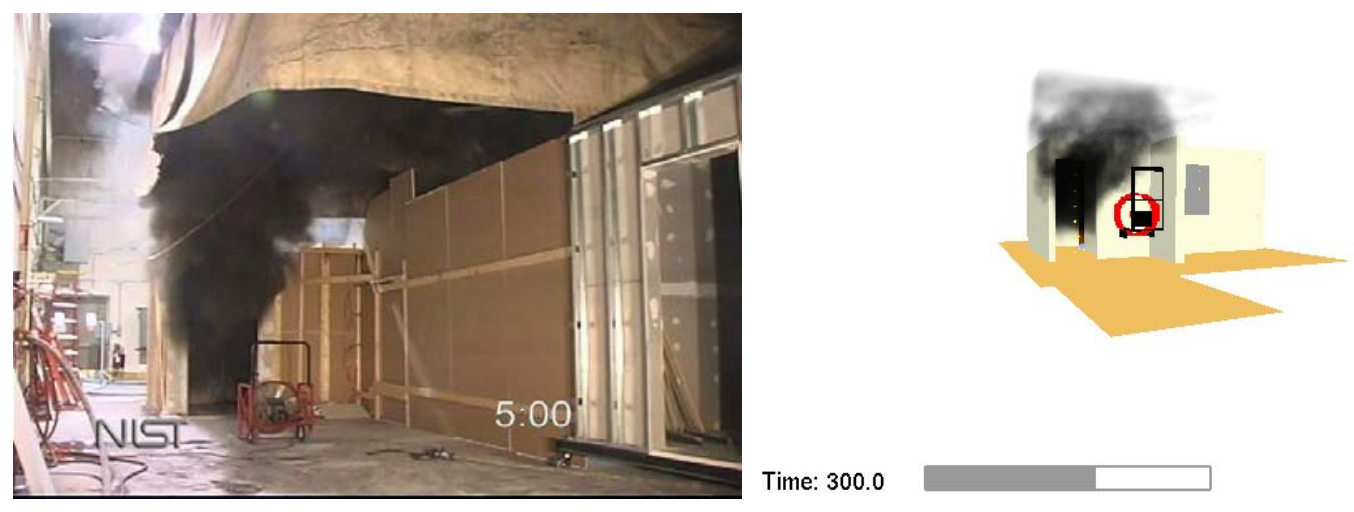

Figure 4-72. Thick Smoke Flows From Corridor Doorway (300 seconds)

At the same time that visibility is lost in the room, Figure 4-72 shows the thick black smoke flowing from the corridor doorway. The smoke in the experiment appears to be thicker than that of the simulation but both have smoke in the same regions of the doorways. Unlike the naturally ventilated simulation the positive pressure ventilated simulation does not over-predict the flame isosurface location. 

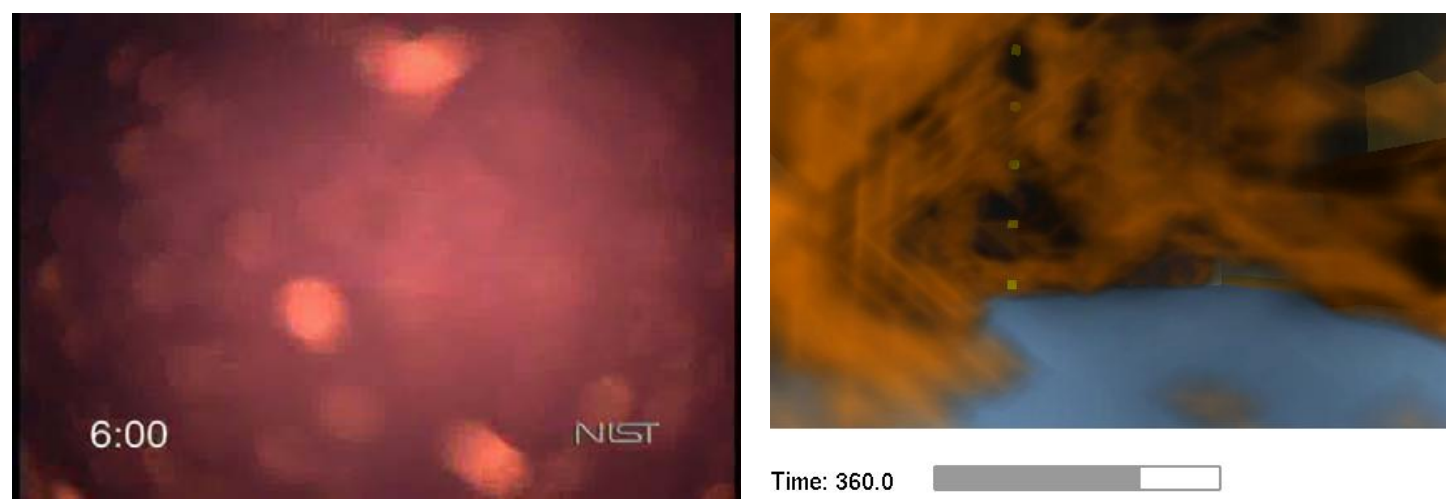

Figure 4-73. Doorway and Window View Obstructed by Flames (360 seconds)

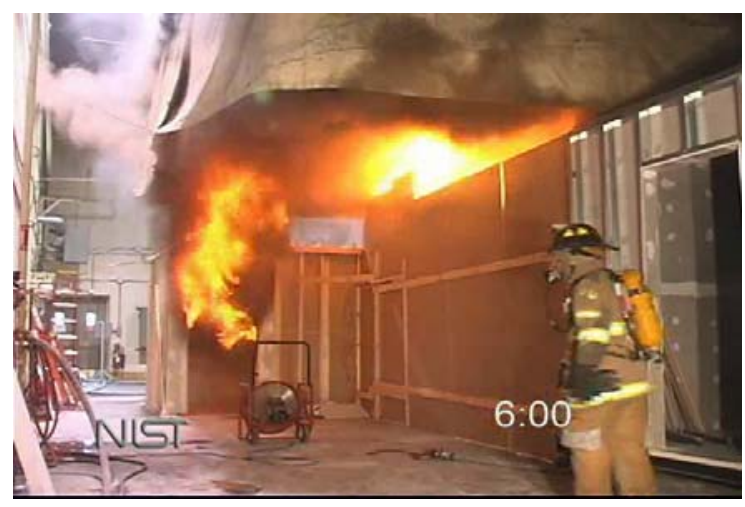

Time: 360.0

Figure 4-74. Doorway View 10 seconds After Fan is Turned On (360 seconds)
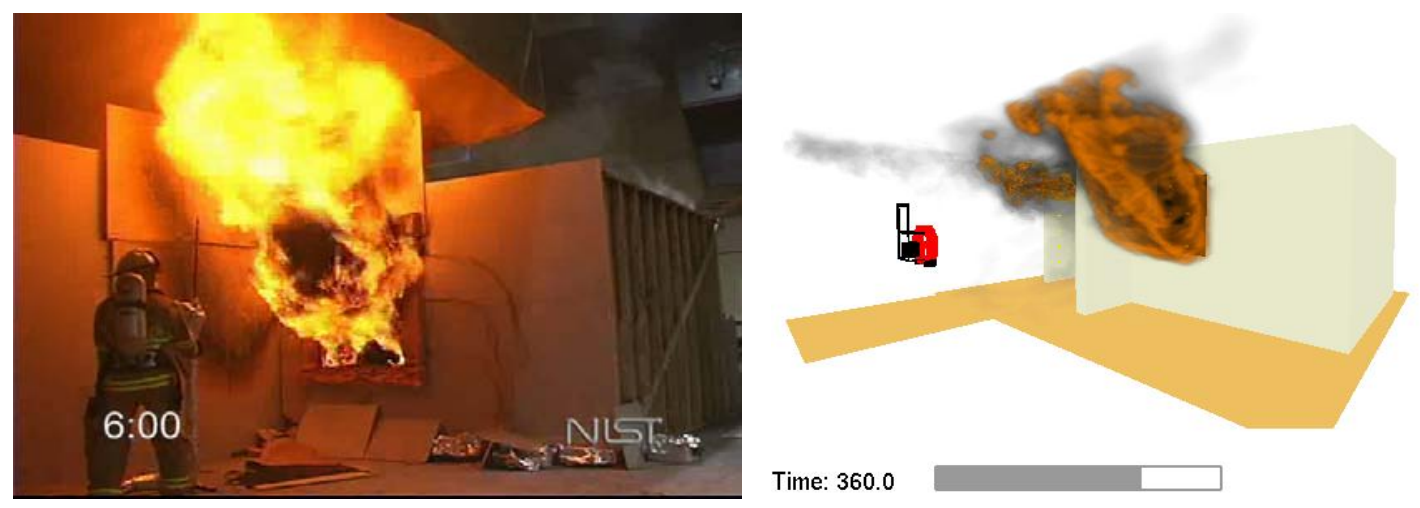

Figure 4-75. Flames From Window (360 seconds) 
Figures 4-73, 4-74 and 4-75 were all captured at 360 seconds after ignition and 10 seconds after the fan was turned on. The internal view shows that the room is fully involved in flames. The experimental frame has some condensation on the lens which evaporates quickly. The external corridor doorway view displays the ignition of the combustion products leaving the doorway both in the experiment and the simulation. The simulation under-predicts the amount of flames coming from the doorway. The final view at 360 seconds is an external view of the window. A large amount of flames are coming from the window in both scenarios. The flames fill the entire cross section of the window just as they did in the naturally ventilated scenario but due to the increased velocity added by the fan the flames extend outward away from the room more than in the naturally ventilated experiment.
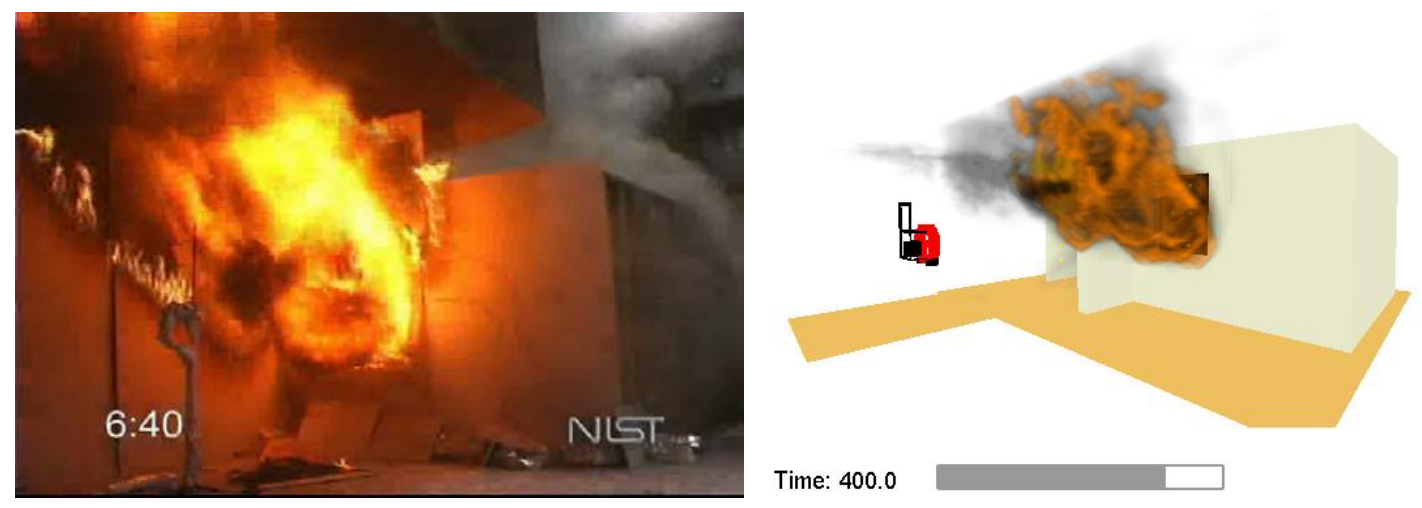

Figure 4-76. Flames Continue From Window (400 seconds)

Figure 4-76 has images taken of the window 55 seconds after the window was opened. Both images show flames filling the entire cross section of the window and exiting the window with force. Both images also have approximately the same amount of smoke being produced as the free burning from the window continues. 


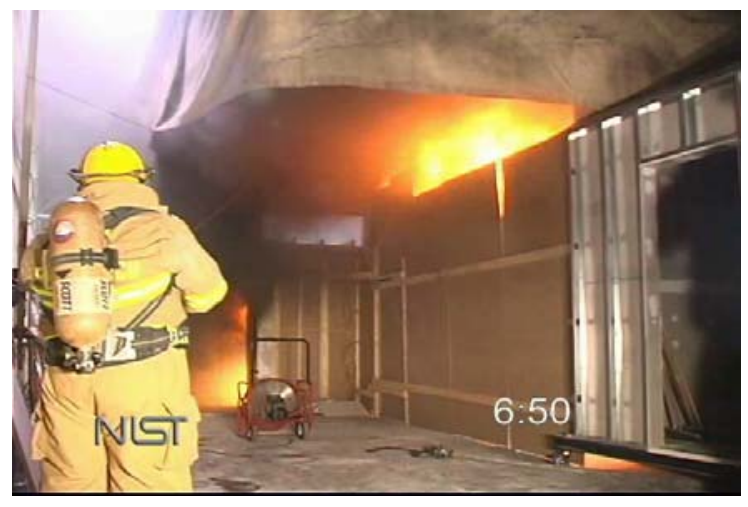

Figure 4-77. Combustion Products Forced into Room by Fan (410 seconds)

At 410 seconds the fan has nearly turned the flow of combustion products back into the room from the corridor doorway as shown in Figure 4-77. In both the experiment and simulation there is some smoke still coming from the top of the doorway but all burning is forced back into the room as can be seen from the glow in both images. This is evidence of the fans ability to reverse strong fire flows and FDS's ability to predict the phenomena.
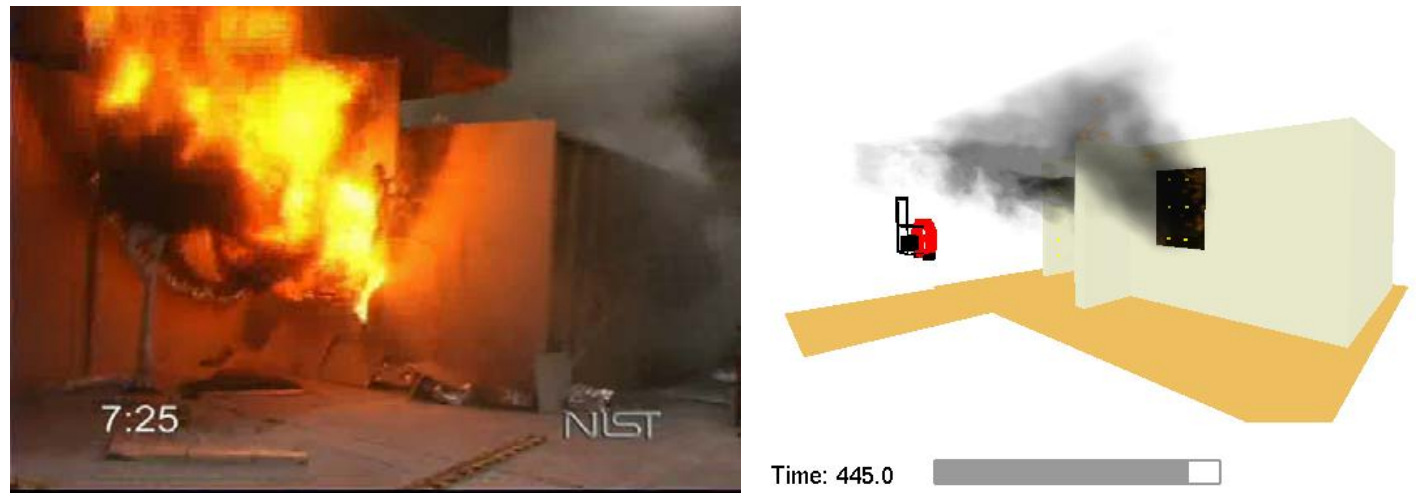

Figure 4-78. Fire in Decay Stage (445 seconds) 

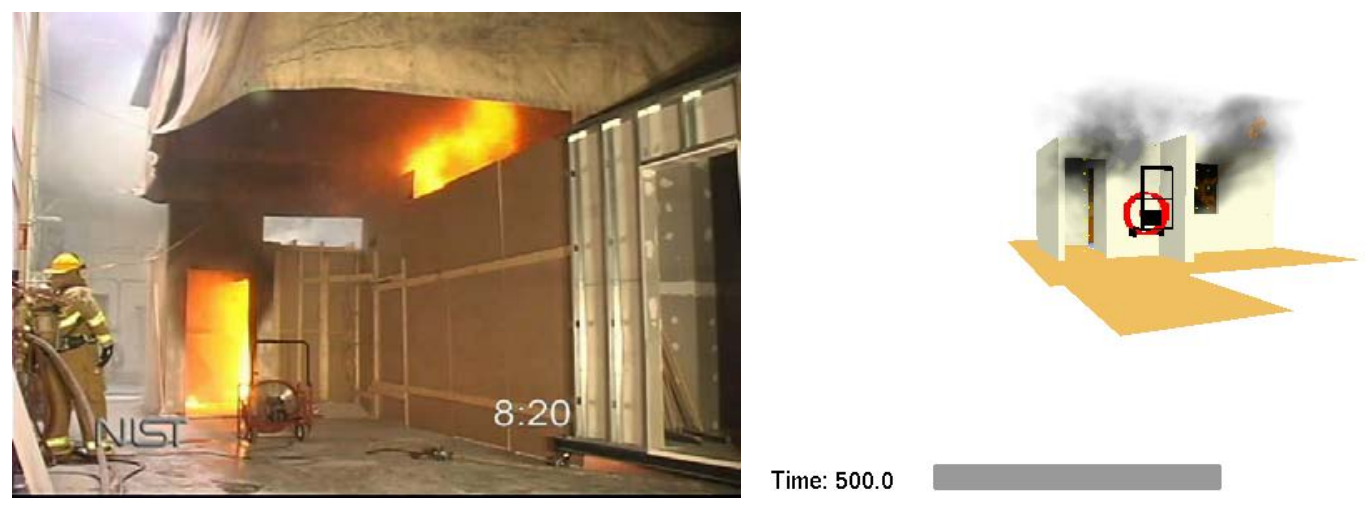

Figure 4-79. Fan Forcing Flow Through Room (500 seconds)

Figures 4-78 and 4-79 show the fire in its decay stage. The experiment experienced its peak heat release rate although it continues to have burning outside of the room. The simulation frame shows significantly less combustion occurring outside the room. This is further evidence that it is difficult in FDS to create furniture that contains the same amount of fuel as actually exist. There is still burning in the room in the simulation but not of the magnitude of the experiment. This under-prediction of flames in the simulation is consistent with the under-prediction of temperatures in the room that was seen in the naturally ventilated scenario.

\subsubsection{Numerical Comparisons}

In this section, values of heat release rate, gas temperatures and gas velocities generated by the positive pressure ventilated FDS simulation will be compared to measurements from the full-scale experiments described in section 4.2.

Figure 4-80 compares the measured heat release rate leaving the experimental room to the heat release rate from the fire within the room as predicted by FDS. The 
experimental heat release rate peaks at $14 \mathrm{MW}$ while the simulation heat release rate peaks at $16 \mathrm{MW}$. The difference in peak time corresponds to the time for the combustion products to leave the corridor doorway and window and reach the oxygen consumption calorimetry instrumentation in the exhaust hood. Both curves increase at a similar slope to the maximum output. This demonstrates that the sudden opening of the window is handled accurately by FDS. As with the naturally ventilated simulation the heat release rate curve in the simulation declines more rapidly than in the experiment. This is also due to the accuracy associated with the modeling of the rooms furnishings.

Figure 4-81 is a comparison of the naturally ventilated and positive pressure ventilated FDS simulations. This helps to factor out the effect of the furniture and isolate the fan's impact on the heat release rate. The naturally ventilated simulation peaked at $11 \mathrm{MW}$ and the positive pressure ventilated simulation peaked at $16 \mathrm{MW}$, an increase of $45 \%$. This compares well with the experimental increase of $60 \%$ for the 200 seconds following ventilation. FDS also has convergence of the heat release rates of the two simulations as the fire burn down. This is based on the 100 seconds from 488 seconds to $588 \mathrm{~s}$, when the PPV simulation terminated. 


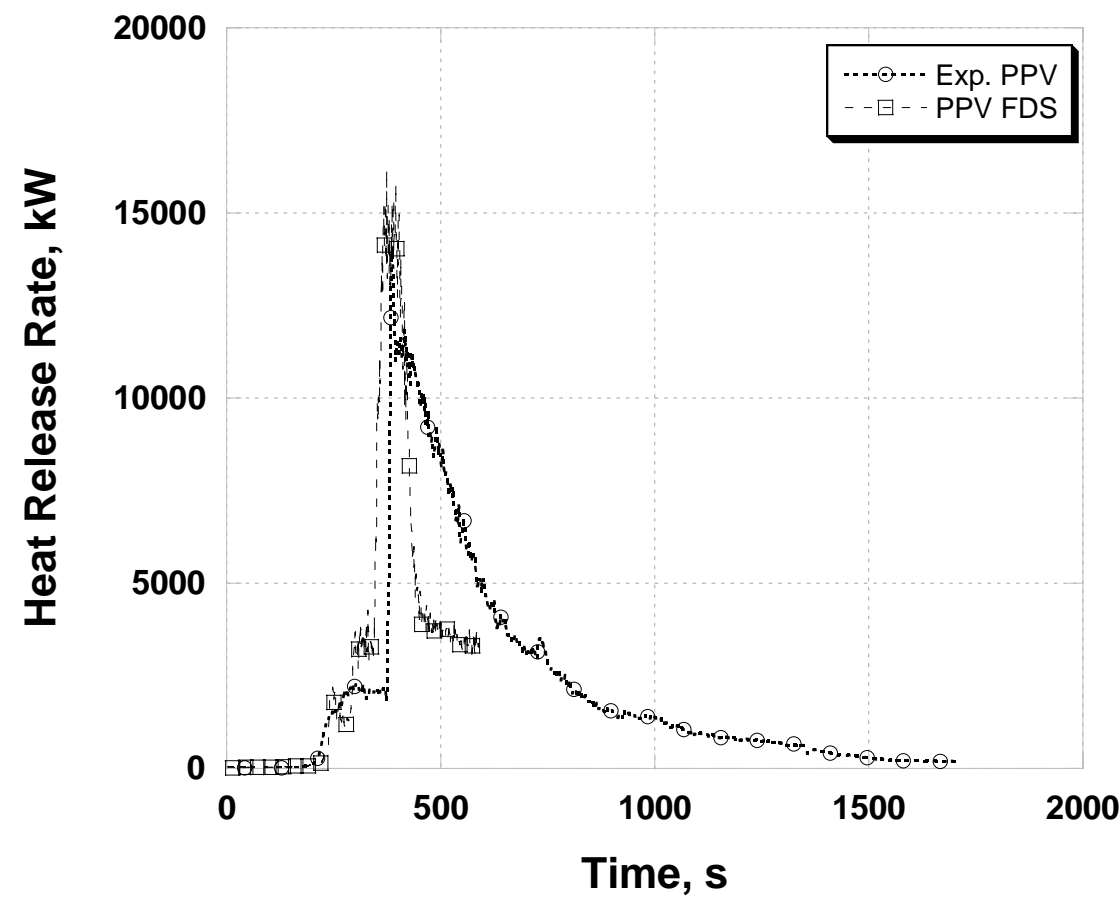

Figure 4-80. FDS and Experimental Positive Pressure Ventilated Heat Release Rate

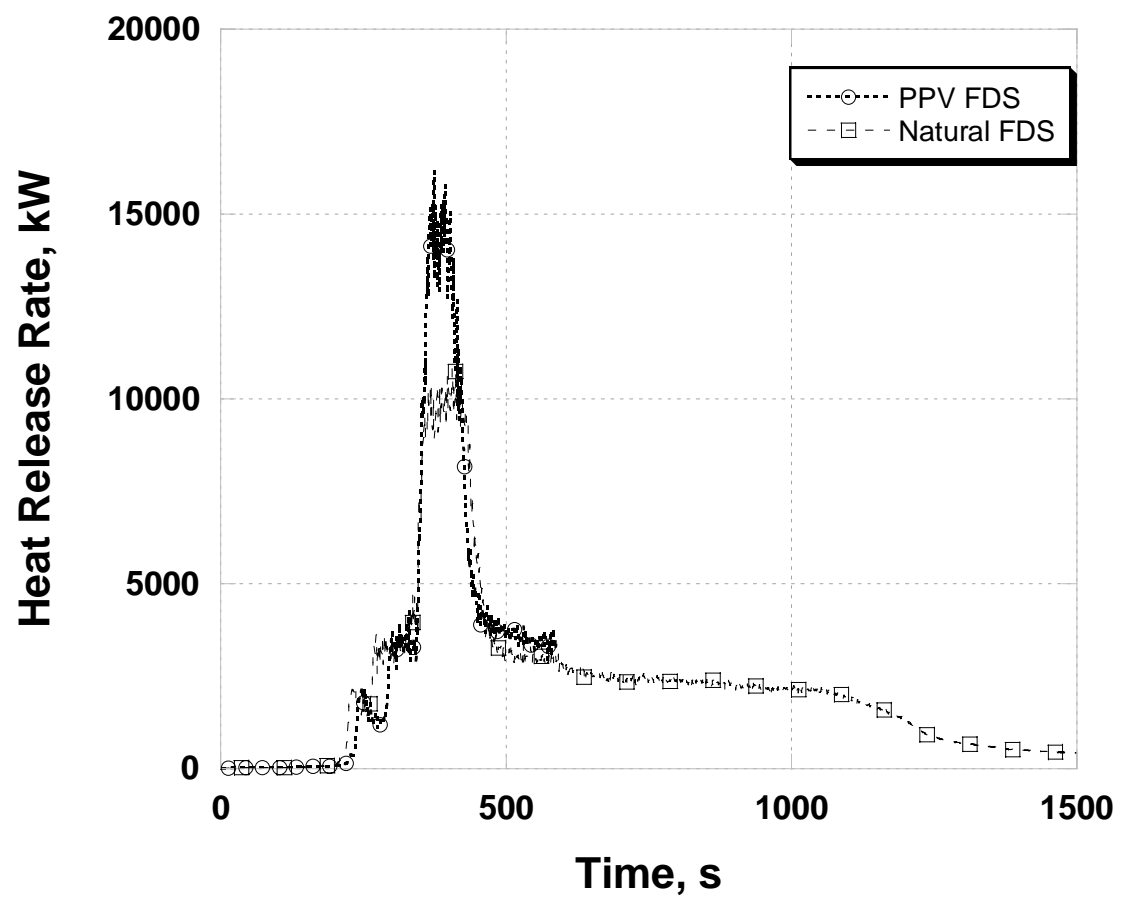

Figure 4-81. FDS Heat Release Rate Comparison of natural and PPV ventilation 
The room gas temperatures in the FDS simulation, illustrated in Figure 4-82, increase similar to those of the experiment in Figure 4-29 (on page 66). At 300 seconds both peak at approximately $800{ }^{\circ} \mathrm{C}\left(1470{ }^{\circ} \mathrm{F}\right)$ at the ceiling prior to ventilation as the fire becomes oxygen limited. Once the window was opened the temperature in the simulation peaked $40 \%\left({ }^{\circ} \mathrm{C}\right)$ higher than that of the experiment. At 500 seconds both the simulation and the experiment are $1000{ }^{\circ} \mathrm{C}\left(1830{ }^{\circ} \mathrm{F}\right)$ at the ceiling and decreasing at a similar rate. By the end of the simulation the ceiling temperatures decreased to $800{ }^{\circ} \mathrm{C}\left(1470{ }^{\circ} \mathrm{F}\right)$ in both cases. The lower level gas temperatures are lower than the experimental temperatures due to radiation effects as documented previously.

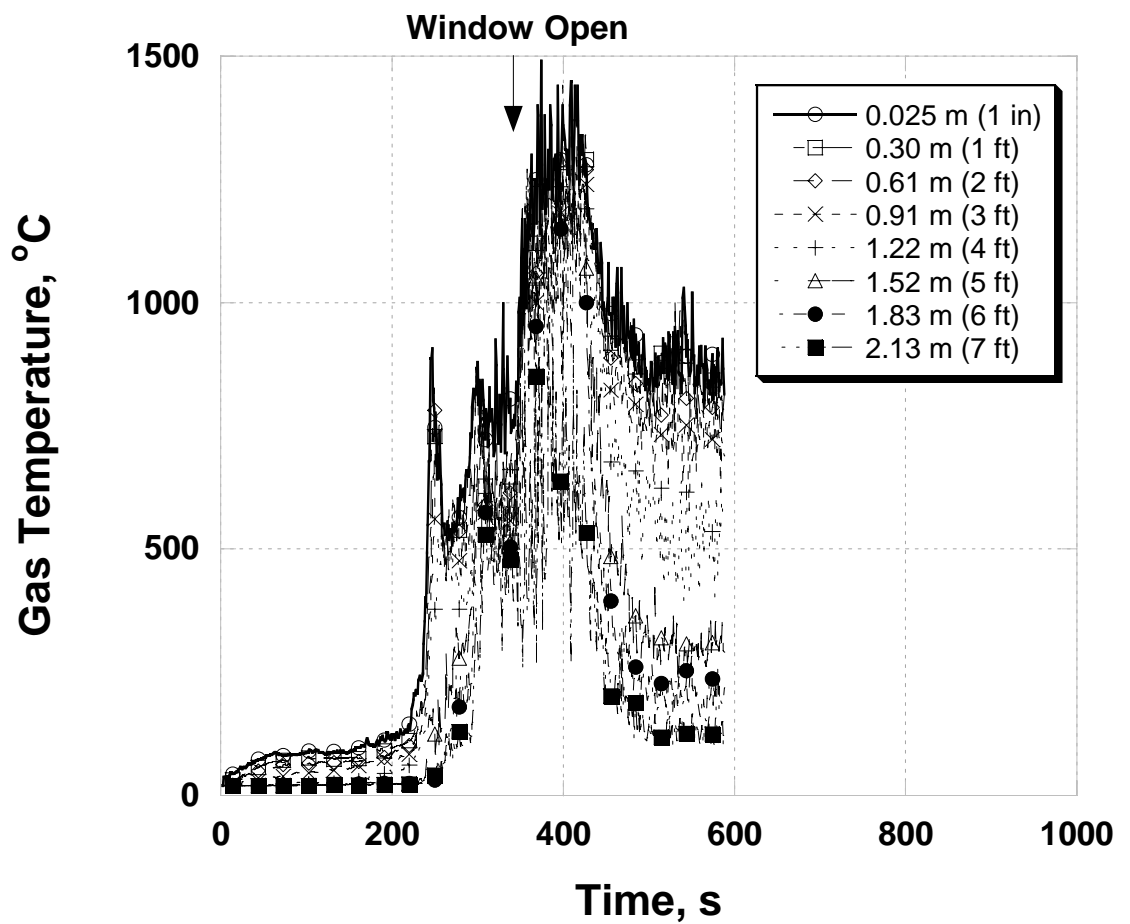

Figure 4-82. FDS PPV Ventilated Room Temperatures 
Figure 4-83 presents the gas temperatures predicted in the fire room doorway. The simulation prediction points correspond to the measurements shown in Figure 4-31 (on page 69). The temperatures at all three points correspond well between both cases. Top temperatures fluctuate between $600{ }^{\circ} \mathrm{C}\left(1110{ }^{\circ} \mathrm{F}\right)$ and $800{ }^{\circ} \mathrm{C}\left(1470{ }^{\circ} \mathrm{F}\right)$ prior to ventilation, peak at $1000{ }^{\circ} \mathrm{C}\left(1830{ }^{\circ} \mathrm{F}\right)$ to $1250{ }^{\circ} \mathrm{C}\left(2280{ }^{\circ} \mathrm{F}\right)$ after ventilation and decline to $600{ }^{\circ} \mathrm{C}\left(1110{ }^{\circ} \mathrm{F}\right)$ at the end of the simulation. Contrary to the previous lower level temperatures that were under-predicted due to radiation effects, the temperatures in the lower half of the door in this simulation match well with the experiment. This could be due to the decrease in radiation effects due to increased amounts of ambient air being forced past the bare-bead thermocouples in the experiment.

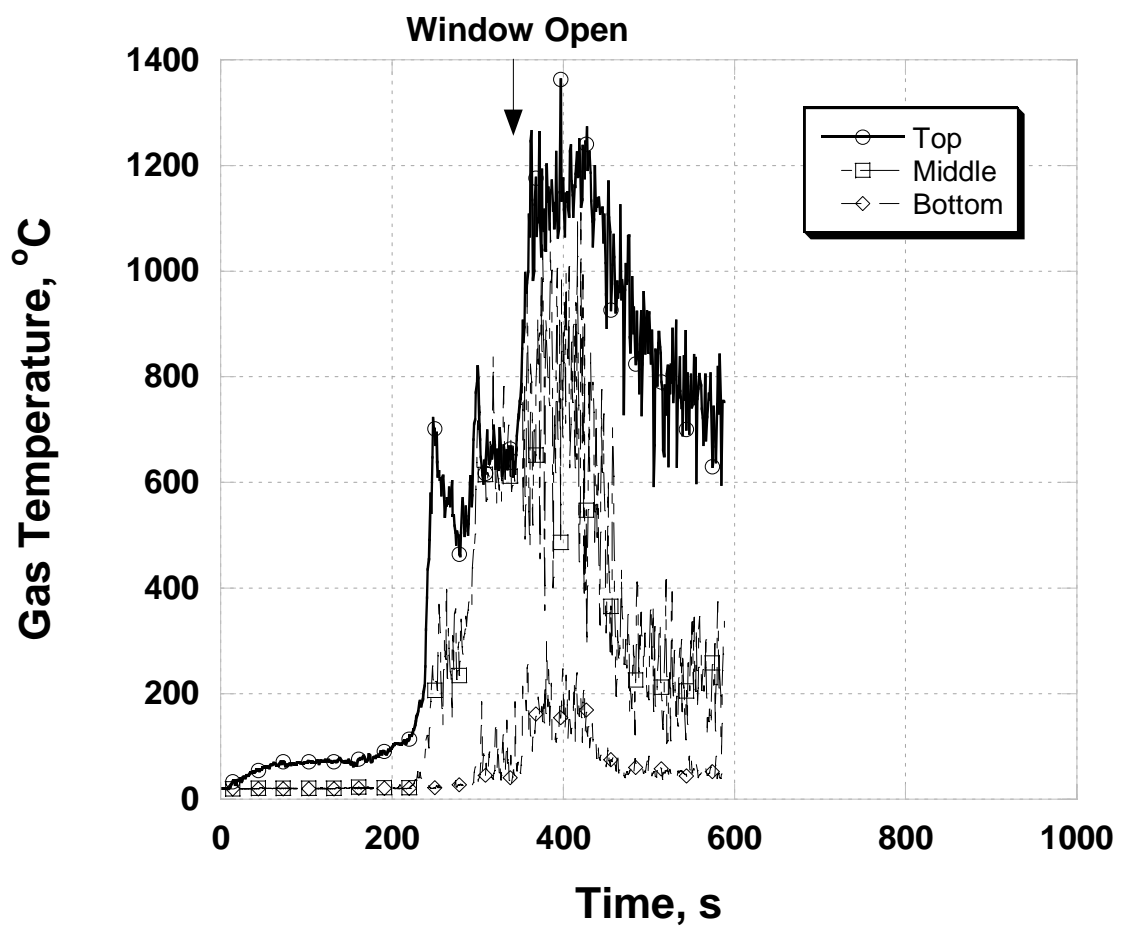

Figure 4-83. FDS PPV Ventilated Room Doorway Temperatures 
Figure 4-84 shows the simulated corridor doorway temperatures that are compared to the experimental values in Figure 4-35 (on page 73). The temperatures in the top third of the doorway increase accurately but become greatly over-predicted as the window is opened and the temperatures peak. For approximately 50 seconds after ventilation the simulated temperatures are double those in the experiment. This corresponds to the slightly longer time the fan in the simulation took to turn the flow around and out the window than the experimental fan. The lower level temperatures remained low in both cases as ambient air was being pulled directly in from the outside.

Figure 4-85 displays the gas velocities exiting the room out of the window. There is no bidirectional flow as the fan is turned on 5 seconds after the window is opened. These velocities are compared to the experimental velocities in Figure 4-39 (on page 77). Simulated velocities ranged from $6 \mathrm{~m} / \mathrm{s}(20 \mathrm{ft} / \mathrm{s})$ to $12 \mathrm{~m} / \mathrm{s}(39 \mathrm{ft} / \mathrm{s})$ at the time of ventilation as compared to experimental values of $10 \mathrm{~m} / \mathrm{s}(33 \mathrm{ft} / \mathrm{s})$ to $19 \mathrm{~m} / \mathrm{s}(62 \mathrm{ft} / \mathrm{s})$. In both cases the velocities decreased at a similar rate following the peak as the fire decreased in magnitude. The addition of the fan in the simulation caused a $3 \mathrm{~m} / \mathrm{s}$ $(10 \mathrm{ft} / \mathrm{s})$ to $5 \mathrm{~m} / \mathrm{s}(16 \mathrm{ft} / \mathrm{s})$ in max velocity which is the same as the increase seen in the experiment. This correlation is favorable for FDS's ability to capture the bulk effect of the PPV fan. 


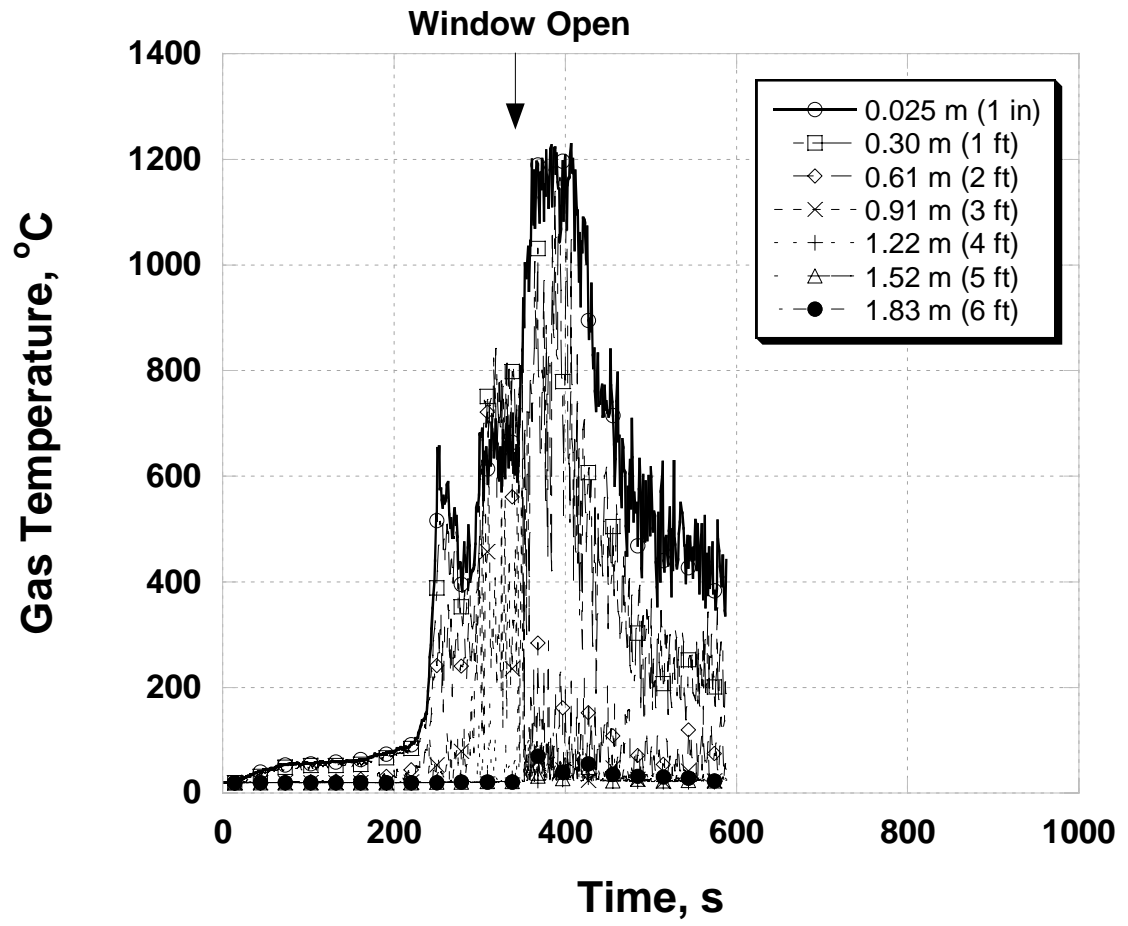

Figure 4-84. FDS PPV Ventilated Corridor Doorway Temperatures

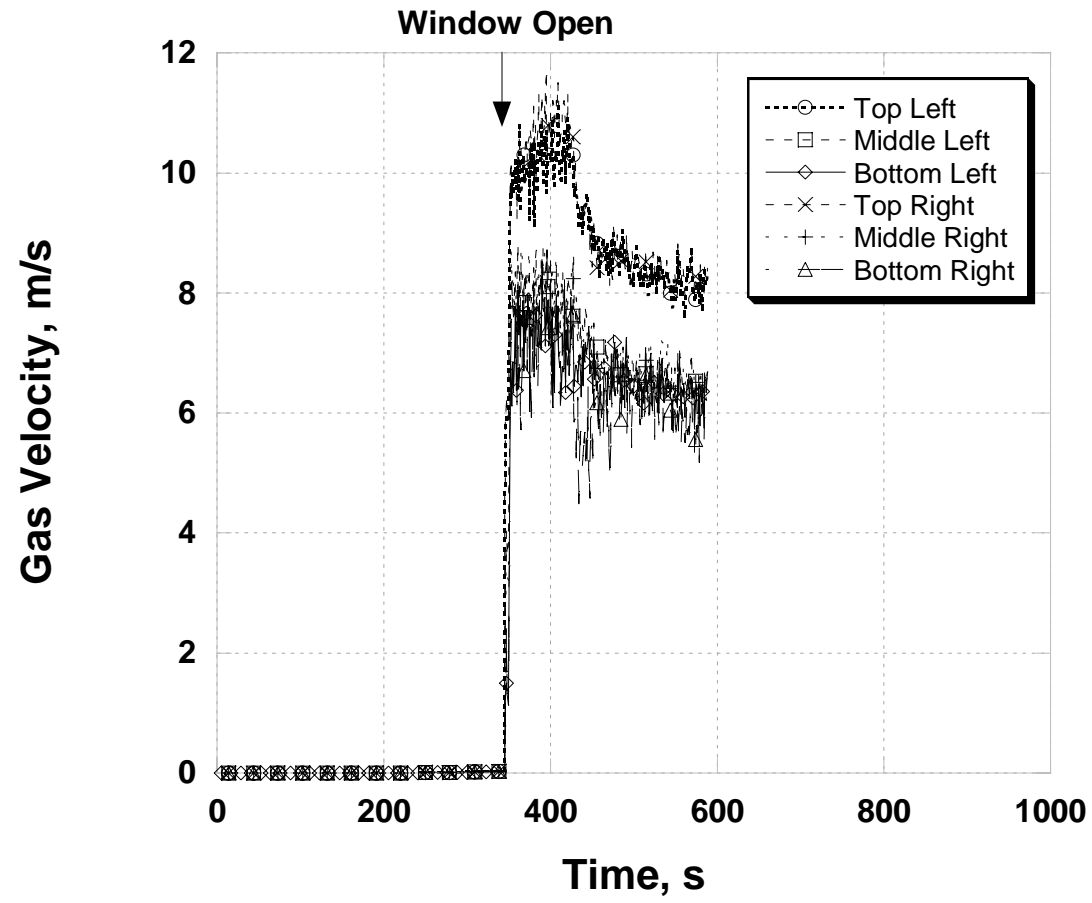

Figure 4-85. FDS PPV Ventilated Window Velocities 
Figure 4-86 displays the gas velocities entering and exiting the room through the room's doorway. There is bidirectional flow as the fan was not able to completely reverse the fire flow at the plane of the doorway. These velocities are compared to the experimental velocities in Figure 4-41 (on page 80). Simulated velocities ranged from $-6 \mathrm{~m} / \mathrm{s}(-20 \mathrm{ft} / \mathrm{s})$ to $5 \mathrm{~m} / \mathrm{s}(16 \mathrm{ft} / \mathrm{s})$ at the time just after ventilation as compared to experimental values of $-6 \mathrm{~m} / \mathrm{s}(-20 \mathrm{ft} / \mathrm{s})$ to $6 \mathrm{~m} / \mathrm{s}(20 \mathrm{ft} / \mathrm{s})$. In both cases the flow was out of the room at the top and into the room at the middle and bottom of the doorway. The addition of the fan in the simulation caused a $2 \mathrm{~m} / \mathrm{s}(7 \mathrm{ft} / \mathrm{s})$ to $4 \mathrm{~m} / \mathrm{s}(13 \mathrm{ft} / \mathrm{s})$ increase in maximum velocity which is the same as the increase seen in the experiment. This correlation is favorable for FDS's ability to capture the bulk effect of the PPV fan as the air is forced into the room.

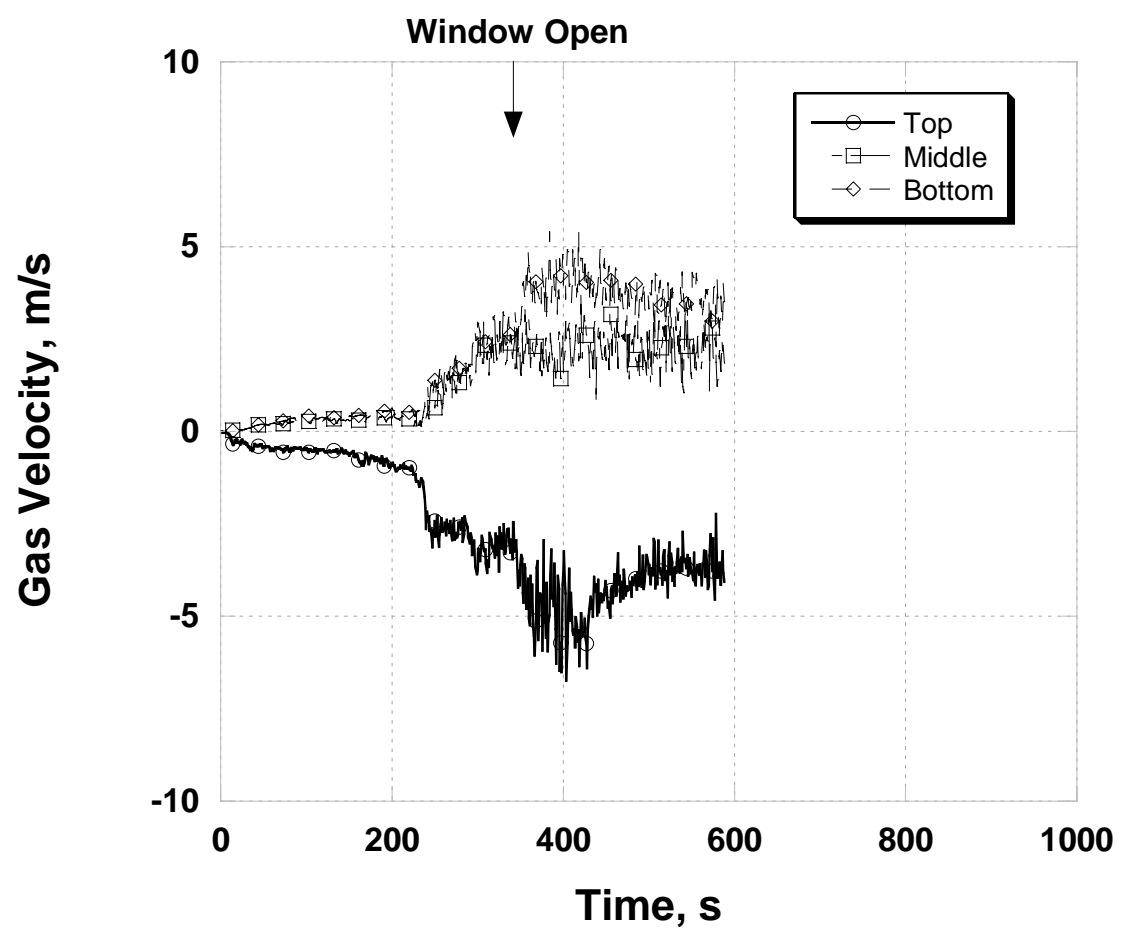

Figure 4-86. FDS PPV Ventilated Room Doorway Velocities 


\subsection{Discussion}

Previous work regarding the impact of positive pressure ventilation on gas temperature, window gas velocity, and mass burning rate has been investigated using different fuel packages and different room/structural configurations. Stott studied typical home furnishings in a single story structure. Svensson utilized flammable liquid fires in three rooms of a larger structure. Ezekoye employed a polyurethane foam fuel in a 4 room residential structure. Different capacity PPV fans were utilized by each study. Instrumentation typically included upper and lower layer gas temperatures and one experimental series included pressure transducers for monitoring gas velocities.

Stott [15] conducted a series of experiments in Preston, U.K. utilizing furnished rooms. These experiments were instrumented with thermocouples but also relied upon subjective feedback from the participants that suppressed the fire or watched from outside. These experiments showed that there was a minor temperature elevation after the use of the fan, approximately $10{ }^{\circ} \mathrm{C}\left(18{ }^{\circ} \mathrm{F}\right)$. The experiments also demonstrated that there was no flame extension to the corridor, the temperature decreased and the visibility improved after the initiation of PPV. The report also stated that the fire growth rate was not greatly increased by the fan. The increase in burning rate as PPV was initiated is consistent with the data collected by this study for a single furnished room. 
Svensson [16] of the Swedish Rescue Services Agency also conducted an experimental study of ventilation during fire fighting operations. This experimental setup utilized three rooms on the first floor of a fire training facility. A $0.5 \mathrm{~m}(1.6 \mathrm{ft})$ diameter heptane pool fire was utilized which generated a heat release rate of $0.37 \mathrm{MW}$. This was a significantly smaller fire (in terms of heat release rate) than the fully furnished rooms in these experiments which released heat at a rate of 11 MW to 14 MW. The smaller heat release rate heptane pool fire generated much lower temperatures, $300{ }^{\circ} \mathrm{C}\left(570{ }^{\circ} \mathrm{F}\right)$, than was monitored in the furnished room, $800{ }^{\circ} \mathrm{C}$ (1470 $\left.{ }^{\circ} \mathrm{F}\right)$. Svensson did report an increase of $40 \%$ in the burning rate after PPV was initiated. This is comparable to the $60 \%$ increase that was produced in the furnished room in this study. The furnished room had a greater fuel surface area which would have been consistent with the difference in the burning rate. Svensson also reported significantly lower pressure differentials. The larger room size may account for some of this difference but the main reason is likely the smaller fan output. The fan used in Svensson's experiments was rated at approximately one third that of the one used in these experiments. This difference in fan size is also consistent with the smaller flows that were recorded in Svensson's experiments.

Another set of experiments was conducted in the United States by Ezekoye, Lan and Nicks [17] of the University of Texas at Austin. These experiments examined positive pressure attack for heat transport in a house fire. The fuel source chosen for those experiments was $9 \mathrm{~kg}$ (19.8 lb) of polyurethane foam, oriented on a rack, capable of generating a peak heat release rate per unit area of $1.2 \mathrm{MW} / \mathrm{m}^{2}$. This fuel 
package produced temperatures of $760{ }^{\circ} \mathrm{C}\left(1400{ }^{\circ} \mathrm{F}\right)$ at the ceiling and $200{ }^{\circ} \mathrm{C}\left(390{ }^{\circ} \mathrm{F}\right)$ at the lower levels but did not appear to cause post flashover conditions that were present in the furnished room fire experiments. The fan flow rate was similar to the one used in the furnished room. The mixing which caused higher temperatures in the lower layer are seen in both sets of experiments. Those experiments only reported temperatures so pressure differential, burn rate and gas flow velocity could not be compared.

There has been very little documented computational fluid dynamics modeling of positive pressure ventilation. The only other documented FDS modeling is briefly explained in the University of Texas at Austin report [17]. In these simulations the fan is prescribed as a single vent at the face of the door. These simulations do not examine the effects of the fan on the fire and only look at the temperatures in a victim room. The authors report that the FDS simulations created similar trends but there are no figures displaying the correlations.

Another CFD model, SOFIE, was used by Gojkovic and Bengtsson [18] in Sweden to examine the possibility of backdraft conditions. A three room setup was used to examine the possible effects of PPV both correctly and incorrectly on an underventilated fire. The fan was prescribed as an inflow boundary in the front door. The authors state, "an inflow boundary does not simulate the characteristics of the fan very well.” The authors also concluded that the PPV causes increased mixing and increased chance of backdraft but for a short duration. 


\subsection{Room Fire Summary}

Compared to natural ventilation, positive pressure ventilation caused lower fire room temperatures, increased window gas flows and higher pressure differentials for this set of furnished room burns. After the peak heat release rate was reached in both experiments, the temperatures with PPV remained $200{ }^{\circ} \mathrm{C}\left(360{ }^{\circ} \mathrm{F}\right)$ to $400{ }^{\circ} \mathrm{C}\left(720{ }^{\circ} \mathrm{F}\right)$ below the temperatures with natural ventilation for 800 seconds. The doorway temperatures with PPV peaked 200 seconds before, but quickly dropped to $200{ }^{\circ} \mathrm{C}$ $\left(390{ }^{\circ} \mathrm{F}\right)$ to $500{ }^{\circ} \mathrm{C}\left(930^{\circ} \mathrm{F}\right)$ below the naturally ventilated temperatures for 900 seconds following the peak in the PPV experiment. The window gas temperatures generated during the PPV experiment peaked 200 seconds before gas temperatures at the same location in the naturally ventilated experiment. In the naturally ventilated experiment, gas temperatures in the top two thirds of the window were higher than the PPV experiment, but gas temperatures in the bottom third were lower due to the inflow of air. Once the fan was running, the PPV corridor temperatures were as much as $500{ }^{\circ} \mathrm{C}\left(930{ }^{\circ} \mathrm{F}\right)$ less than comparable temperatures in the naturally ventilated experiment.

The PPV fan alone generated gas velocities of $5 \mathrm{~m} / \mathrm{s}(16 \mathrm{ft} / \mathrm{s})$ in the window while the naturally ventilated fire generated velocities of nearly $12 \mathrm{~m} / \mathrm{s}$ (39 ft/s). In the experiment with the PPV fan, window gas velocities of nearly $20 \mathrm{~m} / \mathrm{s}$ (66 ft/s) were generated, approximately equal to the additive velocities from the fan and the naturally ventilated fire. The fan quickly forced a unidirectional flow out of the window but took a period of time to completely reverse the flow out of the doorway 
and create a flow into the room. The fan was able to create a more tenable atmosphere as soon as it was turned on by reversing the natural flow out of the corridor, where the fire fighters would be approaching the fire for extinguishment.

The heat release rate of the fire was increased by the fan for the 200 seconds following the peak heat release rate. This is critical because this is the time period during which the fire department would typically be advancing to extinguish the fire. The peak heat release rate for the two experiments occurred at approximately the same time and the rate with the PPV fan was 2 MW higher. The PPV fan caused a $60 \%$ increase in burning rate during this time of initial fire department attack. This reinforces the importance of selecting a ventilation location close to the seat of the fire that allows for all of the combustion products to be ventilated to the exterior of the structure. The PPV ventilated experiment forced the flames at least $1.83 \mathrm{~m}(6 \mathrm{ft})$ out of the room as compared to the $0.91 \mathrm{~m}$ ( $3 \mathrm{ft}$ ) by the naturally ventilated experiment. Flame extension out of the building openings may pose a potential ignition hazard to materials nearby.

While the use of PPV in this particular configuration caused an increase in the room's fire burning rate, it lowered the temperatures in the room, forced all of the combustion products to flow out of the room without affecting the corridor and improved the visibility leading up to and in the room itself. In this experimental configuration a fire fighting team would likely have been able to attack the PPV ventilated fire more easily than the naturally ventilated fire. 
This limited data set indicates that coordination of fire fighting crews is essential to carry out positive pressure ventilation in the attack stages of a fire. In this experiment, ideal coordination was simulated as the window was ventilated in the correct location and the fan was initiated seconds later. Once the fan was turned on, it took approximately 60 seconds to 90 seconds for the fire to reach its peak burning rate and the flow was forced away from the entrance. After this transition, the fire remained at a steady burning rate until the fuel was consumed. This would indicate that for the conditions in this experiment fire fighters should delay 60 seconds to 120 seconds after ventilation and fan start before advancing towards the fire. This would allow the flows to stabilize, temperatures to decrease and visibility to improve. The burning rate of the fire could become steady at the rate determined by the modified air flow and would be less likely to rapidly change as the fire fighters approach. The time to reach this new steady condition could vary with building layout, fire size, fuel load and fan capacity.

The visual and numerical comparisons demonstrate that the fire behavior of a room fire both with and without positive pressure ventilation can be successfully modeled by FDS and visualized with Smokeview. Minor differences exist in the geometry and material properties but the fire dynamics and the net impact of the positive pressure ventilation fan can be captured with a degree of accuracy. 
The heat release rate, gas temperature and gas velocity comparisons show reasonable agreement between the experiments and the model in terms of both trends and range. Again some differences were displayed in the gas temperatures due to radiative effects but that has been documented in other experiments as well [13]. Future simulations should utilize the "THERMOCOUPLE" identification of measurement points instead of "temperature" to better compare the simulation results to experimental results by incorporating the radiative effects in the model as well. The two experiments simulated using FDS, accurately quantified the effects of a positive pressure ventilation fan on a post flashover room fire, and support the use of the model fan on larger scale scenarios that may not be able to be supported by full scale experimental data. 


\section{Chapter 5: Colonial House Practical Scenario}

\subsection{Scenario Overview}

In order to expand the understanding of the effects of positive pressure ventilation it would be very informative to perform experiments in various types of full-scale structures. These structures are very difficult to obtain and very expensive to instrument. Using the lab scale tests documented above as a calibration for the FDS, it is possible to visualize the effects of positive pressure ventilation applications in full-scale scenarios.

A colonial house was chosen due to the potential for many firefighting scenarios. The house has two floors and a basement. The first floor is made up of a study, living room, dining room, kitchen, bathroom, laundry room, sun room, family room and garage. The second floor has four bedrooms and two bathrooms. The basement has an open floor plan and is unfinished.

Two scenarios were examined with a fire in the rear bedroom of the second floor. The fire started next to the bed to simulate a fire that originated in a trashcan. The doors to all of the rooms on the floor were open and the fire grew without intervention for the first 240 seconds. At 240 seconds in both scenarios the front door was removed (opened) to simulate the fire department's arrival at the front door.

Five seconds after the front door opened, the window to the fire room was removed to simulate the fire department venting the fire room. One simulation allowed the fire 
to behave with no other fire department intervention and the second scenario a positive pressure ventilation fan located at the front door was activated at 250 seconds. The purpose of the two scenarios was to analyze the impact of the addition of the positive pressure ventilation fan to the fire conditions.

The simulations were run for 800 seconds. They provide insight into the potential fire development and spread and the potential impact of the positive pressure ventilation implementation. Issues that are addressed include the fans' effect on fire growth, smoke spread, temperatures, oxygen concentrations and velocities in the pathway to the fire room potentially occupied by fire fighters and tenability criteria of adjacent rooms to the fire room that could be occupied by victims of the fire.

\subsection{Computer Simulations}

\subsubsection{Domain}

The computational domain used for this analysis measured $16.4 \mathrm{~m}$ (53.8 ft) wide $\mathrm{x}$ 13.9 m (45.6 ft) deep x 10.0 m (32.8 ft) tall. The computational domain was divided into 3 grids (Figure 5-1). The grid containing the basement (grid 1) measured $16.4 \mathrm{~m}$ (53.8 ft) wide x $13.9 \mathrm{~m}(45.6 \mathrm{ft})$ deep x $2.5 \mathrm{~m}(8.2 \mathrm{ft})$ tall. The grid containing the

first floor (grid 2) measured 16.4 m (53.8 ft) wide x 13.9 m (45.6 ft) deep x 3.125 m

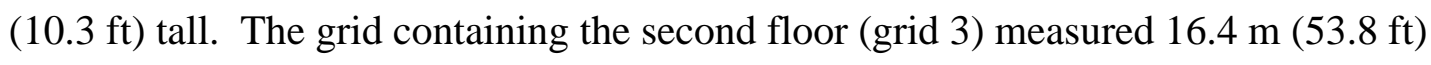
wide x 13.9 m (45.6 ft) deep x $4.4 \mathrm{~m}$ (14.4ft) tall. All three grids were composed of 
$0.15 \mathrm{~m}$ (6 in) cubic grid cells. The domain contained a total of 636,000 grid cells (Figure 5-2).

The use of 3 grids or "multiple meshes" allowed the simulations to be parallel processed. The three meshes were processed on three separate CPU's which greatly reduced computational time. Each mesh contained the same size grid cells which allowed for optimum sharing of data from mesh to mesh. The governing equations were solved with a time step based on the flow speed in the particular meshes. Due to the fact that each mesh can have different time steps, this saves CPU time by updating the meshes only when necessary. When the fan was added for the PPV simulation the boundaries to its domain were also open and the vents for the fan were located as described in chapter 1 (Figure 5-3).

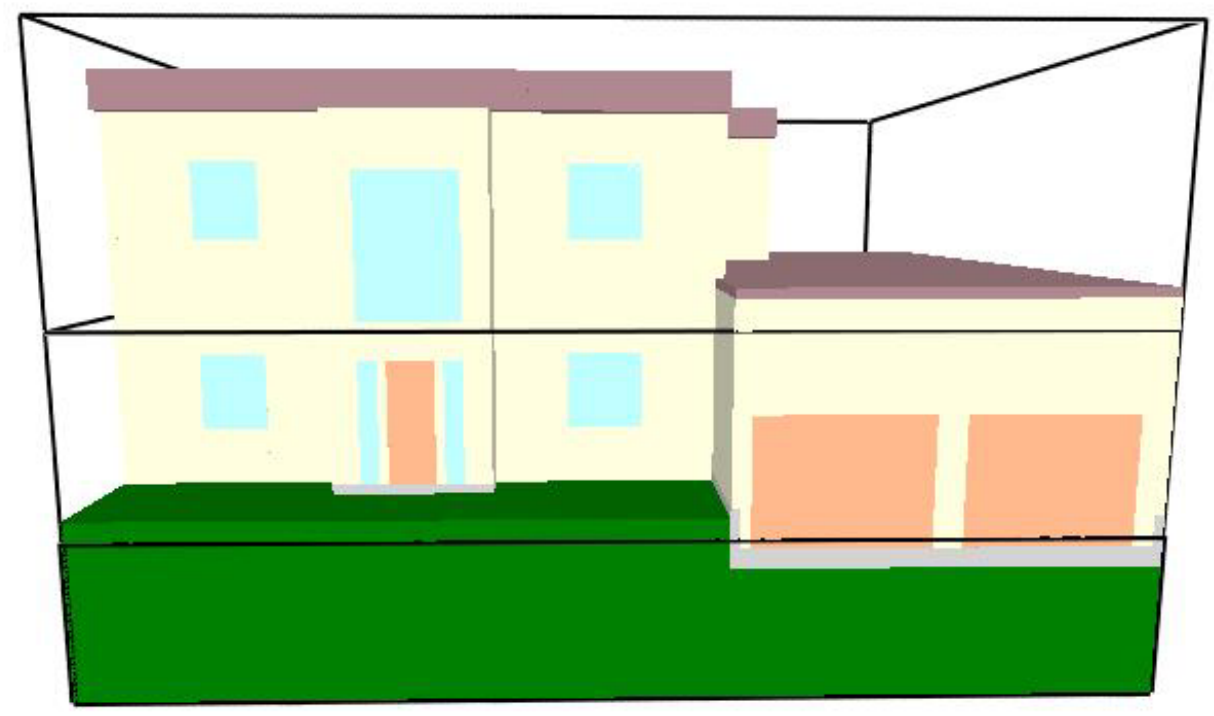

Figure 5-1. Colonial House and Grid Locations 

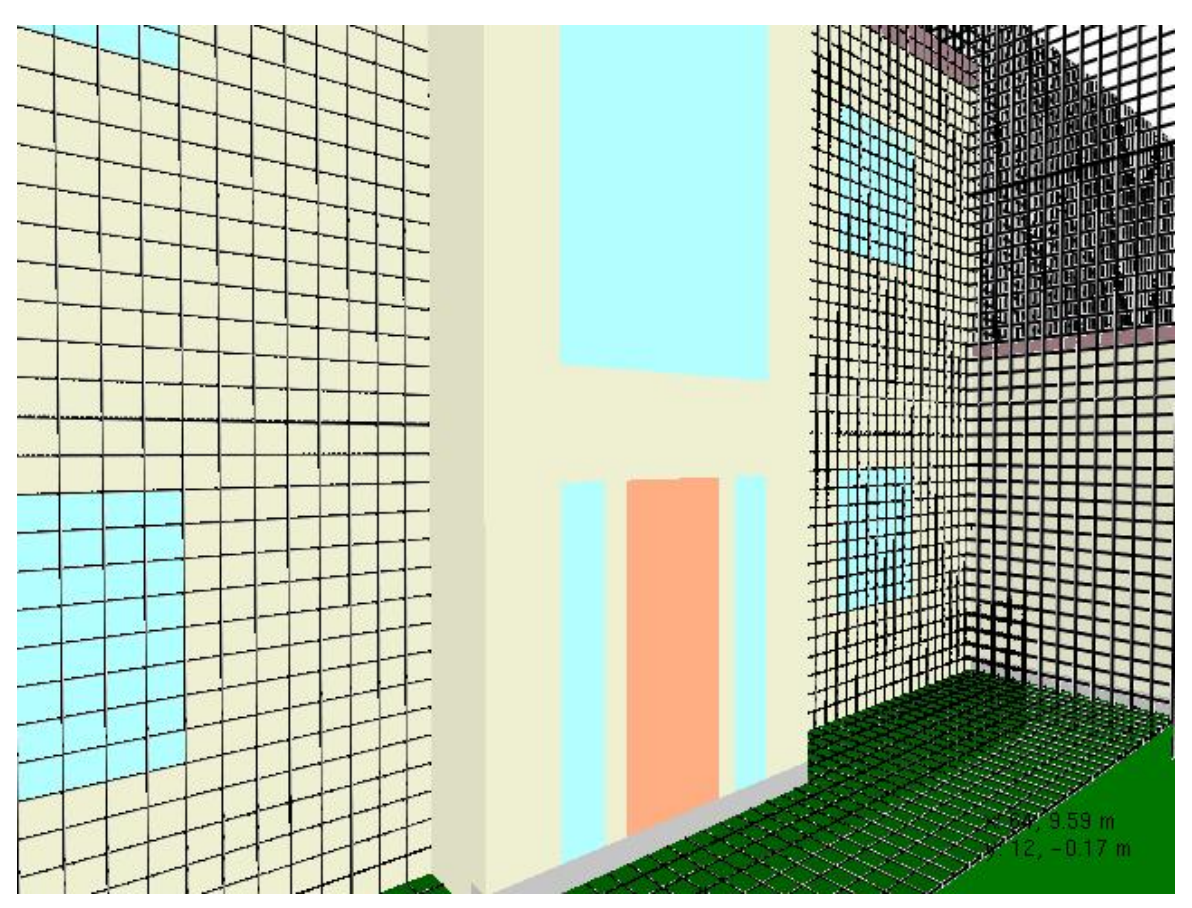

Figure 5-2. Display of Grid Cell Size

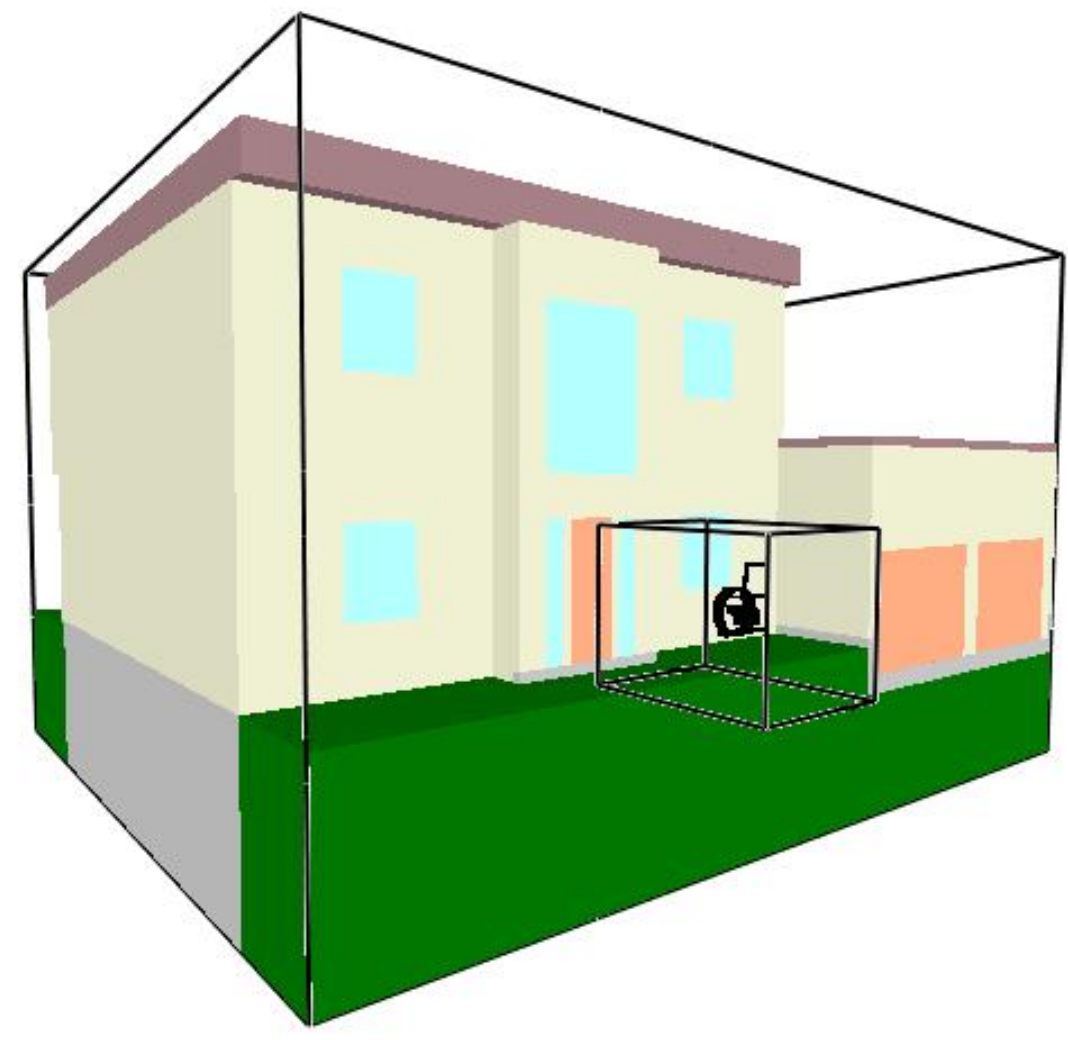

Figure 5-3. Colonial House and PPV Fan Placement 


\subsubsection{Geometry}

The floor plans of the house are shown in Figures 5-4 through 5-11. The size and location of the walls, doorways, windows and furniture are based on the floor plans.

All of these obstructions are adjusted by FDS to correspond to the nearest computational cell location. This results in objects, used in the model, that appear thicker then they would be in reality.

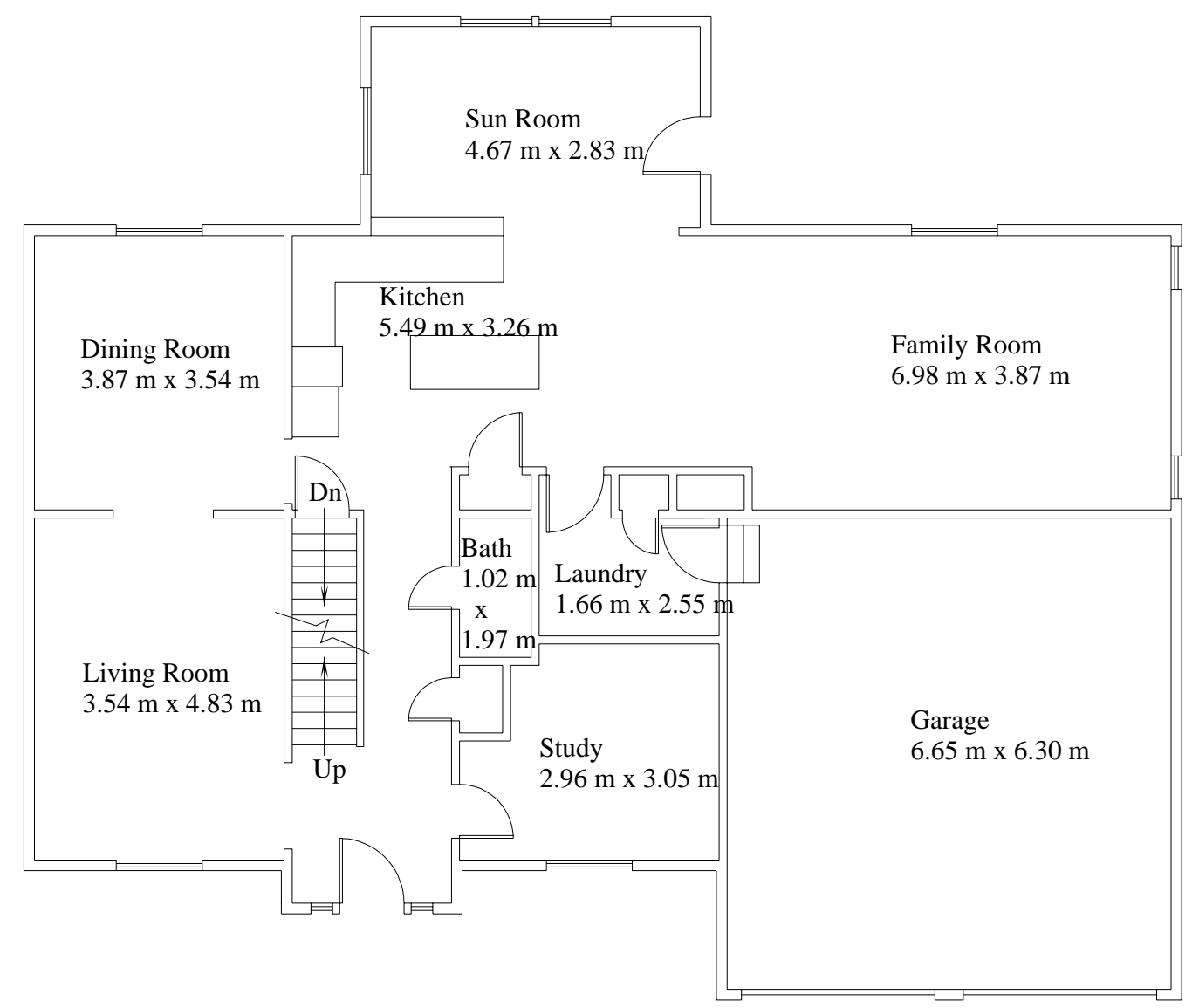

Figure 5-4. Floor Plan of First Floor 


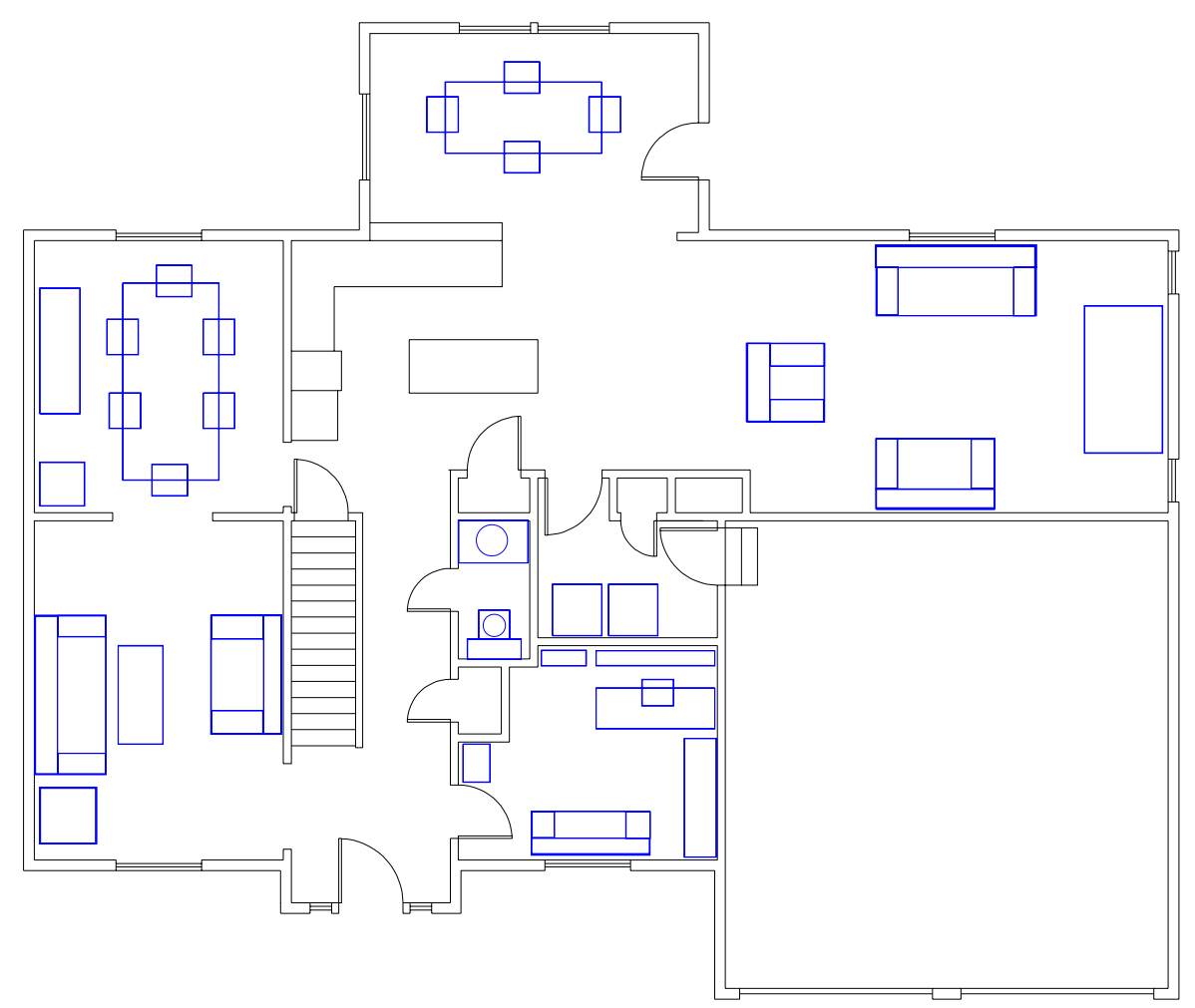

Figure 5-5. Furniture Locations on First Floor

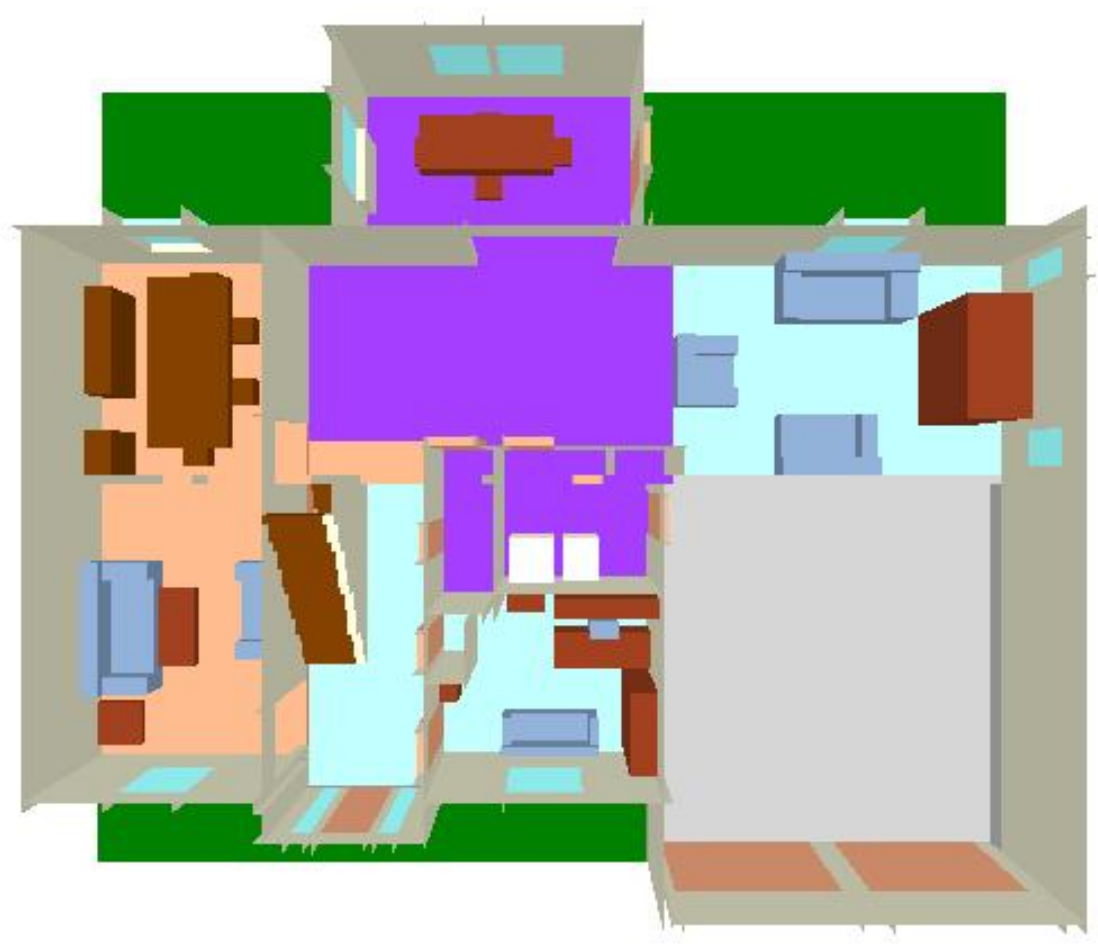

Figure 5-6. Smokeview Display of First Floor 


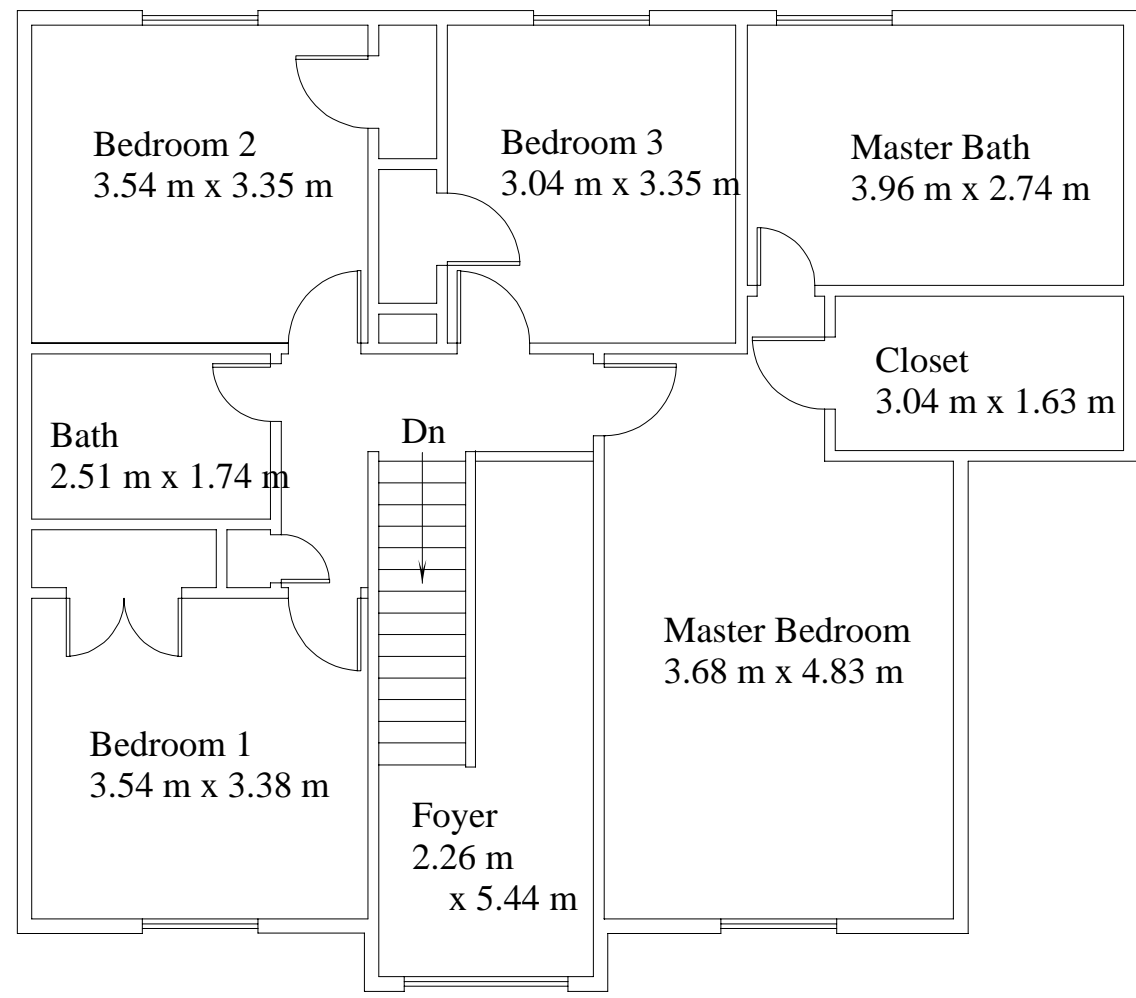

Figure 5-7. Floor Plan of Second Floor

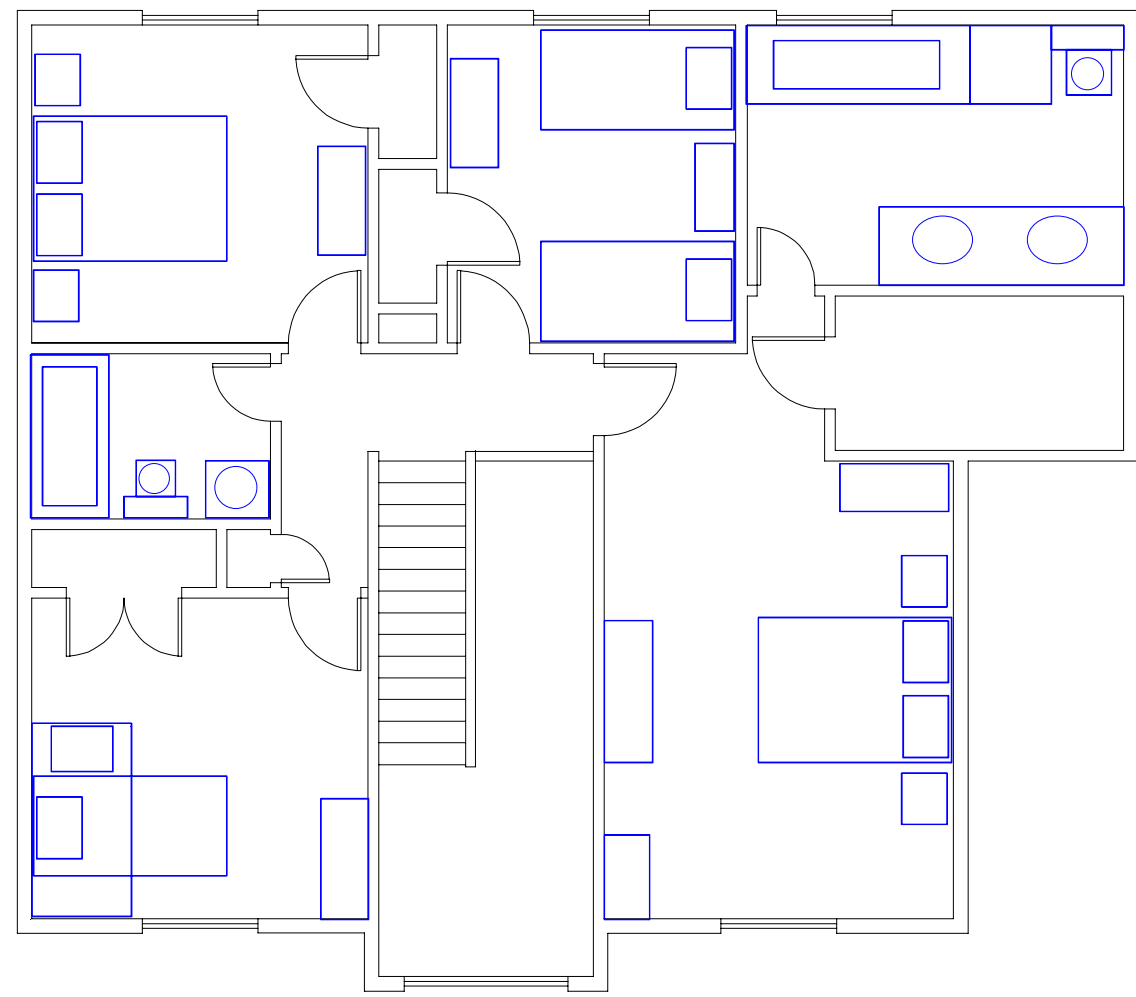

Figure 5-8. Furniture Locations on Second Floor 


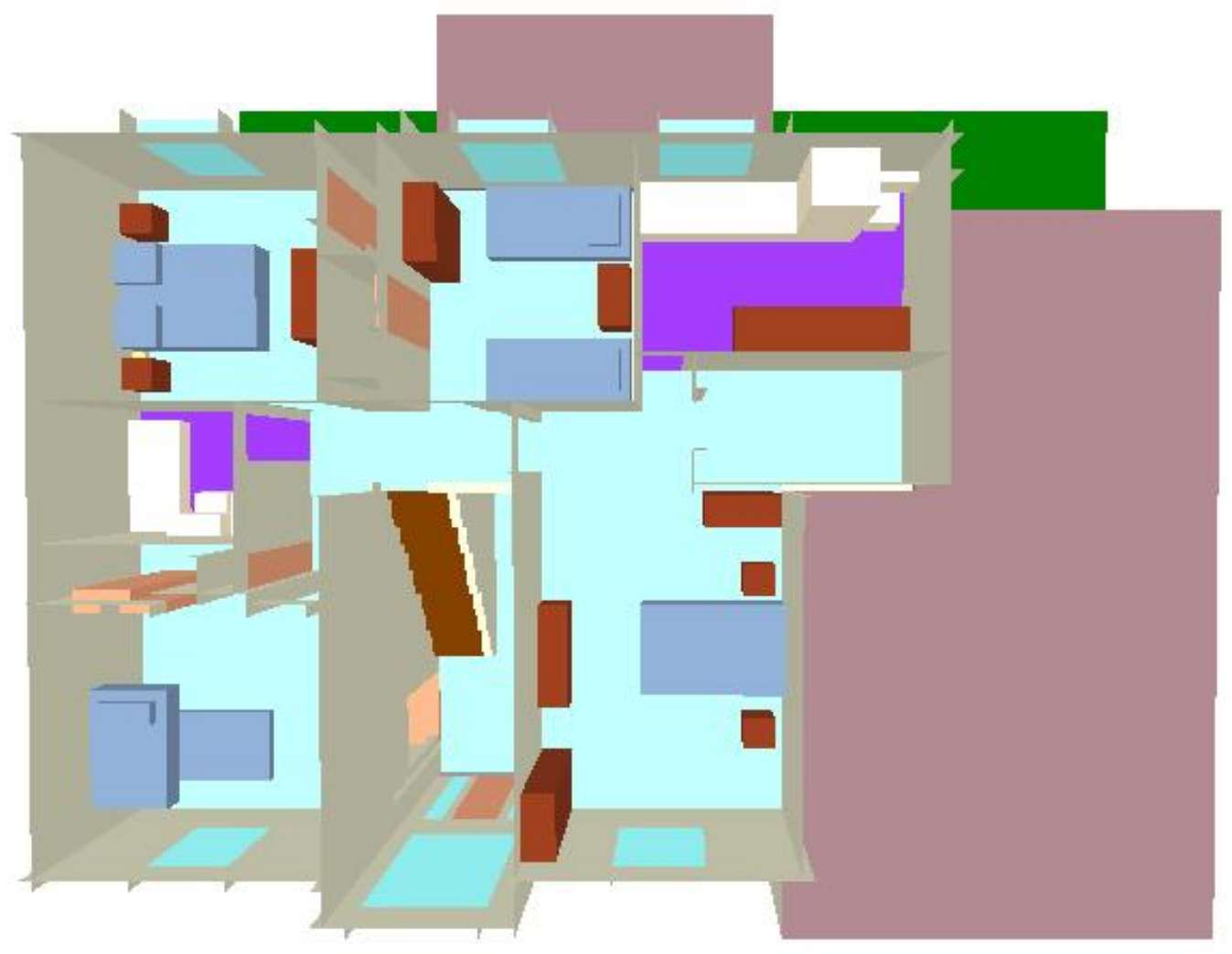

Figure 5-9. Smokeview Display of Second Floor 


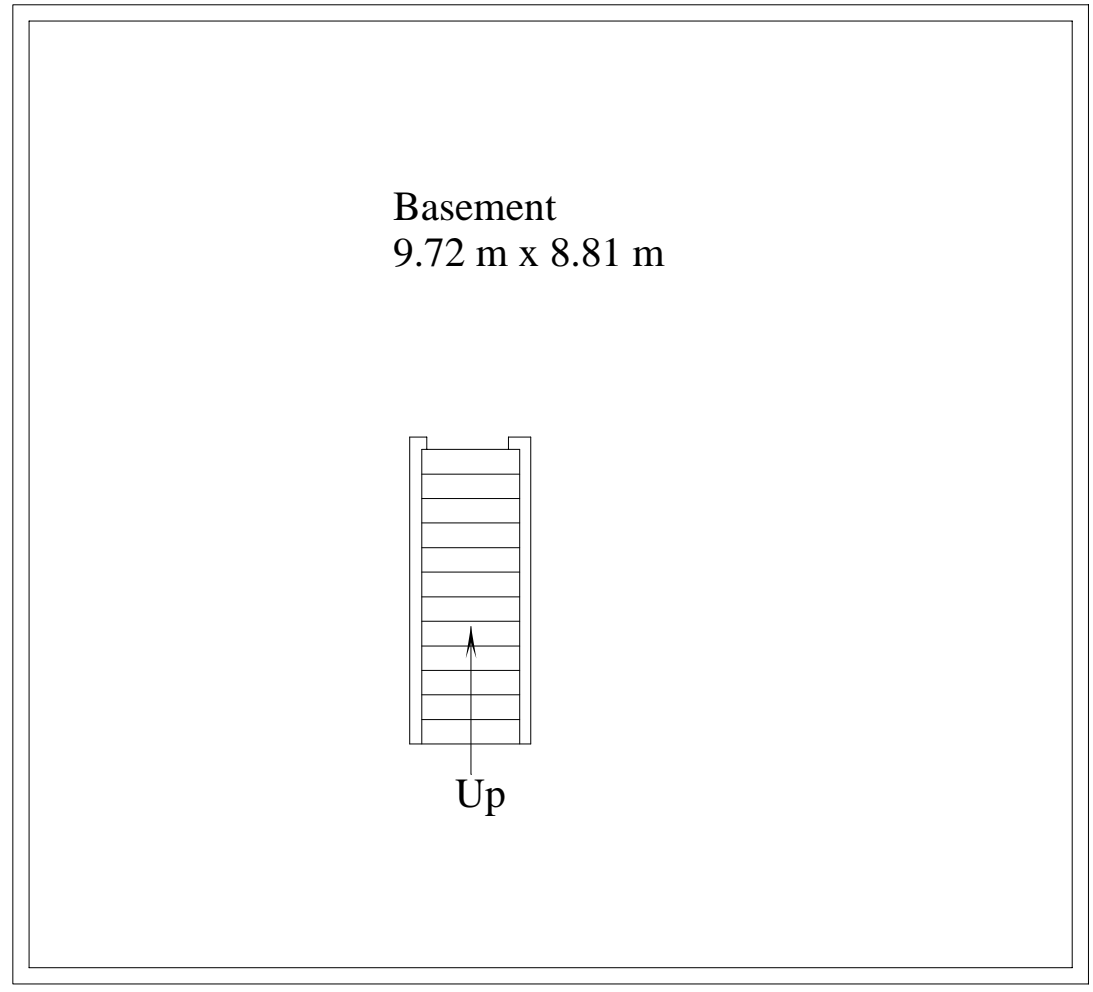

Figure 5-10. Basement Floor Plan

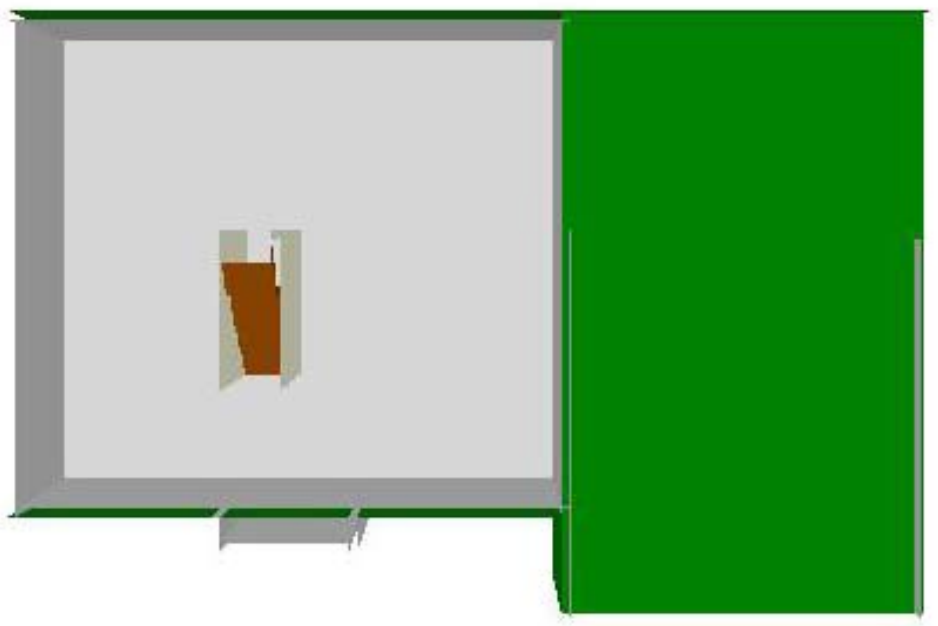

Figure 5-11. Smokeview Display of Basement 


\subsubsection{Vents}

This simulation considered seven vents or openings from the structure to the outside, the front door, the window of the fire room, and five small openings to the roof area. The front door was $0.76 \mathrm{~m}(2.5 \mathrm{ft})$ wide x $2.0 \mathrm{~m}(6.7 \mathrm{ft})$ high. This vent was opened at 240 seconds in both scenarios. The window of the fire room measured $1.1 \mathrm{~m}$ (3.5 ft) wide x $1.25 \mathrm{~m}$ (4.1 ft) high with a $0.8 \mathrm{~m}$ (2.6 ft) sill height (Figure 5-12). This vent was opened at 245 seconds in both scenarios. The small openings in the second floor were placed in all four bedrooms and in the master bathroom to simulate air vents and leaks to the roof area. The front and rear edges of the roof area were open to the exterior of the house to simulate the eaves and leaks of the roof. The small openings to the roof measured $0.3 \mathrm{~m}(1.0 \mathrm{ft})$ long $\mathrm{x} 0.15 \mathrm{~m}(0.5 \mathrm{ft})$ wide

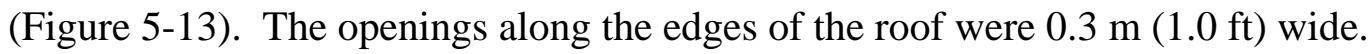
The openings in the ceiling and the roof edges were also open over the entire duration of the simulation.
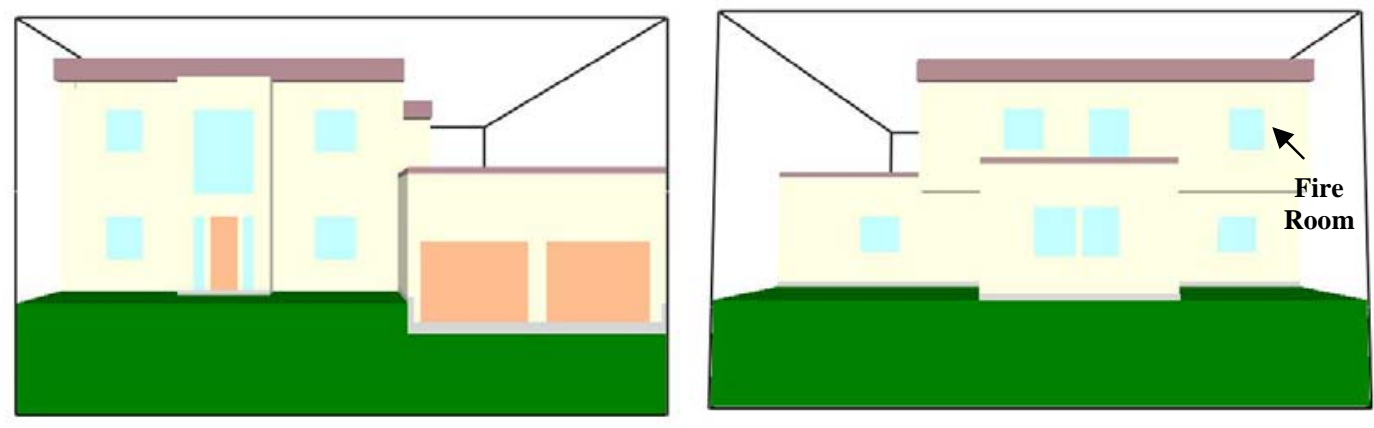

Figure 5-12. Front and Rear View of House 


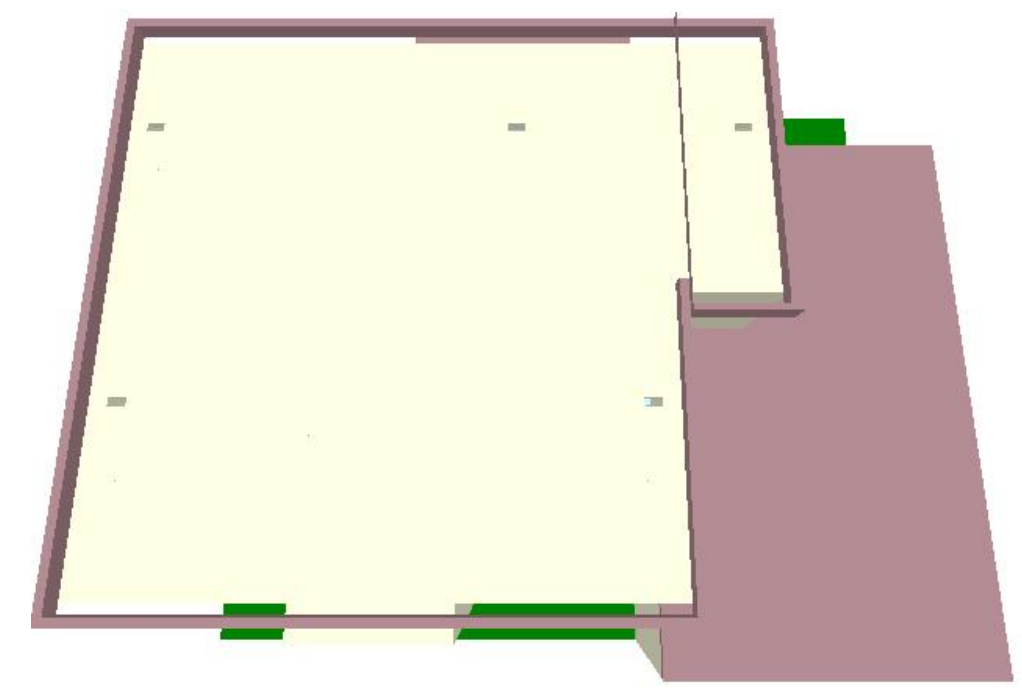

Figure 5-13. Location of Room Vents with Roof Removed

\subsubsection{Materials}

Each obstruction in the domain was given a set of physical and thermal properties that were used in the calculation. Each wall, ceiling, floor and piece of furniture is defined with properties such as ignition temperature, heat of vaporization, density and thickness (see Table 9). All of the walls and the ceiling of the house were gypsum board and the floor was covered in carpet. The primary fuels in the house were upholstery and oak. Figure 5-14 displays a view from inside the front door. Many materials can be identified, the brown steps are oak, the white walls are gypsum board, the light blue floor is carpet, the orange floor is also carpet (aesthetic purposes only) and the light blue couch is upholstery. All of the material properties were derived from the FDS database [6]. 
Table 9. Colonial FDS Input Material Properties

\begin{tabular}{|l|c|c|c|c|}
\hline \multicolumn{1}{|c|}{ Material } & $\begin{array}{c}\text { Ignition } \\
\text { Temperature } \\
\left({ }^{\circ} \mathrm{C}\right)\end{array}$ & $\begin{array}{c}\text { Thickness } \\
(\mathrm{m})\end{array}$ & $\begin{array}{c}\text { Heat Release Rate } \\
\text { Per Unit Area } \\
\left(\mathrm{kW} / \mathrm{m}^{2}\right)\end{array}$ & $\begin{array}{c}\text { Heat of } \\
\text { Vaporization } \\
(\mathrm{kJ} / \mathrm{kg})\end{array}$ \\
\hline Upholstery & 280 & 0.02 & 500 & 1700 \\
\hline Oak & 340 & & & 4000 \\
\hline Plastic & 370 & & 100 & 3000 \\
\hline Carpet & 280 & 0.013 & N/A & N/A \\
\hline Gypsum Board & 400 & 0.0013 & & 2500 \\
\hline Sheet Metal & N/A & 0.02 & N/A & N/A \\
\hline Pine & N/A & 0.2 & N/A & N/A \\
\hline Concrete & N/A & 0.005 & & N/A \\
\hline Glass & N40 & 0.005 & & \\
\hline Thin Oak & N/A & 1.0 & & \\
\hline Floor Tile & & & & \\
\hline Grass & & & & \\
\hline
\end{tabular}




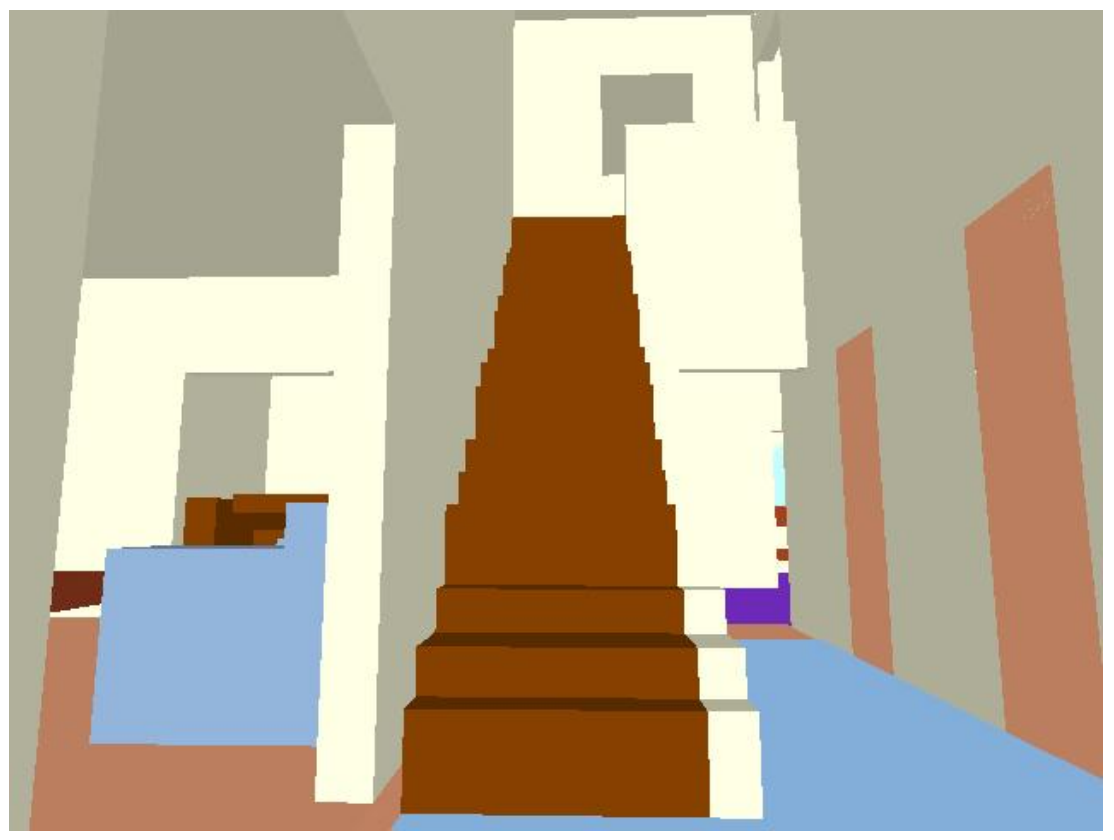

Figure 5-14. View of Interior from Inside the Front Door

\subsubsection{Fire Source}

A vent measuring $0.15 \mathrm{~m} \mathrm{x} 0.15 \mathrm{~m}(0.5 \mathrm{ft} \times 0.5 \mathrm{ft})$ used for ignition was located between the bed and the night stand in the rear bedroom on the second floor. The vent had a defined heat release rate per unit area of $2150 \mathrm{~kW} / \mathrm{m}^{2}$ to simulate a $50 \mathrm{~kW}$ trashcan fire. The vent was placed on top of a $0.15 \mathrm{~m}(0.5 \mathrm{ft})$ cube to simulate a small trashcan. This vent produced fuel for the duration of the simulation (Figure 5-15). 


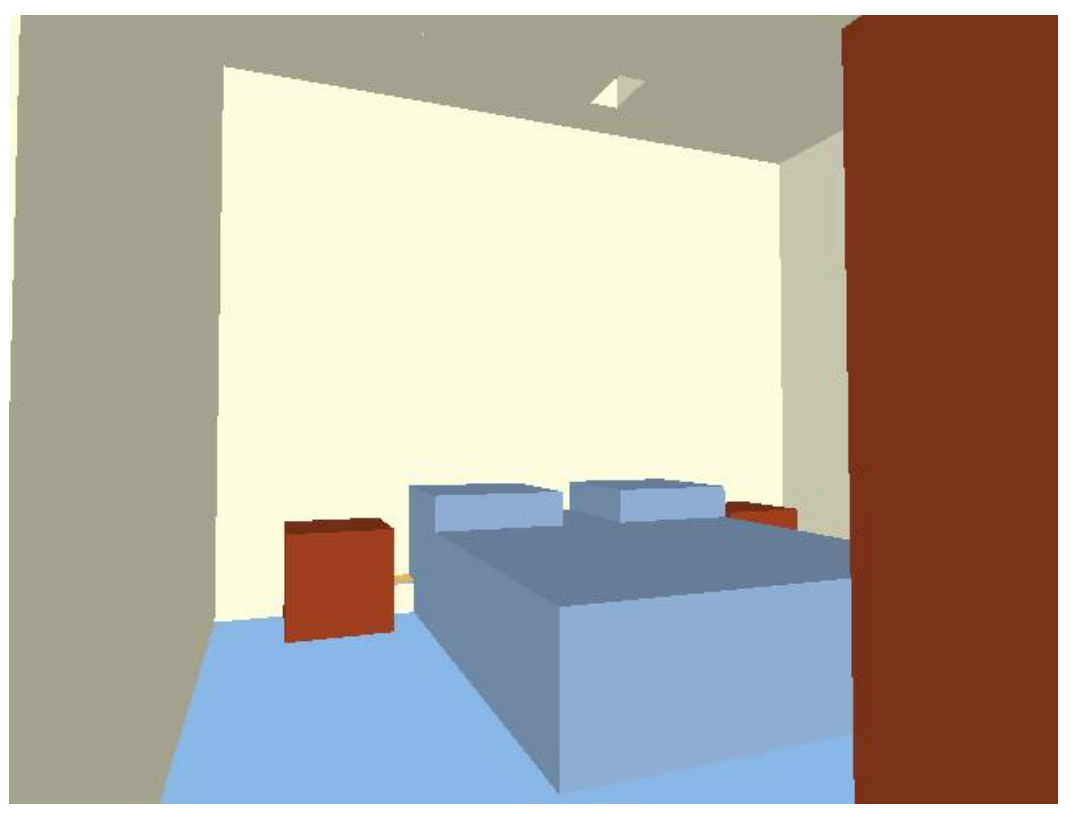

Figure 5-15. Fire Source in Bedroom

\subsubsection{Output Files}

Output files were prescribed to best analyze the fan's effect on fire intensity in and around the fire room, smoke movement, temperatures, oxygen concentrations, and velocities in the pathway from the front door to the fire room potentially occupied by fire fighters and tenability criteria of adjacent rooms to the fire room that could be occupied by victims of the fire. Vertical and horizontal temperature, oxygen and velocity slices were placed through the center of each room and many of the openings. Heat release rate was continually recorded in the domain as well as the flame isosurface locations. Three dimensional smoke was also used for analysis of smoke movement and visibility. Comparisons of these output files between the two scenarios are located in Section 5.3. 


\subsection{Results}

\subsubsection{Fire Growth and Smoke Spread}

Images were rendered from the naturally ventilated and positive pressure ventilated FDS simulations to analyze the effects of the positive pressure ventilation tactic on fire growth and smoke spread. Iso-surfaces of the heat release rate per unit volume and three-dimensional smoke density parameters are displayed in Figures 5-16 through 5-20.

Figure 5-16 shows the fire growth and smoke spread prior to ventilation. These images from 60 seconds to 240 seconds were identical for both ventilation scenarios up to 240 seconds. At 60 seconds the fire is growing between the night stand and the

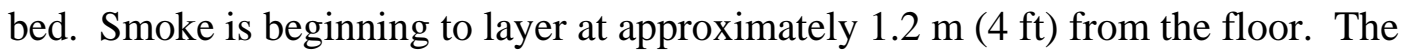
flames begin to attach to the bed at 120 seconds and the smoke layer thickens. At 180 seconds the flames are spreading across the bed and the flames appear to reach the ceiling. The smoke continues to thicken and the layer descends to $0.9 \mathrm{~m} \mathrm{(3 \textrm {ft } )}$ from the floor. By 240 seconds the smoke layer has reached the floor and visibility is significantly decreased in the bedroom of origin. The view is moved to just inside the front door at 240 seconds also. This frame shows the smoke almost reaching the floor in the hallway at the top of the stairs to the second floor. Another view from the exterior at 240 seconds displays smoke coming from the eaves of the roof on the front side of the house. 
Figures 5-17 through 5-20 show comparisons of the two ventilation techniques; natural ventilation on the left and positive pressure ventilation on the right. Figure 5-17 is the comparison five seconds after ventilation of the rear of the house. Both frames have smoke coming from the window and eaves of the roof. There is not much of a different between the two yet. Figure 5-18 shows the front of the house at 360 seconds. The naturally ventilated frame has smoke flowing from the eaves across the whole front of the house. The PPV ventilated frame has increased flow out of the eaves due to the increased flow from the fan. Figure 5-19 is a view of the rear of the house at the same time as the previous Figure. At this time there are flames coming out of the entire cross section of the ventilation window. Both frames have about the same amount of flames with the PPV frame having the flames further out of the frame as opposed to the flames in the naturally ventilated flame that go straight upward. This is another sign of the increased flow created by the positive pressure fan. The final comparison in Figure 5-20 shows the fire in the decay stage at 600 seconds. Flames are no longer projecting from the windows in either frame but the amount of smoke being forced out the window is greater in the PPV simulation. 


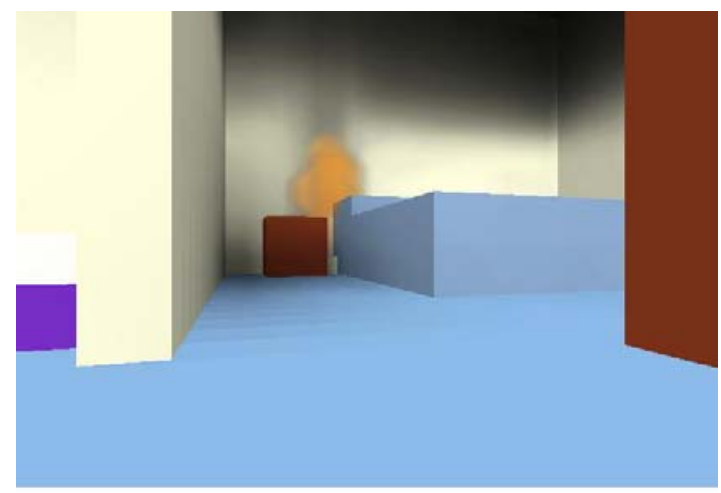

Time: $B 00$

60 seconds

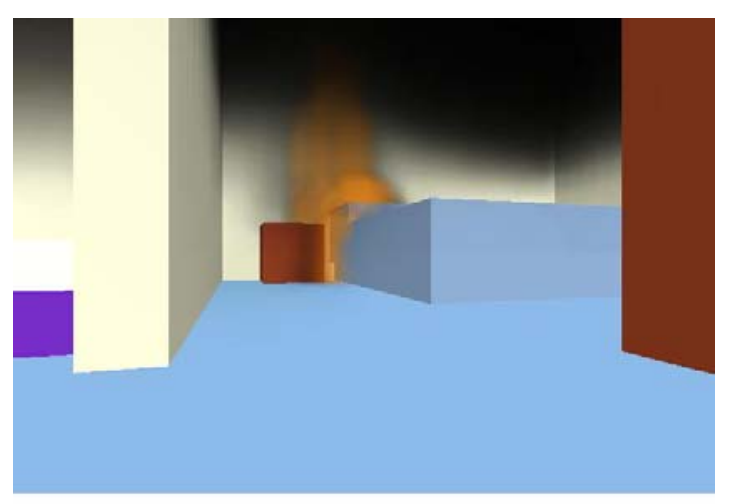

Time: 180.0

180 seconds

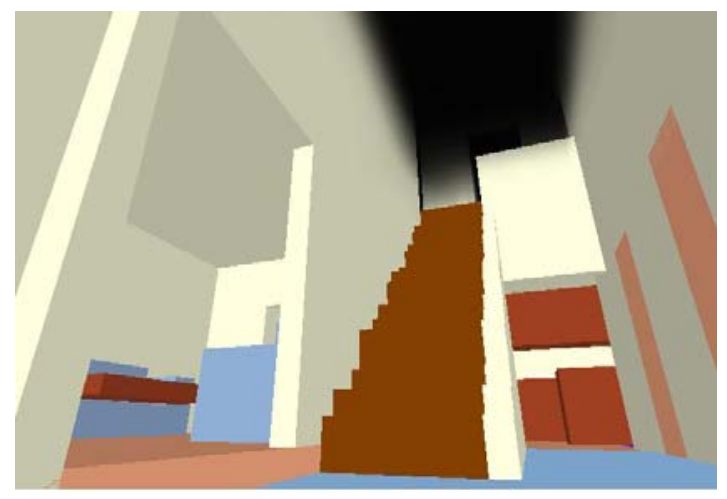

Time: 240.0

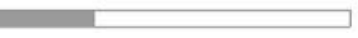

240 seconds

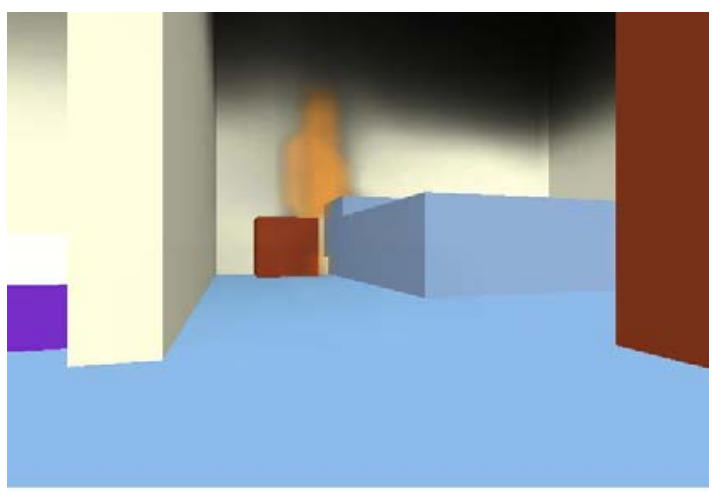

Time: 120.0

120 seconds

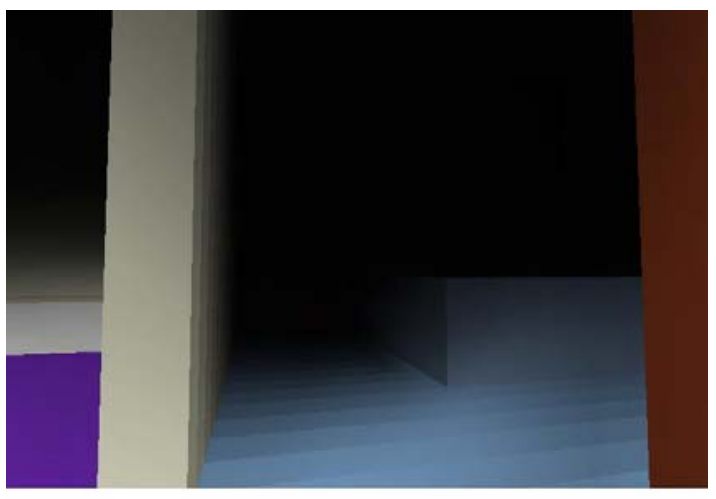

Time: 240.0

240 seconds

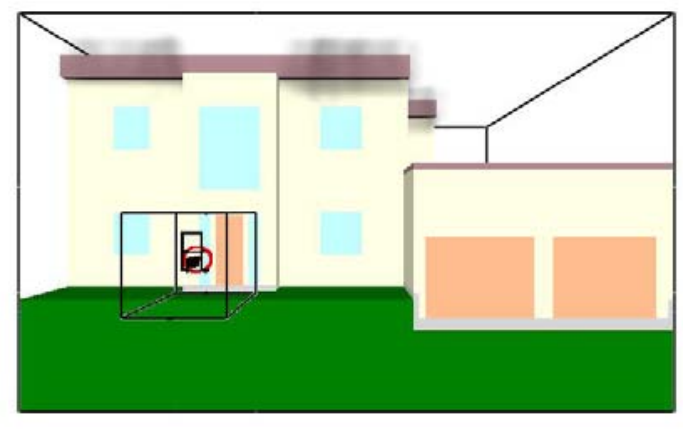

Time- 240.0

240 seconds

Figure 5-16. Growth of Fire Prior to Ventilation, 60 seconds to 240 seconds 

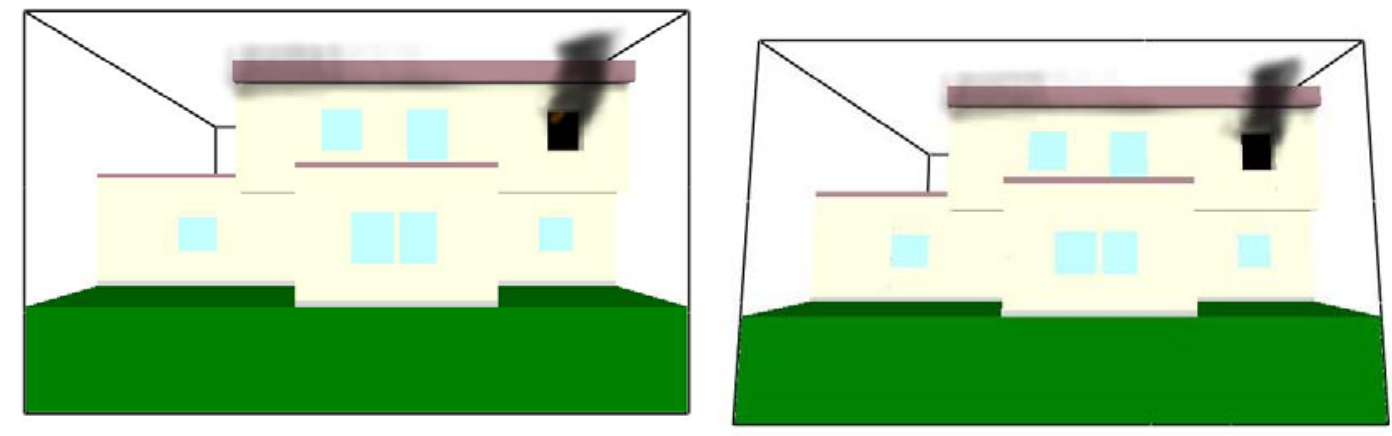

Figure 5-17. Comparison of Simulations at 250 seconds
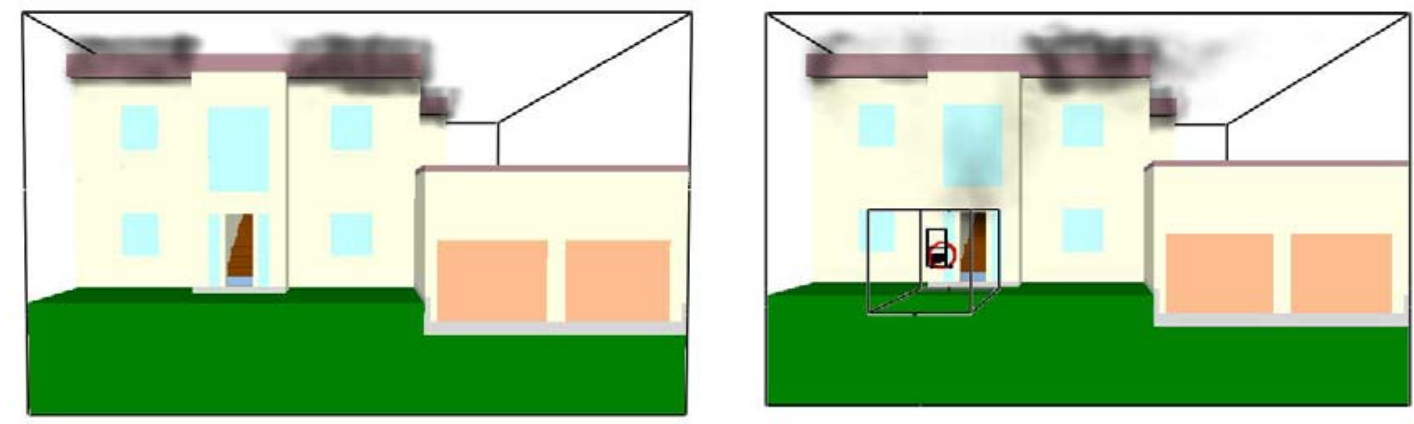

Time: 360.0

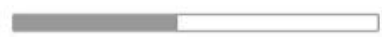

Time: 360.0

Figure 5-18. Comparison of Simulations at 360 seconds
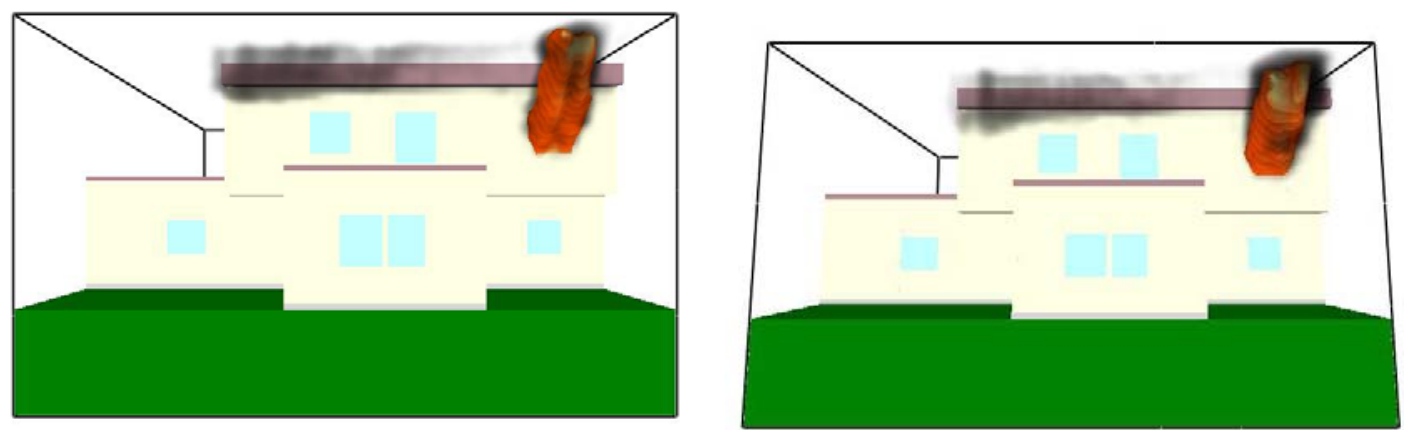

Time 3600

Time 360.0

Figure 5-19. Comparison of Simulations at 360 seconds 


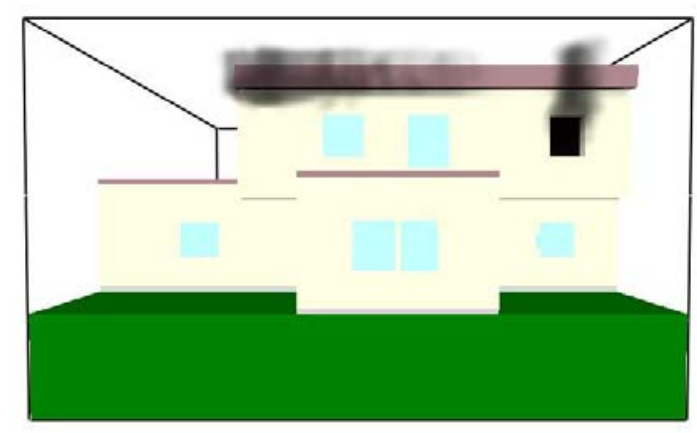

Time: 600.0

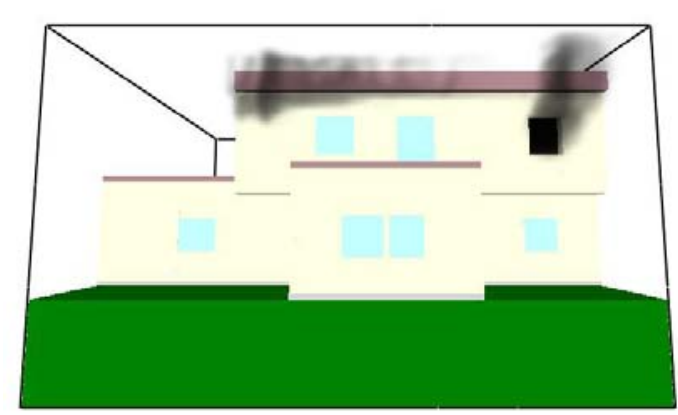

Time: 8000

Figure 5-20. Comparison of Simulations at 600 seconds

\subsubsection{Heat Release Rate}

The heat release rate for the duration of both simulations is plotted in Figure 5-21. As expected the two curves are identical for the first 250 seconds prior to ventilation. After ventilation the naturally ventilated simulation peaks approximately 25 seconds prior to that of the positive pressure ventilated simulation. The reason for this may be due to the proximity of the vent window to the seat of the fire. The naturally ventilated fire was able to pull fresh air from the window while the forced flow of the PPV fan caused the flow to be out of the window and the source of fresh air came from the flow in through the front door of the house. This was seen in the room fire experiment but at a lower magnitude due to the lack of a long distance between the fire room and the fan. 
The heat release rate in both simulations peaked at approximately the same value of 7.3 MW. This is not consistent with the room fire scenario but could also be due to the increased distance between the fire room and the PPV fan. The curves were consistent with the experiments after the peak was achieved. The positive pressure ventilated scenario maintained an elevated heat release rate of approximately $3 \mathrm{MW}$ for the 70 seconds following the peak output. This is very consistent with the room fire comparison which also demonstrated this same duration and a comparable heat release rate difference of $4 \mathrm{MW}$. After this 70 seconds of increased burning, the two curves converged similar to the experimental results.

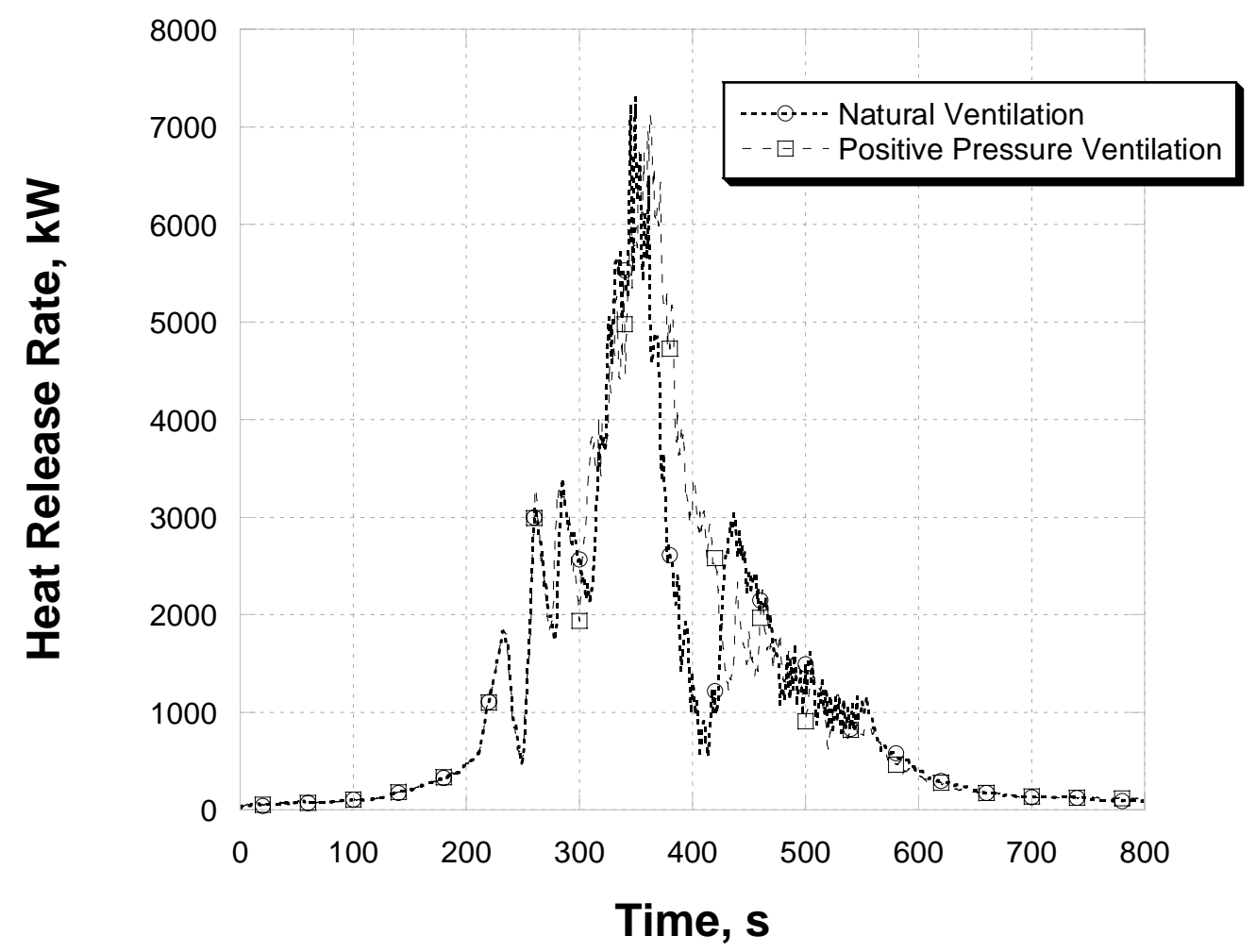

Figure 5-21. Colonial House Heat Release Rate Comparison 


\subsubsection{Temperature}

Temperature slices were examined to assess the tenability conditions that existed for

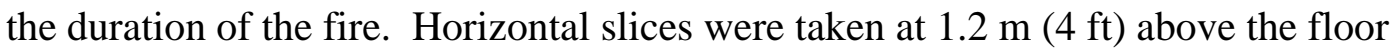
with the geometry above the slice rendered transparent to examine the temperature distribution throughout the floor of the house. Threshold temperatures were chosen for victims and firefighters.

Research by Montgomery [19] in 1975 indicated that in humid air rapid skin burns would occur at $100{ }^{\circ} \mathrm{C}\left(212{ }^{\circ} \mathrm{F}\right)$, and $150{ }^{\circ} \mathrm{C}\left(300{ }^{\circ} \mathrm{F}\right)$ was the exposure temperature at which escape was not likely. In 1947 Moritz [19] experimented on large animals and found that $100{ }^{\circ} \mathrm{C}\left(212{ }^{\circ} \mathrm{F}\right)$ represented the threshold for local burning and hyperemia (general burning). For this analysis, a temperature value of $100^{\circ} \mathrm{C}\left(212^{\circ} \mathrm{F}\right)$ was considered the temperature at which victims could be incapacitated.

Fire fighters operating in structures were also susceptible to injury from temperature exposures. Fire fighter protective clothing standards such as NFPA 1971 refer to exposures of $260{ }^{\circ} \mathrm{C}\left(500{ }^{\circ} \mathrm{F}\right)$ for five minutes [20]. This same temperature was the minimum temperature to which the thread that holds the garments together must endure. Other data exists that a firefighter can survive flashover conditions of $816{ }^{\circ} \mathrm{C}$ $\left(1500{ }^{\circ} \mathrm{F}\right.$ ) for up to 15 seconds. For this analysis, a temperature value of $300{ }^{\circ} \mathrm{C}$ $\left(572{ }^{\circ} \mathrm{F}\right.$ ) was considered the temperature at which firefighter's turnout gear will begin to degrade and it is no longer safe for the fire fighter to remain in the atmosphere. 


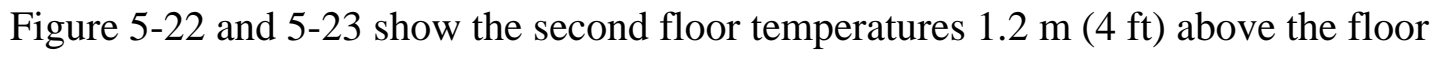
in 100 second intervals for 600 seconds. At 100 seconds the fire is still in the growth stage and the temperatures in both scenarios remain below $100{ }^{\circ} \mathrm{C}\left(212^{\circ} \mathrm{F}\right)$. The temperatures increase to approximately $130{ }^{\circ} \mathrm{C}\left(266{ }^{\circ} \mathrm{F}\right)$ at 200 seconds in both scenarios which is consistent with the fact that ventilation has not taken place. At 200 seconds it can be estimated that victims in the fire room would be incapacitated but fire fighters could operate safely. All other rooms on the second floor remain thermally tenable by both victims and fire fighters.

By 300 seconds the window and front door have been opened for 60 seconds and the fan has been flowing for 50 seconds. In both scenarios the fire room temperatures have reached those consistent with flashover and firefighters can no longer operate in the fire room. The PPV ventilated fire room has lower temperatures than the naturally ventilated scenario. At this time a difference in temperature is obvious in the rooms left of the stairwell and the stairwell itself. The flow created by the PPV fan has kept the temperatures near ambient while the naturally ventilated temperatures are reaching or have reached the tenability limit for victims.

The fire has reached its maximum output by 400 seconds and has heated a good portion of the second floor. The fire room temperature of the PPV ventilated scenario is higher than that of the naturally ventilated scenario but the rest of the second floor is cooler in the PPV scenario. In the naturally ventilated scenario the tenability criteria for victims is reached in all of the second floor rooms but the master 
bathroom in the remote corner from the fire. Temperatures reach as high as $200{ }^{\circ} \mathrm{C}$ (392 ${ }^{\circ} \mathrm{F}$ ) in the stairwell which is not above the fire fighter temperature threshold but it is in the path they would take to attack the fire, thus making advancement more difficult. In the PPV ventilated scenario, the rooms to the left of the stairwell reach the victim incapacitation temperature but the right half of the floor and the stairwell remain thermally tenable for both victims and fire fighters.

The fire continues through its decay stages in the 500 second and 600 second comparisons. The naturally ventilated scenario remains thermally untenable in most of the second floor while the only room that remains untenable for victims in the PPV scenario is the fire room. Through the duration of the fire the addition of the PPV fan increases the amount of tenable area for victims and lowers temperatures in the attack path of the fire fighters.

Figure 5-24 displays comparisons of first floor temperatures $1.2 \mathrm{~m}$ (4 ft) from the floor in two hundred second intervals for six hundred seconds. The first floor remains at ambient temperatures for the duration of the simulation for both ventilation scenarios. 

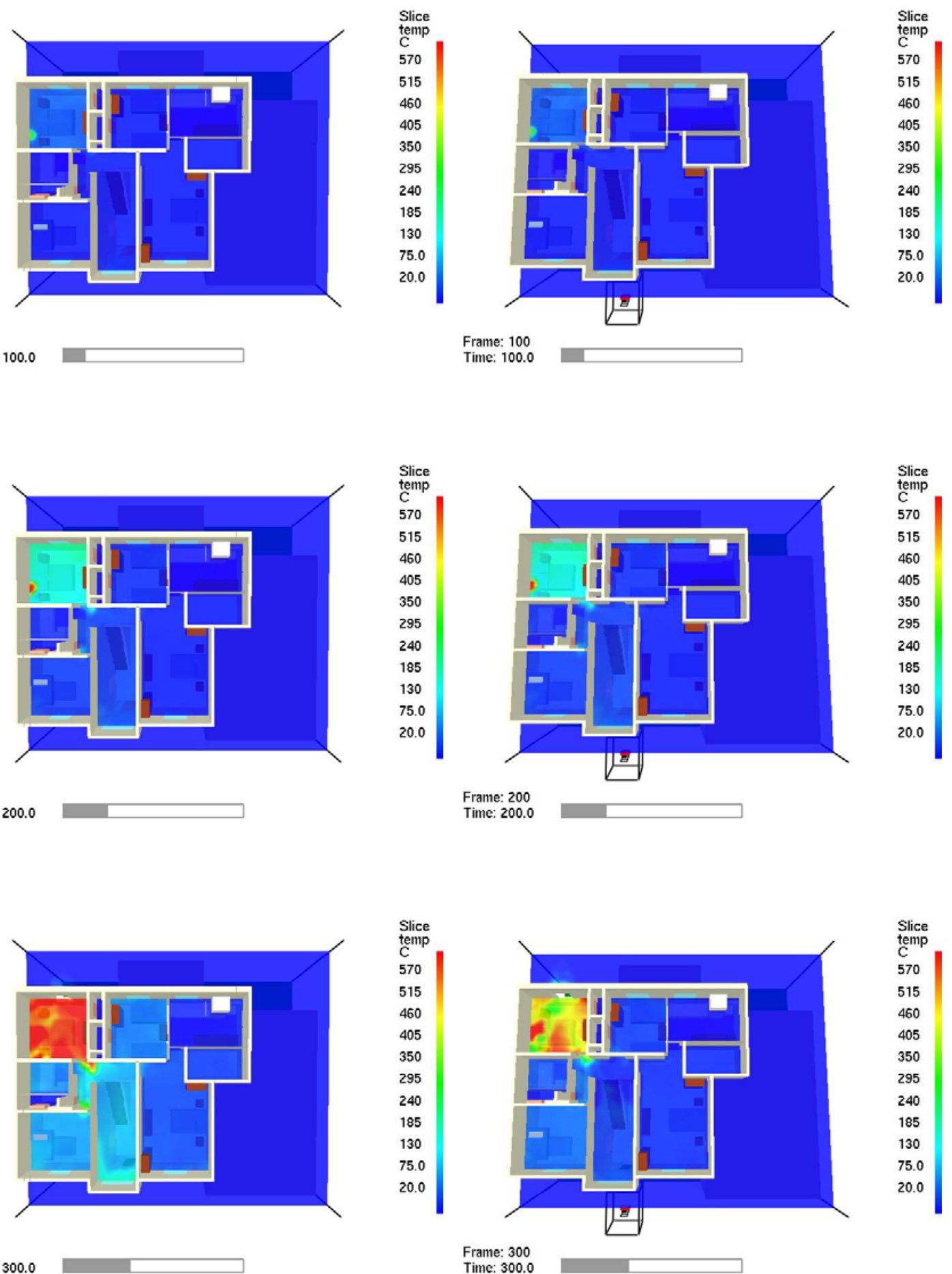

Figure 5-22. Comparison of Second Floor Temperatures 100 seconds to 300 seconds, Naturally Ventilated (Left) and PPV Ventilated (Right) 

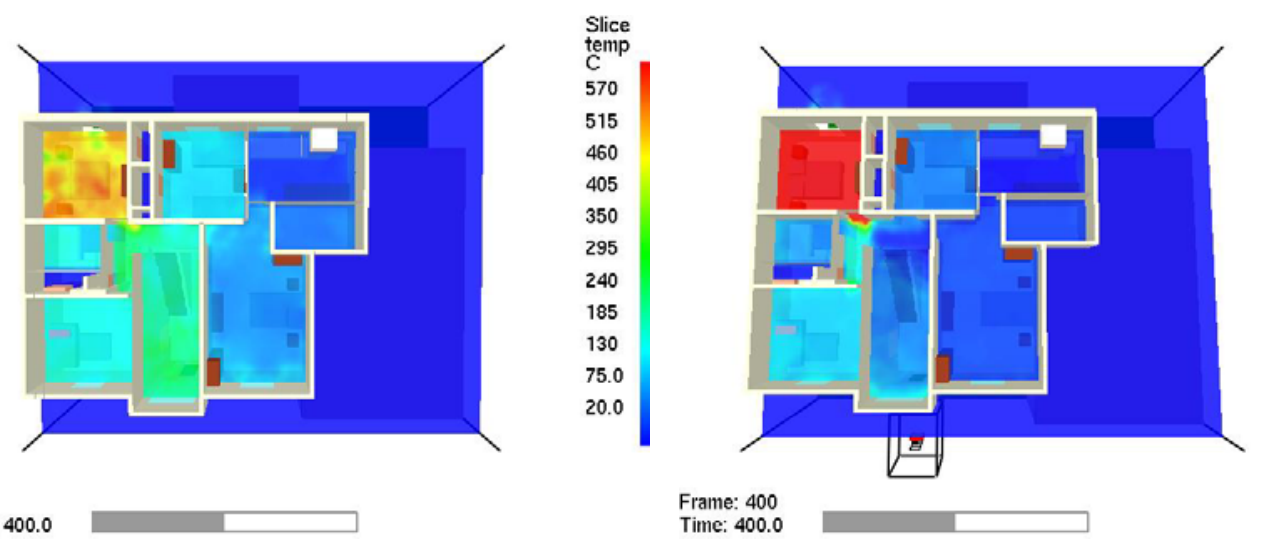

Slice
temp
$C$
570
515
460
405
350
295
240
185
130
75.0
20.0

Time: 400.0

Time: 400.0

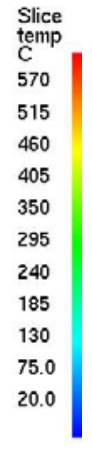

Slice

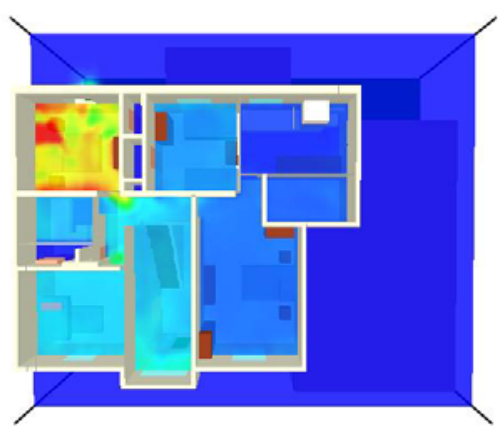

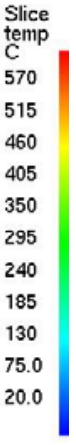

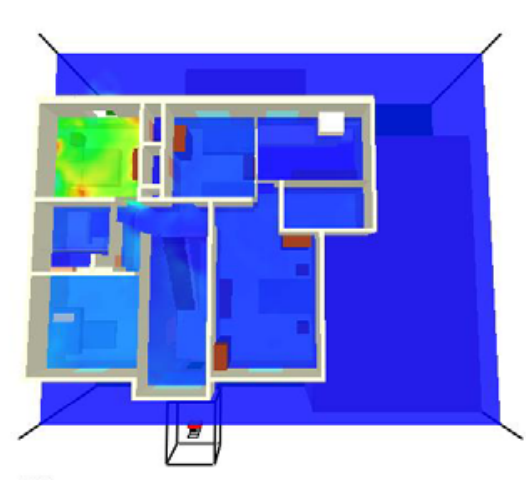

temp

570

515

460

405

350

295

240

185

130

75.0

Time: $\mathbf{5 0 0 . 0}$

Frame: 500

Time: $\mathbf{5 0 0 . 0}$

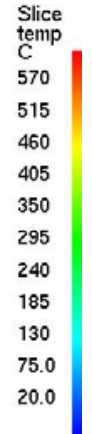

$\begin{aligned} & \text { Slice } \\ & \text { temp } \\ & C\end{aligned}$
570
515
460
405
350
295
240
185
130
75.0
20.0

Time: 600.0

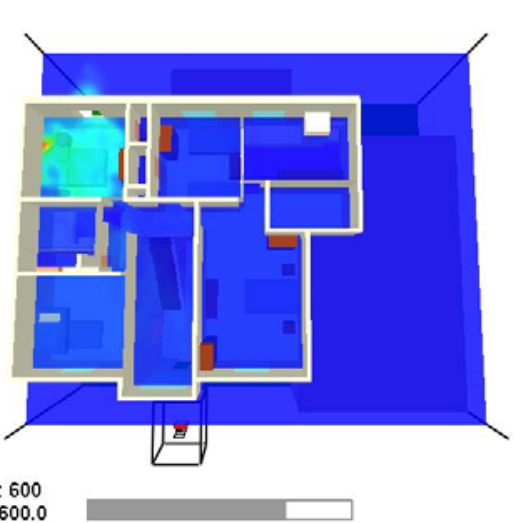

Frame: 600

Time: 600.0

Figure 5-23. Comparison of Second Floor Temperatures 400 seconds to 600 seconds, Naturally Ventilated (Left) and PPV Ventilated (Right) 


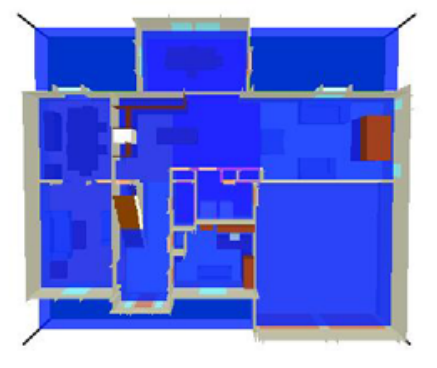

Time: $\mathbf{2 0 0 . 0}$

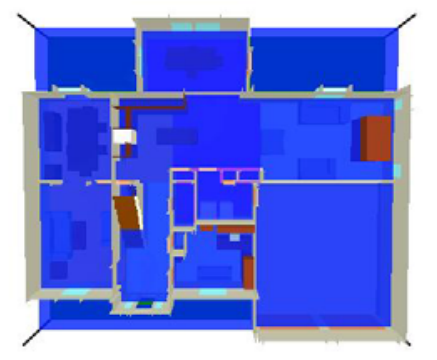

Time: 400.0

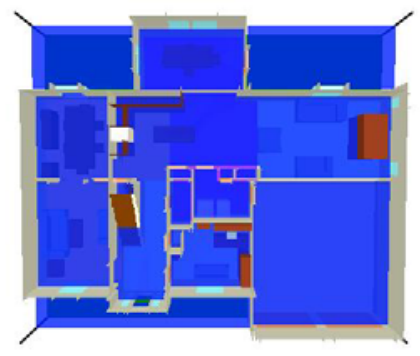

Time: 600.0
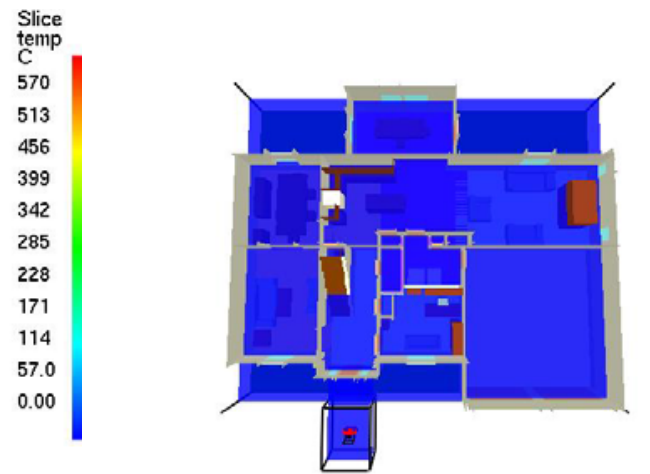

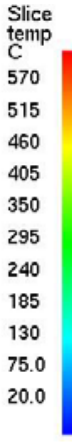

Frame: 200

Time: $\mathbf{2 0 0 . 0}$
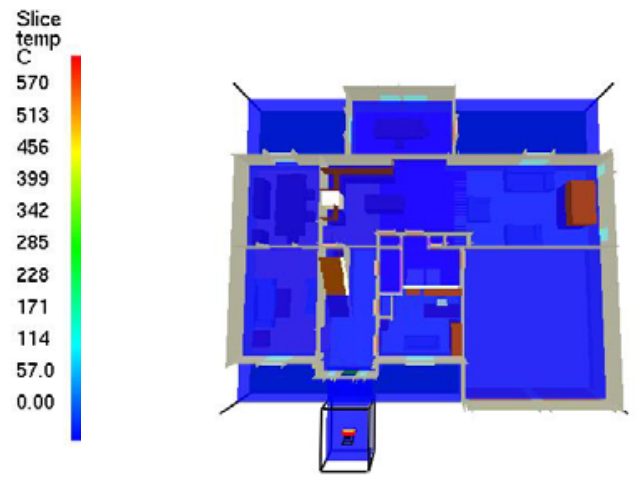

Slice

temp

570

515

460

405

350

295

240

185

75.0

Frame: 400 Time: 400.0

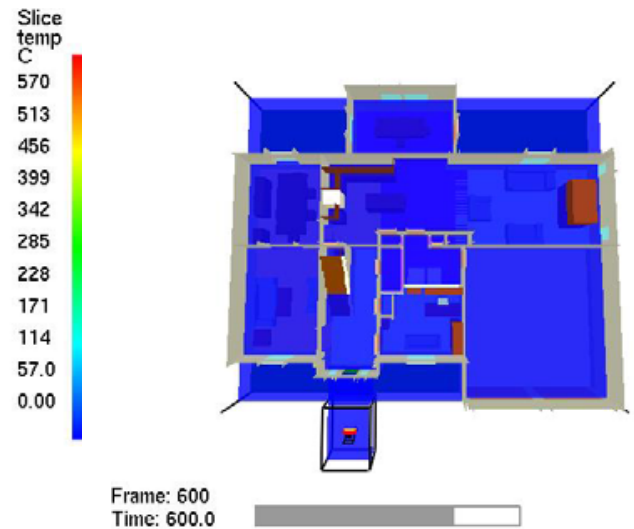

$\begin{aligned} & \text { Slice } \\ & \text { temp } \\ & C\end{aligned}$
570
515
460
405
350
295
240
185
130
75.0
20.0

Figure 5-24. Comparison of First Floor Temperatures 200 seconds to 600 seconds, Naturally Ventilated (Left) and PPV Ventilated (Right) 


\subsubsection{Oxygen}

Oxygen volume fraction concentrations were also examined in the simulations to assess the tenability conditions that existed in the house during the evolution of the fire. This horizontal slice was located at the same elevation as the temperature slice, $1.2 \mathrm{~m}(4 \mathrm{ft})$ above the floor. This analysis utilized a volume fraction of $12 \%$ as the oxygen tenability threshold for victims [21]. It is assumed that fire fighters utilize self contained breathing apparatus. Therefore in this analysis, no oxygen tenability threshold is considered for fire fighters.

Figures 5-25 and 5-26 show the second floor oxygen volume fractions $1.2 \mathrm{~m} \mathrm{(4 \textrm {ft } )}$ above the floor in 100 second intervals for 600 seconds. For the first 200 seconds the entire second floor is tenable for both ventilation scenarios. After ventilation at 300 seconds the fire is much larger and consuming more oxygen even though the window and front door are open. In the naturally ventilated scenario the left hand side of the second floor and the stairwell are approaching untenable conditions while the PPV ventilated scenario remains tenable everywhere but the fire room.

By 400 seconds the entire second floor in the naturally ventilated scenario is untenable with the front left bedroom as low as $5 \%$ oxygen. This same room along with the fire room in the PPV ventilated scenario reaches un-tenability, but the rest of the floor remains tenable. The front left bedroom oxygen level is able to drop so low because it is adjacent to the fire room and all its oxygen is consumed by the fire but 
there is no supply because the window is closed and the fire room draws all the oxygen from the front door.

The final two comparisons show the fire in the decay stage as the oxygen levels rise. The PPV ventilated scenario returns tenability to the second floor much more rapidly than the naturally ventilated scenario. This is expected as the fan is forcing fresh air into the house. This increased oxygen increases the survivability of victims and allows fire fighters to perform overhaul procedures sooner.

Figure 5-27 displays comparisons of first floor oxygen volume fractions $1.2 \mathrm{~m}(4 \mathrm{ft})$ from the floor in 200 second intervals for 600 seconds. The first floor remains at ambient oxygen levels for the duration of the simulation for both ventilation scenarios. 

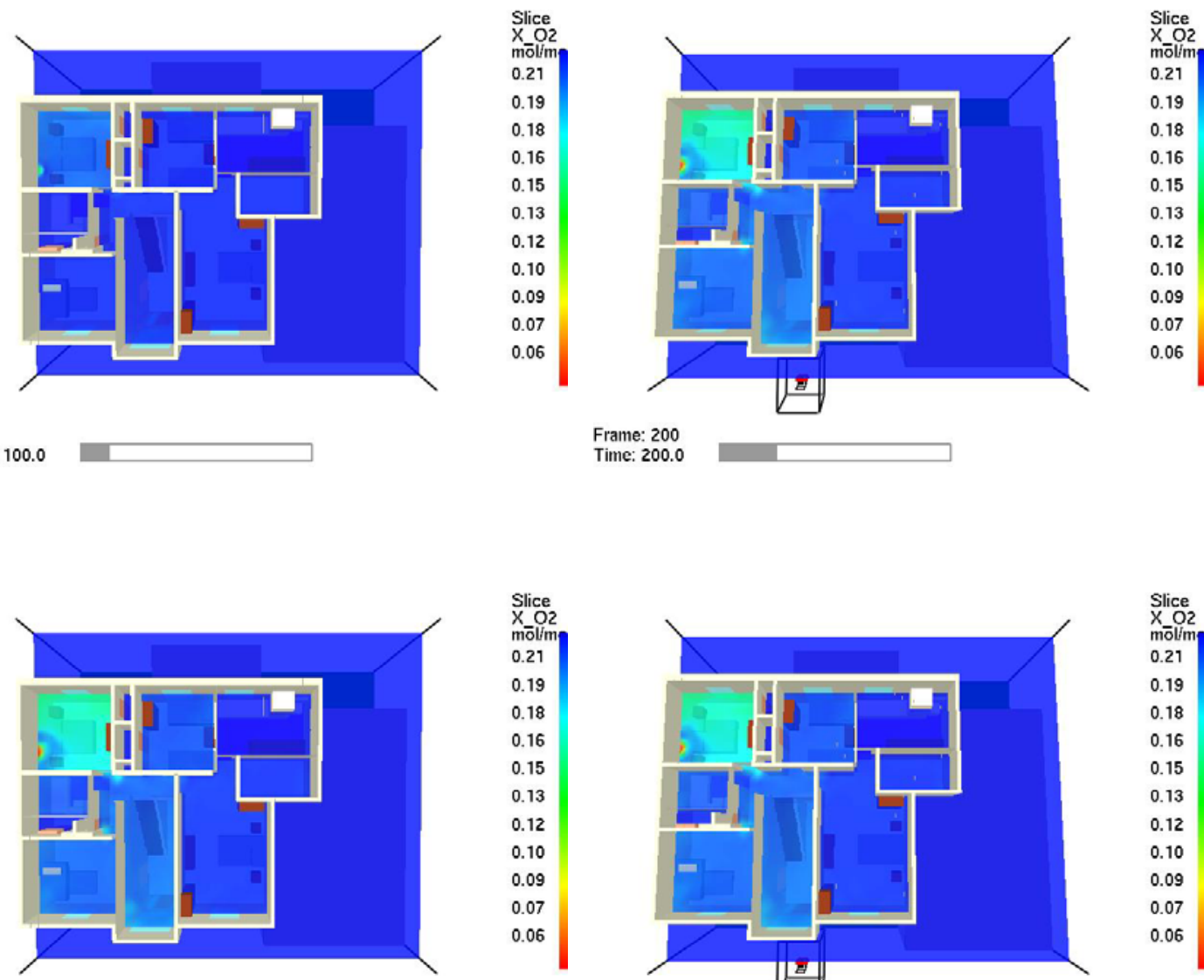

Time: 200.0

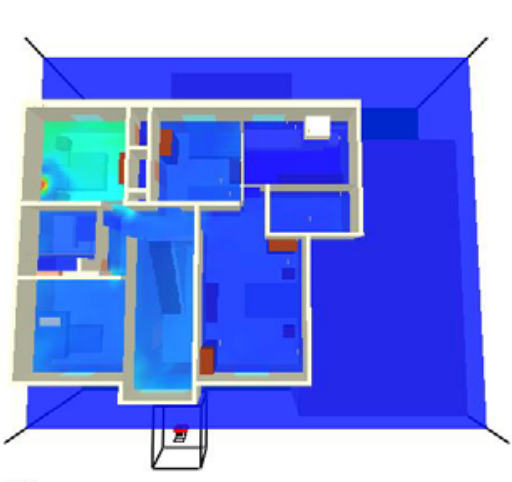

Frame: 200 Time: 200.0
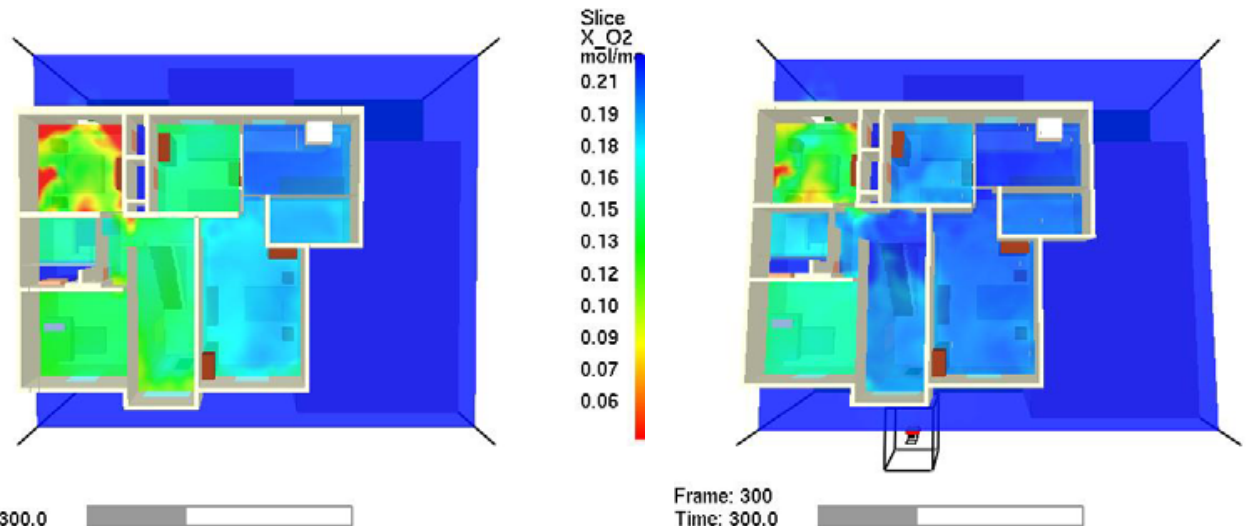

Figure 5-25. Comparison of Second Floor Oxygen Volume Fractions 100 seconds to 300 seconds, Naturally Ventilated (Left) and PPV Ventilated (Right) 

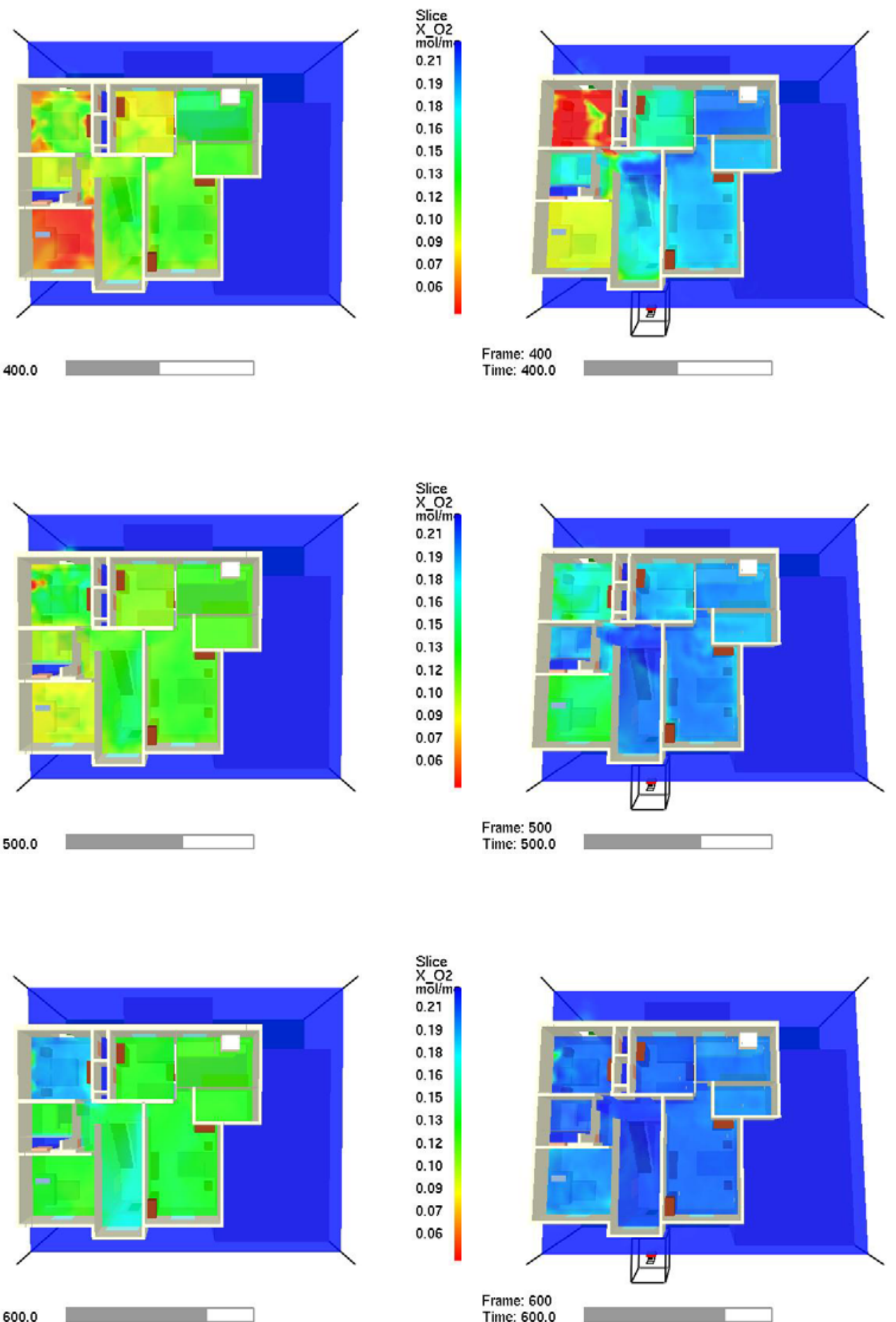

Figure 5-26. Comparison of Second Floor Oxygen Volume Fractions 300 seconds to 600 seconds, Naturally Ventilated (Left) and PPV Ventilated (Right) 


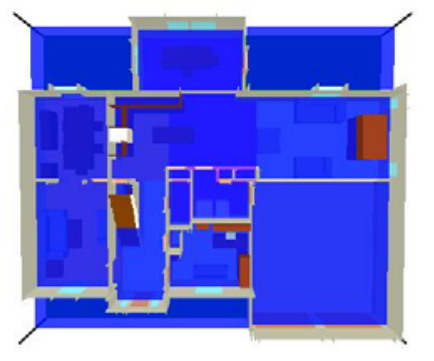

Time: $\mathbf{2 0 0 . 0}$

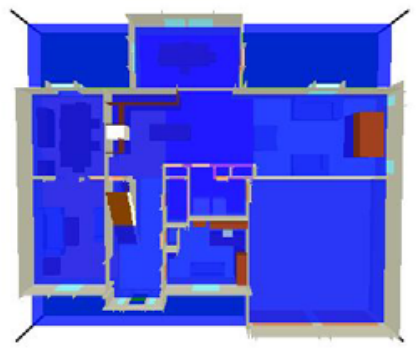

Time: 400.0

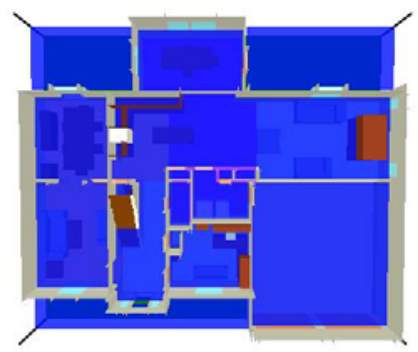

Time: 600.0
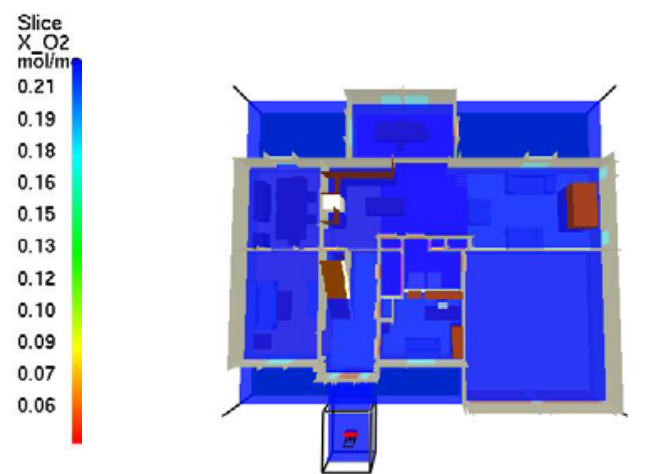

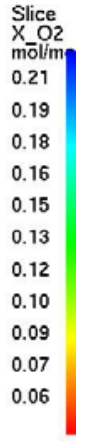

Frame: 200

Time: 200.0
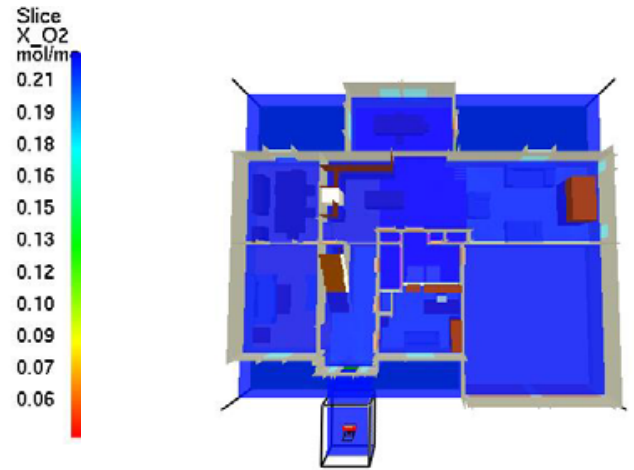

Slice
X_O2
mollm
0.21
0.19
0.18
0.16
0.15
0.13
0.12
0.10
0.09
0.07
0.06

Frame: 400 Time: 400.0
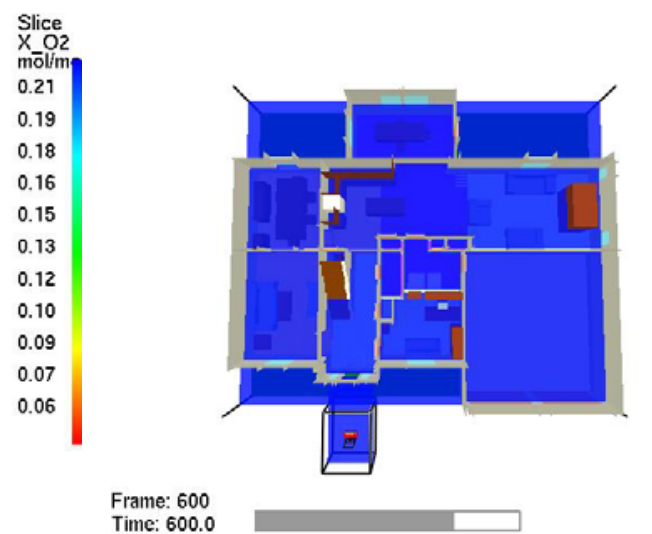

Slice
$\times \quad \mathrm{O}_{2}$
$\mathrm{~mol} / \mathrm{m}$
0.21
0.19
0.18
0.16
0.15
0.13
0.12
0.10
0.09
0.07
0.06

Frame: 600 Time: 600.0

Figure 5-27. Comparison of First Floor Oxygen Volume Fractions 200 seconds to 600 seconds, Naturally Ventilated (Left) and PPV Ventilated (Right) 


\subsubsection{Velocity}

Figures 5-28 through 5-34 are velocity slice files taken at 320 seconds; 80 seconds after the window and front door were opened. Figure 5-28 is located vertically through the center of the fan. This slice shows the cone of air described in chapter 1 and how it covers the entire height of the door. The velocity range is consistent with that achieved in chapter 2 (Figure 2-15).

Figure 5-29 and Figure 5-30 compare the velocities out of the fire room window. From this comparison it can be seen that the velocity is increased by the addition of the PPV fan. The fan increases the flow from approximately $4 \mathrm{~m} / \mathrm{s}(13 \mathrm{ft} / \mathrm{s})$ to $8 \mathrm{~m} / \mathrm{s}$ (26 ft/s) which is consistent with the effect of the fan seen in chapter 4 . Comparing figures 4-39 and 4-40 show how the experimental gas velocities were roughly doubled with the addition of the fan.

Figures 5-31 through 5-34 compare the velocities on the first and second floors $1.2 \mathrm{~m}$ (4 ft) above the floor at 320 seconds. The addition of the fan slightly increases these mid-level velocities through the fire room. This seemingly little change is obscured by the lack of direction. Much of the flow in the naturally ventilated scenario is out of the door and into the hallway while the PPV ventilated flow is forced back into the fire room, hence doubling the difference displayed in the Figures. On the first floor the difference is obvious with the addition of the PPV fan. It can also be observed that some of the flow created by the PPV fan circulates back to the front door. This

could be due to the increased pressure and could be affected by the size of the exhaust vent. 


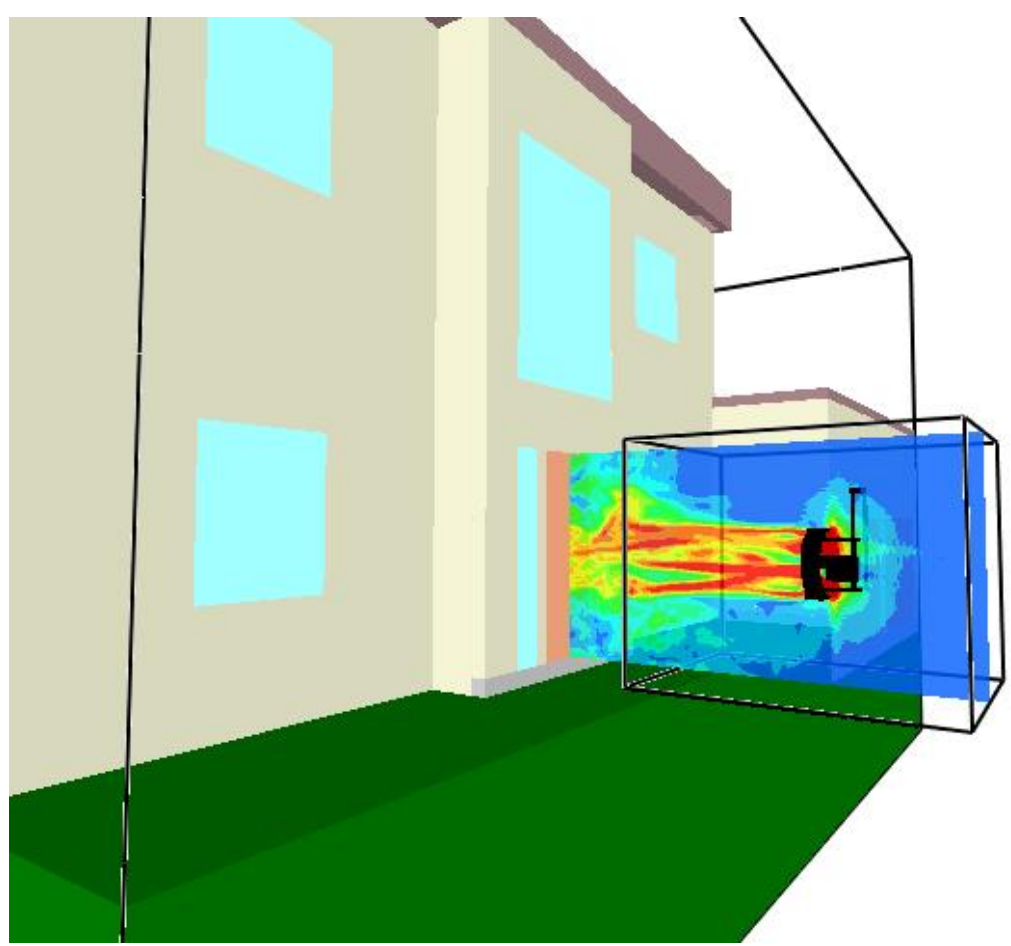

Figure 5-28. Vertical Velocity Slice Through Center of Fan 


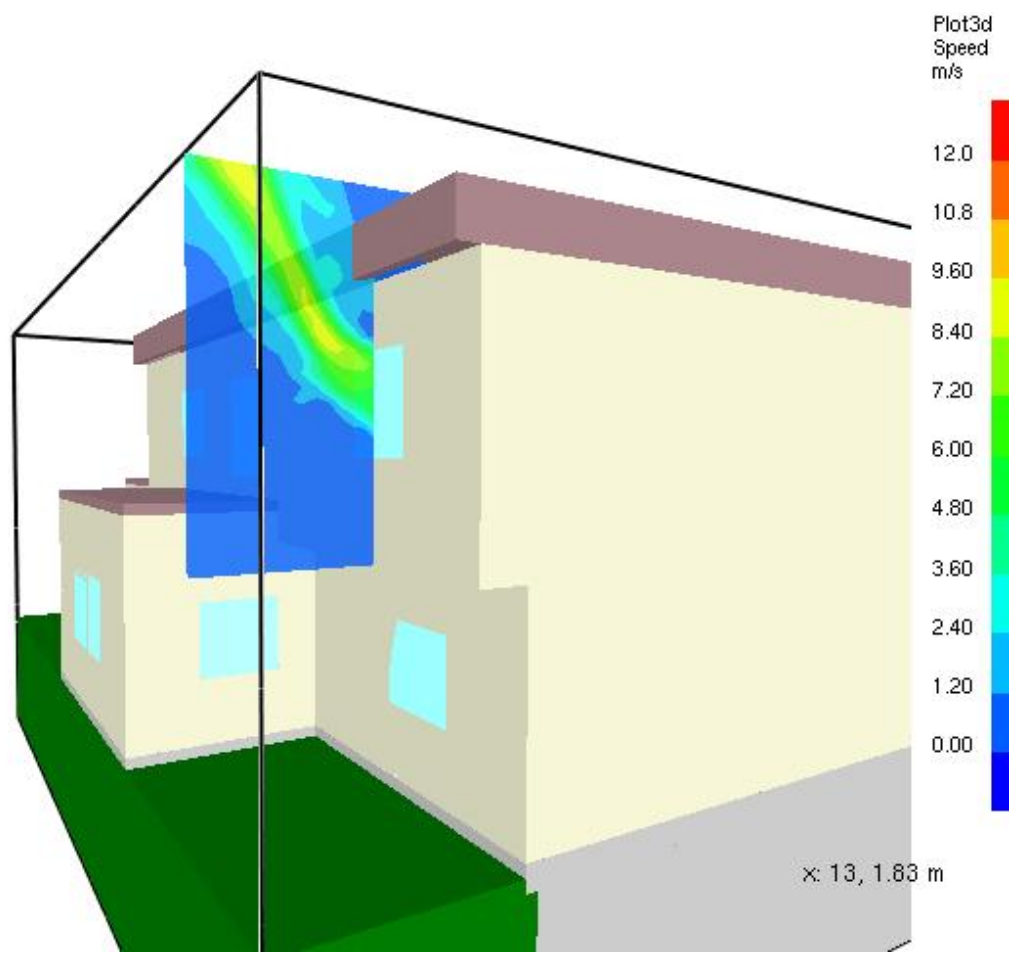

Figure 5-29. Velocity Slice Through Center of Vent Window During PPV Ventilation Scenario at 320 seconds

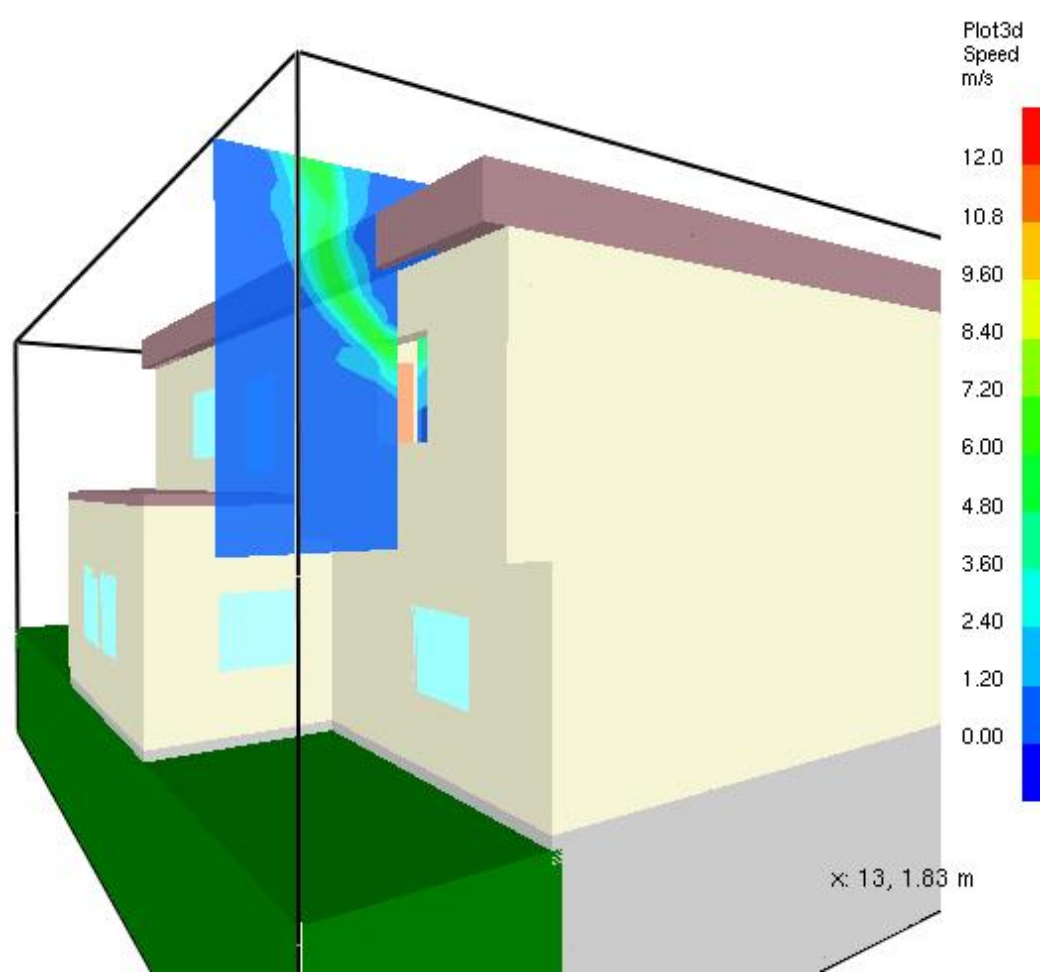

Figure 5-30. Velocity Slice Through Center of Vent Window During Natural Ventilation Scenario at 320 seconds 


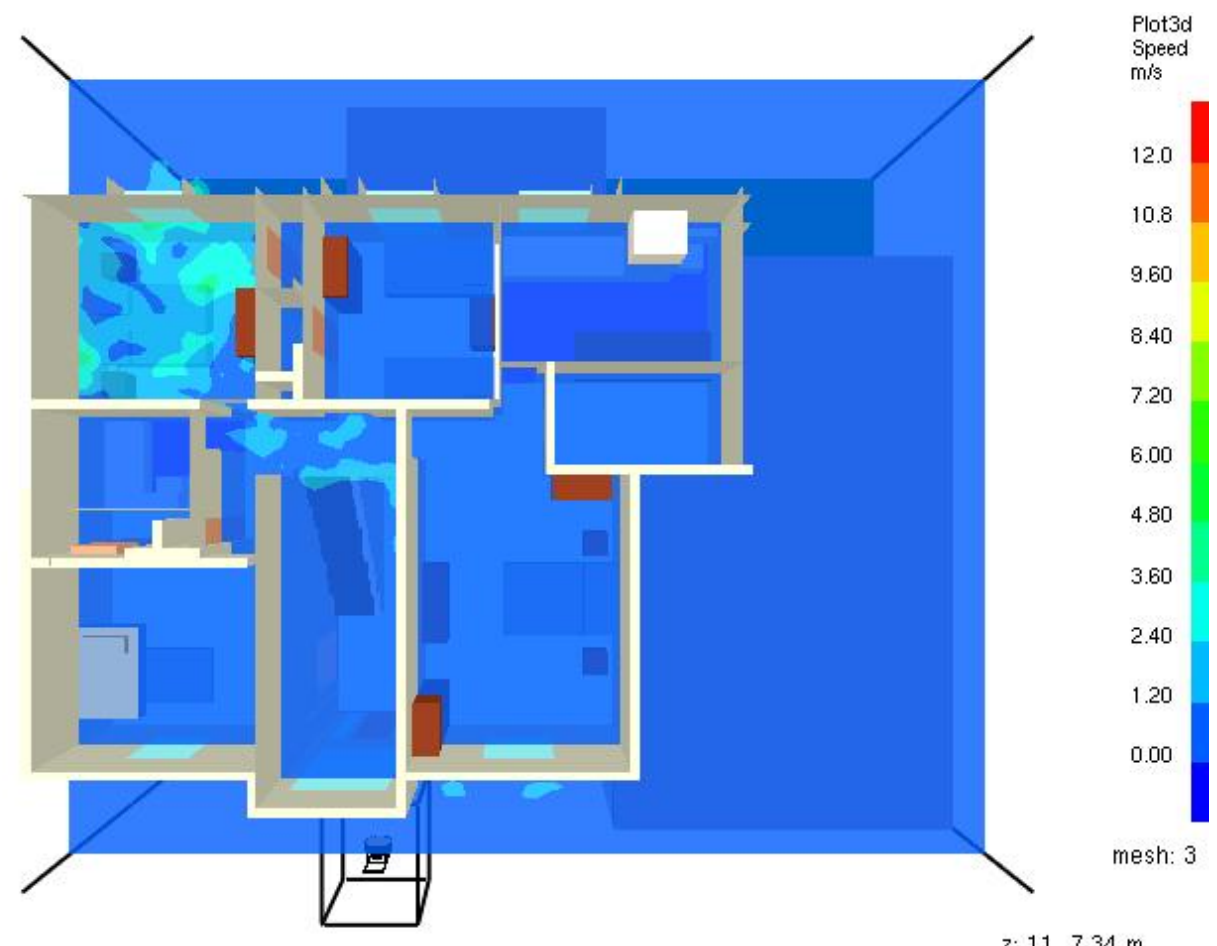

z: $11,7.34 \mathrm{~m}$

Figure 5-31. Horizontal Velocity Slice Through Second Floor During PPV Ventilation Scenario at 320 seconds

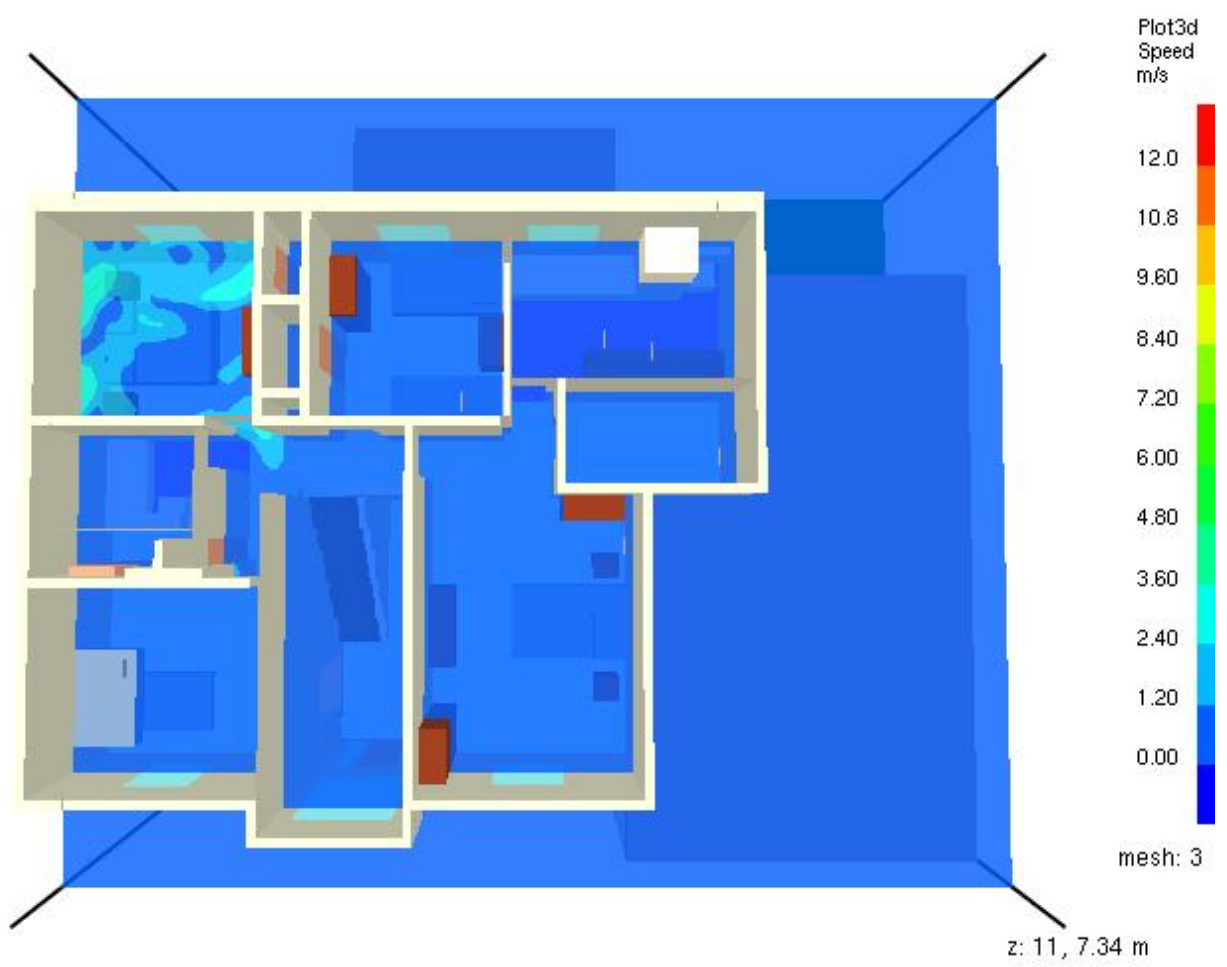

Figure 5-32. Horizontal Velocity Slice Through Second Floor During Natural Ventilation Scenario at 320 seconds 


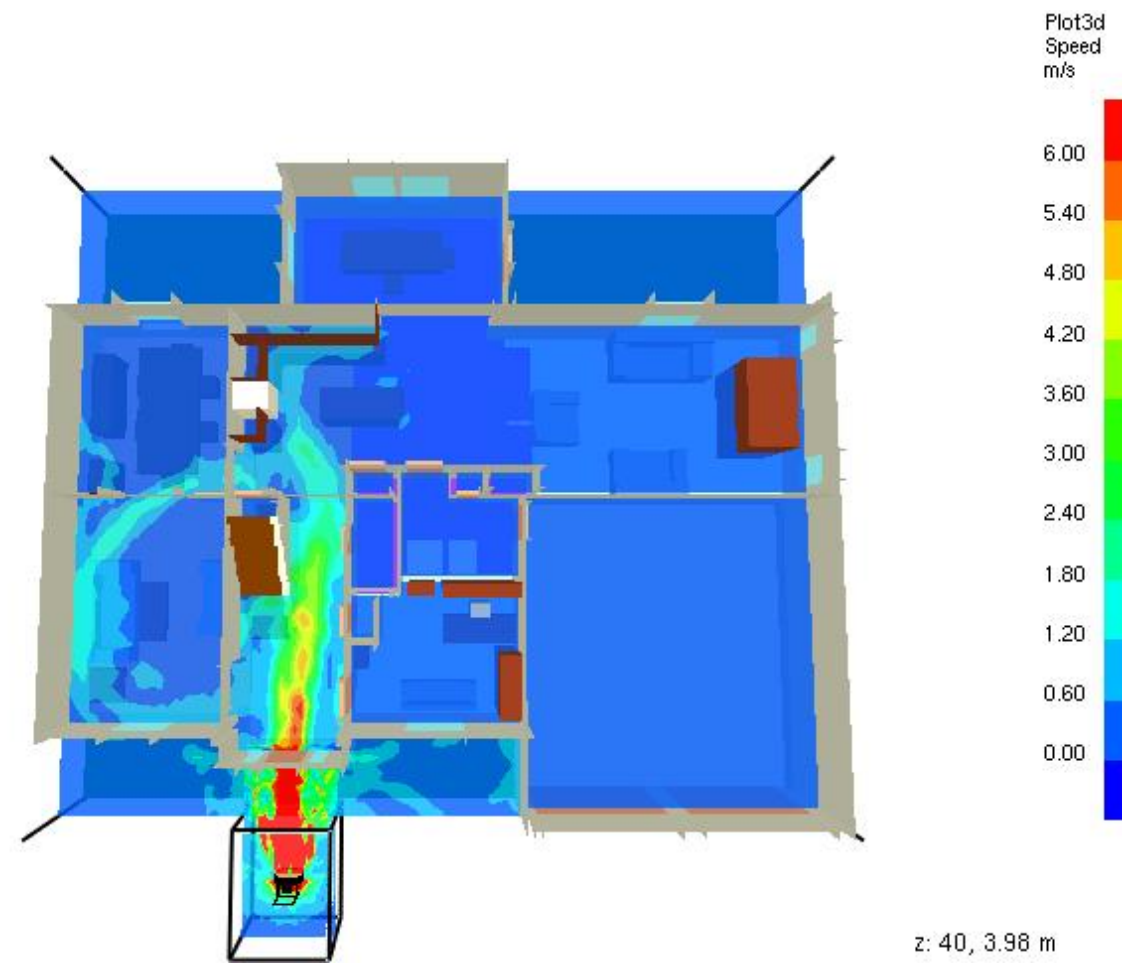

Figure 5-33. Horizontal Velocity Slice Through First Floor During PPV Ventilation Scenario at 320 seconds
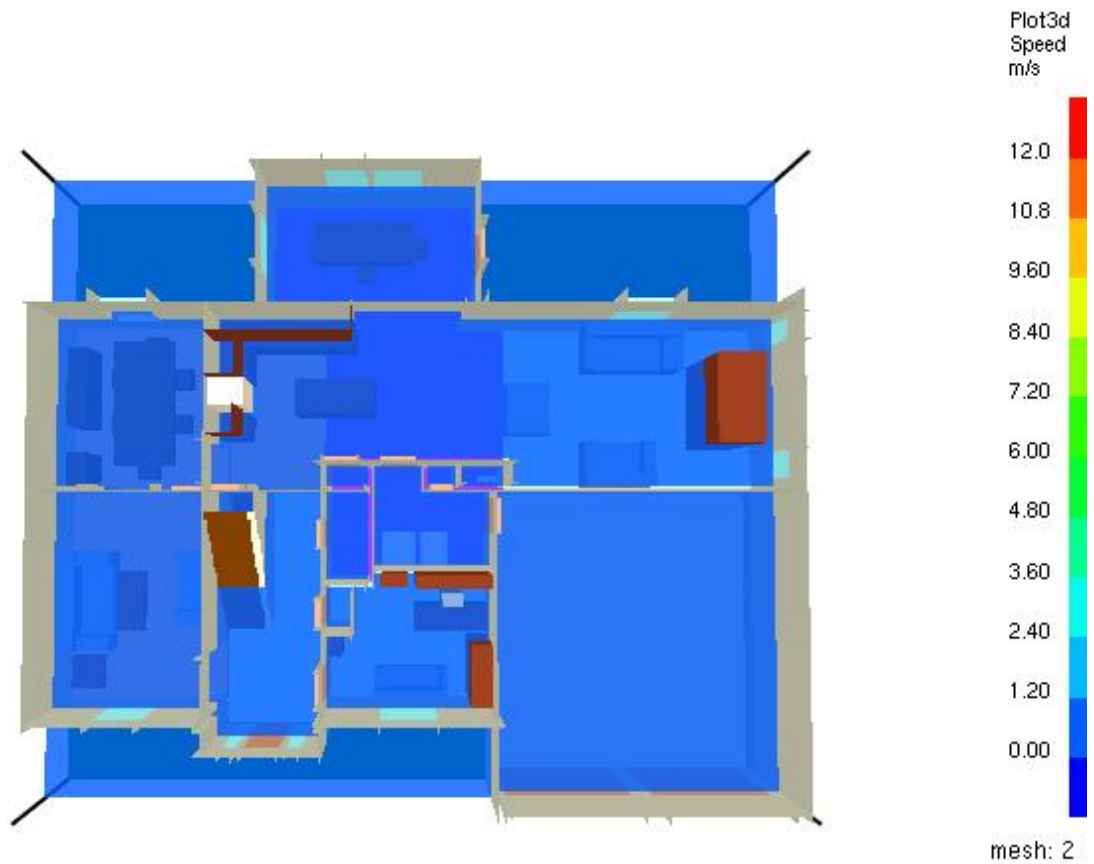

z: $10,4.06 \mathrm{~m}$

Figure 5-34. Horizontal Velocity Slice Through First Floor During Natural Ventilation Scenario at 320 seconds 


\subsection{Colonial House Summary}

Two simulations were run for 800 seconds to examine the effects of a positive pressure ventilation fan on fire spread, smoke movement, temperature, oxygen concentration and velocities in a colonial house. These parameters were compared to smaller scale experimental data and published tenability criteria. There is no direct experimental data that can be used for comparison; however the trends from the room fire experiments were a good guideline to understand the accuracy of the simulations.

Prior to ventilation, fire growth and smoke spread were identical for both simulations. After ventilation the smoke movement out of the eaves and the flames from the fire room window were intensified by the positive pressure ventilation fan. Both of these observations were consistent with the room fire experiments in chapter 4 .

The heat release rate from both simulations peaked at the same maximum value. This is not consistent with the room fire experiments but could be due to the longer path between the fan and the fire. After this peak heat release rate the PPV fan caused an increased heat release rate for approximately 70 seconds which is consistent with the room fire experiments. After this 70 seconds of increased burning the two curves converged just as was seen in the experiments.

In the PPV scenario gas temperatures were lower in all of the rooms on the second floor with the exception of the fire room than the temperatures in the naturally ventilated scenario. By 400 seconds most of the second floor was thermally 
untenable for victims in the naturally ventilated scenario while only one additional room next to the fire room reached the tenability limit in the positive pressure ventilated scenario. The addition of the PPV fan also lowered temperatures in the path to the fire room that would be used by fire fighters to attack the fire. The only room thermally untenable for fire fighters was the fire room. Temperatures on the first floor remained ambient for the duration of both simulations.

Oxygen levels followed similar trends as the temperature. As the temperature increased the oxygen levels typically decreased, as would be expected. Oxygen tenability limits were exceeded on the entire second floor during the naturally ventilated scenario by 400 seconds and was maintained until 600 seconds. Limits were only reached in the fire room and adjacent front bedroom during the PPV ventilated scenario. At 600 seconds the increased flow created by the PPV fan created tenable oxygen limits on the entire second floor. Oxygen levels remained ambient on the first floor for the duration of both simulations.

Velocity slices showed that the fan itself created flow at the doorway that was of the proper magnitude and direction to create the cone of air necessary for positive pressure ventilation. These values were also consistent with laboratory experiments in chapter 2. Much of the flow in the naturally ventilated scenario is out of the fire room door and into the second floor hallway while the PPV ventilated flow forced the fire gases back into the fire room. On the first floor the difference was obvious with the addition of the PPV fan. It was also observed that some of the flow created by the 
PPV fan circulates back to the front door. This could be due to the increased pressure and could be affected by the size of the exhaust vent.

The results of this comparison show that the PPV fan created tenable conditions in the house that would not normally be there under natural ventilation tactics. This is only one ideal scenario with well coordinated ventilation tactics assumed. These simulations follow the fire dynamics seen in laboratory experiments and provide confidence that the positive pressure ventilation tactic can be analyzed without the need for countless full-scale field tests. If full-scale opportunities arise in the future they could be beneficial as there is no true replacement for such data. Countless ventilation scenarios can be performed on this colonial style house at the expense of computational time, examining variables such as ventilating other rooms, ventilating at different times and starting the fire in other rooms. As computers continue to advance in speed and capability this cost will decrease allowing for a more timely result of the impact of the PPV fan. Simulating more scenarios would allow for a better understanding of the tactic, better training and potentially could assist in equipment design. 


\section{Chapter 6: Uncertainty}

\subsection{Experimental}

There are different components of uncertainty in the length measurements, gas temperatures, mass of fuel packages, gas velocity and heat release rate data reported here. Uncertainties are grouped into two categories according to the method used to estimate them. Type A uncertainties are those which are evaluated by statistical methods, and Type B are those which are evaluated by other means [22]. Type B analysis of systematic uncertainties involves estimating the upper (+ a) and lower (- a) limits for the quantity in question such that the probability that the value would be in the interval ( \pm a) is essentially $100 \%$. After estimating uncertainties by either Type A or B analysis, the uncertainties are combined in quadrature to yield the combined standard uncertainty. Multiplying the combined standard uncertainty by a coverage factor of two results in the expanded uncertainty which corresponds to a $95 \%$ confidence interval $(2 \sigma)$.

Components of uncertainty are tabulated in Table 10 (chapter 2 and 3 experiments) and Table 11 (chapter 4 experiments). Some of these components, such as the zero and calibration elements, are derived from instrument specifications. Other components, such as radiative cooling/heating, include past experience with thermocouples in high temperature fuel rich environments.

Each length measurement was taken carefully but due to some construction issues such as the size and straightness of the lumber, the slots for the strings on the grid 
having thickness, and the symmetry of the rather large room the total expanded uncertainty was estimated to $6 \%$. The flow measurements were taken in the complex flow of the positive pressure ventilation fan, which created a total expanded uncertainty of $14 \%$ primarily due to the repeatability and the randomness of the measurements.

The uncertainty in the upper layer gas temperature measurements includes radiative cooling in each of the experimental series, but also includes radiative heating for thermocouples located in the lower layer of the full-scale experiments. Pitts et al. [13] quantified the errors of bare bead thermocouples as ranging from $7 \%$ in the hot upper gas layer to as much as $75 \%$ in the lower layer. The potential for large errors in the lower layer are a function of the effective temperature of the surroundings. In cases where the effective temperature of the surroundings is high, the error can be more significant. In cases, similar to a developing fire in a compartment, the temperature measurement errors in the lower layer are smaller as the fire develops through flashover, since the effective temperature of the floor and walls are relatively cool. Post-flashover, the potential for measurement error increases as the temperature of the surroundings increase. Small diameter thermocouples were used to limit the impact of radiative heating and cooling. This resulted in an estimate of $\pm 15 \%$ total expanded uncertainty in temperature.

Differential pressure reading uncertainty components are derived from pressure transducer instrument specifications. The transducers were factory calibrated and the 
zero and span of each was checked in the laboratory prior to the experiments. The readings from the pressure transducers were used to generate gas velocities.

Load cells were utilized to measure fuel package mass. The load cell was calibrated with a standard mass prior to recording the mass of each fuel item. After obtaining mass data on each of the fuel components, items were selected at random to be reweighed in order to estimate repeatability.

Each length measurement was taken carefully. However due to some construction issues, such as the size and straightness of the lumber, the curves of the furniture, and the symmetry of the large room, the total expanded uncertainty for room dimensions was estimated to be $6 \%$.

Total expanded uncertainties associated with oxygen calorimetry techniques are discussed in greater detail by Bryant et al. [12]. This uncertainty was estimated to be $11 \%$ and included components derived from gas concentrations, temperature and gas flows. This estimation is based on the calorimetry system alone and does not account for the uncertainty that exists due to the experimental configuration. There is a delay time for the combustion gases to reach the hood and calorimetry instrumentation. The heat released within the fire room has an additional uncertainty associated with it. This uncertainty varies during the experiment. After the window was opened the uncertainty was minimized due to the majority of the burning occurring outside of the room. 
Table 10. Mapping and Simple Room Experimental Uncertainty

\begin{tabular}{|l|c|c|c|}
\hline & $\begin{array}{c}\text { Component } \\
\text { Standard } \\
\text { Uncertainty }\end{array}$ & $\begin{array}{c}\text { Combined Standard } \\
\text { Uncertainty }\end{array}$ & $\begin{array}{c}\text { Total Expanded } \\
\text { Uncertainty }\end{array}$ \\
\hline Length Measurements & $\pm 1 \%$ & & \\
$\quad$ Grid Size & $\pm 0.5 \%$ & & \\
String Location & $\pm 0.5 \%$ & $3 \%$ & \\
Fan Stand Height & $\pm 1 \%$ & & \\
Anemometer Location & $\pm 1 \%$ & & \\
Fan Location & $\pm 1 \%$ & & \\
Room Dimensions & $\pm 2 \%$ & & \\
Repeatability & $\pm 2 \%$ & & \\
Random & $\pm 0.5 \%$ & & \\
& $\pm 5 \%$ & & \\
\hline Flow Measurements & $\pm 5 \%$ & & \\
Calibration & & & \\
Repeatability & & & \\
Random & & & \\
\hline Note: Random and repeatability evaluated as Type A, other components as Type B & \\
\hline
\end{tabular}


Table 11. Room Fire Experimental Uncertainty

\begin{tabular}{|c|c|c|c|}
\hline & $\begin{array}{l}\text { Component } \\
\text { Standard } \\
\text { Uncertainty }\end{array}$ & $\begin{array}{l}\text { Combined } \\
\text { Standard } \\
\text { Uncertainty }\end{array}$ & $\begin{array}{c}\text { Total } \\
\text { Expanded } \\
\text { Uncertainty }\end{array}$ \\
\hline $\begin{array}{l}\text { Gas Temperature } \\
\text { Calibration[23] } \\
\text { Radiative Cooling } \\
\text { Radiative Heating } \\
\text { Repeatability }^{1} \\
\text { Random }^{1}\end{array}$ & $\begin{array}{c} \pm 1 \% \\
-5 \% \text { to }+0 \% \\
-0 \% \text { to }+5 \% \\
\pm 5 \% \\
\pm 3 \%\end{array}$ & $-8 \%$ to $+8 \%$ & $\begin{array}{c}-15 \% \text { to }+15 \\
\%\end{array}$ \\
\hline $\begin{array}{l}\text { Differential Pressure } \\
\text { Calibration[11] } \\
\text { Accuracy[11] } \\
\text { Repeatability }^{1} \\
\text { Random }^{1}\end{array}$ & $\begin{array}{l} \pm 2 \% \\
\pm 1 \% \\
\pm 5 \% \\
\pm 5 \%\end{array}$ & $-8 \%$ to $+8 \%$ & $\begin{array}{c}-15 \% \text { to }+15 \\
\%\end{array}$ \\
\hline $\begin{array}{l}\text { Mass of Fuel Package } \\
\text { Zero } \\
\text { Calibration } \\
\text { Repeatability }^{1} \\
\text { Random }^{1}\end{array}$ & $\begin{array}{l} \pm 0.02 \% \\
\pm 1 \% \\
\pm 5 \% \\
\pm 3 \%\end{array}$ & $\pm 6 \%$ & $\pm 12 \%$ \\
\hline $\begin{array}{l}\text { Length Measurements } \\
\text { Instrumentation } \\
\text { Locations } \\
\text { Furniture } \\
\text { Dimensions } \\
\text { Fan Location } \\
\text { Room Dimensions } \\
\text { Repeatability }^{1} \\
\text { Random }^{1} \\
\end{array}$ & $\begin{array}{l} \pm 1 \% \\
\pm 1 \% \\
\pm 1 \% \\
\pm 1 \% \\
\pm 2 \% \\
\pm 2 \%\end{array}$ & $\pm 3 \%$ & $\pm 6 \%$ \\
\hline
\end{tabular}




\subsection{Fire Dynamics Simulator}

FDS can provide valuable insight into how a fire may develop or how the combustion gases will move throughout a structure. However the model is only a simulation. The model output is dependent on a variety of input and default values such as computational cell size, material properties, geometry, and vents.

The ability of the FDS model to accurately predict the temperature and velocity of fire gases has been previously evaluated by conducting experiments, both lab-scale and full-scale, and measuring quantities of interest. For relatively simple fire driven flows, such as buoyant plumes and flows through doorways, FDS predictions are within the experimental uncertainty of the values measured in the experiments [21]. For example, if a gas flow velocity is measured at $0.5 \mathrm{~m} / \mathrm{s}(2 \mathrm{ft} / \mathrm{s})$ with an experimental uncertainty of $\pm 0.05 \mathrm{~m} / \mathrm{s}$ ( $\pm 0.2 \mathrm{ft} / \mathrm{s}$ ), the FDS model gas flow velocity predictions were also within the range between $0.45 \mathrm{~m} / \mathrm{s}(1.5 \mathrm{ft} / \mathrm{s})$ and $0.55 \mathrm{~m} / \mathrm{s}$ $(1.8 \mathrm{ft} / \mathrm{s})$.

In large-scale fire tests reported in [24], FDS temperature predictions were found to be within $15 \%$ of the measured temperatures and the FDS heat release rates were predicted to within $20 \%$ of the measured values. Therefore the results are presented as ranges to address these uncertainties.

These experiments look to prove that using the correct set of inputs; FDS is able to accurately model the flows of positive pressure ventilation fans within a desirable uncertainty. 


\section{Chapter 7: Conclusion}

Data from three sets of full-scale experiments were compared with simulations completed with the computational fluid dynamic model Fire Dynamic Simulator (FDS). The full-scale experiments characterized a Positive Pressure Ventilation (PPV) fan in an open atmosphere, in a simple room geometry and during a room fire. Experimental results were visually and numerically compared to FDS results. The comparison showed reasonable agreement. A concluding scenario was modeled utilizing the calibration of the full-scale experiments to examine the effects of PPV on a fire in a two-story colonial-style house.

Numerous geometries were experimented within FDS to obtain a fan that provided both numerical and visual comparisons that were accurate. The positive pressure ventilation fan mapped in the open atmosphere yielded an average velocity difference between the experiment and the simulation of less than $10 \%$. Visually the experimental flow obtained by using the smoke generator compared well to the FDS simulation. Special attention must be given to the grid cell size, grid location and fan design to accurately model the fan flow.

The simple room geometry experiments added a change in flow direction and a pressure gradient to challenge the computer model. Experimental and simulation comparisons gave a velocity difference of 16.5 percent at the window. The air movement at the window is the result of the pressure change in the room, interaction 
of the geometry of the room and the airflow. Qualitatively the flow visualized using the smoke generator matched the simulation very well.

The room fire experiments incorporated the interaction between the fan flow and a fire. The naturally ventilated and the positive pressure ventilated comparisons showed the fan created higher fire room temperatures, increased window gas flows and higher pressure differentials. The experiments also showed that the PPV fan created a $60 \%$ increase in burning rate during the potential time of fire department attack. Other conclusions indicated by the limited set of data related to fire fighting tactics include the necessity of coordination of fire fighting crews to carry out positive pressure ventilation in the attack stages of a fire and the recommendation to delay advancement towards the fire until conditions created by the fan stabilized 60 seconds to 120 seconds after ventilation.

Computationally, visual and numerical comparisons demonstrate that the fire behavior of a room fire both with and without positive pressure ventilation can be successfully modeled by FDS and visualized with Smokeview. Minor differences exist in the geometry and material properties but the fire dynamics and the net impact of the positive pressure ventilation fan can be captured with a degree of accuracy. In order to expand the understanding of the effects of positive pressure ventilation it would be very informative to perform experiments in various types of full-scale structures. These structures are very difficult to obtain and very expensive to instrument. Using the lab scale tests documented above as a calibration for the Fire 
Dynamic Simulator it was possible to visualize the effects of positive pressure ventilation fan on a colonial style house with a fire on the second floor.

The results of this comparison show that the PPV fan created tenable conditions in the house that would not normally be there under natural ventilation tactics. This is only one ideal scenario with well coordinated ventilation tactics assumed. These simulations follow the fire dynamics seen in laboratory experiments and provide confidence that the positive pressure ventilation tactic can be analyzed without the need for countless full-scale field tests. If full-scale opportunities arise in the future they would be beneficial as there is no true replacement for such data. Countless ventilation scenarios can be performed on this colonial style house at the expense of computational time. As computers continue to advance in speed and capability this cost will decrease allowing for a more timely result of the impact of the PPV fan.

The ability to accurately model the effects of PPV given the proper input parameters in FDS provides a technique to add to the current deficient but fast growing understanding of positive pressure ventilation. Future research should incorporate FDS to answer specific fire department concerns with the use of PPV so that this tool can be utilized safely and effectively. 


\section{References}

1. Carlson, G., “Volunteer’s Corner, Positive Pressure Ventilation, Some Questions,” Fire Engineering, March 1989, p. 9.

2. Coleman, John., “Roundtable, Positive Pressure Ventilation,” Fire Engineering, August 1999, p. 22-32.

3. Yates, Mark, "Positive Pressure Ventilation - The Wind of Change," BCC. United Kingdom. 2001.

4. Tempest Technology Corporation, http://www.tempest-edge.com, January 2003.

5. McGrattan, Kevin B., Baum, Howard R., Rehm, Ronald G., Hamins, Anthony, Forney, Glenn P., "Fire Dynamics Simulator - Technical Reference Guide,” National Institute of Standards and Technology, Gaithersburg, MD., NIST Special Publication 1018, December 2004.

6. McGrattan, Kevin B., Forney, Glenn P., "Fire Dynamics Simulator - User’s Manual,” National Institute of Standards and Technology, Gaithersburg, MD., NIST Special Publication 1019, December 2004.

7. Forney, Glenn P., McGrattan, Kevin B. “User’s Guide for Smokeview Version 4 - A Tool for Visualizing Fire Dynamics Simulation Data," National Institute of Standards and Technology, Gaithersburg, MD., NIST Special Publication 1017, August 2004.

8. Omega Engineering Inc., "User’s Guide for the HH-31A Handheld Anemometer,” Stamford, CT, 1996.

9. Hall, Richard, and Barbara Adams, Essentials of Fire Fighting, $4^{\text {th }}$ ed., Stillwater: Oklahoma State University, 1998.

10. Super Vacuum Manufacturing Company, Inc., http://www.supervac.com, January 2003.

11. Setra Systems, Inc., “Installation Guide, Setra Systems Model 264 Differential Pressure Transducer,” Boxborough, MA., 1999.

12. Bryant, R.A., Ohlemiller, T.J., Johnsson, E.L., Hamins, A.H., Grove, B.S., Guthrie, W.F., Maranghides, A., and Mulholland, G.W., “The NIST 3 MW Quantitative Heat Release Rate Facility”, NIST Special Publication 1007, National Institute of Standards and Technology, Gaithersburg, MD, 2003.

13. Pitts, W.M., E. Braun, R.D. Peacock, H.E. Milter, E.L. Johnsson, P.A. Reneke, and L.G. Blevins, “Temperature Uncertainties for Bare-Bead and Aspirated 
Thermocouple Measurements in Fire Environments," Thermal Measurements: The Foundation of Fire Standards. American Society for Experimenting and materials (ASTM), Proceedings. ASTM STP 1427, December 3, 2001, Dallas, TX.

14. Blevins, L.G. "Behavior of Bare-bead and Aspirated Thermocouple in Compartment Fires.” National Institute of Standards and Technology, Gaithersburg, MD, 1999.

15. Stott, Richard. "Report on PPV Trials at Oxford Road, Preston, U.K.” p. 10-14 January, 2000.

16. Svensson, Stefan. "Experimental Study of Fire Ventilation During Fire Fighting Operations”, Fire Technology, Vol. 37, 2001, p. 69-85.

17. Ezekoye, O., Lan, C., Nicks, R. "Positive Pressure Attack for Heat Transport in a House Fire," The $6^{\text {th }}$ ASME-JSME Thermal Engineering Joint Conference. March 16-20, 2003.

18. Gojkovic and Bengtsson. "Some Theoretical and Practical Aspects on Fire Fighting Tactics in a Backdraft Situation," http://www.firetactics.com/DANIELGOJKOVIC.htm October 2005.

19. Krasny, J., Rockett, J. A.,and Huang, D. "Protecting Fire Fighters Exposed in Room Fires: Comparison of Results of Bench Scale Test for Thermal Protection and Conditions During Room Flashover.” Fire Technology, p. 5-19, (1988).

20. Protective Clothing for Structural Firefighting, NFPA Standard 1971, National Fire Protection Agency, Quincy, MA (2003).

21. McGrattan, Kevin B., Hamins, Anthony, Stroup, David, “Sprinkler, Smoke \& Heat Vent, Draft Curtain Interaction - Large Scale Experiments and Model Development,” National Institute of Standards and Technology, Gaithersburg, MD., NISTIR 6196-1, September 1998.

22. Taylor, B. N. and C. E. Kuyatt, "Guidelines For Evaluating and Expressing the Uncertainty of NIST Measurement Results.” National Institute of Standards and Technology (U.S.) NIST-TN 1297; pp. 20 September, 1994.

23. Omega Engineering Inc., The Temperature Handbook, Vol. MM, pages Z-39-40, Stamford, CT., 2004.

24. McGrattan, Kevin B., Baum, Howard R., Rehm, Ronald G., "Large Eddy Simulations of Smoke Movement,” Fire Safety Journal, vol 30 (1998), p. 161178. 